\title{
Liquid-In-Glass Thermometer Calibration Service
}

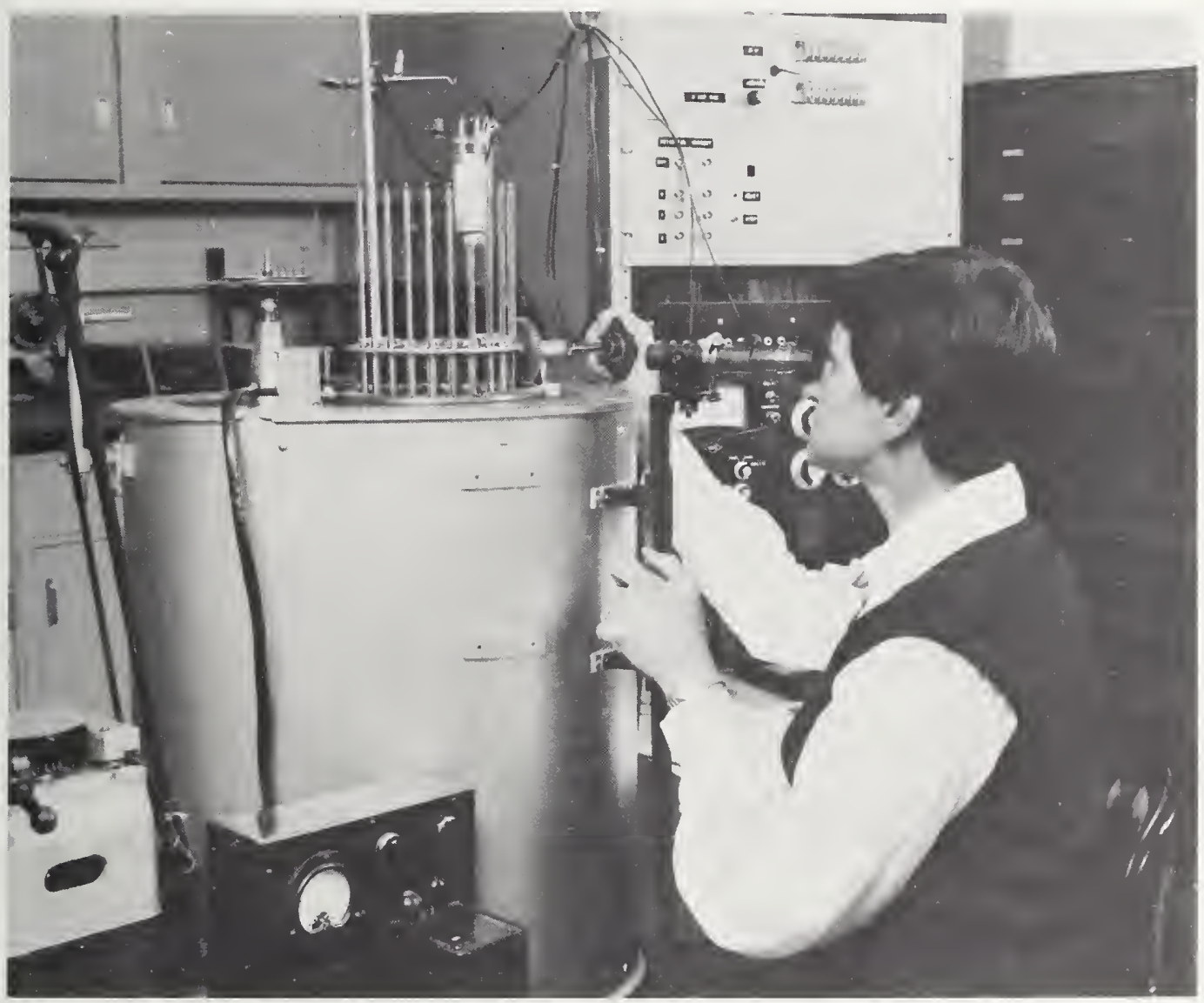

NIST

Special

Publication

250-23

Jacquelyn Wise 


\section{Center for Basic Standards}

The Center for Basic Standards develops and maintains the scientific competencies and laboratory facilities necessary to preserve and continue to refine the base physical quantities upon which the Nation's measurement system is constructed. The Center is responsible for the standards of voltage, current, resistance and impedance, temperature, vacuum, leak rate, pressure, mass, length, time and frequency. The Center collaborates closely with the standardizing laboratories of other countries to ensure that measures used in international trade are fully compatible. The Center also performs research at the frontiers of physics in order to improve measurement capability and quantitative understanding of basic physical processes that underlie measurement science.

\section{Electricity Division}

Maintains and improves the national standards of electrical measurements; conducts experiments to realize the electrical units in terms of the mechanical units; develops stable electrical standards and improved methods for the dissemination of the units of electrical measurements; determines fundamental physical constants related to electrical units; develops instrumentation for precise electrical measurements directly referenced to the national standards; implements techniques for their use and puts them into practical applications; assists in applying scientific and technological development to measurement problems, especially in other areas of NBS research.

\section{Temperature and Pressure Division}

Maintains and improves the national standards of temperature and pressure; conducts research towards the development of new concepts for these standards; calibrates practical standards for the U.S. scientific and technical community in terms of the primary standards; develops methods and devices to assist user groups in the assessment and enhancement of the accuracy of their measurements of temperature and pressure; prepares and promulgates evaluations and descriptions of temperature and pressure measurement processes; coordinates these standards and measurement methods nationally and internationally; and determines the accuracy of the national standards of temperature and pressure with respect to fundamental thermodynamic relations.

\section{Length and Mass Division}

Develops and uses the competence necessary to implement a more accurate measurement system for length and mass; applies research, utilizing the most advanced technology available, to the improvement of our present standards and devises new standards and new methods for their transfer.

\section{Time and Frequency Division}

Maintains, develops, and improves the national standards for time (which are coordinated with the United States Naval Observatory) and frequency, and the time scales based on these standards; carries out research in areas of importance to the further fundamental improvement of frequency standards and their applications focusing on microwave and laser devices, atomic and molecular resonances, and the measurement of fundamental physical phenomena and constants; adapts time and frequency standard devices and concepts to special scientific and technological demands; develops time and frequency measurement methods in the radio frequency, microwave, infrared, and visible radiation regions; coordinates the national time and frequency standards, time scales, and measurement methods nationally and internationally in conjunction with the United States Naval Observatory; operates time and frequency dissemination services, such as radio stations and broadcasts, for the purpose of traceability to the national standards of time and frequency.

\section{Quantum Physics Division}

Engages in research in atomic and molecular physics at the forefront of the field, and performs basic, highly accurate measurements and theoretical analyses that help establish a reliable foundation for scientific and technological measurement and data.

\section{Quantum Metrology Division}

Engages in forefront research in quantum metrology; contributes to new determinations of the fundamental physical constants, and the extension and refinement of the electromagnetic scale and devises, where possible, tests of basic symmetries and invariances. 


\section{NIST MEASUREMENT SERVICES: Liquid-In-Glass Thermometer Calibration Service}

Jacquelyn Wise

Temperature and Pressure Division

Center for Basic Standards

National Measurement Laboratory

National Institute of Standards and Technology

Gaithersburg, MD 20899

September 1988

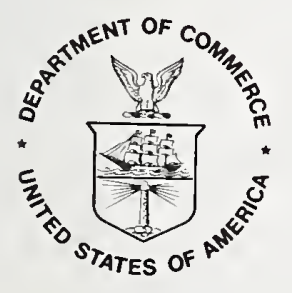

NOTE: As of 23 August 1988, the National Bureau of Standards (NBS) became the National Institute of Standards and Technology (NIST) when President Reagan signed into law the Omnibus Trade and Competitiveness Act. 
Library of Congress Catalog Card Number: 88-600580

National Institute of Standards and Technology Special Publication 250-23, 128 pages (Sept. 1988) CODEN: XNBSAV 


\section{PREFACE}

Calibrations and related measurement services of the National Bureau of Standards provide the means for makers and users of measuring tools to achieve levels of measurement accuracy that are necessary to attain quality, productivity and competitiveness. These requirements include the highest levels of accuracy that are possible on the basis of the most modern advances in science and technology as well as the levels of accuracy that are necessary in the routine production of goods and services. More than 300 different calibrations, measurement assurance services and special tests are available from NBS to support the activities of public and private organizations. These services enable users to link their measurements to the reference standards maintained by NBS and, thereby, to the measurement systems of other countries throughout the world. NBS Special Publication 250, NBS Calibration Services Users Guide, describes the calibrations and related services that are offered, provides essential information for placing orders for these services and identifies expert persons to be contacted for technical assistance.

NBS Special Publication 250 has recently been expanded by the addition of supplementary publications that provide detailed technical descriptions of specific NBS calibration services and, together with the NBS Calibration Services Users Guide, they constitute a topical series. Each technical supplement on a particular calibration service includes:

- specifications for the service

- design philosophy and theory

- description of the NBS measurement system

- NBS operational procedures

- measurement uncertainty assessment error budget

systematic errors

random errors

- NBS internal quality control procedures

The new publications will present more technical detail than the information that can be included in NBS Reports of Calibration. In general they will also provide more detail than past publications in the scientific and technical literature; such publications, when they exist, tend to focus upon a particular element of the topic and other elements may have been published in different places at different times. The new series will integrate the description of NBS calibration technologies in a form that is more readily accessible and more useful to the technical user to achieve high quality measurements. 
The present publication, SP 250-23, NBS Measurement Services: Liquid-inGlass Thermometer Calibration Service, by Jacquelyn A. Wise, is one of approximately 20 documents in the new series published or in preparation by the Center for Basic Standards. It describes calibration technology and procedures utilized in connection with NBS Service Identification Numbers from $31010 \mathrm{C}$ to $31161 \mathrm{~S}$ listed in the NBS Calibration Services Users Guide 1986-88/Revised (pages 47 and 48). Inquiries concerning the contents of these documents may be directed to the author(s) or to one of the technical contact persons identified in the Users Guide.

Suggestions for improving the effectiveness and usefulness of the new series would be very much appreciated at NBS. Likewise, suggestions concerning the need for new calibration services, special tests and measurement assurance programs are always welcome.

Joe D. Simmons, Acting Chief

Office of Physical Measurement Services

Katharine Gebbie, Acting Director

Center for Basic Standards 
1.0 Description of Service . . . . . . . . . . . . 1

1.1 General . . . . . . . . . . . . . . . . . . . 1

1.2 Types of Thermometers Accepted for Calibration at NBS . . 1

1.3 Procedures For Submitting A Thermometer for Calibration. . 2

1.4 Shipping Instructions . . . . . . . . . . . . . . . . . 2

2.0 Design Philosophy and Theory . . . . . . . . . . . . . . . 3

2.1 General Description of Liquid-in-Glass Thermometers . . . . 3

2.2 Three Immersion Depths for Liquid-in-Glass Thermometers . . 4

2.3 Materials of Construction . . . . . . . . . . . . . . . . . 6

2.4 Scale Design and Workmanship . . . . . . . . . . . . . . . 7

2.5 Scale Dimensions . . . . . . . . . . . . . . . . . 8

2.6 Reference Point . . . . . . . . . . . . . . . 9

3.0 Temperature Scale and Primary Standard Thermometer . . . . . . . 10

3.1 International Practical Temperature Scale . . . . . . . . 10

3.2 Standard Platinum Resistance Thermometer . . . . . . . . . 12

3.3 AC Bridge. . . . . . . . . . . . . . . . . . . . 14

4.0 Description of the Measurement System . . . . . . . . . . . . . 14

4.1 Laboratory Environment . . . . . . . . . . . . . . 14

4.2 Calibration Baths . . . . . . . . . . . . . . . . . . . . 15

4.2.1 Ice Bath . . . . . . . . . . . . . . . . . . . . . . 16

4.2.2 Steam Bath . . . . . . . . . . . . . . . 17

4.2.3 Water and 0il Baths . . . . . . . . . . . . 20

4.2.4 Tin Bath. . . . . . . . . . . . . . . . . 23

4.2.5 Cryostat. . . . . . . . . . . . . . . . . 24

4.2.6 Liquid Nitrogen and Liquid Oxygen Points . . . . . . 26

5.0 Operational Procedures . . . . . . . . . . . . . . . . . . 28

5.1 Examination and Preparation of Thermometers for

Calibration . . . . . . . . . . . . . . . . . 28

5.2 Number and Choice of Calibration Points . . . . . . . . . . 30

5.3 Types of Thermometers and How They Are Calibrated . . . . . 31

5.3.1 Total-immersion Thermometers . . . . . . . . . . . 31

5.3.2 Partial-immersion Thermometers . . . . . . . . . . 32

5.3.3 ASTM Thermometers . . . . . . . . . . . . . 32

5.3.4 Calorimetric Thermometers . . . . . . . . . 33 
5.3.5 Beckmann Thermometers . . . . . . . . . . . . 33

5.3.6 Clinical Standard Thermometers . . . . . . . . . 35

5.3.7 Kinematic Viscosity Thermometers . . . . . . . . . . 35

5.3.8 Low-temperature Thermometers . . . . . . . . . . . . 35

5.4 Stem-temperature Measurement . . . . . . . . . . . . . 36

5.5 Checking the Standard Platinum Resistance Thermometer

at the Triple Point of Water . . . . . . . . . . . . 37

5.6 Use of Ice Bath . . . . . . . . . . . . . . . . . . . . . . 38

5.7 Placement of Thermometers in Calibration Baths . . . . . . 40

5.8 Placement of Faden and Auxiliary Thermometers for

Measurement of Stem Temperatures . . . . . . . . . . . . . 41

5.9 Regulating the Bath, Reading Sequence, and Recording Data . 49

6.0 Calculations. . . . . . . . . . . . . . . . . . . 51

6.1 Computation of Bath Temperature . . . . . . . . . . . . . 51

6.2 Determining Corrections of Thermometers Being Calibrated . 58

6.3 Stem-Temperature Corrections . . . . . . . . . . . . . . 59

6.3.1 Emergent Stem-temperature Correction using Two Auxiliary Thermometers . . . . . . . . . . . . . 64

6.3.2 Emergent Stem-temperature Correction using Two Faden Thermometers . . . . . . . . . . . . 64

6.3.3 Emergent Stem-temperature Correction using One Auxiliary Thermometer . . . . . . . . . . . . 66

6.3.4 Emergent Stem-temperature Correction using One Faden Thermometer . . . . . . . . . . . 66

6.3 .5 Too-deep Immersion Correction . . . . . . . . . 67

6.3.6 Faden Correction . . . . . . . . . . . . . . 68

6.3.7 Emergent Stem-temperature Correction for

6.3.8 Emergent Stem-temperature Correction for Beckmann
Thermometers . . . . . . . . . . . 70

7.0 Documentation . . . . . . . . . . . . . . . . 70

7.1 Report of Calibration . . . . . . . . . . . . . 70

8.0 Internal Quality Control . . . . . . . . . . . . . 78

8.1 Use of Check Standards . . . . . . . . . . . . . . 79

8.2 Comparison of Corrections and Evaluation of Data on 79

9.0 Assessment of Uncertainties . . . . . . . . . . . . . . . . 81

9.1 Current Tolerance and Uncertainty Values . . . . . . . . 81

9.2 Evaluation of Uncertainties . . . . . . . . . . . . 88 
10.0 Glass Changes and Recalibration of Thermometers . . . . . . . 115

10.1 Glass Changes . . . . . . . . . . . . . . . 115

10.1 .1 Temporary Changes . . . . . . . . . . . 116

10.1.2 Permanent Changes . . . . . . . . . . . . 117

10.2 Recalibration of Liquid-in-Glass Thermometers . . . . . 118

11.0 Future . . . . . . . . . . . . . . . . . . 119

12.0 Bibliography . . . . . . . . . . . . . . 119 



\subsection{General}

This service provides calibrations for a variety of thermometers covering the range from -196 to $+538{ }^{\circ} \mathrm{C}$. The majority of the thermometers are liquid-in-glass but other types are calibrated as well; thermistors, industrial platinum resistance thermometers, thermocouples, and digital thermometer systems. The customer's thermometers are calibrated in constant temperature baths in terms of the National Bureau of Standards (NBS) primary standard, a calibrated platinum resistance thermometer. The primary standard maintains calibrations traceable to the International Practical Temperature Scale (1968), referred to as IPTS-68, with an accuracy of approximately $5 \mathrm{mK}$ at the lower temperature range and $2 \mathrm{mK}$ at the higher range. The customer is provided a Report of Calibration or Report of Test which contains results of the calibration and other important information related to his particular thermometer.

Typical uncertainties for the most accurate liquid-in-glass thermometers in four temperature ranges are listed below. A more detailed discussion of uncertainties is given in Section 9.

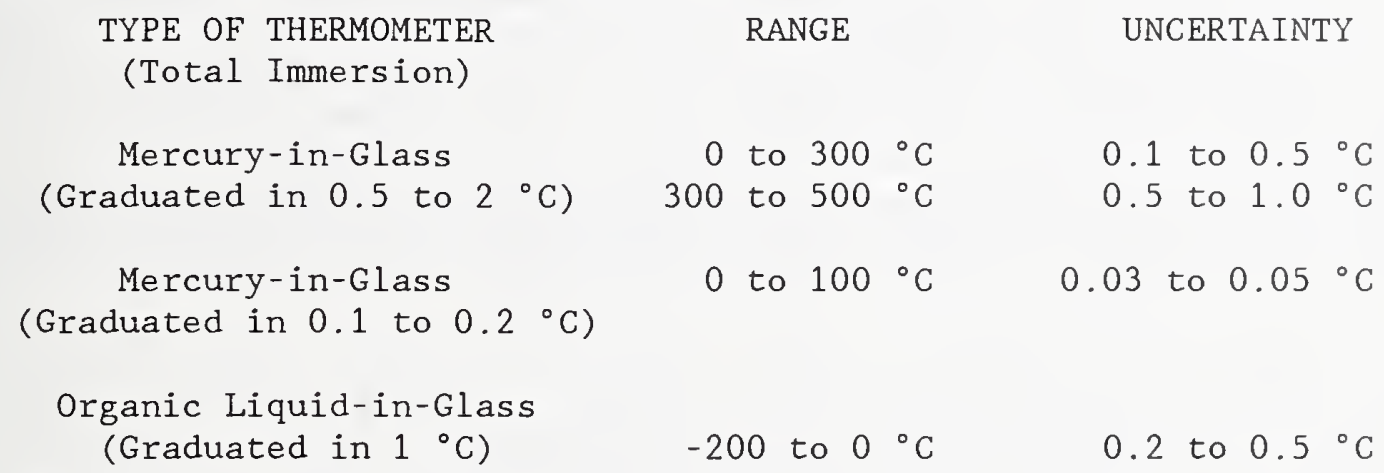

Twice a year NBS offers a 5-day Precision Thermometry Seminar. One full day is devoted to liquid-in-glass thermometry and includes lectures as well as "hands-on" laboratory experience.

\subsection{Types of Thermometers Accepted for Calibration at NBS}

Not all liquid-in-glass thermometers are acceptable for calibration at NBS. In general, the thermometer must be of an acceptable design and workmanship and be compatible with the existing calibration facilities. The type known as laboratory or chemical thermometers, consisting of a solid stem with graduation lines and numbers permanently etched or placed on the stem, are regularly accepted. Other types such as Beckmann, calorimetric, and enclosed scale (Einschluss) laboratory thermometers are also regularly accepted. Industrial or mechanical type thermometers with special mountings may be accepted for test if they can be inserted in the comparison baths, or if the thermometer can be detached easily from the mounting. 
Any thermometer, such as a household thermometer, consisting of a paper, plastic or metal mounting containing the scale graduations and attached to the unmarked glass thermometer by metal clips, is not acceptable for calibration. Maximum self-registering mercury-in-glass clinical thermometers are no longer tested at NBS.

It is advisable to contact the NBS liquid-in-glass thermometry laboratory if there is any doubt about the acceptability of a thermometer for calibration. Every effort will be made to assist you in selecting an appropriate thermometer for a particular measurement application.

\subsection{Procedures for Submitting A Thermometer for Calibration}

Calibrations are conducted in accordance with policies described in NBS Special Publication 250. The cost will depend on the number of calibration points requested, the temperature range, and the quantity of thermometers submitted. NBS should be contacted for information about tests not specifically outlined in the above publication. If the required measurements appear feasible, and, in the opinion of NBS, are sufficiently important to justify the work, such tests will be undertaken for a special fee determined by the nature of the work and time involved.

A letter or purchase order requesting the test may be sent to NBS either with the thermometer or separately. However, no calibration will begin until both the thermometer and letter or purchase order have been received. The request should include the quantity and serial numbers of the thermometers, the calibration points required, and the suggested method for return shipment. If the customer wants his thermometer insured for return shipment, a statement to that effect must appear on the request with a value assigned; otherwise, the thermometer will be returned uninsured.

NBS will assign a test number to each calibration request and acknowledge the receipt of the thermometer. The acknowledgment will state the estimated cost of the calibration and the estimated completion date. Any difficulties with the calibration that may be anticipated will also be mentioned in the acknowledgment, as well as the name of an NBS contact who can answer further questions that may arise.

\subsection{Shipping Instructions}

Thermometers should be packed firmly in their individual cases to assure safe shipment. A rigid material, such as wooden slats or corrugated paper, can be wrapped around the thermometer case as an additional safeguard against breakage. The package should contain enough packing material to absorb any shock that it may receive. Each shipment should include a packing list stating the number of thermometers shipped, the name of the company submitting them, and, if applicable, the company's purchase order number. The thermometers should be sent to: 
National Bureau of Standards

Route 270 and Quince Orchard Road

Gaithersburg, Maryland 20899

Attention: Jacquelyn Wise

Thermometers will be returned via the method requested by the customer. If no preference is stated, NBS will select a best method. The thermometers will be packed in the same boxes and manner in which they were received, unless the boxes were damaged when they arrived. Shipping charges, both to and from NBS will be paid by the customer. All reasonable care will be taken in handling thermometers at NBS, but the risk of damage either in shipment or during calibration must be assumed by the customer.

\subsection{Design Philosophy and Theory}

\subsection{General Description of Liquid-in-Glass Thermometers}

The liquid-in-glass thermometer works on the principle of thermal expansion. As the temperature of the thermometer increases, the liquid and the glass of the thermometer expand with different expansion coefficients, causing the liquid to advance up the capillary tube. The top of the liquid column, known as the meniscus, will eventually come to rest when the temperature of the thermometer is in equilibrium with the temperature of its environment. The temperature of the thermometer can then be read from the scale on the stem.

The principal features of a typical liquid-in-glass thermometer are shown in Figure 1. However, all of the features shown would not necessarily be incorporated in any one thermometer.

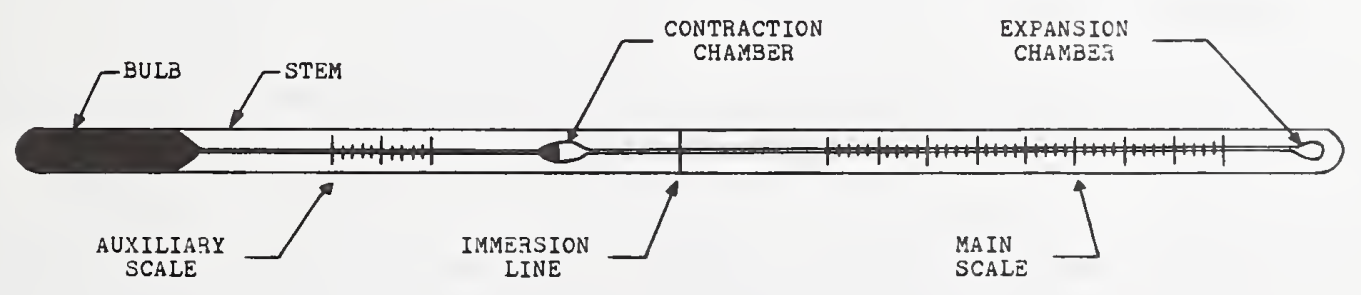

Fig. 1. Principal features of a solid-stem liquid-in-glass thermometer. 
The bulb of the thermometer is a thin glass-walled reservoir for the thermometer liquid. It contains a volume equivalent to a specific number of degrees of the scale depending upon the expansion coefficients of the thermometric liquid and the bulb glass. For example, for mercury in a bulb made of "normal" glass, the bulb volume is equivalent to approximately 6,222 times the volume of a 1 degree length of the capillary on the scale for Celsius thermometers, or 11,200 times the volume of a 1 degree length of the capillary on the scale for Fahrenheit thermometers. For organic thermometric liquids with expansion coefficients higher than that of mercury, the bulb volumes are correspondingly smaller.

The stem of a thermometer is the glass capillary through which the thermometric liquid advances or retreats with changes in temperature. It can be a heavy glass stem with a very small capillary in the center or it can be an enclosed scale stem, in which a very small capillary tube is attached to a glass scale and enclosed in a glass sleeve.

The main scale is graduated in degrees or multiples or submultiples of degrees. Frequently, the main scale is the only scale on the thermometer. However, some thermometers have an additional short scale, known as an auxiliary scale, when a suitable reference temperature, such as the ice point, is not included in the range of the main scale. The reference temperature is used to check the calibration of the thermometer as a function of time or use.

The expansion chamber is an enlargement at the top of the capillary bore. In gas-filled thermometers, it prevents an excessive buildup of internal pressure when the liquid advances toward the top of the scale. An expansion chamber should have a volume equal to or greater than the volume of a $20 \mathrm{~mm}$ length of uniform capillary. Smaller enlargements do not qualify as expansion chambers.

The contraction chamber is an enlargement of the capillary bore located below the main scale or between the main scale and an auxiliary scale. It serves to reduce the length of capillary needed to reach the main scale from the reference point or to prevent contraction of the entire liquid column into the bulb.

\subsection{Three Immersion Depths for Liquid-in-Glass Thermometers}

Liquid-in-glass thermometers are designed to be used at one of the three immersion depths illustrated in Figure 2.

A total-immersion thermometer is designed to indicate temperatures correctly when the bulb and all but about $12 \mathrm{~mm}$ of the liquid column are immersed in the bath medium and exposed to the temperature being measured. The top $12 \mathrm{~mm}$ of the liquid column should be above the bath medium so that the thermometer can be read and the mercury does not distill at high temperatures. The meniscus should never be at or below the surface of the bath medium. 


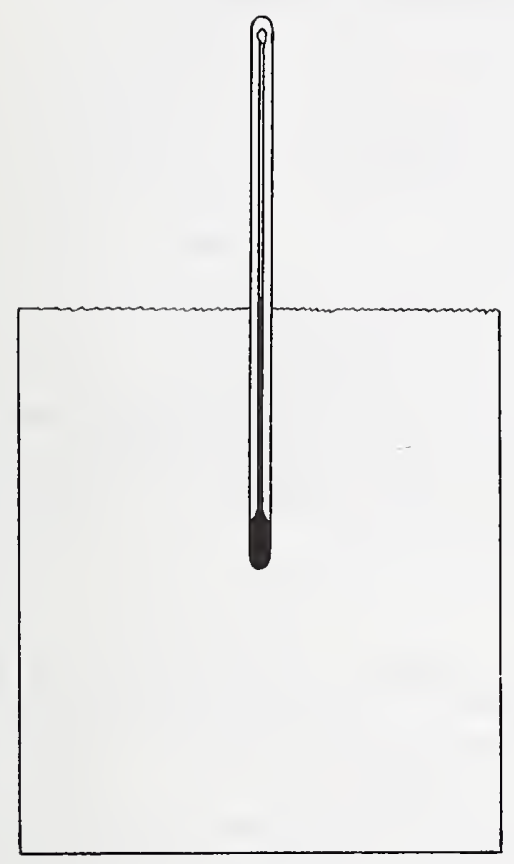

TOTAL IMUERSION

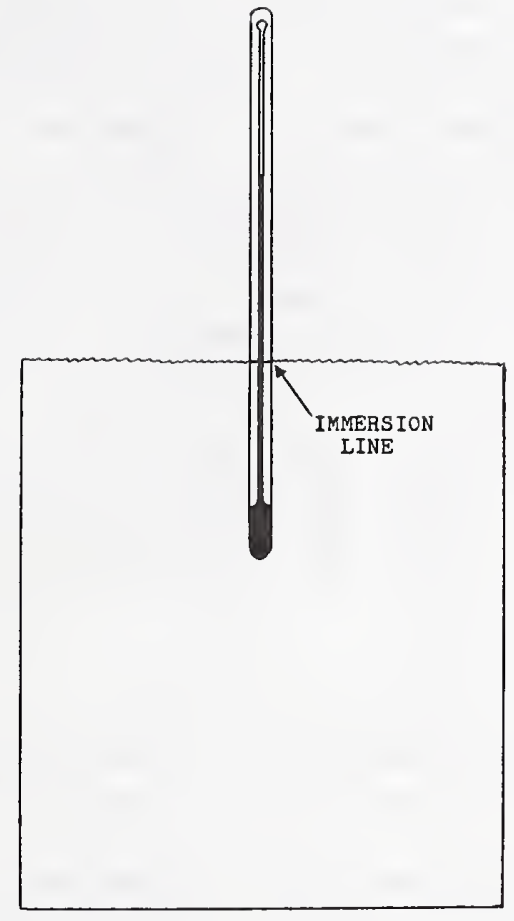

P A R T I A L I M ME B S ION

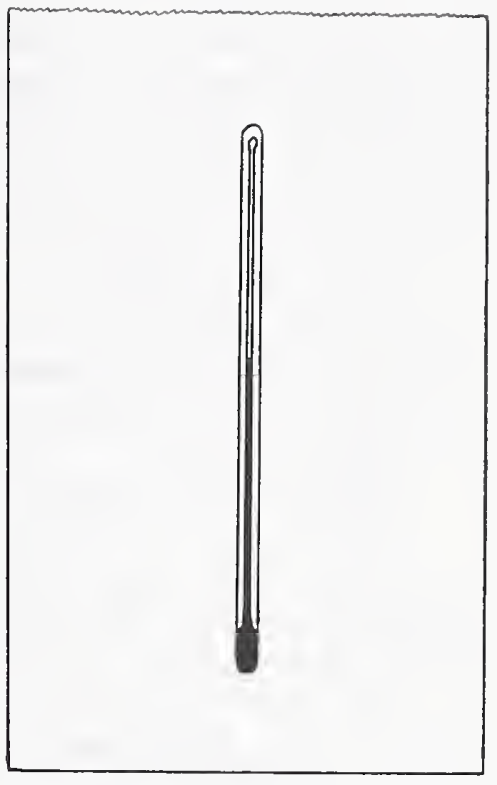

COMPLETE IMMERSION

Fig. 2. Three ways a liquid-in-glass thermometer can be used.

A partial-immersion thermometer is designed to indicate temperatures correctly when the bulb and a specified portion of the stem are exposed to the temperature being measured. The remaining portion of the stem will be at the ambient temperature, which is usually different from the temperature being measured. The segment of the stem from the immersion line to the meniscus of the liquid column will be referred to throughout the text as the "emergent-stem." Partial-immersion thermometers must be clearly marked "partial immersion" or the equivalent (for example, "76 mm immersion"), or have a conspicuous line permanently placed on the stem to indicate the proper depth of immersion. (The immersion depth is from the bottom of the bulb.) The immersion line must be at least $13 \mathrm{~mm}$ above the top of the bulb. There are some special purpose partial-immersion thermometers that need not be marked with an immersion line. These include thermometers made for use in a specific manner or in a particular instrument, such as a viscometer or a flash-point tester where the thermometer is always mounted in a specific arrangement for that instrument.

A complete-immersion thermometer is designed to indicate temperature correctly when the whole thermometer, including the expansion chamber, is subjected to the temperature being measured. Thermometers made in the United States are generally not designed to be used at complete immersion. 
A thermometer is designed to be used at only one of the above immersion depths and it is normally calibrated at that depth. If the thermometer is used at immersion depths other than that at which it was calibrated and intended to be used, the temperature reading will be in error. This error can be as large as several degrees. However, if a total-immersion thermometer must be used at partial immersion or a partial-immersion thermometer must be used at total immersion, a stem-temperature correction can be computed (see Sections 5.8 and 6.3) and applied to the thermometer reading to obtain the correct temperature reading. No such stemtemperature correction can be made for complete-immersion thermometers used at total or partial immersion, or for total- or partial-immersion thermometers used at complete immersion. This is due to the additional error produced by different pressures on the thin-walled bulb and expansion chamber when the thermometer is completely immersed as opposed to having the bulb at a more shallow depth and the expansion chamber above the bath.

\subsection{Materials of Construction}

The cleanliness of the thermometer bulb, bore, and liquid filling have a pronounced effect on the performance of a thermometer. The proper choice of thermometer glass is also important for good performance. The thermometer, and especially the bulb, must be made of glass suitable for use in the temperature range indicated on the stem. Several types of glass commonly used in the manufacture of thermometer bulbs are listed in Table 1 along with Thompson's [1] estimate of reasonable upper temperature limits for each type. Thompson's estimates are based on the work of Liberatore and Whitcome [2]. Significant changes in bulb volume may occur if the bulb is heated for long periods of time at temperatures within $130{ }^{\circ} \mathrm{C}$ of the strain point of the bulb glass, i.e., the temperature at which the glass has a viscosity of $10^{14.5}$ poises [3]. Thermometers may be used intermittently, to within approximately 70 celsius degrees of the strain point. It should be noted that the use of a glass with a high strain point, such as borosilicate glass, results in better thermometer performance and stability even in thermometers used at temperatures much lower than the exposure limits given in Table 1.

The thermometer must also be adequately annealed to enable the bulb volume to remain reasonably stable with continued use. This is especially true for a thermometer graduated above $300{ }^{\circ} \mathrm{C}$. The quality of the thermometer glass and the adequacy of the annealing process may be determined from the stability of the reference-point readings. A method for testing bulb stability is described in The American Society for Testing and Materials Method E-77 [4].

All high-temperature thermometers should be filled with a dry inert gas such as nitrogen under sufficient pressure to prevent separation of the mercury at any temperature indicated on the scale. Total-immersion thermometers graduated above $150{ }^{\circ} \mathrm{C}$ must be filled with gas to minimize the distillation of mercury from the top of the column. An expansion chamber at the top of the capillary or a specified length of uniform capillary above the highest graduation is essential for thermometers containing a 


\begin{tabular}{|l|c|r|r|r|r|}
\hline & \multirow{2}{*}{$\begin{array}{l}\text { Strain } \\
\text { Point }\end{array}$} & \multicolumn{3}{|c|}{ Exposure Limits } \\
\cline { 2 - 5 } & & \multicolumn{2}{|c|}{ Continuous } & \multicolumn{2}{|c|}{ Intermittent } \\
\cline { 2 - 6 } & ${ }^{\circ} \mathrm{C}$ & ${ }^{\circ} \mathrm{C}$ & ${ }^{\circ} \mathrm{F}$ & ${ }^{\circ} \mathrm{C}$ & ${ }^{\circ} \mathrm{F}$ \\
\cline { 2 - 6 } & & & & & \\
Corning normal 7560 & 500 & 370 & 700 & $430 *$ & $805 *$ \\
Kimble R6 & 490 & 360 & 680 & 420 & 790 \\
Jena 16 III & 495 & 365 & 690 & 425 & 795 \\
Corning borosilicate 8800 & 529 & 400 & 750 & 460 & 860 \\
Jena borosilicate 2954 & 548 & 420 & 790 & 480 & 900 \\
Corning 1720 & 668 & 540 & 1005 & 600 & 1110 \\
Jena Supremax 2955 & 665 & 535 & 995 & 595 & 1100 \\
\hline
\end{tabular}

[1] Data taken from Ref. [1].

" $405^{\circ} \mathrm{C}$ or $760^{\circ} \mathrm{F}$ if Corning Standard Thermometer 0041 glass is used for the stem.

gas. The gas must have an adequate area for compression when the mercury is advanced toward the top of the scale; otherwise, excessive pressure in the capillary will break the thermometer.

For thermometers graduated below $150{ }^{\circ} \mathrm{C}$, a gas filling is optional but strongly recommended. The mercury column of a vacuous thermometer will tend to separate easily if the thermometer is inverted or subjected to a sudden shock.

\subsection{Scale Design and Workmanship}

Solid-stem thermometers must have the graduation marks placed directly on the stem and opposite the enamel backing. If the thermometer is of the enclosed-scale type, the graduated scale must be securely fastened to prevent relative displacement between the scale and the capillary, or a datum line should be conveniently located to indicate whether the scale is in its original position. The graduation marks should be clear cut, straight, of uniform width, and in a plane perpendicular to the axis of the thermometer.

The scale should be graduated in $0.1,0.2$, or 0.5 degree intervals or in decimal multiples. The divisions should be numbered in such a manner that the identification of any graduation is not unnecessarily difficult. Thermometers with scales graduated in 0.25 degree intervals, or submultiples, can look very much like thermometers graduated in 0.2 degree 
intervals or decimal multiples and can be read incorrectly. If the thermometers are graduated in 0.1 or 0.2 degree intervals (or decimal multiples), every fifth mark should be longer than the intermediate ones and a number should appear at every tenth mark. Thermometers graduated in 0.5 degree intervals (or decimal multiples) require three lengths of graduation marks. These consist of alternating short and intermediate marks, with every tenth line distinctly longer than the others. A number should appear at every 10 th or 20 th mark. Examples are given in Figure 3.

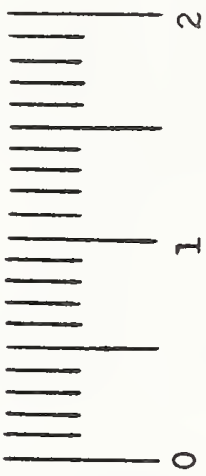

0.1

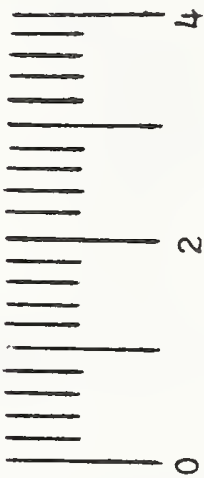

0.2

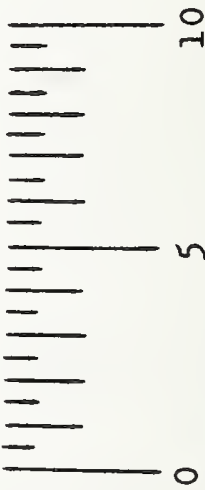

0.5

Fig. 3. Scale graduations for thermometers in intervals of $0.1,0.2$, and 0.5 degree.

The scale must not be extended to temperatures beyond which the particular thermometer glass is suited. A thermometer made of borosilicate glass, for example, should never be graduated to $500{ }^{\circ} \mathrm{C}$. It would be ruined in a short time if used at that temperature.

\subsection{Scale Dimensions}

Although optimum line width depends in some measure on the intended use of a particular thermometer, coarse graduation marks do not represent good design. If the thermometer indications are to be observed precisely (for example to 0.1 of a division), the width of the graduation marks should not exceed 0.2 of the interval between the center lines of the graduations. In instances where the thermometer must be read quickly or in poor light, and less precision is expected, somewhat wider lines may be acceptable.

The graduation marks must not be too closely spaced. The closest permissible spacing depends on the fineness and clearness of the marks. In no case should the distance between center lines of adjacent graduation marks on a solid-stem thermometer be less than $0.4 \mathrm{~mm}$. The minimum permissible interval between graduation marks for an enclosed-scale thermometer is $0.3 \mathrm{~mm}$ if the lines are ruled on a milk-glass scale; otherwise, the minimum 
is also $0.4 \mathrm{~mm}$. The minimum in no case represents good design, and welldesigned thermometers will have graduation intervals considerably larger than the specified minimum.

In order for a thermometer to be usable over the entire range of the scale, the graduation marks must not be placed too close to any enlargement in the capillary. Appreciable errors may result if any of the following conditions exist.

(1) There is insufficient immersion of the mercury in the main bulb or a capillary enlargement;

(2) the graduation marks have been placed over parts of the capillary that have been changed by manufacturing operations; or

(3) the graduations are so close to the top of the thermometer that excessive gas pressure results when the mercury is raised to this level.

The distances given below are considered minimum limits commensurate with good thermometer design:

(a) A $13 \mathrm{~mm}$ length of uniform capillary between the bulb and the immersion line or the lowest graduation, if the graduation is not above $100{ }^{\circ} \mathrm{C}$; a $30 \mathrm{~mm}$ length if the graduation is above $100{ }^{\circ} \mathrm{C}$.

(b) A $5 \mathrm{~mm}$ length of uniform capillary between an enlargement and the graduation next below, except at the top of the thermometer.

(c) A $10 \mathrm{~mm}$ length of uniform capillary between an enlargement, other than the bulb, and the graduation next above, if the graduation is not above $100{ }^{\circ} \mathrm{C}$; a $30 \mathrm{~mm}$ length if the graduation is above $100{ }^{\circ} \mathrm{C}$.

(d) A $10 \mathrm{~mm}$ length of uniform capillary above the highest graduation, if there is an expansion chamber; a $30 \mathrm{~mm}$ length if there is no expansion chamber.

These dimensions are shown in Figure 4.

\subsection{Reference Point}

Thermometers graduated above $150{ }^{\circ} \mathrm{C}$, or precision thermometers with an expected accuracy of better than $0.1{ }^{\circ} \mathrm{C}$ when calibrated for actual temperature measurement, must have a reference point. The effects of changes in the bulb volume on the thermometer indications may be followed throughout the life of the thermometer by periodic testing at the reference point. From the reference point observations, the thermometer corrections can be kept current (see Section 10.2). If a suitable reference point, either the ice or steam point, is not included in the range of the main scale, a short auxiliary scale containing a fixed point should be provided. To prevent the thermometer from being unduly long, a contraction chamber may be introduced between the auxiliary scale and the main scale. 

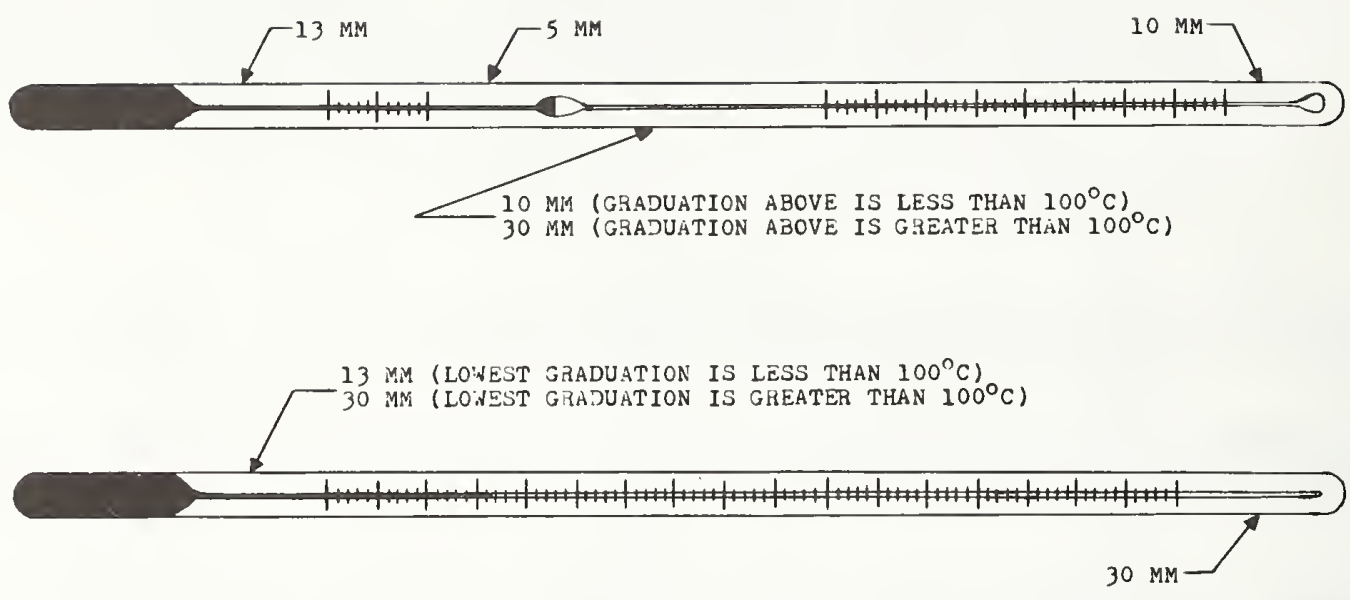

Fig. 4. Minimum distances for scale placement on a liquid-in-glass thermometer.

Any auxiliary scale must have graduations identical to those on the main scale, both dimensionally and in terms of temperature, and they must extend for a short interval both above and below the reference point. Similarly, when the main scale ends near a reference point, the graduations must be continued for a short interval beyond the reference temperature.

Reference points are not needed on thermometers intended for differential measurements (such as calorimetric thermometers), nor on thermometers graduated below $150{ }^{\circ} \mathrm{C}$, if they are not to be calibrated to an accuracy of better than $0.1{ }^{\circ} \mathrm{C}$.

\subsection{Temperature Scale and Primary Standard Thermometer}

\subsection{International Practical Temperature Scale}

The scale to which measurements of temperature should ultimately be referred is the Kelvin Thermodynamic Temperature Scale (KTTS). Values of temperature expressed on the KTTS are designated by the symbol $T$. The unit of temperature is the Kelvin, symbol $\mathrm{K}$, which is a base unit of the Systeme Internationale (SI), and is defined as "the fraction 1/273.16 of the thermodynamic temperature of the triple point of water." 
Because of the difficulties that are encountered in the practical realization of the KTTS, it has been necessary to define and utilize practical temperature scales. The International Temperature Scale and defining text was first adopted in 1927 and later revised in 1948. The Eleventh General Conference of Weights and Measures in 1960 changed the name of the scale to the International Practical Temperature Scale (IPTS) of 1948 and adopted a revised text of the scale, although numerically the scale was not changed. In 1968, in accordance with the power given to it by Resolution 8 of the Thirteenth General Conference of Weights and Measures, the International Committee of Weights and Measures adopted the International Practical Temperature Scale of 1968 [5], henceforth referred to as IPTS-68. The IPTS-68 replaced the International Practical Temperature Scale of 1948 and may be expressed either as a Kelvin scale or as a Celsius scale.

The present Celsius scale has its zero $0.01 \mathrm{~K}$ below the triple point of water (the ice point, which is essentially $0{ }^{\circ} \mathrm{C}$, can be realized by pure ice in equilibrium with pure water saturated with air at one standard atmosphere). The value of a temperature expressed on the Thermodynamic Celsius Temperature Scale is designated by the symbol $t$ and is related to the value on the KTTS by:

$$
t=\mathrm{T}-273.15 \mathrm{~K}
$$

The unit of the Celsius Scale is the degree Celsius, symbol ${ }^{\circ} \mathrm{C}$, which by definition is equal in magnitude to the Kelvin.

Values of temperature expressed on the International Practical Kelvin Scale are designated by the symbol $\mathrm{T}_{68}$, and values of temperature expressed on the International Practical Celsius Temperature Scale are designated by the symbol $t_{68}$. The relationship between $T_{68}$ and $t_{68}$ is:

$$
t_{68}=T_{68}-273.15 \mathrm{~K} \text {. }
$$

The units of $T_{68}$ and $t_{68}$, like the thermodynamic scales, are the Kelvin, symbol $\mathrm{K}$, and degree Celsius, symbol ${ }^{\circ} \mathrm{C}$.

The IPTS-68 was designed to be in agreement within the uncertainty of the KTTS at the time. The IPTS-68 is intended to provide scientific and industrial laboratories throughout the world with a common basis for stating temperatures. Calibrations of thermometers at NBS, therefore, are made with reference to values of temperature on the IPTS- 68 .

Although values of temperature on the IPTS-68 are expressed in degrees Celsius, thermometers that are graduated on the Fahrenheit Scale can be calibrated with reference to the IPTS-68 by using the conversion formula:

$$
\text { (temperature value in } \left.\left.{ }^{\circ} \mathrm{F}\right)=(9 / 5) \text { (temperature value in }{ }^{\circ} \mathrm{C}\right)+32 \text {. }
$$

The National Bureau of Standards has been performing calibrations with reference to the IPTS -68 since July, 1969. All Reports of Calibration and Reports of Test issued after that date clearly indicate this scale. 
In the range of temperature normally covered by liquid-in-glass thermometry, the IPTS-68 is defined by the following fixed points:

(1) The equilibrium between the liquid and vapor phases of oxygen (condensation point of oxygen at one standard atmosphere) at $-182.962{ }^{\circ} \mathrm{C}$,

(2) The equilibrium between solid, liquid, and vapor phases of water (triple point of water) at $0.01{ }^{\circ} \mathrm{C}$,

(3) The equilibrium between the liquid and vapor phases of water at one standard atmosphere (normal boiling point of water) at $100{ }^{\circ} \mathrm{C}$,

(4) The equilibrium between the solid and liquid phases of tin (freezing point of tin at one standard atmosphere) at $231.9681{ }^{\circ} \mathrm{C}$. (This point may be used as an alternative to the boiling point of water.)

(5) The equilibrium between solid and liquid phases of zinc (freezing point of zinc at one standard atmosphere) at $419.58{ }^{\circ} \mathrm{C}$.

Additionally, the temperatures on the IPTS-68 in the range of -182.96 to $+630.7{ }^{\circ} \mathrm{C}$ are defined in terms of a standard platinum resistance thermometer that has been calibrated at the above fixed points, with interpolations and extrapolations between and beyond these points being accomplished by employing specified equations [5].

At NBS, liquid-in-glass thermometer indications, except at the ice point, are compared directly with temperatures measured with a standard platinum resistance thermometer and an NBS-built Cutkosky AC resistance bridge [6] (see Figure 5).

\subsection{Standard Platinum Resistance Thermometer}

A standard platinum resistance thermometer (SPRT) has a resistor made of platinum of sufficient purity that the finished thermometer will have a value of the resistance at $100{ }^{\circ} \mathrm{C}$ divided by the resistance at $0{ }^{\circ} \mathrm{C}$ $[R(100) / R(0)]$ not less than 1.3925 or alpha, defined as $(\mathrm{R}(100)-\mathrm{R}(0)) / 100 \mathrm{R}(0)$, not less than 0.003925. The typical SPRT has an ice-point resistance of about $25.5 \mathrm{ohms}$ and is called a 25 -ohm thermometer; its resistor is wound from about $61 \mathrm{~cm}$ of $0.075 \mathrm{~mm}$ diameter wire.

The insulation material that supports the resistor and leads must not contaminate the platinum during the annealing of the assembled thermometer nor when subjected for extended periods of time to temperatures to which the thermometer is normally exposed. The insulation resistance between the leads must be greater than $5 \times 10^{9}$ ohms at $500{ }^{\circ} \mathrm{C}$ if the error introduced by insulation leakage in the leads of a 25-ohm thermometer is to be less than the equivalent of 1 micro ohm. For SPRT's the most commonly used insulation is mica. 


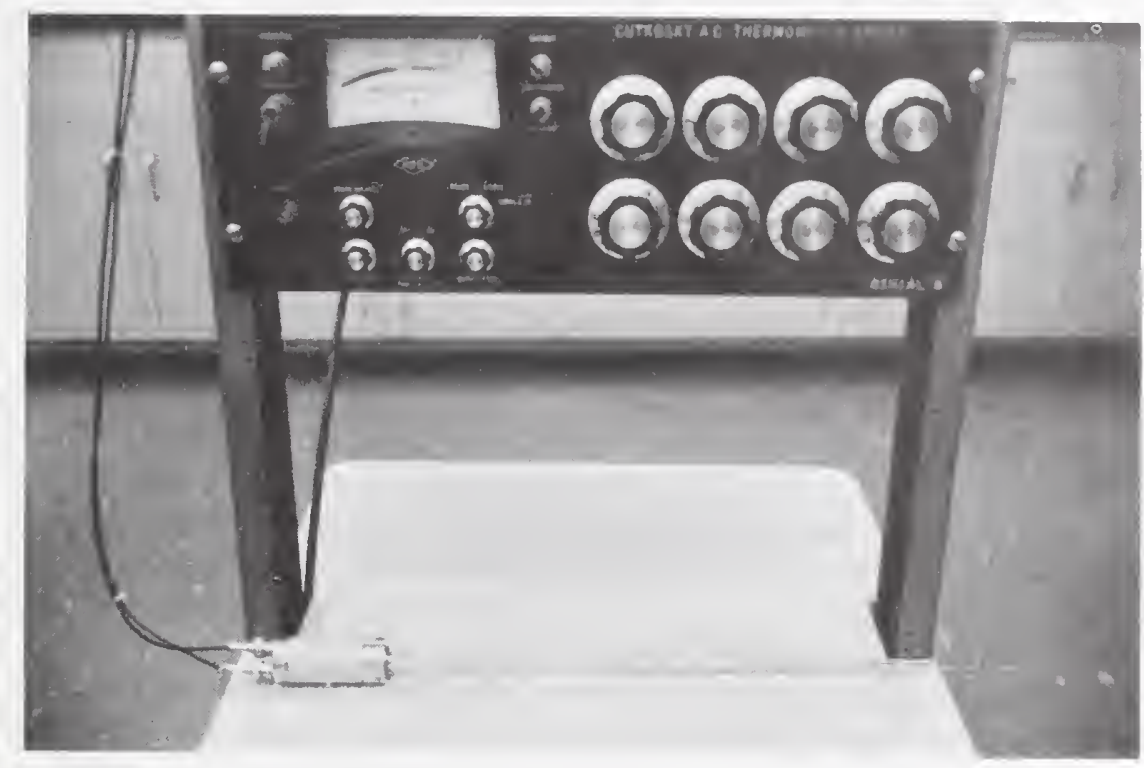

Fig. 5. Standard platinum resistance thermometer and Cutkosky AC resistance bridge used for calibrating liquid-inglass thermometers.

The configuration of the resistor is inevitably the result of compromise between conflicting requirements. The resistor must be free to expand and contract without constraint from its support. This characteristic is the so called "strain-free" construction. If the platinum were not free to expand, the resistance of the platinum would not only be a function of temperature but would also relate to the strain that results from the differential expansion of the platinum and its support.

The sensing elements of all SPRT's have four leads. The four leads define the resistor precisely by permitting measurements that eliminate the effect of the resistance of the leads. The resistor winding is made as noninductive as possible, often bifilar.

Because the junction of the leads is electrically a part of the measured resistor, the leads extending immediately from the resistor must also be of high purity platinum; the lengths of these leads are often as short as $8 \mathrm{~mm}$. Either gold or platinum wire is employed in continuing these leads within the thermometer. Gold does not seem to contaminate the resistor and is easily worked. Measurement of the resistor may be facilitated if the four leads are made of the same material with the length and diameter the same so that the leads have about equal resistances at any temperature. This statement is also applicable to leads that are external to the protecting envelope. 
The hermetic seal through the soft glass envelope at the thermometer head has been made using short lengths of tungsten wire, to the ends of which platinum lead wires are welded. The external platinum leads are soft soldered to copper leads that are mechanically secured to the head. More recently the hermetic seal has been made using commercially available "electronic-type" metal-to-glass seals. Coaxial leads are required when an $\mathrm{AC}$ bridge is used to determine the resistance of the SPRT.

\subsection{AC Bridge}

If the current is reversed sufficiently rapidly, it is usually said that the bridge is an "AC" bridge. Bridges operating at 400 hertz have been built at the NBS based on a design by Cutkosky [6]. These bridges were designed for use with SPRT's. The bridge uses an inductive ratio divider that eliminates the need for calibrating the bridge because the initial uncertainty of the divider is about 2 parts in $10^{8}$ and appears to be stable. Additionally, the bridge requires only one manual resistance balance, the phase angle balance is automatic, and incorporates a built-in phase-sensitive null detector which can easily resolve 1 micro ohm in 25 ohms. A small error (usually less than 10 micro ohms) may be introduced in measuring a 25-ohm SPRT unless coaxial leads are used between the bridge and the thermometer head. (The heads of SPRT's have been modified to contain two BNC coaxial connectors. The two leads from one end of the SPRT coil were connected to the center "female" contacts of the BNC receptacles and the two leads from the other end of the SPRT were connected to the outer shells or the shield contacts.) For precision measurements the length of the pair of coaxial leads should not be greater that 15 meters to limit the dielectric losses of the shunt capacitance. Preliminary measurements on 25-ohm SPRT's indicate that, if the leads do not affect the measurements, the accuracy of the measured value in ohms of a thermometer element is limited by the accuracy to which the reference standard resistor is known. However, in the accurate determination of the resistance ratio, $R(t) / R(0)$, the stability, rather than the accuracy, of the reference standard is the important requirement.

\subsection{Description of the Measurement System}

\subsection{Laboratory Environment}

The laboratory should be maintained at a constant temperature and humidity. Many thermometers that are submitted for calibration will be intended for use at partial immersion. In this case it is important that the emergent stem remain at a constant temperature while the thermometer is being tested. For example, if there is a one degree change in the laboratory temperature, an error of approximately $0.01{ }^{\circ} \mathrm{C}$ can result in the calibration of a partial-immersion thermometer with 50 degrees of stem emerging from the bath. The temperature of the calibration laboratory at NBS is maintained at $23{ }^{\circ} \mathrm{C} \pm 1$ degree. The humidity is maintained near 50\% to keep any electronic components in the laboratory from being adversely affected. 
The calibration baths that use oil as the medium are operated under a hood which is isolated from the ventilation system of the building and exhausted directly outside.

The thermometers submitted for calibration and the standard platinum resistance thermometers are stored in map cases which have corrugated paper placed on the bottom of each drawer to keep the thermometers from rolling into each other when the drawer is opened. Immediately before and after calibration, thermometers are stored vertically in a thermometer rack designed especially for this purpose.

\subsection{Calibration Baths}

In most instances, the liquid-in-glass thermometer scale corrections are determined by comparing its scale indications in a series of stirred liquid comparison baths with the temperature of the bath medium measured by a standard platinum resistance thermometer.

All electrically heated constant temperature comparison baths at NBS have the heating coils isolated from the volume where the thermometers are placed. There is an unrestricted path of flow for the bath medium, which is stirred at a sufficient rate to maintain a uniform temperature throughout the bath. Heat loss from the baths is minimized by a 5 to $7 \mathrm{~cm}$ thickness of insulation around the bath and an insulated cover. A holder containing the thermometers is fitted into the top cover. This holder can be rotated, enabling each thermometer to appear in the field of view of a vertically adjustable 10 power telescope attached to each bath. The telescope is always kept perpendicular to the thermometers being read.

The comparison baths used to calibrate thermometers above $0{ }^{\circ} \mathrm{C}$ are manually controlled by adjusting the current to the heating coils through a rheostat. For calibration below $0{ }^{\circ} \mathrm{C}$ the temperature is automatically controlled.

All baths at NBS were evaluated to determine the temperature gradient throughout the medium. This was done by placing three standard platinum resistance thermometers at various locations and depths in the medium. The thermometers were read simultaneously and the maximum difference between the three readings at each temperature was considered to be caused by the gradient. In addition to the temperature gradient throughout the medium, there are large variable gradients in liquid baths in the region close to the surface, due to large heat loses at the surface because of radiation and evaporation. The depth to which the surface conditions affect the temperature regulation depends upon the bath liquid and the operating temperature. Obviously, thermometers must be immersed deep enough to avoid this unregulated region. Henceforth, this unregulated region of the bath will be referred to as the "unknown temperature region." The depth of such region will be given with the description of each bath.

A discussion of the NBS calibration baths is given in the following sections. 


\subsubsection{Ice Bath}

An ice bath (see Figure 6) is a fixed-point apparatus used to determine the reference point on liquid-in-glass thermometers at $0{ }^{\circ} \mathrm{C}$. No standard thermometer is needed to realize the temperature of the ice and water mixture. If it is made properly, the uncertainty of the medium is no greater than $0.005{ }^{\circ} \mathrm{C}$.

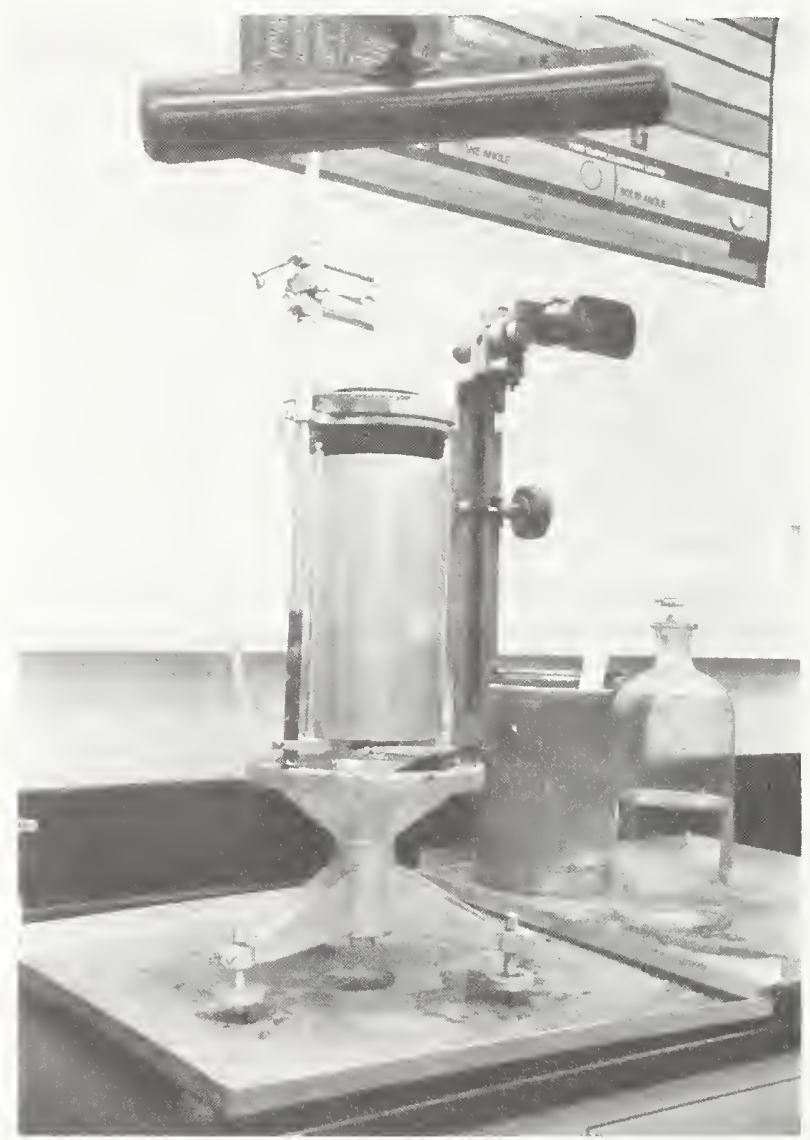

Fig. 6. Ice point bath.

The ice bath is perhaps the most valuable and essential reference temperature apparatus in the liquid-in-glass thermometer calibration laboratory, because all liquid-in-glass thermometers suffer changes in bulb volume (due to thermal expansion and other factors). Recalibration at the ice point is sufficient in most cases to correct for such changes (see Section 5.2, NBS Monograph 150 [7]).

The ice bath at NBS consists of a glass Dewar flask approximately $36 \mathrm{~cm}$ deep and $8 \mathrm{~cm}$ in diameter. The outside of the flask is covered with 
electrical or waterproof adhesive tape and enclosed in a metal sleeve to protect the operator in the event that it should break. The flask is supported by a structure that will not allow it to tip over easily. A clip is placed above the flask to hold the thermometer perpendicular to the telescope. A siphon is placed in the bottom of the flask to remove excess water that will form due to the melting of the ice during the day. A small soft mallet, which is used to gently tap the thermometers before reading, is available.

A still and storage tank are used to keep the laboratory supplied with an adequate amount of distilled water. The distilled water that is produced is frozen to form blocks of distilled water ice. The freezer and containers used for this purpose are not used for anything else and kept as clean and free from impurities as possible. The containers are washed thoroughly with soap and water and rinsed two or three times with distilled water before being used initially.

An ice shaver is used to shave the ice to the proper size. The ice chips should be approximately 2 to $5 \mathrm{~mm}$ in diameter. These particles are smaller than those produced by crushing or chipping the ice.

The shaved ice and air saturated distilled water are placed in the Dewar flask and allowed to reach a constant temperature, a process which takes approximately 15 to 30 minutes. After this time, any excess water should be siphoned off and additional ice added. When the ice bath is ready for use, there should be no floating ice in the flask and no excess water on the surface. There should be as much ice as can be forced into the flask and sufficient distilled water to fill the small crevices between the ice chips. Failure to follow this procedure can lead to vertical or radial temperature gradients which can result in a calibration error as large as $0.01{ }^{\circ} \mathrm{C}$ in the ice point.

Whenever the ice bath is used, care should be taken not to contaminate the ice or water. Plastic gloves should be worn by the operator or hands washed often while taking ice points. It is important that impurities, such as salt from the hands, not be allowed to come in contact with the ice. This will cause a depression of the freezing point and result in an error in subsequent ice-point determinations.

\subsubsection{Steam Bath}

Although the ice point at $0{ }^{\circ} \mathrm{C}$ is most often the reference point, the steam point at $100{ }^{\circ} \mathrm{C}$ is sometimes used. The steam bath or hypsometer used at NBS and its schematic drawing are shown as Figures 7 and 8 , respectively. This bath is used only if the $100{ }^{\circ} \mathrm{C}$ mark is too close (less than $50 \mathrm{~mm}$ ) to the bulb or contraction chamber to permit adequate immersion of these large volumes of mercury in an oil bath. Approximately 1,000 $\mathrm{ml}$ of distilled water is placed in the boiler. A Fisher burner is ignited under the boiler and in approximately one hour the bath is ready to be used.

Steam produced from the boiler circulates within a double-walled steam jacket permitting free circulation of steam around the thermometers 


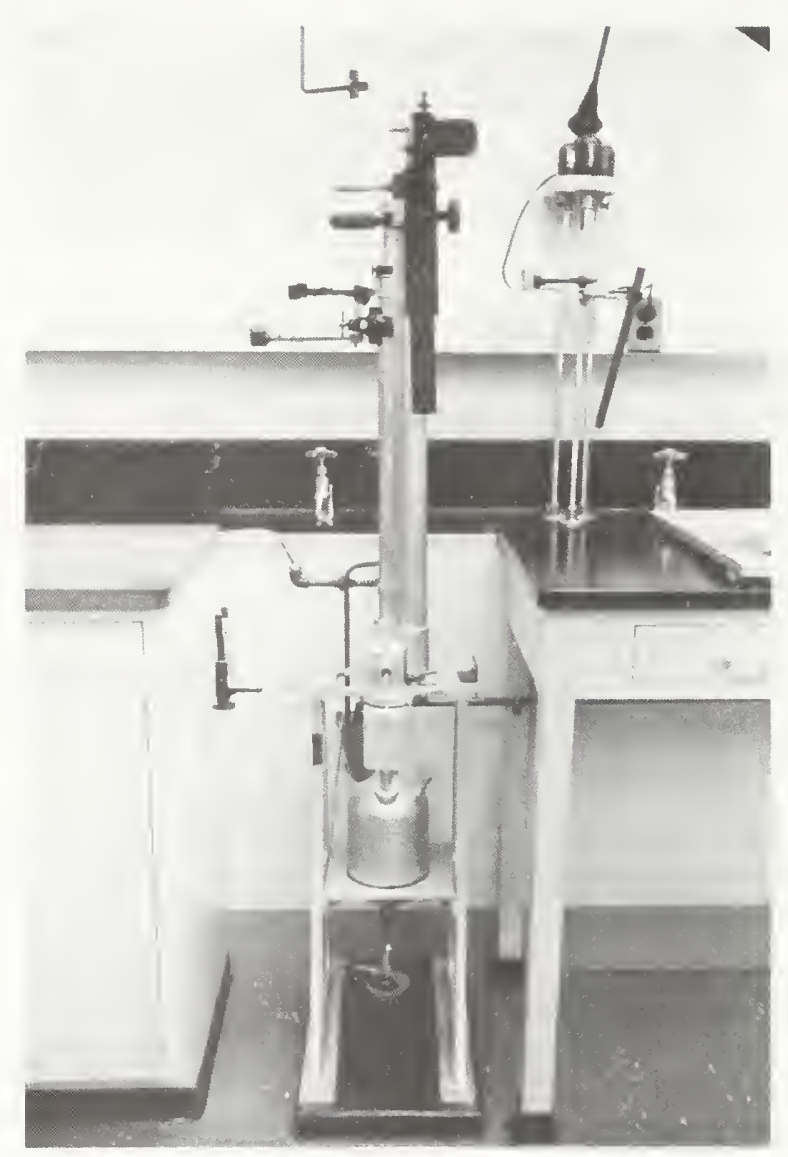

Fig. 7. Steam point bath.

suspended within this space. Water condenses and drips from the thermometer. A provision is made both for relieving any excess pressure in the space surrounding the thermometers and for determining the excess pressure by means of a small differential manometer.

When the steam bath is used as a comparison bath, the temperature of the steam is determined at the time of test with a standard platinum resistance thermometer.

The steam bath can also be used as a fixed-point apparatus. In this case a barometer is used, since the temperature of the steam depends on the prevailing atmospheric pressure. The usual adjustments must be made to the barometer reading, including any necessary corrections for the value of local acceleration of gravity, for the difference in height between the steam bath and the barometer, and for any excess pressure above atmospheric in the steam jacket. After the corrected pressure reading is obtained, the temperature of the steam can be derived from the values given in Table 2 . 


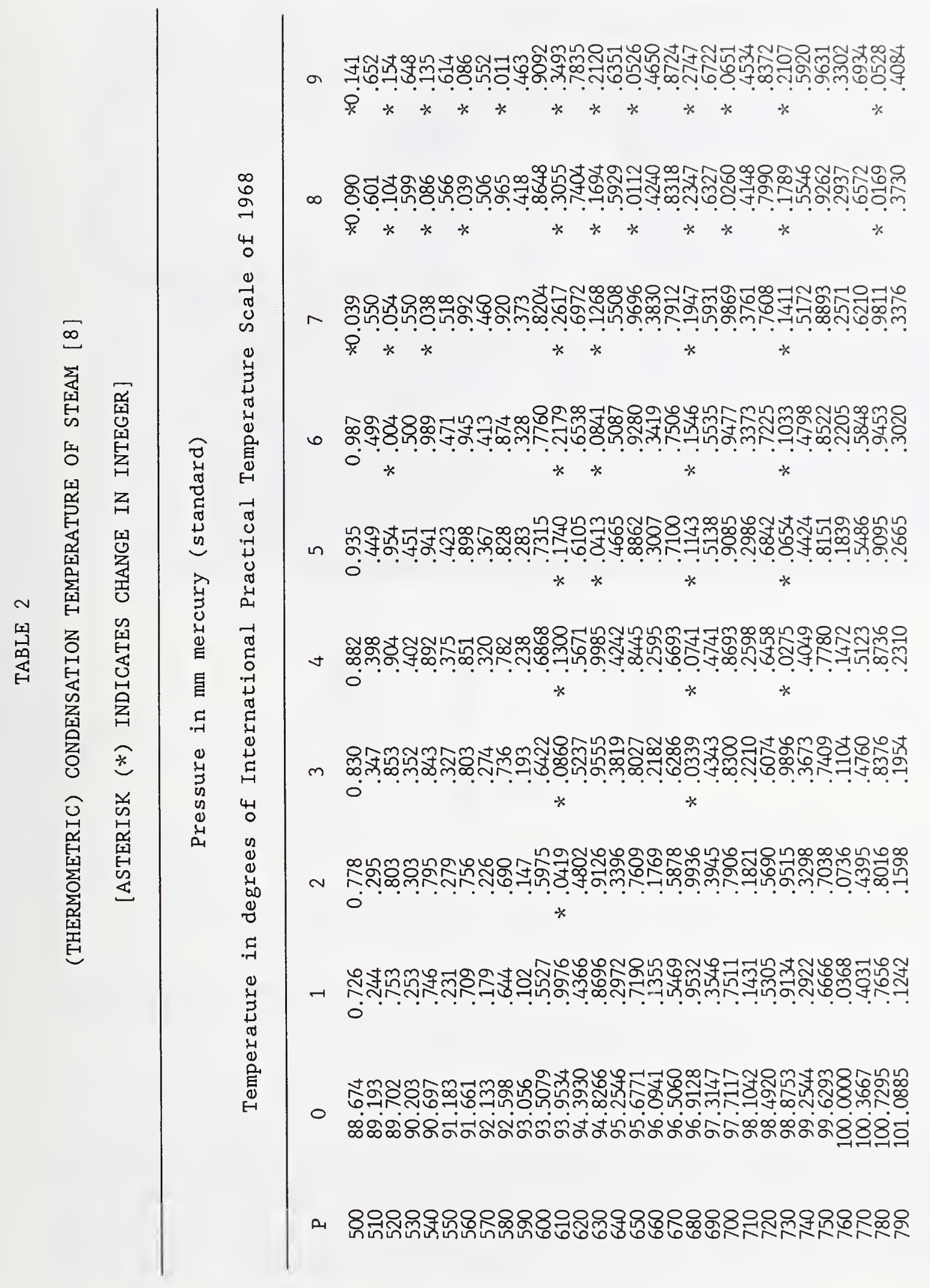




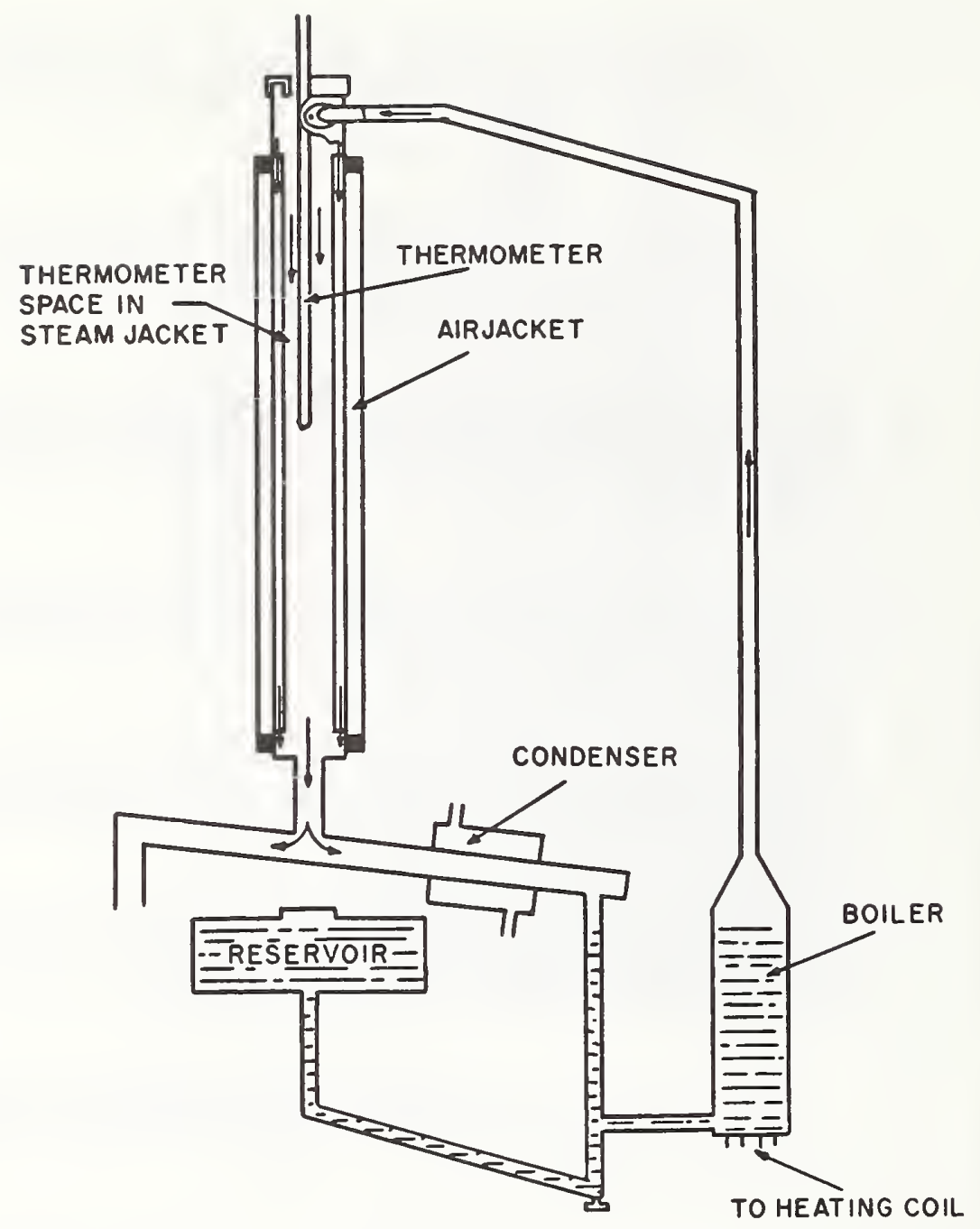

Fig. 8. Schematic drawing of the steam point bath.

With a barometer accurate to $0.1 \mathrm{~mm}$ mercury, this procedure is capable of an accuracy of 0.002 to $0.003{ }^{\circ} \mathrm{C}$. The Fortin type barometer will usually suffice for all but the most exacting measurements.

\subsubsection{Water and Oil Baths}

The designs are the same for both the water and the oil baths that are used at NBS. A photograph of an oil bath is shown as Figure 9 and a drawing is given as Figure 10. The baths consist of two cylindrical wells of different diameters with connecting passages at the top and bottom. The heating coil and stirrer are located in the smaller well, leaving the larger well unobstructed for the insertion of the thermometers. The fluid 


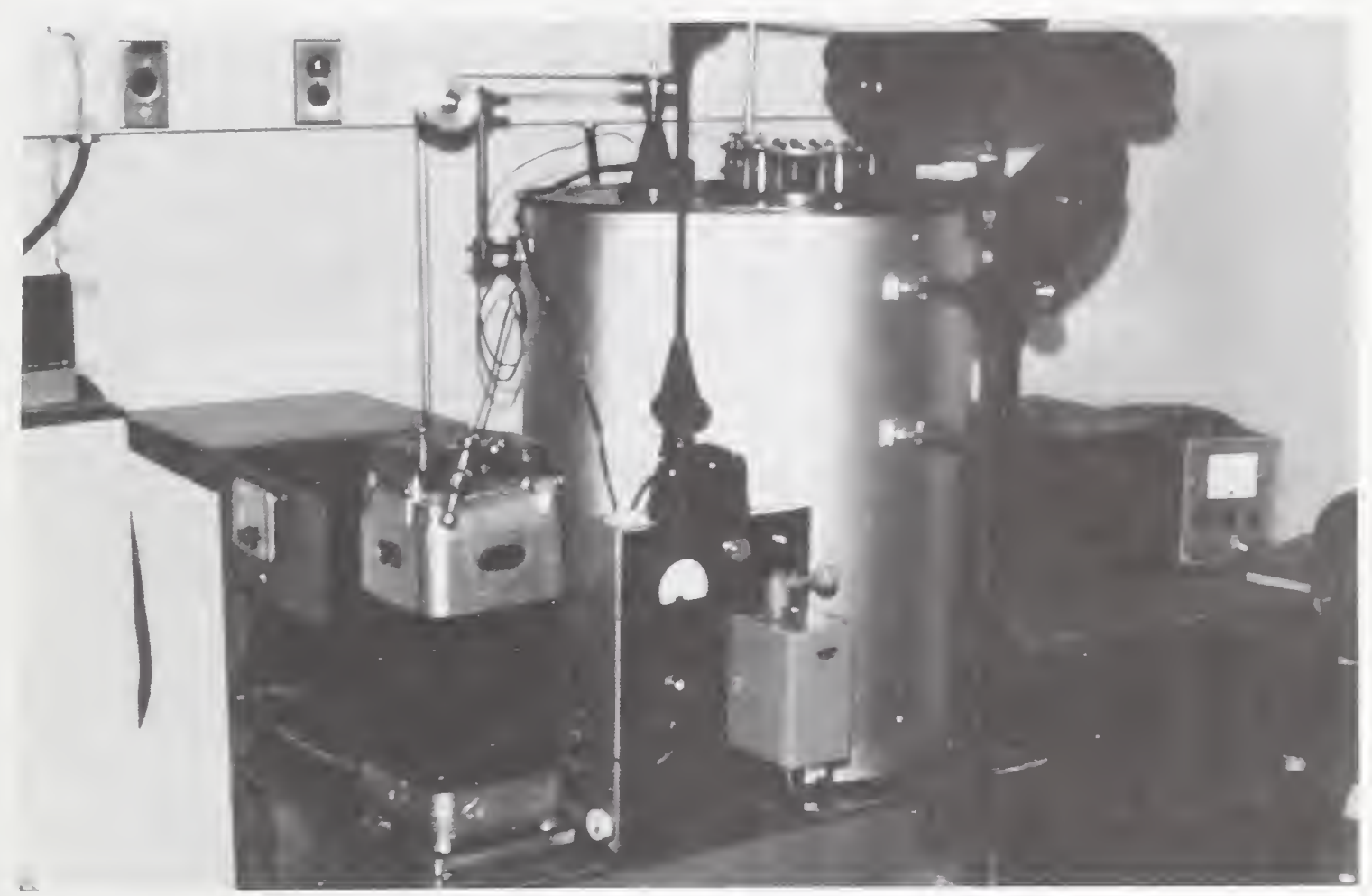

Fig. 9. Oil bath.

is forced past the heating coils, through the bottom opening into the larger well, around the thermometers, and back into the smaller well through the connecting passage at the top.

For calibration in the range of +1 to $+95{ }^{\circ} \mathrm{C}$, distilled water is used as the bath medium. Distilled water is preferable to tap water, since no chemical deposits will form at the top of the bath. Water is plentiful, clean, and does not produce harmful vapors. Some distilled water is added each day before the bath is used, since some of the water will escape through the overflow tube due to expansion when heated. The level of the water should be no more than $10 \mathrm{~mm}$ below the top of the thermometer holder (see figure 10).

For calibration from approximately +1 to $22{ }^{\circ} \mathrm{C}$, the bath water is cooled by adding ice made from distilled water to bring the temperature of the bath below the lowest calibration point. When the ice has melted, the stirrer is turned on and the water is heated to bring the meniscus of the thermometer under test to within one scale division of the calibration point. No heat is added to the water when calibrating in this range, since the temperature of the bath will rise at a steady rate, due to heat from the room. Measured gradients in the water bath do not exceed $0.01{ }^{\circ} \mathrm{C}$. The unknown temperature region is $25 \mathrm{~mm}$ deep. 


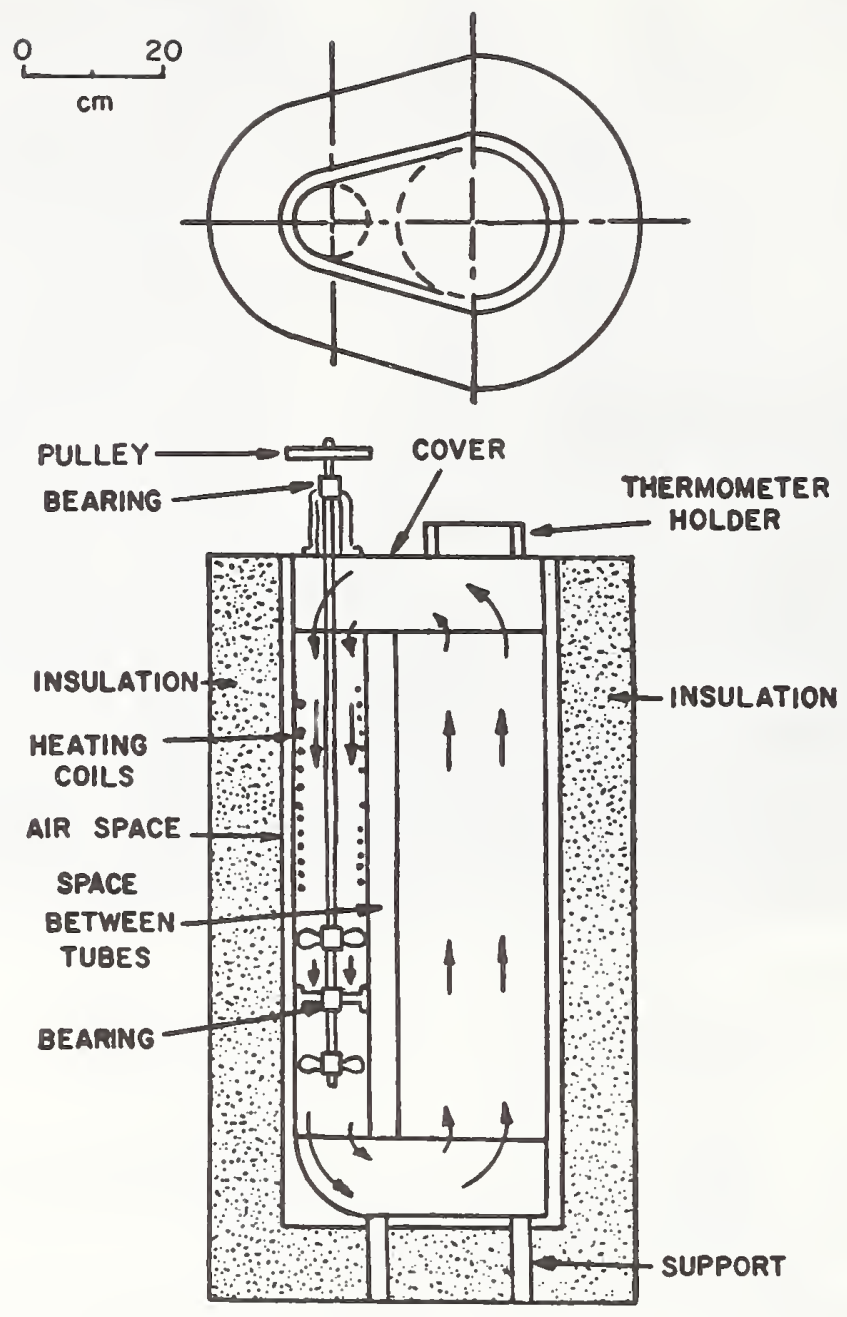

Fig. 10. Drawing of water and oil baths.

Two oil baths are maintained at NBS. One, called the low temperature oil bath, is used to calibrate thermometers in the range of +95 to $+200{ }^{\circ} \mathrm{C}$. An oil purchased from EXXON, known as Zerice $46^{1}$, is used. Before starting,

${ }^{1}$ Certain commercial equipment, instruments, or materials are identified in this paper in order to adequately specify the experimental procedures. Such identification does not imply recommendation or endorsement by the National Bureau of Standards, nor does it imply that the materials or equipment identified are necessarily the best available for the purpose. 
the oil level is first raised to within $25 \mathrm{~mm}$ of the top of the bath by hand pumping oil from an overflow collection pan under the bath. As thermometers are calibrated at the higher temperatures, the bath oil will expand and leave through the overflow tube and is collected in the pan below the bath. The temperature gradients in the low temperature oil bath range from $0.01{ }^{\circ} \mathrm{C}$ at $100{ }^{\circ} \mathrm{C}$ to $0.025{ }^{\circ} \mathrm{C}$ at $200{ }^{\circ} \mathrm{C}$. The unknown temperature region is $50 \mathrm{~mm}$ deep.

For calibration in the range of +200 to $+300{ }^{\circ} \mathrm{C}$ the high temperature oil bath is used. The bath medium is an oil called Extra Hecla from Mobil oil corporation. The oil that exits from the overflow tube is collected in an overflow collection pan. Before the bath is used, oil is poured into the bath to within $70 \mathrm{~mm}$ from the top of the bath. Temperature gradients in the high temperature oil bath are no greater than $0.05{ }^{\circ} \mathrm{C}$. The unknown temperature region is $50 \mathrm{~mm}$ deep.

\subsubsection{Tin Bath}

The tin bath is used to calibrate thermometers in the range of +300 to $+538{ }^{\circ} \mathrm{C}$. The medium is $99.9 \%$ pure tin, conforming to Federal Specification QQ-T-371C, Grade A, and can be purchased from Nathan Trotter, Philadelphia, Pennsylvania.

A picture and drawing of the tin bath are shown as Figures 11 and 12 , respectively. It consists of two coaxial cylinders arranged in such a way as to permit the molten tin to circulate between the walls of the two cylinders and through the inner cylinder by means of openings at the top and bottom. The stirring propeller is situated near the bottom of the inner cylinder, leaving the majority of the space for the reentrant tubes (not shown in the drawing) into which the thermometers are inserted. The heater coils are wound on the outside of the outer cylinder. The gradients in the tin bath range from 0.1 to $0.2{ }^{\circ} \mathrm{C}$. The unknown temperature region is $76 \mathrm{~mm}$ deep.

The evening before the tin bath is to be used, a clock is set to automatically turn the bath on in the early morning hours. This is necessary, since it takes approximately four hours for the bath to reach a temperature of $350{ }^{\circ} \mathrm{C}$. If a temperature above $500{ }^{\circ} \mathrm{C}$ is needed, the clock should be set to turn the bath on at 3:00 am.

Before the tin bath can be used, oxidized tin, formed when the bath was last used, must be removed. To do this, the reentrant tube holder is removed and placed on the hook attached near the top of the stirring shaft. The oxide of tin is at the top of the bath and can be removed easily with special implements stored near the bath. Some residue, which will cling to the reentrant tubes, is removed and this must be done immediately after the tubes are withdrawn from the bath. Fresh tin is added to bring the level of the molten tin within 2 to $3 \mathrm{~cm}$ from the top of the inner cylinder. When all of the oxide of tin has been removed and the level raised, the tubes are placed back into the molten tin bath. The stirrer is turned on and the current to the heater coil is adjusted to control the bath at the desired temperature. 


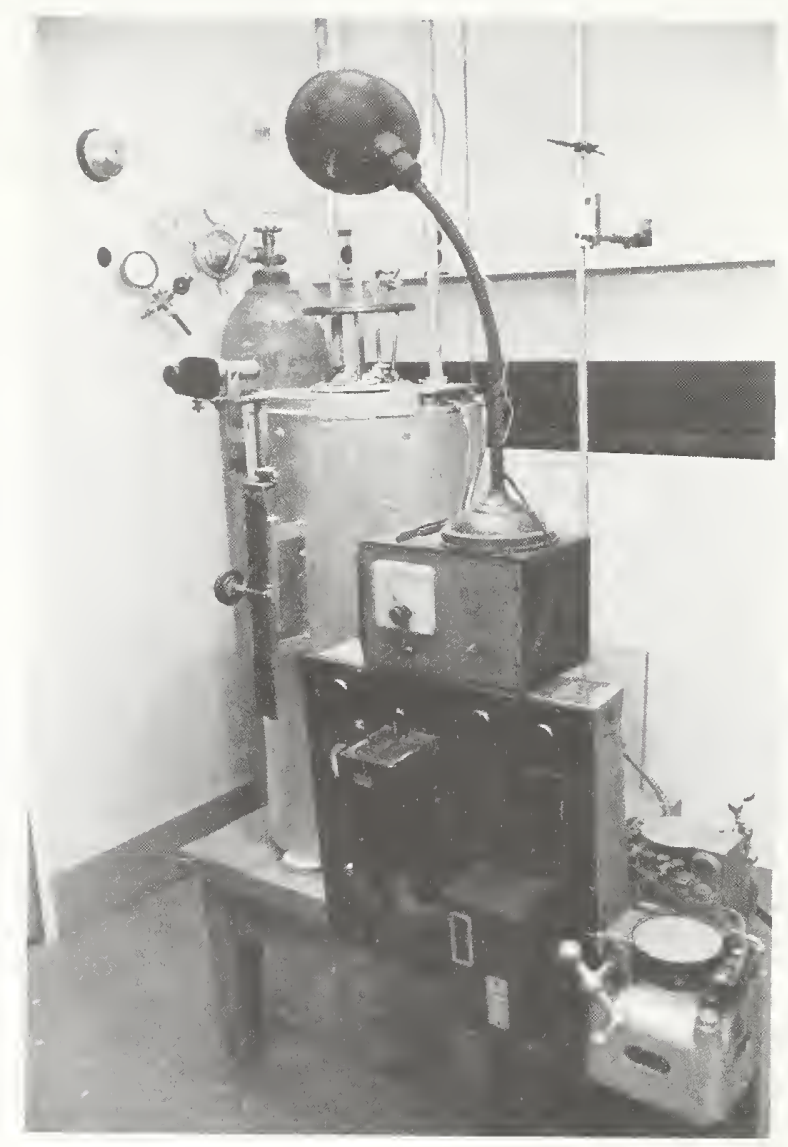

Fig. 11. Tin bath.

\subsubsection{Cryostat}

Calibrations from -1 to $-110{ }^{\circ} \mathrm{C}$ are made in the cryostat shown as Figure 13. A vertical section drawing is shown as Figure 14. The cryostat consists of an inner Dewar flask, D, which contains the bath liquid. This flask is surrounded by liquid nitrogen contained in the outer Dewar flask, C. The rate of heat transfer between the bath liquid and the liquid nitrogen is controlled by the presence or absence of gas or air in the space between the walls of the inner Dewar flask. When the lowest temperature desired for the day is reached, the rate of heat transfer is retarded by evacuating the gas or air through the side tube, $M$, which is connected to a vacuum system. Vigorous stirring of the bath liquid is maintained by the propeller, I, which circulates the liquid around the walls of the stirrer tube, P, similar to the flow of the molten tin in the tin bath. The temperature of the bath is thermostatically controlled by 

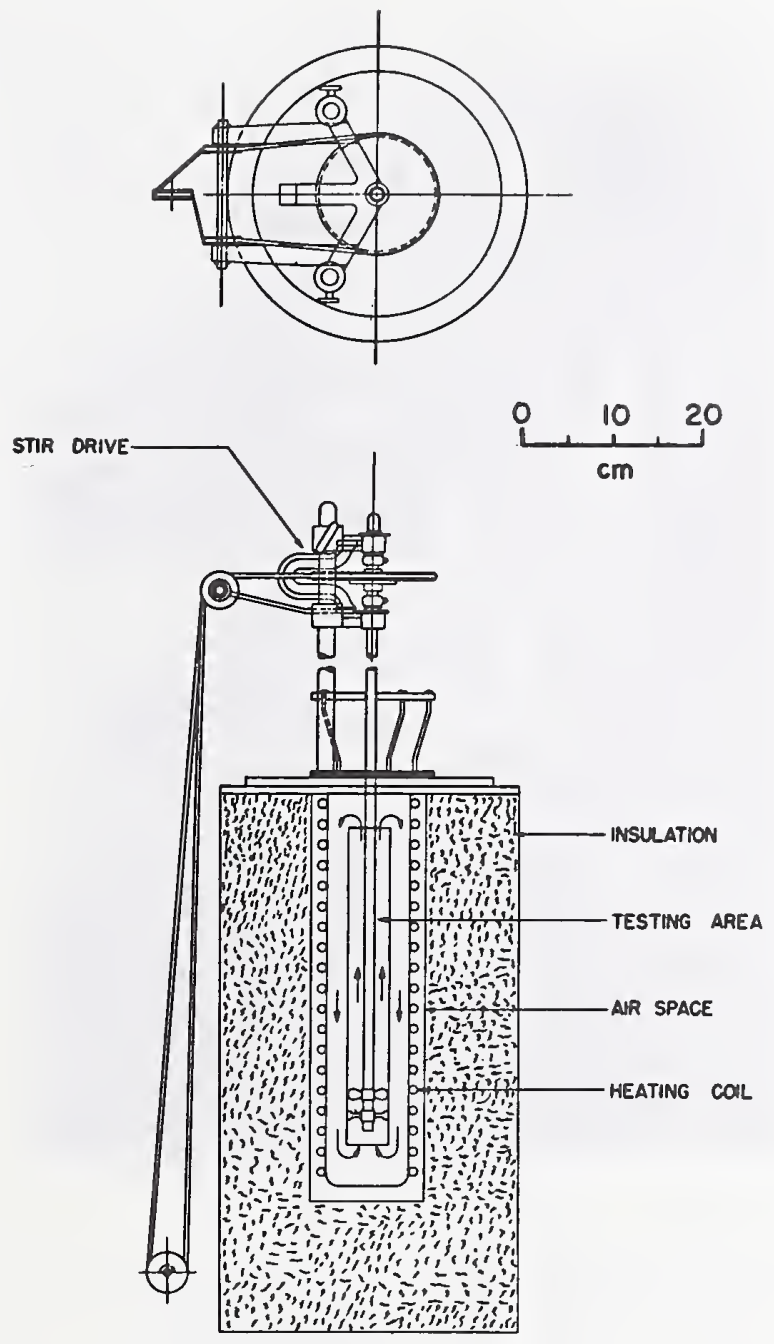

Fig. 12. Drawing of tin bath.

heater coils, $J$, wound on the outside of the stirrer tube. The thermometers are immersed inside the stirrer tube, thus shielding them from the heater coils.

The bath liquid is a five-component mixture containing by weight $14.5 \%$ of chloroform, $25.3 \%$ of methylene chloride, $33.4 \%$ of ethyl bromide, $10.4 \%$ of transdichloroethylene, and 16.48 of trichloroethylene. This mixture freezes at approximately $-150{ }^{\circ} \mathrm{C}$, but readily absorbs moisture and becomes cloudy at somewhat higher temperatures. For this reason calibrations are not performed in this bath below $-110{ }^{\circ} \mathrm{C}$. Another liquid that has been 


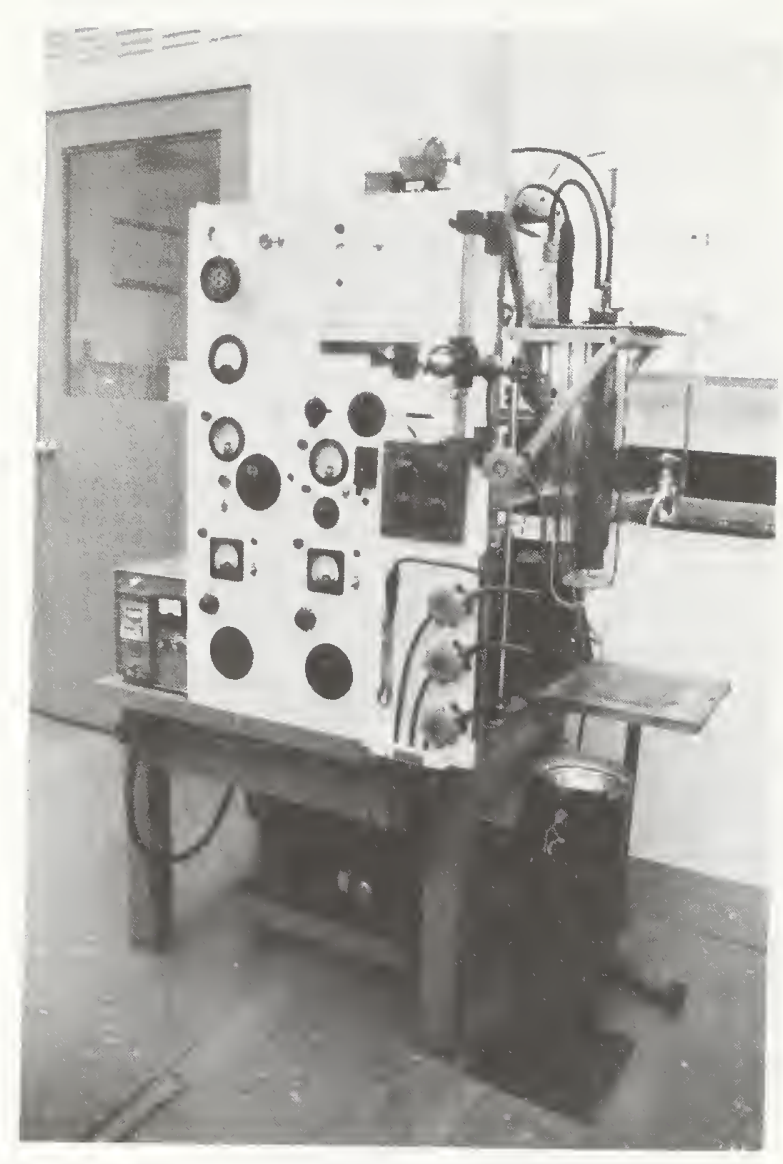

Fig. 13. Cryostat.

used as the bath medium is 2-methylpentane. Measured gradients in the cryostat did not exceed $0.01{ }^{\circ} \mathrm{C}$. The unknown temperature region is $25 \mathrm{~mm}$ deep.

\subsubsection{Liquid Nitrogen and Liquid Oxygen Points}

A comparison measurement can be made at approximately $-196{ }^{\circ} \mathrm{C}$ (boiling point of nitrogen) and $-183^{\circ} \mathrm{C}$ (boiling point of oxygen). A silvered Dewar flask with a narrow transparent vertical strip is used as a container for the liquid nitrogen or oxygen. The liquid is agitated by bubbling nitrogen or oxygen gas in the corresponding liquid through a glass tube with an outlet near the bottom of the flask. The apparatus, shown with thermometers inserted, is pictured in Figure 15. 


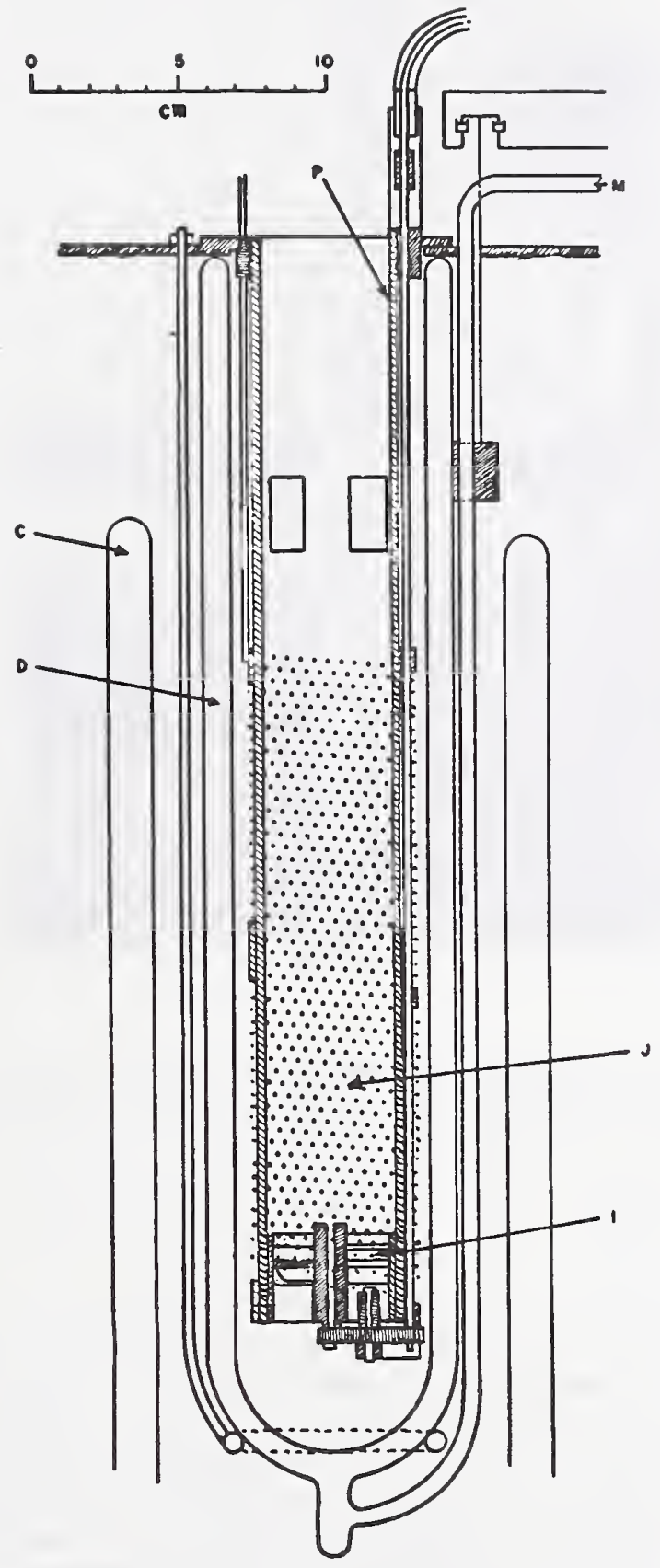

Fig. 14. Vertical section of the cryostat. 


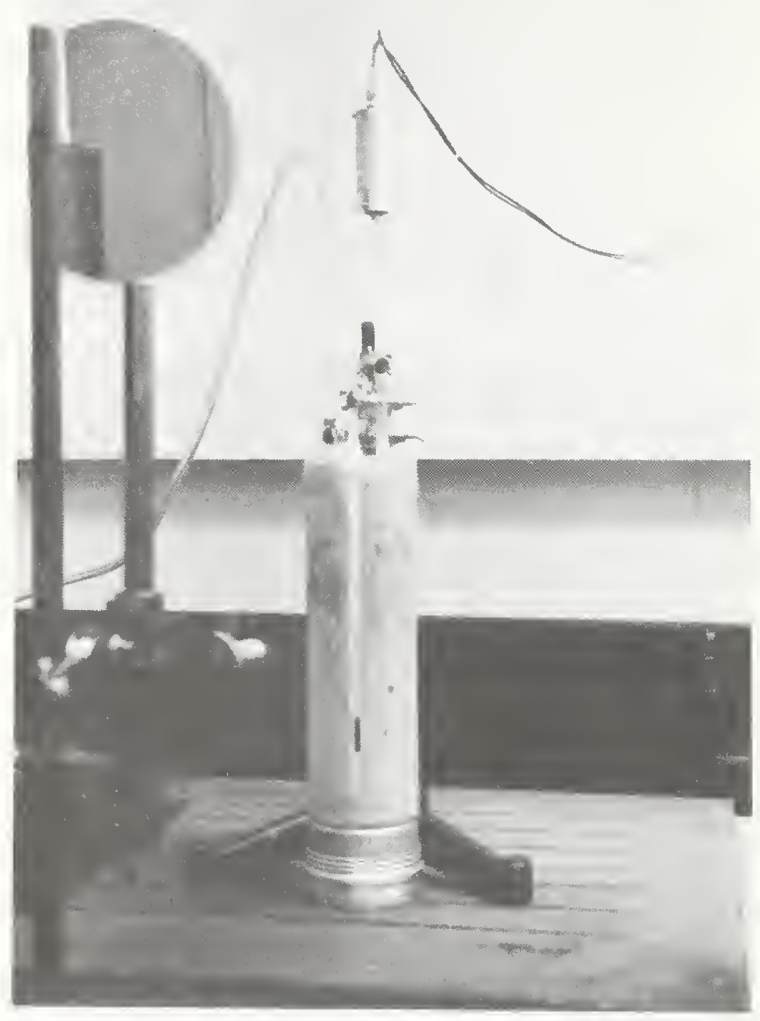

Fig. 15. Apparatus used to calibrate thermometers at the boiling point of nitrogen and oxygen.

\subsection{Operational Procedures}

\subsection{Examination and Preparation of Thermometers for Calibration}

Every thermometer submitted for calibration is examined under a 15 to 20 power microscope for defects. One reason for this visual inspection is to detect a separated mercury column or small droplets of mercury that may be at the top of the thermometer. This can occur because of rough handling that may be encountered during shipping. All of the separated mercury must be reunited with the main column before the thermometer can be calibrated. There are three ways that the mercury can be reunited.

a) The bulb of the thermometer may be cooled in a solution of common salt, ice, and water (or other cooling agent) to bring the mercury down slowly into the bulb. If the salt solution does not provide sufficient cooling, carbon dioxide snow (dry ice) may be used. Since the temperature of the 
dry ice is approximately $-78{ }^{\circ} \mathrm{C}$, and mercury freezes at approximately $-40{ }^{\circ} \mathrm{C}$, the mercury will solidify. The lower half of the bulb is cooled and never the stem or mercury column. Moderate tapping of the bulb on $a$ rubber pad or stopper or similar soft spongy object, or the application of centrifugal force, by swinging the thermometer in a short arc, usually serves to unite the mercury into the bulb. In the event that the mercury has solidified, care must be taken to warm the top of the bulb first, so that pressures in the bulb, due to expanding mercury, may be relieved.

b) If there is a contraction chamber above the bulb or an expansion chamber at the top of the thermometer, the separated portion of the mercury is first driven into either chamber by warming or cooling the bulb. The thermometer is then tapped laterally against the hand to shatter the separated portion into droplets. The thermometer is next heated or cooled to drive the main column into the contraction chamber or the expansion chamber to pick up the droplets. If the bulb is heated, it should be done uniformly. Great care is necessary to avoid filling the expansion chamber completely with mercury, which might produce pressures large enough to burst the bulb. The expansion chamber should never be more than $2 / 3$ full. This procedure should not be used if the thermometer requires heating above $260{ }^{\circ} \mathrm{C}$.

c) As a last resort, especially for thermometers with no expansion chambers, small separated portions of the column or droplets of mercury at the top can be converted to mercury vapor by placing the top of the thermometer in an oil bath (200 to $250{ }^{\circ} \mathrm{C}$ ). The vapor condenses in the cooler capillary, which extends outside of the bath medium. When distillation is complete and no mercury remains at the top of the thermometer, the thermometer bulb is then placed in the bath and heated, causing the droplets, which are now on the thermometer scale, to be collected by the rising mercury column.

The procedure for thermometers containing organic liquids is similar. Separated liquid in the stem can be vaporized and permitted to drain down the capillary. Another method consists of gently tapping the stem above the separation against the palm of the hand, forcing the organic liquid to break away from the wall of the capillary and flow down the bore to join the main column.

Rough handling during shipping can also cause gas bubbles to form in the bulb, a defect that also can be detected during the visual examination. These gas bubbles will expand at a greater rate than the mercury that should be in these spaces; therefore, they must be removed. This is done by a procedure known as "washing" the bulb with a large gas bubble. Instructions for washing are as follows: Bring all of the mercury into the bulb as outlined in section (a). Hold the thermometer in a horizontal position and gently tap it against the hand to form a large gas bubble in the bulb. Force the bubble to travel around the wall of the bulb by rotating the thermometer and tapping it against the palm of the hand. When the large gas bubble has come in contact with the entire inner surface of the bulb, rotate the bubble to the top and reunite the mercury as described above. 
The third reason for examining each thermometer under a microscope is to look for foreign material in the capillary and defects in the thermometer. The foreign materials most often found are glass chips or oxides of mercury. These objects can hold gas or mercury and cause the reading of the thermometer to vary when the thermometer is repeatedly inserted into a regulated constant-temperature bath. The capillary of the thermometer must be clean and free of any foreign material, and it must also appear to have a uniform diameter. If any variation in the diameter of the capillary can be seen under the microscope, the thermometer is not acceptable for calibration. The distance between each scale graduation must be uniform and the scale must be placed on the thermometer according to NBS specifications (see Section 2.5). The thermometer must be numbered correctly, be free of cracks in the glass, and have a serial number. If any of the above conditions are not met in a thermometer that has been submitted for calibration, it will be ineligible for test.

\subsection{Number and Choice of Calibration Points}

A thermometer submitted for test should be calibrated at several points, over at least $80 \%$ of the main scale, and at the reference point (if there is one on the thermometer).

A thermometer is usually calibrated at points spaced uniformly over the entire range of the main scale. The number of calibration points chosen depends on the range of scale, graduation interval, and accuracy desired. The interval between the calibration points should not be unnecessarily small, nor should it be so large as to destroy confidence in interpolated corrections for temperature values between the calibration points.

For thermometers not graduated above approximately $200{ }^{\circ} \mathrm{C}$, it is generally accepted that the interval between these points should not exceed 100 scale divisions, if the corrected temperature values between the calibration points are to have an expected uncertainty of approximately one-half of one scale division. If uncertainties of one or two-tenths of a scale division are desired, it will be necessary to reduce the calibration interval to every 40 or 50 scale divisions. If a thermometer is graduated above $200{ }^{\circ} \mathrm{C}$, a 40 to 50 scale division calibration interval is required to produce corrected temperature values with expected uncertainties of approximately one-half of a scale division, and a 20 to 25 scale division calibration interval is necessary for expected uncertainties to be approximately one or two-tenths of a scale division.

The above results were derived from analysis of data taken on more than 50 NBS owned thermometers purchased from 1930 through 1956 for use as laboratory standards. The data indicated that there was considerable variation among individual thermometers and that scale corrections obtained over a given interval for a particular thermometer were not sufficient to predict whether or not more calibration points were required. The above studies represent only a few of the many types of thermometers submitted to NBS for calibration and may not necessarily be applicable to other types. Experience with a particular type of thermometer seems to be the most reliable guide in the choice of its calibration points. 
If a thermometer is submitted to NBS for calibration and the calibration points are not specified on the purchase order, it will be tested at a reference point and at intervals of approximately every 100 scale divisions. If it is an ASTM thermometer, it will be calibrated at the temperatures suggested in ASTM designation E-1, Standard Specification for ASTM Thermometers [9]. A calibration should never consist of fewer than two points on the main scale, and should always be tested at a reference point, whether on the main scale or on an auxiliary scale.

\subsection{Types of Thermometers and How They are Calibrated}

Thermometers usually are calibrated according to their types. A particular thermometer will only be calibrated differently if the customer specifically requests it. A discussion is presented in this section on the calibration of several types of thermometers.

\subsubsection{Total-immersion Thermometers}

Total-immersion thermometers are pointed and graduated by the manufacturer to indicate correct temperatures when the bulb and the portion of the stem containing the thermometric liquid are subjected to the temperature being measured. While these thermometers are designed for immersion of all the mercury, it is not desirable to immerse the portion of the stem above the meniscus. The heating of this portion to high temperatures could cause excessive gas pressures resulting in erroneous readings and could possibly cause permanent damage to the bulb. Distillation of the mercury could also occur.

In practice, a short length of mercury column, approximately 6 to $12 \mathrm{~mm}$, often must be left emergent from the bath or medium being measured so that the meniscus is visible. If the temperature difference between the bath medium and its surroundings is large, an appreciable temperature gradient may exist around the thermometer stem near the surface of the bath. This condition becomes more serious when a total-immersion thermometer is intentionally used at partial immersion, perhaps because it is too long for the calibration bath and cannot be immersed to the proper depth. If either situation exists, an emergent-stem correction, as explained in Section 6.3, will be necessary. The correction may be as large as 20 Celsius degrees if the length of the emergent liquid column and the difference in temperature between the bath and the space above it are large.

If the thermometer has a contraction chamber, it must be immersed well below the surface of the bath medium. The contraction chamber contains a large amount of mercury and this mercury must be at the same temperature as the mercury in the bulb for the thermometer to give a correct reading. If there is a large temperature gradient near the surface of the bath, as is the case in the oil and tin baths, the contraction chamber must be placed below this gradient, even if this means changing the calibration point. 
These thermometers are calibrated starting at the lowest temperature requested and proceeding in sequence to the highest point. At each calibration point the thermometer must be immersed deeper into the calibration bath to maintain the proper immersion.

\subsubsection{Partial-immersion Thermometers}

In many instances the use of a total-immersion liquid-in-glass thermometer for temperature measurements is inconvenient or impossible. Partialimmersion thermometers are designed with scales graduated to indicate correct temperatures when the thermometers are immersed to specified depths. Partial-immersion thermometers must have an immersion line or the immersion depth engraved or printed on the back. These thermometers are immersed only to the immersion line or specified depth. The portion of the stem that contains mercury above the immersion line is known as the emergent stem. It tends to reach ambient temperature or the temperature prevailing above the calibration bath. Unless otherwise stated, each Report of Calibration issued by NBS gives corrections which are applicable for temperatures prevailing above the comparison baths. No stemtemperature correction is necessary when these thermometers are used under conditions similar to those existing during calibration. However, if conditions differ, especially the temperature of the emergent stem, the necessary emergent-stem correction must be calculated as shown in Section 6.3. An unsteady or irreproducible environment surrounding the emergent stem, together with the inherent difficulty of estimating or measuring the emergent-stem temperature with sufficient accuracy, can contribute markedly to the uncertainty of a given thermometer indication. If the emergent stem is to have a specified stem temperature, as is the case with all ASTM partial-immersion thermometers, a stem-temperature correction must be made as described in Section 6.3. For these reasons, tolerances and uncertainties expected of partial-immersion thermometers are not as stringent as those for total-immersion thermometers.

Calibration points are taken in the same sequence as for total-immersion thermometers and the same precaution must be followed concerning the proper immersion of the bulb and contraction chamber.

\subsubsection{ASTM Thermometers}

Over 120 different thermometer specifications are listed in ASTM Designation E-1, Standard Specification for ASTM Thermometers [9]. The thermometers were designed to be used in specific equipment and test methods and are identified by having the acronym "ASTM" and a number written on the back. Specification E-1 lists the calibration points, stem temperatures for ASTM partial-immersion thermometers, and any special procedure that must be followed. An ASTM thermometer should be tested in accordance with the procedure outline in E-1 [9], and E-77, Verification and Calibration of Liquid-in-Glass Thermometers [4]. 
In some cases it is only necessary to accurately measure a temperature difference rather than the absolute temperature. Calorimetric thermometers were designed for this purpose. Since the accuracy of these thermometers at any one temperature is of less importance than the accuracy of the temperature intervals, no reference point is required. They are usually $600 \mathrm{~mm}$ long, cover a short range of temperature (typically 6 to 16 degrees), and are graduated in intervals of $0.01,0.02$, or 0.05 degree. The thermometers are calibrated at total immersion, usually every 50 to 100 scale divisions (one or one-half degree intervals), and starting at the lowest point. Because of the very small capillary diameter, they must be tapped lightly at each reading to eliminate a possible error due to a sticking mercury column, and they must be heated to the maximum calibration point before testing. Heating to the top point initially causes the bulb to expand to the maximum volume and eliminates the error that will occur because of the gradual expansion of the bulb as the thermometer is heated. In order to register accurate temperature differences, the bulb must be expanded before calibration and use. The thermometer should be calibrated within 2 to 3 hours after it has been heated.

\subsubsection{Beckmann Thermometers}

A Beckmann thermometer is an enclosed-scale type and is constructed in a manner that permits mercury to be removed from, or added to, the bulb, making it possible to use the same thermometer for differential temperature measurements in various temperature ranges [10]. The scale usually consists of 5 to 6 Celsius degrees (some micro types have a scale containing only 3 Celsius degrees) and graduated in intervals of $0.01{ }^{\circ} \mathrm{C}$.

The "setting" of a Beckmann thermometer refers to the temperature of the bulb when the reading on the scale is $0^{\circ}$. When the setting is changed, enabling the thermometer to be used at a higher or lower temperature range, the quantity of mercury affected by a temperature change is not the same. Therefore, two equal changes in temperature at different settings cause different indications on the scale, and a "setting factor" must always be used to convert reading differences into actual temperature differences whenever the thermometer is used at any setting other than the one at which the scale was calibrated. These setting factors combine corrections for the different quantities of mercury during equal temperature changes, and the difference between the mercury-in-glass scale and the International Practical Temperature Scale of 1968. Table 3 lists setting factors calculated for thermometers of Jena $16^{\text {III }}$ glass or, its American equivalent, Corning normal. The scale calibrations for Beckmann thermometers as reported by NBS are applicable for a setting of $20{ }^{\circ} \mathrm{C}$. Consequently, the setting factor is 1.0000 at this temperature. For a setting other than $20{ }^{\circ} \mathrm{C}$, the observed temperature difference must be multiplied by the appropriate setting factor as shown in the example given below the table. 
TABLE 3

SETTING FACTORS FOR BECKMANN THERMOMETERS

For any scale length up to $15^{\circ}$

\begin{tabular}{c|c||c|c}
\hline Setting & Factor & Setting & Factor \\
\hline $0^{\circ} \mathrm{C}$ & 0.9935 & $55^{\circ} \mathrm{C}$ & 1.0092 \\
5 & 0.9951 & 60 & 1.0102 \\
10 & 0.9967 & 65 & 1.0112 \\
15 & 0.9984 & 70 & 1.0121 \\
20 & 1.0000 & 75 & 1.0129 \\
25 & 1.0014 & 80 & 1.0137 \\
30 & 1.0029 & 85 & 1.0146 \\
35 & 1.0042 & 90 & 1.0154 \\
40 & 1.0056 & 95 & 1.0162 \\
45 & 1.0070 & 100 & 1.0170 \\
50 & 1.0082 & & \\
\hline
\end{tabular}

As an illustration, suppose the following observations were made:

$$
\begin{array}{r}
\text { Setting }=25^{\circ} \mathrm{C} \quad \begin{array}{rr}
\text { Lower reading }=2.058^{\circ} \\
\text { Upper reading }=5.127^{\circ}
\end{array} \\
\begin{array}{r}
\text { Observed reading }=2.058 \\
\text { Correction from report }=\underline{+.005}
\end{array} \\
\text { Corrected upper reading }=5.119 \\
\text { Corrected lower reading }=\underline{2.0063} \\
\text { Difference }=3.056 \\
\text { Difference multiplied by setting factor } 1.0014=3.060 \\
\text { Corrected difference }=3.060
\end{array}
$$

For most Beckmann thermometers, the large bulb is joined to a fine capillary (which is backed by a milk-glass scale) by a capillary of much larger diameter. This large capillary is a source of some uncertainty when the thermometer is used at partial immersion and this portion is not entirely immersed. For appropriate emergent-stem corrections refer to Section 6.3.8.

The Beckmann thermometer is a calorimetric thermometer and must be heated to the highest test point, calibrated at total immersion, tapped gently before reading, and calibrated at intervals of every 0.5 degree. Unlike most thermometers calibrated at NBS, the Beckmann thermometer is calibrated starting at the highest calibration point, usually the 6 degree point, and proceeding to the 0 degree point on the scale. 


\subsubsection{Clinical Standard Thermometers}

Clinical standard thermometers are used by the manufacturers of fever thermometers, which are used for measuring body temperatures. In the United States they are marked in degrees Fahrenheit with a range of approximately +90 to $+112^{\circ} \mathrm{F}$. They are provided with an auxiliary scale at $32^{\circ} \mathrm{F}$ and are graduated in intervals of $0.1^{\circ} \mathrm{F}$. The calibration points are usually $32,98,102$, and $106^{\circ} \mathrm{F}$ and they are heated to $108^{\circ} \mathrm{F}$ before calibrating to initially expand the bulbs. Since they are heated to $108{ }^{\circ} \mathrm{F}$ before calibrating, the ice points are taken after test. They are generally tested at total immersion and at partial immersion, immersed to approximately the $92^{\circ} \mathrm{F}$ mark.

\subsubsection{Kinematic Viscosity Thermometers}

When measuring the viscosity of liquids, it is imperative to accurately measure one specific temperature. Kinematic viscosity thermometers are designed for this purpose and have a short 3 to 5 degree range with an auxiliary scale for an ice point. These thermometers are calibrated at two points on the main scale. Ice points are measured afterwards.

\subsubsection{Low-temperature Thermometers}

The use of mercury-in-glass thermometers for low temperature measurements is limited by the freezing point of mercury, which is $-38.9{ }^{\circ} \mathrm{C}$. This limit may be extended to lower temperatures by forming an eutectic alloy consisting of mercury and 8.5 percent by weight of thallium. The freezing point of this alloy is approximately $-59{ }^{\circ} \mathrm{C}$. However, small differences in the quantity of thallium present have the effect of markedly raising the freezing point of the alloy. It has also been found that some thermometers containing this liquid have behaved erratically in the range of -59 to $-57^{\circ} \mathrm{C}$. Consequently, thermometers using a mercury-thallium alloy as the liquid should not be used below $-56{ }^{\circ} \mathrm{C}$.

Temperature measurements from $-56{ }^{\circ} \mathrm{C}$ to approximately $-200{ }^{\circ} \mathrm{C}$ can be made by using thermometers containing organic liquids. Alcohol, toluene, pentane, or other organic liquids, alone or in mixtures, have been used as fluids for low temperature thermometers. All of these fluids have limitations, and thermometers containing organic liquids are not considered to be as reliable as thermometers containing mercury or mercury-thallium alloy.

Organic liquids have the disadvantage of wetting a surface and leaving a film on the wall of the capillary when the liquid column recedes. This may lead to significant errors in the temperature indications if sufficient precautions are not taken. The thickness of the film on the capillary wall will depend, mainly on the viscosity of the liquid, the interfacial action between the liquid and glass, and the rate at which the thermometer is cooled. Whenever possible the rate of cooling should be slow with the bulb cooled first, enabling the viscosity of the organic fluid in the capillary to be kept as low as possible until the final temperature is reached. This 
minimizes the amount of liquid left on the capillary wall. should always be allowed to assure complete drainage.

Sufficient time conditions this may take an hour or more.

In addition to good drainage characteristics, a satisfactory low temperature fluid should not contain water, dirt, or other foreign material which will separate from the liquid. Because low-temperature thermometers are frequently designed for use above room temperature, the vapor pressure of the liquid must be low to prevent distillation at these higher temperatures. Any dye, added to the fluid for improved visibility, should be chosen for good color fastness with respect to light exposure or chemical action with the organic liquid.

\subsection{Stem-temperature Measurement}

When a thermometer is calibrated and used under conditions of total immersion, no difficulty is encountered when the scale corrections are applied as given on the report. The temperature of the thermometer bulb and the portion of the stem containing the mercury is definitely defined as being at the temperature of the bath medium.

Occasionally it becomes necessary to use a total-immersion thermometer with a portion of the stem emergent from the bath medium, which is different from the calibration conditions of total immersion. The temperature of the environment above the bath, or apparatus containing the thermometer, may differ markedly from the temperature of the thermometer bulb. It is also possible to have pronounced temperature gradients along the length of exposed mercury column. A correction can be calculated to account for the difference in temperature between the bulb and the emergent stem. A reliable estimate of the mean temperature of the emergent stem is required and should actually be measured. The determination of the stem temperature should be repeated each time the thermometer is used in this way, or the accuracy of the correction will depend upon the constancy of the environmental temperature over a period of time. Significant variations in the temperature of the emergent stem may occur due to air circulation and variations in ambient temperature, even though the location of the thermometer does not change.

The same situation occurs in the case of partial-immersion thermometers. The reported scale corrections apply only for the indicated depth of immersion and a particular stem temperature. If the thermometer is used under conditions other than specified, the reported scale corrections are no longer applicable, and a stem-temperature correction is required.

A faden thermometer gives the most accurate measurement of the emergentstem temperature $[11,12]$. These thermometers have long bulbs measuring between 5 and $20 \mathrm{~cm}$, with wall thicknesses and bore sizes nearly the same as the stem of an ordinary thermometer. The bulb length is selected to approximate that of the emergent stem whose temperature is to be measured. The stem of the faden thermometer has a finer capillary than the bulb and is usually graduated in intervals of 2, 5, or 10 Celsius degrees. The reading of the faden thermometer will indicate the mean temperature value 
of the area surrounding the bulb, which is also the mean temperature value of the adjacent portion of the thermometer stem. Stem-temperature measurements taken at NBS are based upon the use of faden thermometers whenever possible (see figure 19(b)).

An auxiliary thermometer can be used if a faden thermometer is not available. It should be approximately $150 \mathrm{~mm}$ long with a scale of 0 to $100{ }^{\circ} \mathrm{C}$, graduated in intervals of $1^{\circ}$, and with a conventional bulb of about 10 to $15 \mathrm{~mm}$ long (see figure 19(a)). Auxiliary thermometers are used most often in conjunction with faden thermometers to measure the emergent-stem temperature of partial-immersion thermometers. Figure 16 shows schemes for measurement of emergent-stem temperatures.

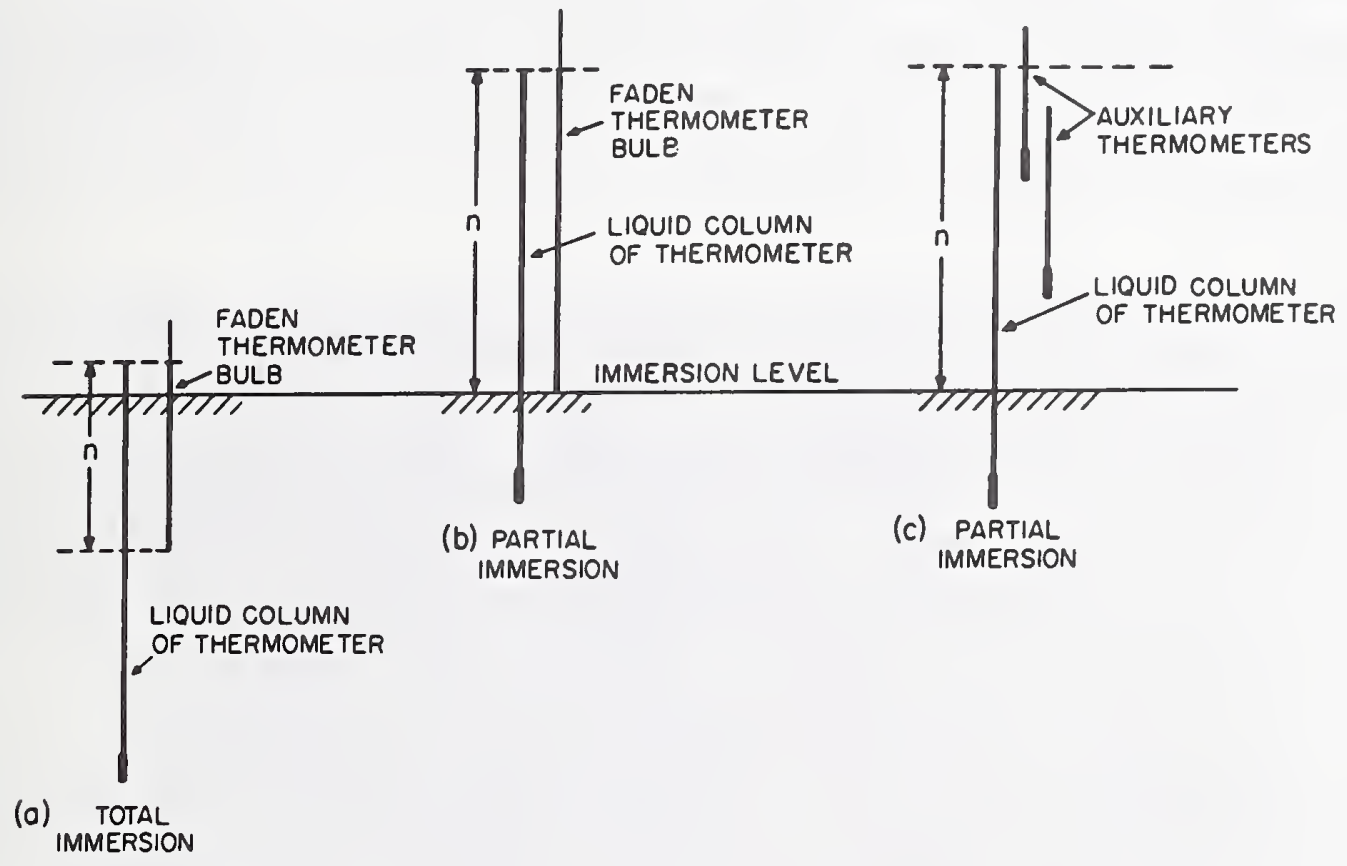

Fig. 16. Schemes for measurement of emergent-stem temperatures.

5.5 Checking the Standard Platinum Resistance Thermometer at the Triple Point of Water

Every day the standard platinum resistance thermometer is used, its resistance is determined at the triple point of water to check whether it is still in calibration and to obtain the resistance at the $0{ }^{\circ} \mathrm{C}$ point for the purpose of calculating the temperature of the bath medium (see Section 6.1). This is done by placing the standard platinum resistance thermometer in a properly prepared triple point of water cell [13]. The reentrant well of the triple point of water cell is first filled with ice water. A small 
piece of foam is placed at the bottom of the reentrant well, enabling the standard platinum resistance thermometer to have something soft on which to rest. An aluminum bushing, which is approximately $50 \mathrm{~mm}$ long, is placed inside of the reentrant well on the foam and is made to fit snugly around the portion of the standard platinum resistance thermometer containing the platinum coil. Before inserting the thermometer in the cell, it should be checked to see that the ice mantle is moving freely around the reentrant well. If not, a warming rod is inserted for a short interval to melt the ice around the well. After inserting the standard platinum resistance thermometer, it is covered with a black cloth to eliminate any error in the resistance reading caused by ambient room radiation, especially from ceiling lights. The standard platinum resistance thermometer is allowed to remain in the triple point of water cell for a minimum of 15 minutes to equilibrate with the current on. The AC bridge is balanced and the resistance at the triple point of water is recorded.

The resistance value on the standard platinum resistance thermometer is compared with previous resistance values at the triple point of water. If the value has changed by an amount equal to or exceeding $0.001{ }^{\circ} \mathrm{C}$, then the standard platinum resistance thermometer is sent to the platinum resistance thermometer calibration laboratory for recalibration.

It is desirable to determine the resistance at $0{ }^{\circ} \mathrm{C}$ under the conditions at which the thermometer is used to measure temperatures. Changes in the thermometer can occur faster at higher temperatures and, therefore, as a laboratory practice, if the standard platinum resistance thermometer is going to be used below $150{ }^{\circ} \mathrm{C}$, the triple point of water is taken at the beginning of the day. If the standard platinum resistance thermometer is going to be used above $150{ }^{\circ} \mathrm{C}$, the triple point of water is taken at the end of the day, after being out of the bath medium for at least 15 minutes.

\subsection{Use of Ice Bath}

A fresh ice bath is made each time it is needed. (An ice bath from a previous day is discarded.) As ice melts throughout the day, water is siphoned off and new ice added. When it is determined that the ice is not floating and that there is no excess water at the surface of the ice, then the bath is ready for use.

For proper calibration at $0{ }^{\circ} \mathrm{C}$, each liquid-in-glass thermometer should be inserted to a specified depth (the immersion depth) into the ice bath. Total-immersion thermometers should be inserted into the ice bath until the $0{ }^{\circ} \mathrm{C}$ mark on the thermometer scale is within one scale division of the top of the bath. For partial-immersion thermometers, the depth is indicated either by an additional line scribed on the glass (immersion line) or by a number given on the back of the thermometer. In order to prepare the bath to accept the thermometer, an area of ice at the center of the bath is loosened with an object such as a clean glass rod and at a depth approximately equal to the immersion depth.

The thermometer to be calibrated at the ice point is cleaned with cool distilled water. (Never rinse with warm water, since it may expand the 
bulb.) The thermometer is gently placed through the holder and into the region of loosened ice. If the thermometer touches a firm surface before it is immersed to the immersion line or $0{ }^{\circ} \mathrm{C}$ mark, the thermometer should be removed and the ice loosened further down into the bath to enable the thermometer to be immersed to the proper depth. If the thermometer does not rest on a firm foundation and the immersion line or $0{ }^{\circ} \mathrm{C}$ mark passes below the surface of the bath, it must be repacked and an area of ice loosened to a more shallow depth.

After the thermometer is properly immersed and is being held perpendicular to the observer's telescope, ice is firmly packed around the thermometer. It is important to keep the ice clean while using the ice bath. The operator's hands should also be kept clean or plastic gloves should be used for this purpose. When the thermometer is resting on a solid section of ice in the bath and cannot be immersed further, when it is perpendicular to the telescope, when ice is firmly packed to the immersion line or one scale division below the $0{ }^{\circ} \mathrm{C}$ mark, and when any excess water is siphoned from the ice bath, then the thermometer is ready to be read as shown in Figure 17.

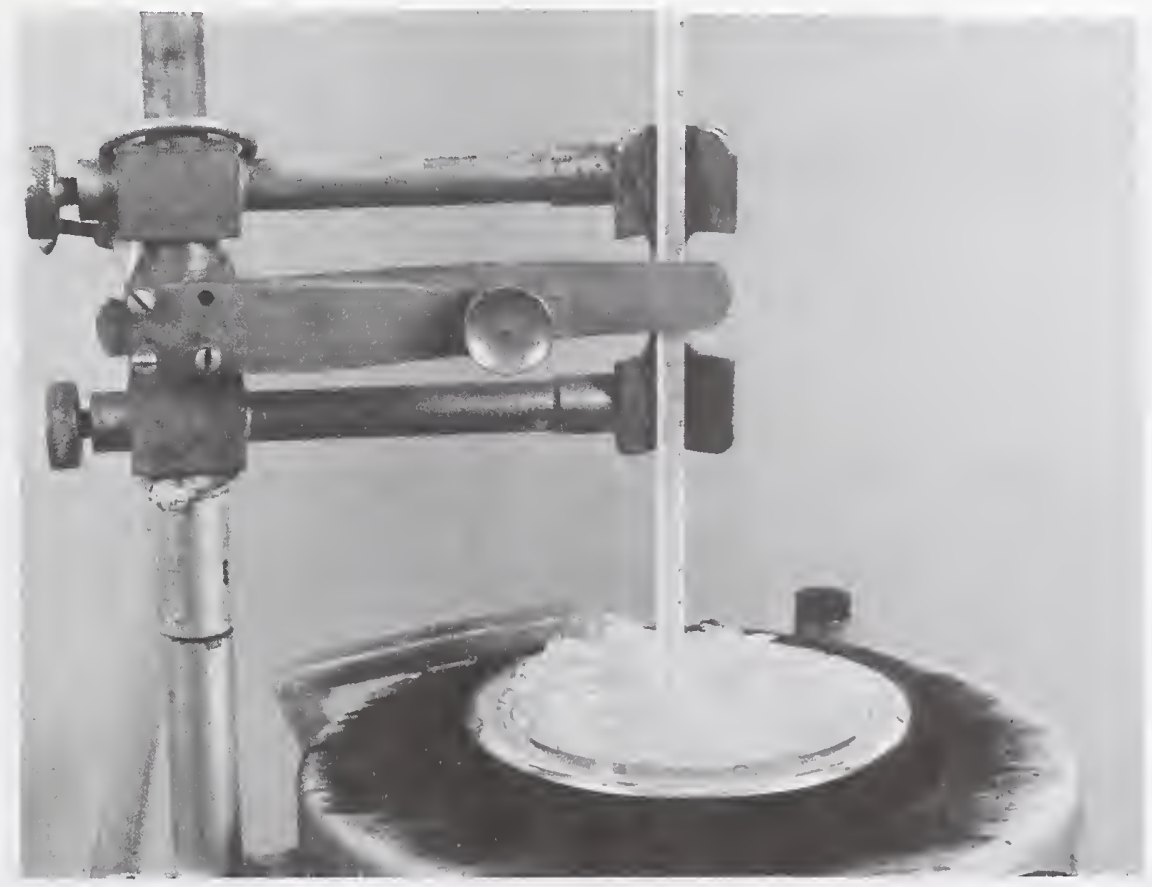

Fig. 17. Thermometer properly placed in the ice point bath.

The thermometer should remain in the ice bath for approximately one or two minutes, or until the readings no longer change. (Thermometers using organic fluid instead of mercury as the liquid will require approximately 
15 minutes, because the organic fluid tends to cling to the wall of the capillary.) When stability is reached (the meniscus stops moving), the operator gently taps the thermometer to free a possible sticking mercury meniscus and records the ice-point reading.

\subsection{Placement of Thermometers in Calibration Baths}

The thermometers to be calibrated are placed in the calibration bath in a circular arrangement with the standard platinum resistance thermometer in the middle of the group within the circle. This placement is shown in Figure 18. Total-immersion thermometers are immersed with the meniscus of the mercury column approximately 6 to $12 \mathrm{~mm}$ from the surface of the bath medium, and partial-immersion thermometers are immersed to the immersion line or to the specified depth. The check standard thermometer, which is placed in the bath to monitor the system as discussed in Section 8 , is placed at the end of the batch. It is essential that the bulb and contraction chamber of each thermometer being calibrated be below the unknown temperature region near the top of the calibration bath (see section 4.2).

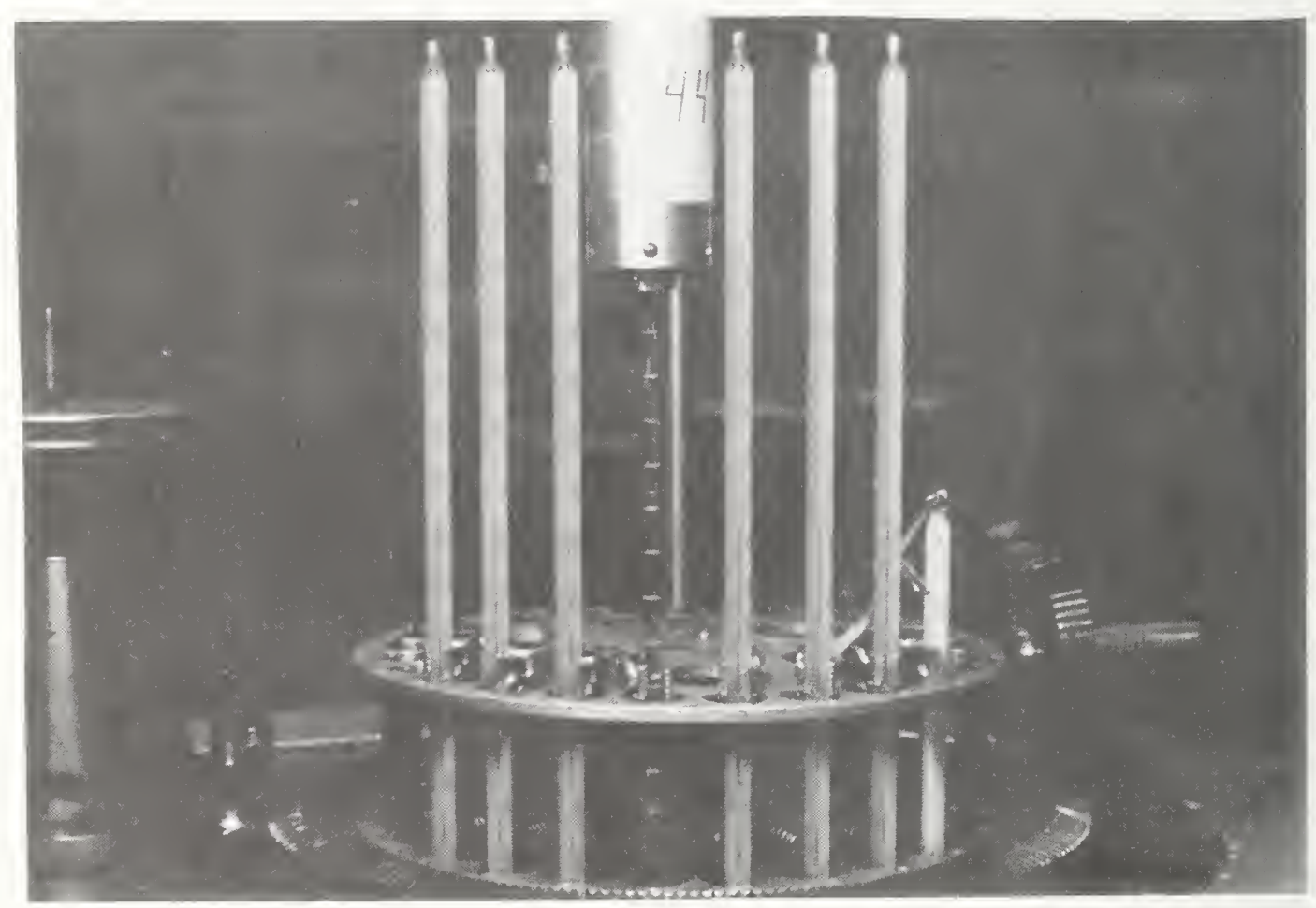

Fig. 18. Placement of thermometers in holder of a calibration bath. 
5.8 Placement of Faden and Auxiliary Thermometers for Measurement of Stem Temperatures

Faden or auxiliary thermometers, or their combinations, are used to measure the mean emergent-stem temperature from the immersion line to the top of the mercury column (meniscus) of the partial-immersion thermometer.

Figure 19(a) shows an ASTM 33C thermometer, which is being calibrated at $40{ }^{\circ} \mathrm{C}$. The correction should reflect an emergent-stem temperature of $30{ }^{\circ} \mathrm{C}$ as specified by ASTM E-1, Standard Specification of ASTM Thermometers [9]. The length of the emergent-mercury column is $314 \mathrm{~mm}$. In this example two auxiliary thermometers are used to measure the temperature of the emergent-mercury column. The centers of the auxiliary thermometer bulbs are placed adjacent to the stem at distances of $105 \mathrm{~mm}$ and $209 \mathrm{~mm}$ from the immersion line. The indication of the bottom auxiliary thermometer gives the average temperature of the lower portion of the emergent stem of the thermometer under test and the top auxiliary thermometer gives the average temperature of the upper portion of the emergent stem. The average temperature of the emergent stem is the average temperature of the two auxiliary thermometers.

A combination of faden thermometers can also be used to measure the emergent-stem temperature as shown in Figure 19(b). Two faden thermometers, of $200 \mathrm{~mm}$ and $114 \mathrm{~mm}$ bulb lengths, are placed adjacent to the emergent-mercury column. The bottom of the $200 \mathrm{~mm}$ faden thermometer bulb is placed in a horizontal plane with the immersion line. The bottom of the $114 \mathrm{~mm}$ faden thermometer bulb is placed with the bottom on its bulb in a horizontal plane with the top of the $200 \mathrm{~mm}$ faden thermometer bulb. Instead, a $200 \mathrm{~mm}$ and a $100 \mathrm{~mm}$ faden thermometer could be used along with an auxiliary thermometer to measure the emergent-stem temperature of the remaining top $14 \mathrm{~mm}$ portion.

Figure 20(a) shows an ASTM 34C thermometer with one auxiliary thermometer being used to measure the emergent-stem temperature. The thermometer is being calibrated at $45^{\circ} \mathrm{C}$ and the correction should reflect a stem temperature of $37^{\circ} \mathrm{C}$ as specified in ASTM E-1, Standard Specification for ASTM Thermometers [9]. The emergent-stem temperature must be measured to determine whether it is $37^{\circ} \mathrm{C}$ and, if it is not, to correct for the difference. There is a $120 \mathrm{~mm}$ length of emergent-mercury column from the immersion line to the meniscus. The center of the auxiliary thermometer bulb is placed at the $60 \mathrm{~mm}$ distance. The temperature indication of the auxiliary thermometer, will be the average temperature of the emergentmercury column adjacent to it. If a faden thermometer is available, it should be used instead of the auxiliary thermometer. This is shown in Figure 20(b). The faden thermometer bulb should be as long as the emergent-mercury column plus or minus 8 or $9 \mathrm{~mm}$. Since a $120 \mathrm{~mm}$ faden thermometer is not available, either a $114 \mathrm{~mm}$ or a $129 \mathrm{~mm}$ faden thermometer can be used. The bottom of the $114 \mathrm{~mm}$ faden thermometer bulb is placed in a horizontal plane with the immersion line.

It is essential that the bulb and the contraction chamber of liquid-inglass thermometers be below the unknown temperature region. In the 


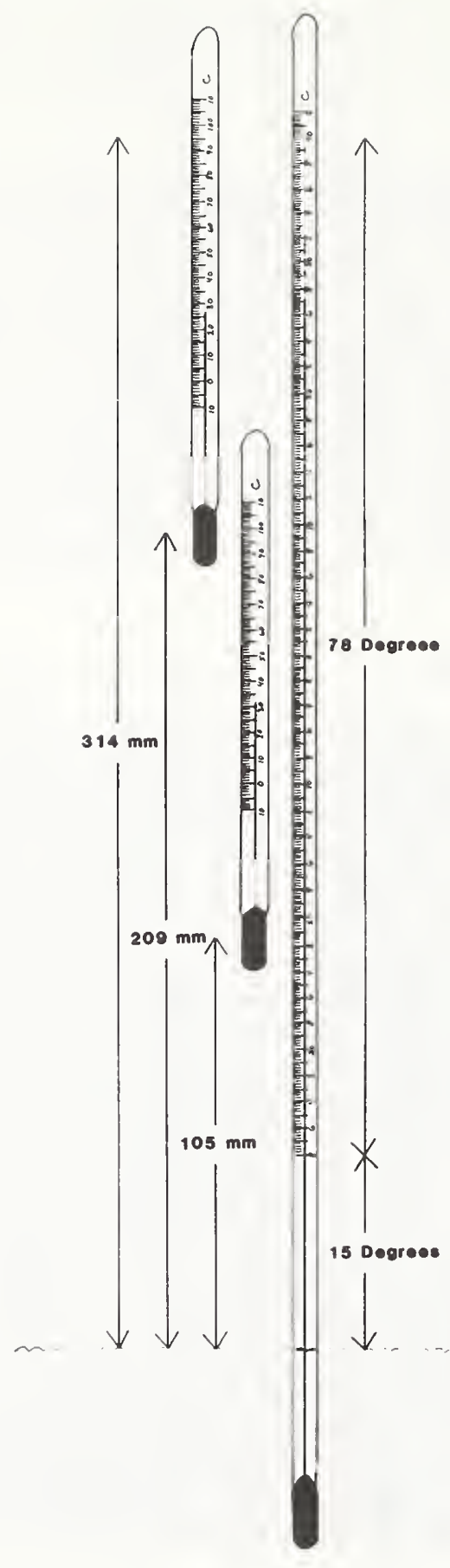

Fig. 19(a). Measuring the emergent-stem temperature of an ASTM $33 \mathrm{C}$ thermometer using two auxiliary thermometers. 


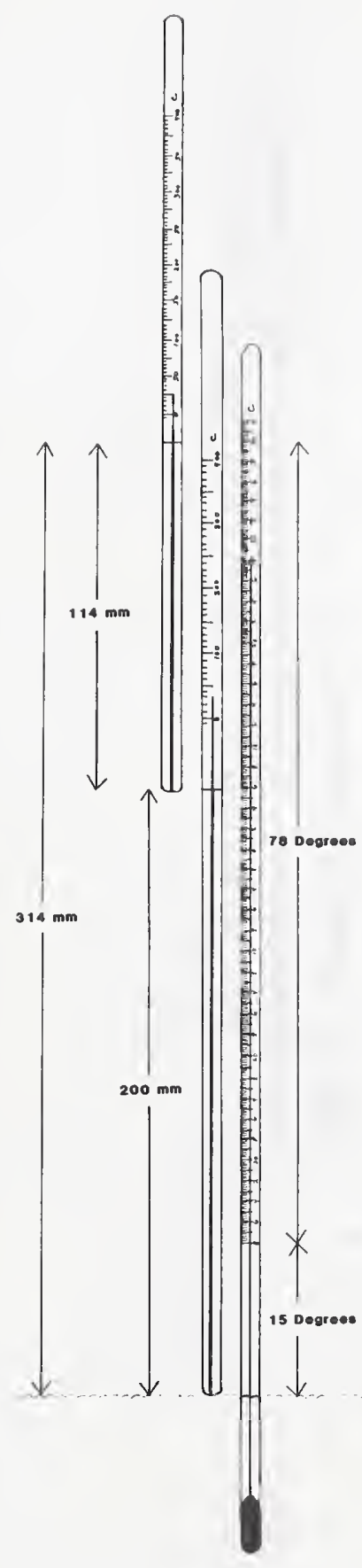

Fig. 19(b). Measuring the emergent-stem temperature of an ASTM $33 \mathrm{C}$ thermometer using two faden thermometers. 


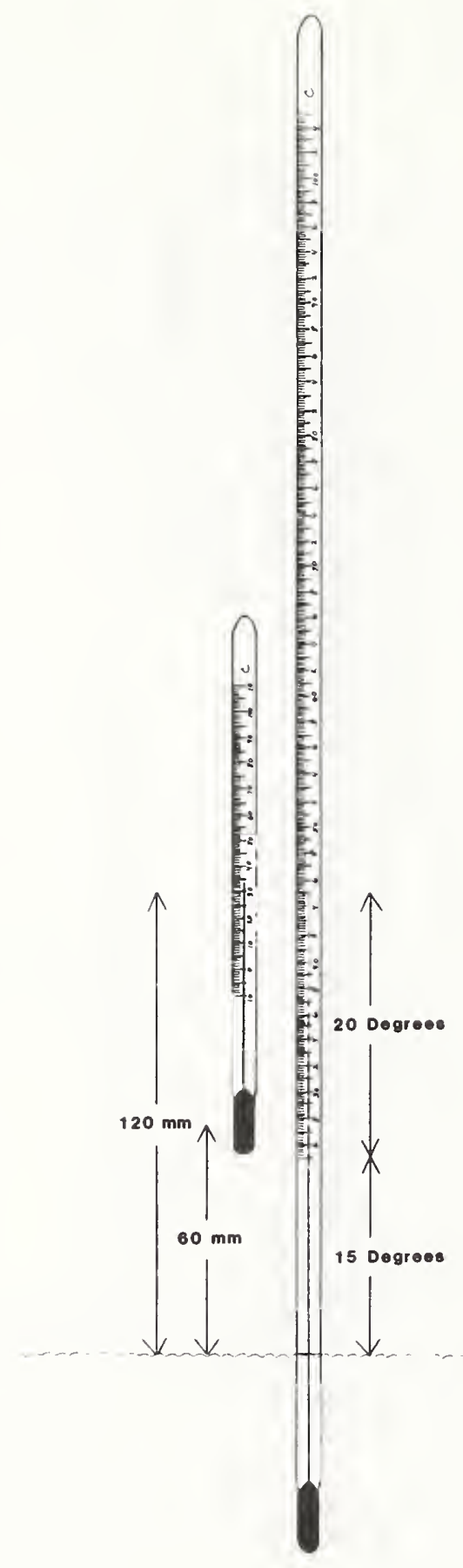

Fig. 20(a). Measuring the emergent-stem temperature of an ASTM $34 \mathrm{C}$ thermometer using one auxiliary thermometer. 


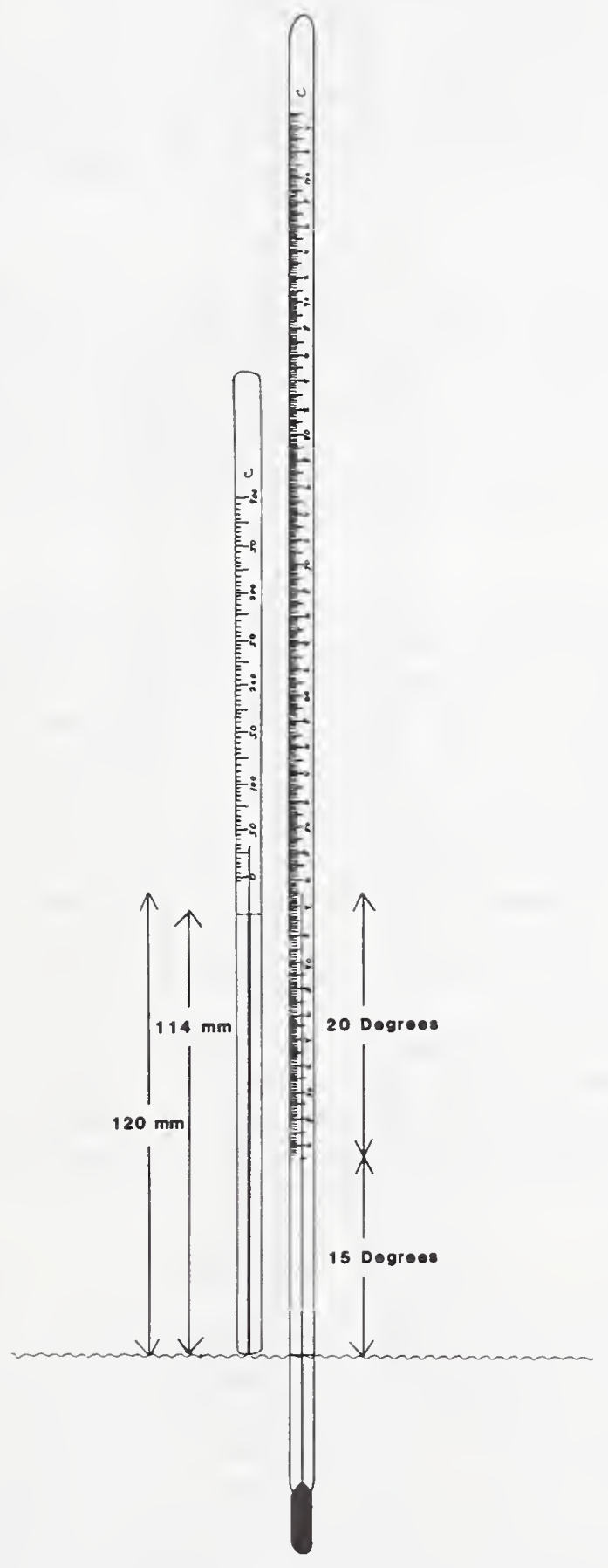

Fig. 20(b). Measuring the emergent-stem temperature of an ASTM $34 \mathrm{C}$ thermometer using one faden thermometer. 
cryostat and water bath, the top of the bulb or the top of the contraction chamber must be immersed a minimum of $25 \mathrm{~mm}$. In the oil baths the bottom of the bulb must be immersed a minimum of $76 \mathrm{~mm}$ and the top of the contraction chamber immersed a minimum of $50 \mathrm{~mm}$. In the tin bath the bottom of the bulb must be immersed $130 \mathrm{~mm}$ and the top of the contraction chamber $76 \mathrm{~mm}$. If it is not possible to calibrate at a temperature requested because of this restriction, the calibration point must be changed to one higher on the scale to permit adequate immersion of the bulb and contraction chamber.

Occasionally it is necessary to immerse a partial-immersion thermometer more than the specified depth. An example of this is the ASTM 11C thermometer. It is made to be used at an immersion of $25 \mathrm{~mm}$ and has a scale from -6 to $+400{ }^{\circ} \mathrm{C}$. When calibrating this thermometer, it is essential that the bulb not be in the unknown temperature region of the bath medium. In this case it would be necessary to immerse the ASTM 11C thermometer deeper into the bath medium until the bulb is in the known temperature region.

For the ASTM 11C thermometer, it is necessary to measure the temperature of the emergent stem and correct for any difference there might be between the observed value and the value specified in ASTM E-1, Standard Specification for ASTM Thermometers [9]. When the faden thermometer is placed adjacent to the stem from the immersion line to the meniscus, the lower portion of the faden thermometer will be in the bath medium also. The error introduced by immersing the ASTM thermometer too deep will be corrected when the stem-temperature correction is calculated (see section 6.3). The bottom of the faden thermometer bulb must always be in a horizontal plane with the immersion line of the partial-immersion thermometer no matter where the immersion line may be. This example is shown in Figure 21(a).

If the partial-immersion thermometer is not an ASTM thermometer, a stemtemperature measurement would not be made. However, a correction must still be made for the error in the thermometer reading due to a portion of the stem above the immersion line being in the bath medium. This correction is referred to as a too-deep immersion correction.

When the thermometer is placed in the bath, it is noted how deep the immersion line is under the bath surface. This distance is measured in $\mathrm{mm}$. The center of an auxiliary thermometer bulb is placed above the meniscus of the partial-immersion thermometer exactly one-half the distance that the thermometer is placed too deep into the bath. For example, if a partial-immersion thermometer is placed in a bath with the immersion line $50 \mathrm{~mm}$ below the surface of the bath, the center of the bulb of an auxiliary thermometer should be placed $25 \mathrm{~mm}$ above the meniscus. This scheme is shown in Figure 21(b), using the ASTM 11C thermometer discussed above as an example. The location of the auxiliary thermometer must be changed for each calibration point (as the meniscus rises) and the room temperature must be recorded as part of the data.

When corrections are given for total-immersion thermometers, they are applicable for the portion of the stem containing the mercury being at the 


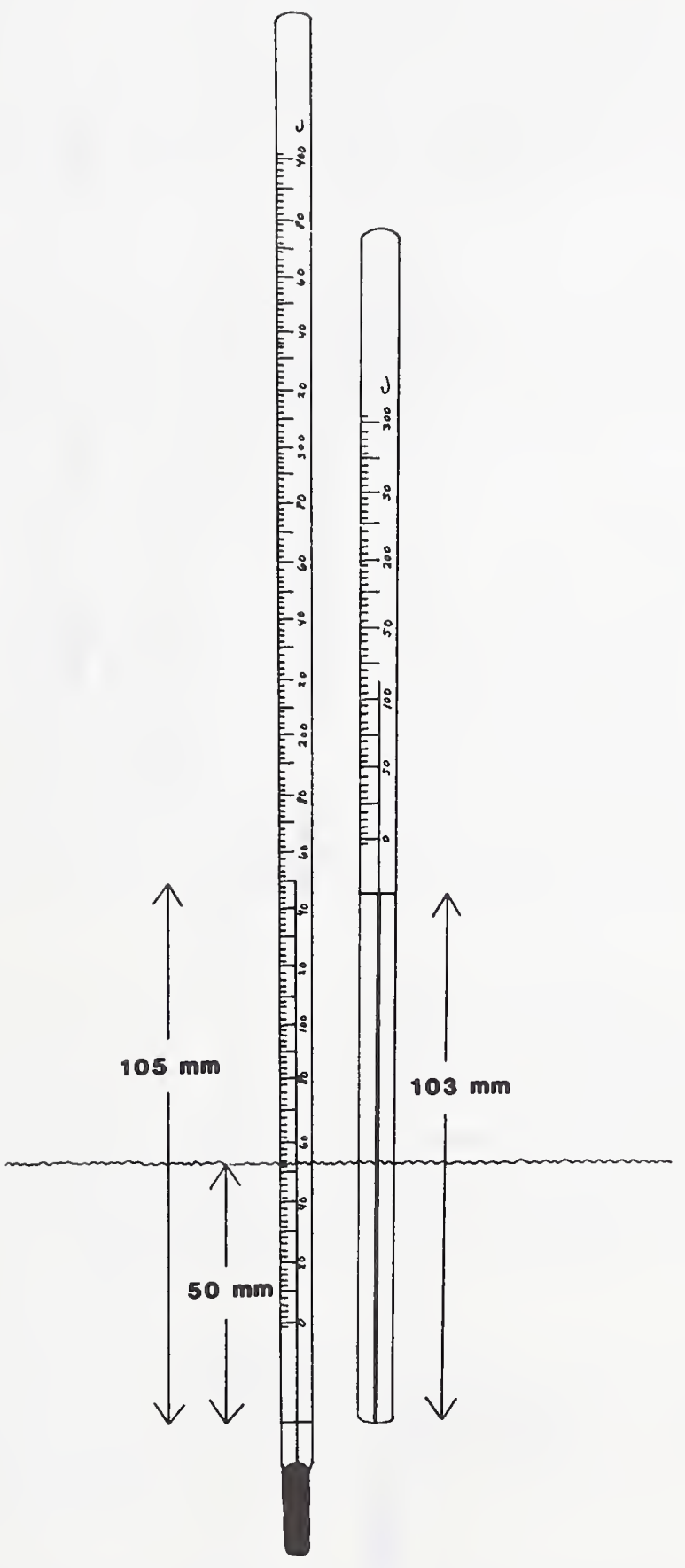

Fig. 21(a). Measuring the emergent-stem temperature of an ASTM 11C partial-immersion thermometer with the immersion line below the surface of the bath medium. 


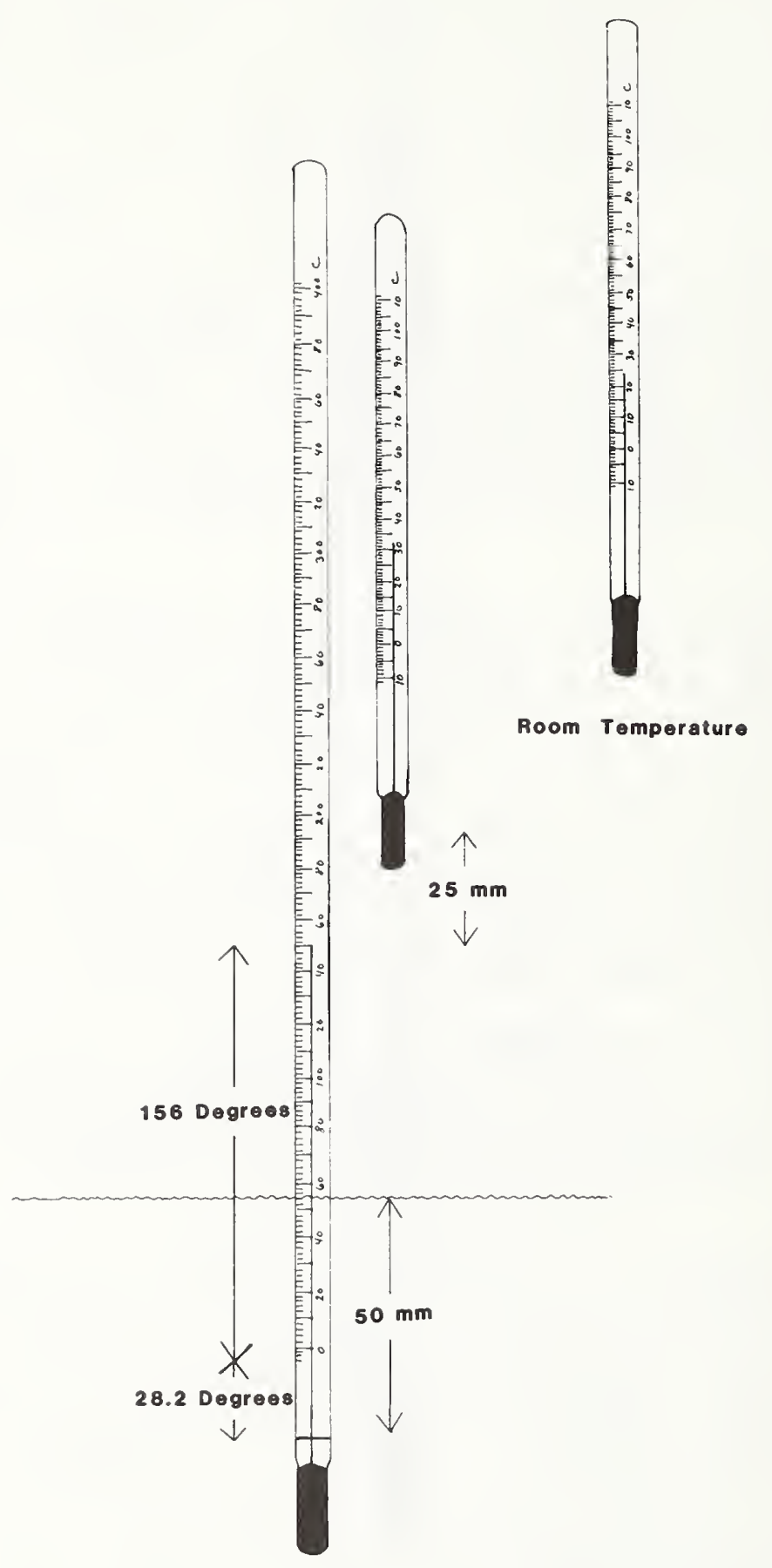

Fig. 21(b). Placement of auxiliaxy thermometers needed to obtain data for a too-deep immersion correction. 
same temperature as the bulb. Because of the $50 \mathrm{~mm}$ region of unknown temperature near the top of the oil baths and a $76 \mathrm{~mm}$ region of unknown temperature near the top of the tin bath, a faden thermometer must be placed in the bath to determine the temperature of this unknown region and to correct for the temperature difference. A $100 \mathrm{~mm}$ faden is used for this measurement in the oil baths (for temperatures above $150{ }^{\circ} \mathrm{C}$ ) and a $200 \mathrm{~mm}$ faden is used in the tin bath. The top of the faden bulb is placed on a horizontal plane with the meniscus of the thermometer under test as shown in Figure 22.

The gradients of the unknown region in the cryostat, water bath, and in the range of 100 to $150{ }^{\circ} \mathrm{C}$ in the low temperature oil bath do not result in corrections. Experimentation and calculations have indicated that the stem-temperature error is not significant when a portion of the stem containing mercury is in this region of these baths.

\subsection{Regulating the Bath, Reading Sequence, and Recording Data}

In most cases thermometers are calibrated at NBS from the lowest point to the highest point as requested by the customer. If the highest point is $300{ }^{\circ} \mathrm{C}$ or above, an ice point is taken and the highest point is calibrated first. Three days later the ice point is taken again and compared with the first ice point. If they agree within the uncertainty of that particular type of thermometer (see Tables 14-17), then the thermometer calibration is completed starting from the lowest point to the highest point. If the ice points do not agree within the uncertainty value, the thermometer is found ineligible for test because of improper annealing or improper thermometer glass.

The lowest calibration point on most liquid-in-glass thermometers calibrated at NBS is the ice point $\left(0{ }^{\circ} \mathrm{C}\right)$. The ice-point readings are recorded for each thermometer in a set. The thermometers are placed in the calibration bath and the temperature of the bath medium is regulated. Maximum current is directed to the heater coils to bring the temperature of the medium within plus or minus one scale division of the calibration point. Regulation is maintained by adjusting current to the coils through a rheostat enabling the bath temperature to rise at a rate of no more than one scale division in 3 minutes.

Control in the cryostat is maintained through the use of two separate sets of heating coils. One set is manually adjusted to cause the temperature of the bath to decrease slowly. The current in the second set of heating coils automatically turns on or off to control the temperature of the medium in a narrow range.

When the bath temperature regulation is maintained, the thermometers are read and data recorded in the following sequence: standard platinum resistance thermometer, thermometers T0 through TX, standard platinum resistance thermometer, thermometers TX through T0, standard platinum resistance thermometer. Whenever the standard platinum resistance thermometer is read, it is placed in front of the telescope to help minimize errors due to temperature gradients in the calibration bath. A 


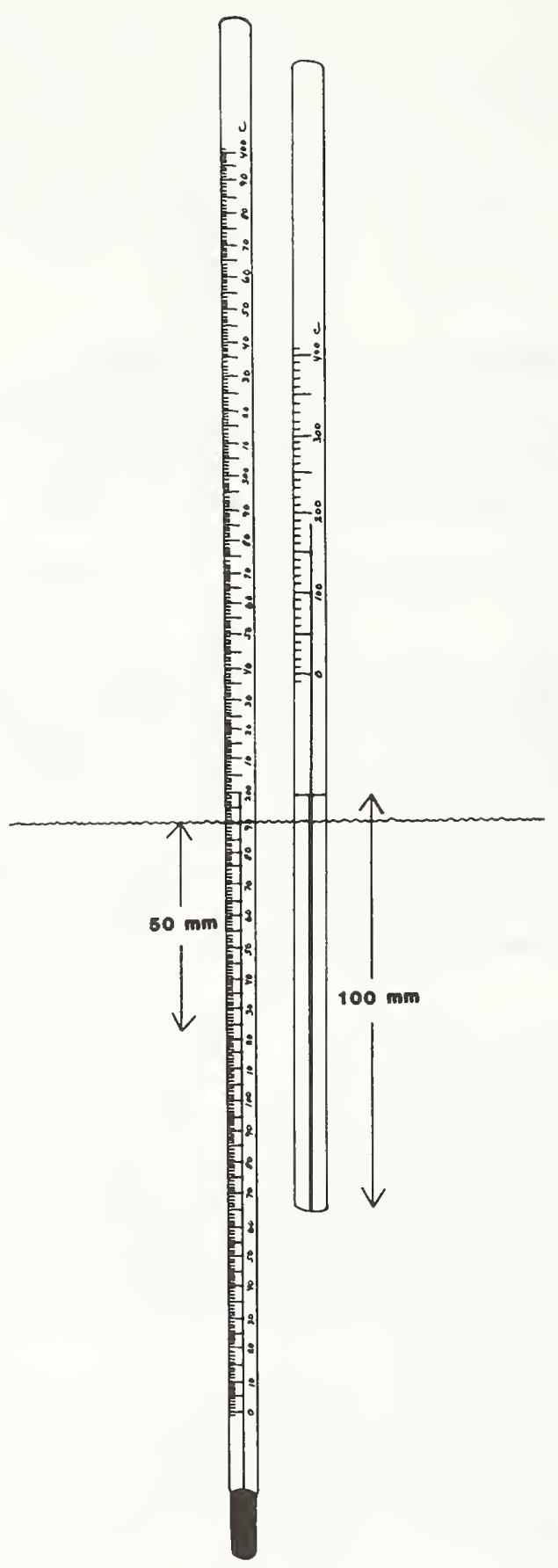

Fig. 22. Measuring the temperature of the portion of a total-immersion thermometer stem that is in the unknown temperature region of the oil bath using a $100 \mathrm{~mm}$ faden thermometer. 
current of $1 \mathrm{ma}$ is used for the standard platinum resistance thermometer and the amplification is adjusted so that the value in the seventh dial $(0.00001 \Omega)$ can be seen. The phase is adjusted to zero on the AC bridge meter. The phase/signal selector switch is changed to signal and the bridge dials are set to produce a null on the meter. The dial readings are recorded. Thermometers graduated in $0.01,0.02,0.05$, or 0.1 degree are read to three decimal places; thermometers graduated in $0.2,0.5$, or 1.0 degree are read to two decimal places; and thermometers graduated in 2.0 or 5.0 degrees are read to one decimal place. One of the thermometers that is calibrated, usually thermometer TX, is an NBS owned check standard, which will be discussed in Section 8. Any faden or auxiliary thermometers used for stem-temperature determinations are read and recorded after this sequence. The room temperature is recorded if a too-deep immersion correction is to be made. A sample data sheet for a routine batch calibration is shown in Table 4. A sample data sheet incorporating all of the stem-temperature corrections shown in the examples in Section 5.8 is given in Table 5. Both examples show data taken by one operator.

If two calibration operators are available, one should record the observed thermometer readings while the other reads the thermometers. The two operators should switch positions and take a second set of readings. It is preferable to have two observers, since this procedure will reduce operator bias and reading errors.

After a set of data is obtained at a calibration point, it is inspected to see that it looks reasonable. The calibrator examines the data for reading errors and to insure that the temperature of the calibration bath rose at the rate stated above. It is not acceptable for the temperature of the bath to decrease while data is being recorded.

\subsection{Calculations}

Once the data has been recorded in the format shown in Tables 4 and 5, and after inspection indicates that there are no suspicious data points, the corrections to the thermometers are computed as explained in the following sections.

\subsection{Computation of Bath Temperature}

The data given in Table 4 for a routine batch calibration is reproduced in Table 6 with computations added. The thermometers in the example are all total immersion, with a range of -2 to $+102{ }^{\circ} \mathrm{C}$, and graduated in intervals of $0.2^{\circ}$.

The first step is to average the two resistance values determined for the standard platinum resistance thermometer at the triple point of water taken on the day the calibrations were performed. This average resistance value at the triple point of water, $R(T P)$, is converted to the resistance value at the ice point, $R(0)$, by multiplying it by a factor of 0.99996101, which 
TABLE 4

SAMPLE DATA SHEET

ROUTINE BATCH CALIBRATION

READINGS

$\begin{array}{cccc}\text { NBS } & \text { TEST NUMBER } & \text { CK. STD. } \\ \text { T0 } & \text { T1 } & \text { T2 } & \text { T3 } \\ -0.10 & -0.10 & +0.03 & -0.11 \\ - & & & \\ & & & \\ 19.92 & 19.94 & 19.93 & 19.71 \\ 19.93 & 19.95 & 19.93 & 19.71\end{array}$

BRIDGE SPRT

$5 \quad 445$

25.46480

25.46480

27.48504

510

515

$\begin{array}{llll}39.90 & 39.90 & 39.88 & 39.67\end{array}$

29.48379

390

402

$\begin{array}{llll}39.92 & 39.91 & 39.88 & 39.67\end{array}$

31.48629

633

638

$\begin{array}{llll}59.86 & 59.93 & 59.89 & 59.67 \\ 59.86 & 59.94 & 59.90 & 59.67\end{array}$

$\begin{array}{llll}80.03 & 79.96 & 79.90 & 79.81\end{array}$

33.48653

$\begin{array}{llll}80.04 & 79.96 & 79.90 & 79.81\end{array}$

659

664

$\begin{array}{llll}99.88 & 99.86 & 99.86 & 99.74\end{array}$

35.44998

$\begin{array}{llll}99.88 & 99.88 & 99.87 & 99.74\end{array}$

5005

5019 
SAMPLE DATA SHEET

STEM-TEMPERATURE CORRECTIONS READINGS
T4

NBS TEST NUMBER
T5
$\begin{array}{ccc}\text { T6 } & \text { T7 } \\ \text { ASTM 33C } & \text { ASTM 34C } & \text { ASTM 11C } \\ \text { 50 MM } & 50 \text { MM } & 25 \text { MM }\end{array}$

IMMERSION IMMERSION IMMERSION

$$
+0.43
$$

$+0.5$

$+0.132$

$+0.18$

39.924

39.924
39.936

---

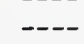

\subsection{6}

39.97

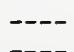

$-$

\subsection{6}

39.97
- ---

39.924

39.936

(1)

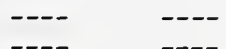

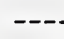

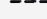

$---$

\begin{tabular}{|c|c|c|c|c|}
\hline---- & --- & 44.86 & ---- & 44.807 \\
\hline--- & ---- & 44.87 & ---- & 44.809 \\
\hline
\end{tabular}

25.46480

25.46480

29.50189

196

199

29.50189
196
199

29.98976

989

999

29.98976

989

999

35.47688

698

707

$\begin{array}{llllll}100.52 & --- & --- & --- & --- & 100.40 \\ 100.52 & --- & --- & --- & --- & 100.40\end{array}$

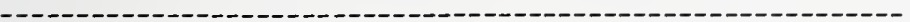

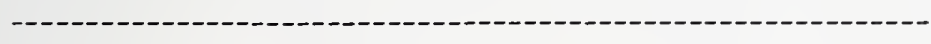

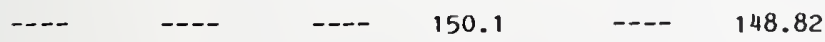

$\begin{array}{llll}--- & -- & 150.1 & 148.82\end{array}$

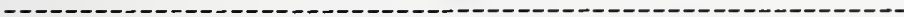

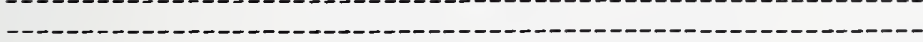

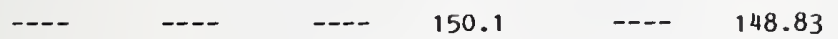

$\begin{array}{lllll}- & \ldots & \ldots & 150.1 & 148.83\end{array}$
40.19180

190

200

45.08799

829

859
FADEN

AUXILIARY

AUXI

18

AUX1 AUX2

3126

AUX1

33
$114 \mathrm{MM}$

33.3

199.50

$\begin{array}{lllll}--- & --- & -- & 199.56 \\ --- & --- & --- & --- & 199.56\end{array}$

199.56

\section{$100 \mathrm{MM}$}

140.0

103 MM 100 MM

$112.9 \quad 140.0$ $\begin{array}{cc}200 & 114 \\ 30.0 & 25.0\end{array}$

199.50 


\begin{tabular}{|c|c|c|c|c|c|}
\hline NBS & TEST N & JMBER & CK. STD. & & IDGE \\
\hline T0 & $\mathrm{T} 1$ & T2 & T3 & & $5 \quad 445$ \\
\hline & & & & & 25.46480 \\
\hline-0.10 & -0.10 & +0.03 & -0.11 & & 25.46480 \\
\hline------ & ---- & ------ & - - - - - - & $\mathrm{R}(\mathrm{TP})$ & $=25.46480^{a}$ \\
\hline+0.10 & +0.10 & -0.03 & $+0.11^{\mathrm{f}}$ & $\mathrm{R}(0)$ & $=25.46381^{b}$ \\
\hline$-\cdots-\cdots--$ & ----- & ------ & ------ & & \\
\hline 19.92 & 19.94 & 19.93 & 19.71 & $t=19.97{ }^{\circ} \mathrm{C}^{\mathrm{e}}$ & 27.48504 \\
\hline 19.93 & 19.95 & 19.93 & 19.71 & & 510 \\
\hline------- & ----- & ------ & -------- & & 515 \\
\hline+.05 & +.03 & +.04 & $+.26^{f}$ & $R(t$ & $=27.48510^{\mathrm{c}}$ \\
\hline------- & ------ & ------- & ------ & $R(t) / R(0$ & $=1.079379^{d}$ \\
\hline 39.90 & 39.90 & 39.88 & 39.67 & $t=39.84^{\circ} \mathrm{C}$ & 29.48379 \\
\hline 39.92 & 39.91 & 39.88 & 39.67 & & 390 \\
\hline------- & 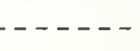 & ----- & ------ & & 402 \\
\hline-.07 & -.06 & -.04 & +.17 & $R(t$ & $=29.48390$ \\
\hline------- & ------ & ------- & ------- & $R(t) / R(0$ & $=1.157875$ \\
\hline 59.86 & 59.93 & 59.89 & 59.67 & $\mathrm{t}=59.87^{\circ} \mathrm{C}$ & 31.48629 \\
\hline 59.86 & 59.94 & 59.90 & 59.67 & & 633 \\
\hline - - - - - - - & ------ & ------ & -------- & & 638 \\
\hline+.01 & -.07 & -.03 & +.20 & $R(t$ & $=31.48633$ \\
\hline------ & $\ldots-\cdots$ & ------- & ------ & $R(t) / R(0$ & $=1.236513$ \\
\hline 80.03 & 79.96 & 79.90 & 79.81 & $\mathrm{t}=80.00^{\circ} \mathrm{C}$ & 33.48653 \\
\hline 80.04 & 79.96 & 79.90 & 79.81 & & 659 \\
\hline$----\cdots$ & $\ldots---$ & ------ & $-\ldots-\ldots$ & & 664 \\
\hline-.04 & +.04 & +.10 & +.19 & $R(t$ & $=33.48659$ \\
\hline-------- & ----- & ------- & $-\cdots-\cdots$ & $R(t) / R(0$ & $=1.315066$ \\
\hline 99.88 & 99.86 & 99.86 & 99.74 & $t=99.88^{\circ} \mathrm{C}$ & 35.44998 \\
\hline 99.88 & 99.88 & 99.87 & 99.74 & & 5005 \\
\hline-------- & $--\ldots$ & ------ & $-\cdots---$ & & 5019 \\
\hline .00 & +.01 & +.02 & +.14 & $R(t$ & $=35.45007$ \\
\hline 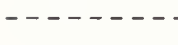 & ---- & $\ldots$ & ---- & $R(t) / R(0$ & $=1.392175$ \\
\hline
\end{tabular}

Footnotes:

a average resistance at triple point of water

b resistance value at $0{ }^{\circ} \mathrm{C}$

c average resistance value

d resistance ratio

e temperature of bath medium

$f$ corrections given on Reports of Calibration for thermometers tested at temperature e 
was derived from information given in NBS Monograph 126, Platinum Resistance Thermometry [13] and the article in Metrologia, The International Practical Temperature Scale of 1968 Amended Edition of 1975 [5].

Since the derivation of this factor is not explicitly outlined in either of the above publications, it is explained below.

The triple point of water cell has an axial well for the thermometers and the triple point temperature is obtained whenever the ice is in equilibrium with a liquid-vapor surface. The equilibrium temperature $t_{68}$ between the ice and liquid water at a depth $h$ below the liquid-vapor surface is given by:

$$
t_{68}=A+B h
$$

$$
\begin{aligned}
\mathrm{A}= & 0.01{ }^{\circ} \mathrm{C} \\
\mathrm{B}= & -7 * 10^{-4} \mathrm{~m}^{-1}{ }^{\circ} \mathrm{C} \\
\mathrm{h}= & \text { height of the water column in the triple point cell } \\
& \text { from the middle of the SPRT coil to the water surface }
\end{aligned}
$$

(Note: * indicates multiplication throughout the text)

The value $h$ varies from cell to cell. Since the hydrostatic head of water from the middle of the SPRT coil to the water surface of the cell used for the calibration given in Table 6 was $0.315 \mathrm{~m}$, the value $t_{68}$ of the triple point of water is calculated to be:

$$
\begin{aligned}
& t_{68}=A+B h \\
& t_{68}=0.01+\left(-7 * 10^{-4}\right) *(0.315) \\
& t_{68}=+0.0097795
\end{aligned}
$$

To convert $t_{68}$ to $t^{\prime}$ the $m\left(t^{\prime}\right)$ relation is used ( $c^{f}$, equation 10 of reference [5]). Then there is obtained:

$$
t^{\prime}=(0.0097795) *(1.000450)
$$

The value for the resistance at $0{ }^{\circ} \mathrm{C}, \mathrm{R}(0)$, is calculated from the resistance at the triple point of water according to the following formula:

$$
R(t) / R(0)=1+A t^{\prime}+B t^{\prime 2}
$$

Since $t^{\prime 2}$ is very small, the last term is dropped. The value A is determined from the formula:

$$
A=\alpha(1+\delta / 100)
$$

The $\alpha$ and $\delta$ values are given with the report of calibration for each standard platinum resistance thermometer. For the resistance thermometer used in Table 6 the value of $\alpha$ was 0.003926378 and $\delta$ was 1.496448 . The value $A$ is calculated to be: 


$$
\begin{aligned}
& A=\alpha(1+\delta / 100) \\
& A=(0.003926378) *[1+(1.496448 / 100)] \\
& A=0.0039851342
\end{aligned}
$$

Knowing the value for $A$ and the value $t^{\prime}$ at the triple point of water, the factor used to convert the $R(T P)$ value to the $R(0)$ value can be determined as shown below:

$$
\begin{aligned}
& \mathrm{R}(\mathrm{TP}) / \mathrm{R}(0)=1+\mathrm{At}^{\prime} \\
& \mathrm{R}(0)=\mathrm{R}(\mathrm{TP}) *\left[\left(1 /\left(1+\mathrm{At} \mathrm{t}^{\prime}\right)\right]\right. \\
& \mathrm{R}(0)=\mathrm{R}(\mathrm{TP}) *[1 /(1+(0.0039851342) *(0.0097839))] \\
& \mathrm{R}(0)=(25.46480) *(0.99996101) \\
& \mathrm{R}(0)=25.46381
\end{aligned}
$$

After the value $R(0)$ is determined, the calculation of the bath temperatures can be made. The first step is to find the average of the three resistance readings at each temperature. This value is called $R(t)$. Since the tables computed for the standard platinum resistance thermometers are based on a ratio of the resistance at a stated temperature to the resistance at the ice point (the ratio of $R(t) / R(0)$ ), the value $R(t)$ at each calibration point must be divided by $R(0)$. The computation of the value $R(t) / R(0)$ for the first temperature in Table 6 is given below:

$$
\begin{aligned}
& R(t)=27.48510 \\
& R(0)=25.46381 \\
& R(t) / R(0)=1.079379
\end{aligned}
$$

It is then determined where in the platinum resistance thermometer table this ratio falls. A portion of the table for the standard platinum resistance thermometer used in the example is given in Table 7. The computed value for $R(t) / R(0)$ of 1.079379 is between 19 and $20{ }^{\circ} \mathrm{C}$. The temperature of the calibration bath medium is, therefore, 19 and some decimal value. To obtain the decimal portion of the temperature, the $R(t) / R(0)$ value at $19{ }^{\circ} \mathrm{C}$ is subtracted from the $\mathrm{R}(\mathrm{t}) / \mathrm{R}(0)$ value in the example and the difference is multiplied by the inverse difference, which is the inverse (reciprocal) of the difference between successive values of $R(t) / R(0)$, given on the line at $20{ }^{\circ} \mathrm{C}$. This procedure is shown below:

The table value for $R(t) / R(0)$ at $19{ }^{\circ} \mathrm{C}$ for PRT 445 is 1.075531 The table value for $R(t) / R(0)$ at $20^{\circ} \mathrm{C}$ for PRT 445 is 1.079494 The value 1.079379 falls between these two ratios.

The temperature of the calibration bath will be 19.XX.

From $R(t) / R(0)$ subtract $R(t) / R(0)$ at $19{ }^{\circ} \mathrm{C}$ and multiply by the inverse difference given for the nominal temperature of $20{ }^{\circ} \mathrm{C}$. 
TABLE 7

ONE PAGE OF A STANDARD PLATINUM

RESISTANCE THERMOMETER TABLE

October 17, 1978, IPTS-68 Table for Resistance Thermometer 445

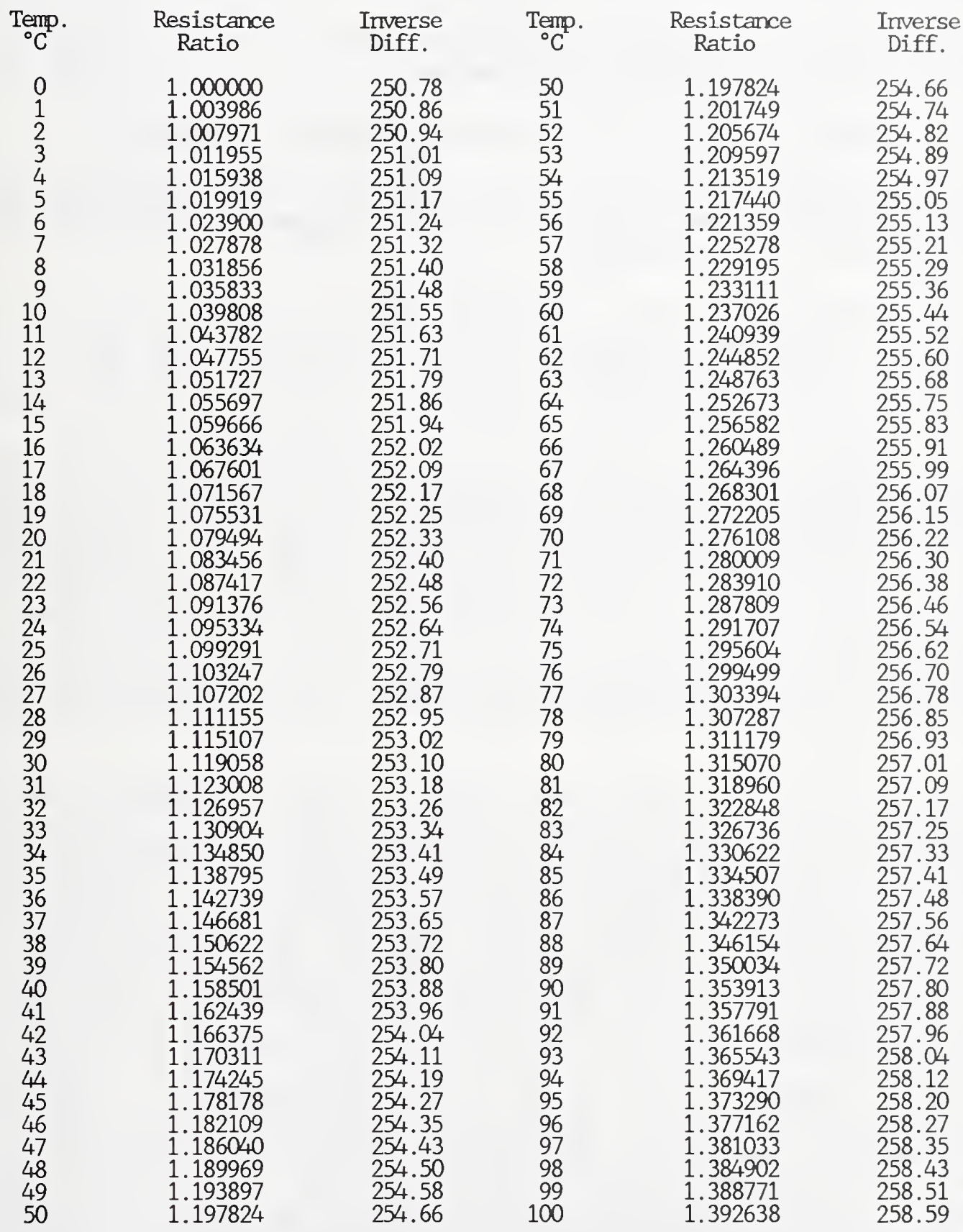




$R(t) / R(0)=1.079379$
$R(t) / R(0)$ at $19{ }^{\circ} \mathrm{C}=1.075531$
Difference $=0.003848$
Decimal Value $=$ Difference*Inverse Difference
Decimal value $=(0.003848) *(252.33)$
Decimal value $=0.97$

The calculated temperature of the calibration bath at the first calibration point is $19.97^{\circ} \mathrm{C}$.

This procedure is repeated at each calibration point to determine the temperature of the calibration bath medium.

\subsection{Determining Corrections of Thermometers Being Calibrated}

After the correct temperature of the calibration bath medium is calculated at each calibration point, corrections for thermometers T0, T1, T2, and check standard, T3, are determined.

The two readings of each thermometer being calibrated and the check standard are averaged and compared with the computed temperature of the bath medium. If the thermometer under test reads higher than the bath temperature, the correction is negative; if the thermometer under test reads lower than the bath temperature, the correction is positive.

Using the data taken for the thermometers in Table 6 at the first calibration point and the computed bath temperature of $\mathrm{T}=19.97{ }^{\circ} \mathrm{C}$, we calculate that their respective corrections are $+0.05,+0.03,+0.04$, and $+0.26{ }^{\circ} \mathrm{C}$ at $20{ }^{\circ} \mathrm{C}$. This procedure is followed for the other temperatures, thereby generating the data for the Reports of Calibration for these three thermometers.

(The Report of Calibration for thermometer serial number $\mathrm{T} 0$ is given as Figures 24 and 25.)

Readings at the ice point are taken on the thermometers that were calibrated not less than 72 hours after test. The second readings at the ice point should agree with the initial ice-point readings within the expected uncertainty of the thermometer. Thermometers with a range of 0 to $+100{ }^{\circ} \mathrm{C}$ and graduated in $0.2^{\circ}$ have an expected uncertainty of $0.05^{\circ}$ at the calibration points. The ice point readings should agree within this limit. If the two ice point readings are not in agreement, indicating that the bulb has not recovered from expanding after heating (due probably to improper annealing), then the thermometer must be completely recalibrated.

The data are analyzed to see if the results are reasonable. A very useful technique for analysis is to plot the calibration data. An example for a total-immersion thermometer graduated in $0.2{ }^{\circ} \mathrm{C}$ divisions is shown in Figure 23. The corrections at $80{ }^{\circ} \mathrm{C}$ and $100{ }^{\circ} \mathrm{C}$ are suspect for two reasons: 1) the magnitude of the difference between two adjacent corrections is approximately one scale division, and 2) the sign of the correction changes. A deviation curve as shown in Figure 23 is possible 


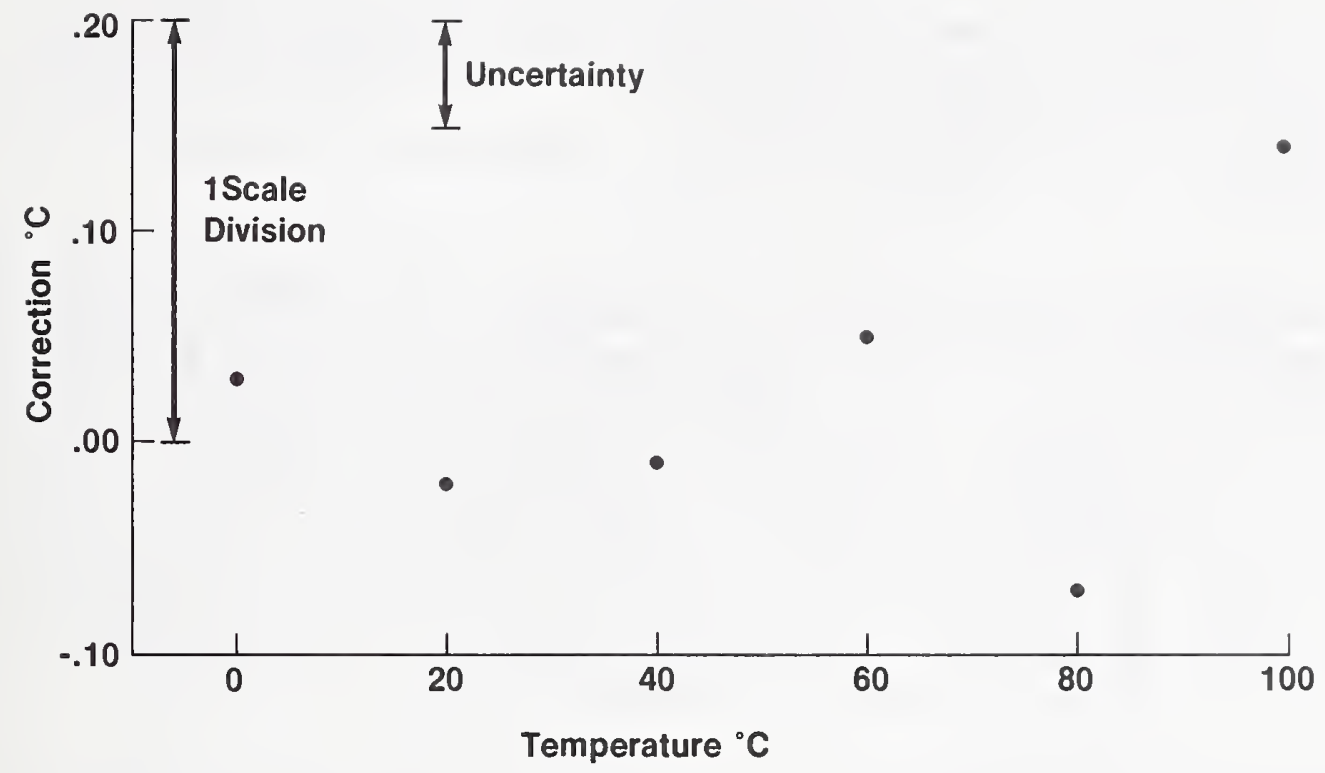

Fig. 23. Thermometer correction versus temperature.

for liquid-in-glass thermometers. If these data were taken by two observers, the probability for reading error is small and recalibration in this case is not necessary. If, on the other hand, the data were obtained by one observer, the thermometer should be recalibrated at $80^{\circ} \mathrm{C}$ and $100{ }^{\circ} \mathrm{C}$.

The plot may indicate another effect. If the trend of the curve is downward as the temperature is increased, the thermometer probably has gas in the bulb. The gas must be removed (see Section 5.1) and the thermometer retested.

\subsection{Stem-Temperature Corrections}

If the thermometer being calibrated is a total-immersion thermometer used at partial immersion, with a portion of the emergent stem containing the liquid above the bath or in the unknown temperature region, or a partialimmersion thermometer requiring a correction that reflects a specified emergent-stem temperature, it will be necessary to correct for the variation in the stem temperature.

The following formula, or some variation of it, will be used to determine stem-temperature corrections.

$$
\text { Stem-temperature correction }=k n\left(t_{o b s}-t_{s p}\right)
$$

$\mathrm{k}=$ differential expansion coefficient of mercury (or other thermometric liquid) in the particular kind of glass of which the thermometer is made 
$\mathrm{n}=$ number of scale degrees equivalent to the length of emergent stem (including the evaluated region above the immersion line)

$t_{\mathrm{obs}}=$ observed mean temperature of the emergent stem (Faden or auxiliary thermometer reading)

$t_{s p}=$ specified mean temperature of the emergent stem (for which reported scale corrections apply)

All stem-temperature corrections require that four values be determined. The first value is the differential expansion coefficient of mercury (or other thermometric liquid) in the particular kind of glass from which the thermometer is made $(k)$. The coefficient $k$ varies for different kinds of glass, or for different temperature intervals, i.e, different values of $\left(t_{1}-t\right)$. For purposes of computing the emergent-stem correction, the value of $\mathrm{k}$ may be considered as depending on the average of $t_{1}$ and $t$. Values of $k$ as the function of $\left(t_{1}+t\right) / 2$ for two widely used thermometric glasses are given in Table 8. If the kind of glass is not known, it is permissible to use $k=0.00016$ for mercury thermometers graduated in degrees Celsius and $k=0.00009$ for mercury thermometers graduated in degrees Fahrenheit.

The expansions of liquids such as alcohol, toluene, etc., vary quite rapidly with the temperature causing $k$ to vary considerably for different temperature intervals. An approximate stem correction for such thermometers may be calculated by setting the value of $k$ as equal to 0.001 for Celsius thermometers or 0.0006 for Fahrenheit thermometers.

The second value needed for computing the stem-temperature correction is the number of scale degrees equivalent to the length of emergent stem $(n)$. This is essentially the number of degrees that is in the incorrect temperature environment. If it is a total-immersion thermometer with a portion of the stem above the bath, then the value $n$ would be the number of degrees from the degree mark at the surface of the bath medium to the meniscus (the top of the mercury column). If the thermometer is a partial-immersion thermometer, the value $\mathrm{n}$ would be the number of degrees from the immersion line to the meniscus. Since partial-immersion thermometers are not graduated to the immersion line, there is a portion of the stem containing no scale divisions. It must be determined how many degrees could be inscribed on this portion of stem and the number included in the value $n$. One way of doing this is to measure the distance from the immersion line to the lowest scale graduation, then move the ruler on the thermometer scale and determine how many degrees this distance represents.

The third value needed is the observed average temperature of the emergent stem $\left(t_{o b s}\right)$. This value is found by actually measuring the temperature environment where the emergent stem is located. The preferred way of doing this involves the use of faden thermometers. Because the availability of faden thermometers is limited, the emergent-stem temperature can also be measured using one or more auxiliary thermometers, which are usually not as reliable [12]. Whether one, two, or even three faden or auxiliary thermometers are needed depends on the length of mercury column emergent from the bath. Any combination of faden and/or auxiliary thermometers can be used for this purpose. 
TABLE 8

VALUES OF THE DIFFERENTIAL COEFFICIENT OF CUBICAL EXPANSION OF MERCURY IN GLASS ( $k$ ) FOR MERCURY-IN-GLASS THERMOMETERS

Table $8(a)$

\begin{tabular}{ccc}
$\begin{array}{c}\text { Mean Temperature } \\
\left(t_{1}+t\right) / 2\end{array}$ & $k$ & $k$ \\
& "Normal" Glass & "Borosilicate" Glass \\
\hline $0^{\circ}$ & For Celsius Thermometers \\
100 & 0.000158 & 0.000164 \\
150 & .000158 & .000164 \\
200 & .000158 & .000165 \\
30 & .000159 & .000167 \\
350 & .000161 & .000170 \\
400 & .000164 & .000174 \\
450 & ----- & .000178 \\
& ----- & .000183 \\
\end{tabular}

For Fahrenheit Thermometers

\begin{tabular}{rrr}
\hline $0^{\circ}$ & 0.000088 & 0.000091 \\
200 & .000088 & .000091 \\
300 & .000088 & .000092 \\
400 & .000089 & .000093 \\
500 & .000090 & .000095 \\
600 & .000092 & .000097 \\
700 &..---- & .000100 \\
800 &.---- & .000103 \\
\hline
\end{tabular}

Table $8(b)$

Bath Temperature ${ }^{\circ} \mathrm{C}$

$\begin{array}{llllllllll}\text { Faden } & 150 & 200 & 250 & 300 & 350 & 400 & 450 & 500 & 550\end{array}$

Thermometer

Reading ${ }^{\circ} \mathrm{C}$

$\begin{array}{rrrrrrrrrr}100 & .000165 & 166 & 167 & 168 & 170 & 171 & 173 & 176 & \\ 150 & 165 & 166 & 167 & 169 & 171 & 173 & 175 & 177 & \\ 200 & 166 & 167 & 169 & 170 & 172 & 174 & 176 & 179 & \\ 250 & 167 & 168 & 170 & 172 & 174 & 176 & 178 & 181 & \\ 300 & & 170 & 172 & 174 & 176 & 178 & 180 & 184 & \\ 350 & & & 174 & 176 & 178 & 180 & 183 & 186 & \\ 400 & & & & 178 & 180 & 182 & 185 & 189 & 193 \\ 450 & & & & & 182 & 184 & 189 & 193 & 197 \\ 500 & & & & & & & & 197 & 201\end{array}$




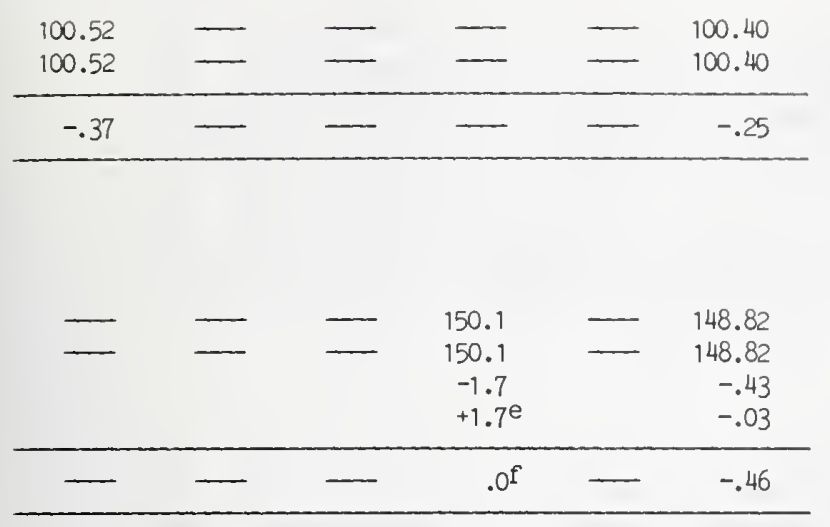

\begin{tabular}{rrrrr}
- & - & 150.1 & - & 148.83 \\
150.1 & -1.7 & 148.83 \\
-1.7 & & -.43 \\
& +1.7 & -.03 \\
\hline- & .0 & - & -.46 \\
\hline
\end{tabular}

$t=100.15{ }^{\circ} \mathrm{C} \quad 35.47688$

698

707

$R(t)=35.47698$

$R(t) / R(0)=1.393231$

$$
\begin{array}{rrrr}
t=148.39 \propto & 40.19077 & 103 \mathrm{~mm} & 100 \mathrm{~mm} \\
096 & 112.9 & 140.0 \\
106 & +.6 & 0.0 \\
R(t)=40.19093 & -.9 & +2.2 \\
R(t) / R(0)=1.578355 & 112.6 & 142.2
\end{array}
$$

$(103 * 112.6) / 103=112.6$

$0.00016^{*} 184.2 *(112.6-54)=+1.7$

$0.000165 * 100 * 0.31 *(148-142)=(-) .03$

$$
\begin{aligned}
& t=148.400^{\circ} \mathrm{C} \quad 40.19180 \\
& 190 \\
& 200 \\
& R(t)=40.19190 \\
& 32-(24-23)=311 \\
& (50-(50 /(1+0.00016 *(148-31)))) * 1.8=+1.7 \mathrm{~m} \\
& 0.000165 * 100 * 0.31 *(148-142)=(-) .03
\end{aligned}
$$

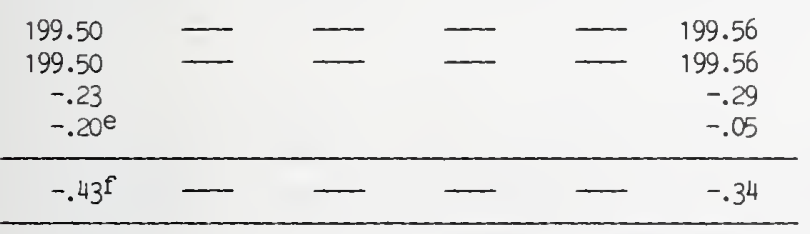

$\begin{array}{rrr}t=199.27{ }^{\circ} \mathrm{C} & 45.08799 & 100 \mathrm{~m} \\ 829 & 187.0 \\ 859 & 0.0 \\ R(t)=45.08829 & +2.8 \\ R(t) / R(0)=1.770681 & 189.8\end{array}$

$0.000167 * 100 * 1.3 *(199-190)=(-) .20^{n}$ $0.000167 * 100 * 0.31 *(199-190)=(-) .05$

aobserved temperature of the lower portion of the emergent stem

bobserved temperature of the upper portion of the emergent stem

CAverage temperature of the emergent stem

dCalculation of stem-temperature correction

Emergent stem-temperature correction

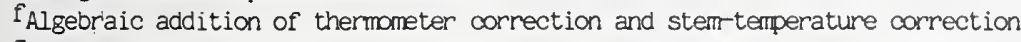

Bice-point correction

hIriterpolated scale correction of faden thermometer

icorrected faden thermometer reading

jTemperature of environment above the mercury column

koom temperature

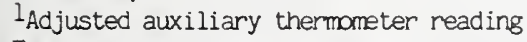

Calculation of too-deep immersion correction

nalculation of faden correction 
The fourth value is the specified average temperature of the emergent stem $\left(t_{s p}\right)$. This value is the temperature that the emergent stem should be. If the thermometer is a total-immersion thermometer having a portion of the stem out of the medium being measured or in an unknown temperature region, the specified temperature of that portion of the stem will be the temperature of the thermometer bulb or medium in which the bulb is located. If it is an ASTM partial-immersion thermometer, the specified temperatures will be the values given in ASTM E-1, Standard Specification For ASTM Thermometers [9].

The stem-temperature correction is added to or subtracted from the thermometer correction. Examples are given in Table 9, which are the computed results of Table 5, and are discussed in the following sections. The temperature of the bath medium and thermometer corrections were determined as discussed in Sections 6.1 and 6.2.

\subsubsection{Emergent Stem-temperature Correction Obtained using Two Auxiliary Thermometers}

Thermometer T5 is an ASTM 33C thermometer and at $40{ }^{\circ} \mathrm{C}$ the correction should reflect an emergent stem temperature of $30{ }^{\circ} \mathrm{C}$ as specified in ASTM E-1 [9]. This example is shown in Figure 19(a). The length of the emergent-mercury column is equal to $314 \mathrm{~mm}$ and the centers of the auxiliary thermometer bulbs are placed adjacent to the stem $105 \mathrm{~mm}$ and $209 \mathrm{~mm}$ from the immersion line. (Generally an auxiliary thermometer should be used every $120 \mathrm{~mm}$ to $150 \mathrm{~mm}$ length of mercury column emergent from the bath.)

The indication on the auxiliary thermometer 1 gives the average temperature of the lower portion of the emergent stem of $\mathrm{T} 5$ and auxiliary thermometer 2 the average temperature of the upper portion of the emergent stem of T5. The average temperature of the emergent stem is the average temperature of the two auxiliary thermometers.

The average observed stem temperature $\left(t_{o b s}\right)$ is $28.5{ }^{\circ} \mathrm{C}[(31+26) / 2]$, the specified stem temperature $\left(t_{s p}\right)$ is $30^{\circ} \mathrm{C}$, the coefficient of expansion of mercury in normal glass for Celsius thermometers is 0.00016 , and the number of degrees emergent from the bath, including the evaluated portion from the immersion line to the first graduation ( $n$ ), is 93 degrees.

$$
\begin{aligned}
\text { Emergent stem-temperature correction } & =\mathrm{kn}\left(t_{\mathrm{obs}}-t_{\mathrm{sp}}\right) \\
& =0.00016 *(93) *(28.5-30) \\
& =-0.02{ }^{\circ} \mathrm{C}
\end{aligned}
$$

Notice that the values $t_{\mathrm{obs}}$ and $t_{\mathrm{sp}}$ are reversed in the above formula, as compared with the one given in NBS Monograph 150 [7], since the correction is applied to a correction and not to the thermometer reading.

\subsubsection{Emergent Stem-temperature Correction using Two Faden Thermometers}

For this example the same ASTM 33C thermometer, serial number T5, will be discussed using the same thermometer readings and bath temperature. A $200 \mathrm{~mm}$ faden thermometer was used to measure the temperature of the lower 
FADEN THERMOMETER CORRECTIONS

Faden Thermometer Length

$100 \mathrm{~mm} \quad 103 \mathrm{~mm} \quad 114 \mathrm{~mm} \quad 200 \mathrm{~mm}$

Ice-Point

Correction $\quad 0.0+0.6+0.9+1.0$

rection

Scale Correction

Temperature

${ }^{\circ} \mathrm{C}$

$\begin{array}{rrrrr}0 & 0.0 & 0.0 & 0.0 & 0.0 \\ 50 & +0.1 & -1.0 & -2.1 & -0.3 \\ 100 & +1.2 & -1.0 & -2.4 & +0.2 \\ 150 & +2.4 & -0.6 & -2.4 & +2.0 \\ 200 & +2.9 & -0.8 & -2.8 & +2.6 \\ 250 & +3.9 & -1.1 & -2.8 & +3.0 \\ 300 & +4.1 & -1.4 & -3.0 & +2.7\end{array}$

portion of the stem and a $114 \mathrm{~mm}$ faden thermometer was used to measure the temperature of the upper portion as shown in Figure 19(b). Since the faden thermometers had been calibrated, ice-point corrections and scale corrections at the indicated temperatures were applied. (Given in Table 10 are the corrections for the faden thermometers used in these examples.)

To determine the temperature of the emergent stem ( $\left.t_{o b s}\right)$, the lengths of the faden thermometers in millimeters are multiplied by the faden thermometer readings. The results are added and divided by the total length of the emergent mercury column.

$$
\begin{aligned}
\text { Emergent-stem temperature } & =[(200) *(30.8)+(114) *(24.9)] / 314 \\
& =28.7{ }^{\circ} \mathrm{C} .
\end{aligned}
$$

Occasionally it may be necessary to use a faden thermometer that is longer then the emergent mercury column. If this is the case, a second faden thermometer of the appropriate length must be placed with the top of its bulb on a horizontal plane with the top of the bulb of the longer faden thermometer and the bottom of the bulb adjacent to the meniscus of the thermometer being calibrated. The stem temperature is then determined by subtracting the length of the upper faden thermometer multiplied by the reading from the length of the lower faden thermometer multiplied by the reading and dividing this value by the distance from the immersion line to the meniscus of the thermometer being calibrated. 
Calculating the stem-temperature correction after the temperature of the emergent stem is determined is identical with the one discussed in Section 6.3.1. The calculation is given below:

$$
\begin{aligned}
\text { Emergent Stem-temperature correction } & =\mathrm{kn}\left(t_{\mathrm{obs}}-t_{\mathrm{sp}}\right) \\
& =0.00016 *(93) *(28.7-30) \\
& =-0.02{ }^{\circ} \mathrm{C} .
\end{aligned}
$$

6.3.3 Emergent Stem-temperature Correction using One Auxiliary Thermometer

Thermometer $\mathrm{T} 6$ is an ASTM 34C thermometer. Since the length of the emergent-mercury column is only $120 \mathrm{~mm}$, placing the center of the bulb of one auxiliary thermometer adjacent to thermometer $\mathrm{T} 6 \quad 60 \mathrm{~mm}$ from the immersion line is sufficient to measure the average temperature of the emergent stem. This example is shown in Figure 20(a).

In the example the observed stem temperature $\left(t_{o b s}\right)$ is $33{ }^{\circ} \mathrm{C}$, the specified stem temperature $\left(t_{s p}\right)$ is $37^{\circ} \mathrm{C}$, the coefficient of expansion of mercury in glass ( $k$ ) is 0.00016, and the number of degrees from the immersion line to the mercury meniscus $(n)$ is 35 degrees. The stem-temperature correction is computed below:

$$
\begin{aligned}
\text { Emergent stem-temperature correction } & =\mathrm{kn}\left(t_{\mathrm{obs}}-t_{\mathrm{sp}}\right) \\
& =0.00016 *(35) *(33-37) \\
& =-0.02{ }^{\circ} \mathrm{C} .
\end{aligned}
$$

\subsubsection{Emergent Stem-temperature Correction using One Faden Thermometer}

The same example given in Section 6.3.3 and Figure 20(b) will be used to discuss the stem-temperature correction for ASTM thermometer 34C using one faden thermometer to determine the temperature of the emergent-mercury column $\left(t_{o b s}\right)$. The thermometer readings and bath temperature will be the same.

Ice-point and scale corrections are applied to the faden thermometer reading (See Table 10) and the result will be the temperature of the emergent stem $\left(t_{o b s}\right)$. The other values are the same as given in Section 6.3.3. The emergent stem-temperature correction is given below:

$$
\begin{aligned}
\text { Emergent stem-temperature correction } & =\mathrm{kn}\left(t_{\mathrm{obs}}-t_{\mathrm{sp}}\right) \\
& =0.00016 *(35) *(32.8-37) \\
& =-0.02{ }^{\circ} \mathrm{C} .
\end{aligned}
$$

If Fahrenheit thermometers are calibrated, the stem-temperature corrections will be the same as shown in the above examples, except for the value of $k$. The equivalent values of $k$ for Fahrenheit thermometers are given in Table 8 . 


\subsubsection{Too-deep Immersion Correction}

Sometimes it is necessary to immerse a partial-immersion thermometer with the immersion line below the surface of the bath medium. This will be the case if the distance from the immersion line to the bottom of the thermometer bulb is less then $76 \mathrm{~mm}$ in the temperature range of 100 to $300{ }^{\circ} \mathrm{C}$, or $130 \mathrm{~mm}$ in the range of 300 to $538{ }^{\circ} \mathrm{C}$. Thermometer $\mathrm{T} 7$ of Table 9 and Figure 21(b) will be used to discuss this correction referred to as a "too-deep immersion correction".

The placement of the auxiliary thermometer used to measure the temperature of the environment, where a portion of the mercury column would be if the thermometer was immersed to the immersion line, is shown in Figure 21(b) and discussed in section 5.8. In the example the auxiliary thermometer (AUX) read $32{ }^{\circ} \mathrm{C}$ and the room temperature (RT) was $24^{\circ} \mathrm{C}$. The auxiliary thermometer reading must be adjusted to represent a room temperature of $23{ }^{\circ} \mathrm{C}$. The following formula is used:

$$
\text { Adjusted auxiliary thermometer reading (aux) }=\text { AUX- }(\mathrm{RT}-23)
$$

In the example the adjusted auxiliary thermometer reading (aux) would be $31{ }^{\circ} \mathrm{C}[32-(24-23)]$.

The formula used to determine the too-deep immersion correction is a variation of the stem-temperature correction formula and is given below:

$$
\text { Too-deep immersion correction }=\left\{D-\left[D /\left(1+k\left(t_{b}-a u x\right)\right)\right]\right\} B
$$

D = distance from the immersion line to the surface of the bath medium in millimeters (distance the thermometer is in too deep)

$\mathrm{k}=$ coefficient of expansion of mercury in glass

$t_{b}=$ temperature of bath medium

aux $=$ adjusted auxiliary thermometer reading

$\mathrm{B}=$ number of degrees per millimeter at the calibration point on the thermometer under test.

In the example the thermometer is immersed $50 \mathrm{~mm}$ too deep into the bath; therefore, $\mathrm{D}$ is equal to 50. The coefficient of expansion of mercury in glass $(k)$ is 0.00016 and the bath temperature $\left(t_{b}\right)$ to the nearest degree was computed to be $148{ }^{\circ} \mathrm{C}$. As shown above, the adjusted auxiliary thermometer reading (aux) was calculated to be $31{ }^{\circ} \mathrm{C}$. The value for $\mathrm{B}$ was found by placing a $1 \mathrm{~cm}$ plastic scale across the thermometer at the calibration point and counting the number of degrees that are encompassed by the $1 \mathrm{~cm}$ of scale length. This value is usually determined to the nearest one-tenth of a scale division and was found to be 18 degrees per $\mathrm{cm}$. A decimal point shift will give the number of degrees per mm (1.8). From these values the too-deep immersion correction can be determined as shown below:

$$
\begin{aligned}
\text { Too-deep immersion correction } & =\left\{\mathrm{D}-\left[\mathrm{D} /\left(1+\mathrm{k}\left(\mathrm{t}_{\mathrm{b}}-\mathrm{aux}\right)\right)\right]\right\} \mathrm{B} \\
& =\{50-[50 /(1+0.00016(148-31))]\} 1.8 \\
& =+1.7^{\circ} \mathrm{C} .
\end{aligned}
$$


If the computed correction is positive, it is added to the thermometer correction. If the computed correction is negative, it is subtracted from the thermometer correction. The resulting correction is applicable when this thermometer is used at an immersion of $25 \mathrm{~mm}$.

If this correction is to be made on thermometers calibrated in the tin bath (300 to $538^{\circ} \mathrm{C}$ ), the formula to be used is:

$$
\text { Too-deep immersion correction }=\left\{D-\left[D /\left(1+k\left(t_{b}-a u x-60\right)\right)\right]\right\} B
$$

A value of 35 is substituted for the 60 if the thermometer is inserted more that $50 \mathrm{~mm}$ too deep into the tin bath medium.

In addition to the too-deep immersion correction computed above for thermometers calibrated in the tin bath, a correction represented by the formula given below must also be applied:

$$
\begin{aligned}
& 0.00016 * \mathrm{~L} * \mathrm{~B} * 35=(-) \text { correction } \\
& \mathrm{L}=\text { length from actual point of immersion to point of reading } \\
& \text { (mercury meniscus) in millimeters } \\
& \mathrm{B}=\text { number of degrees per millimeter at the calibration point } \\
& \text { on the thermometer under test }
\end{aligned}
$$

This correction will always be subtracted from the thermometer correction.

\subsubsection{Faden Correction}

A variation of the stem-temperature correction formula is used when a total-immersion thermometer is calibrated above $150{ }^{\circ} \mathrm{C}$, and a portion of the mercury column is in the region of unknown temperature near the surface of the oil or tin bath. The correction is referred to as a "Faden correction." Thermometer serial number T4 calibrated at $200{ }^{\circ} \mathrm{C}$ will be used as an example.

A $100 \mathrm{~mm}$ faden thermometer is placed as discussed in Section 5.8 and shown in Figure 22. The ice-point and scale corrections are applied to the faden thermometer reading. The formula for this correction is given below:

$$
\begin{aligned}
& \quad \text { Faden correction }=\operatorname{kLB}\left(t_{b}-t_{f}\right) \\
& k=\text { coefficient of expansion of mercury in glass } \\
& L=\text { length of faden thermometer bulb in mm } \\
& B=\text { number of degrees per mm at the calibration point on the } \\
& \text { thermometer under test } \\
& t_{b}=\text { temperature of bath medium } \\
& t_{f}=\text { corrected faden thermometer reading }
\end{aligned}
$$

Since this type of stem-temperature correction is used at high temperatures and for thermometers made of borosilicate glass as well as normal glass, the value for the coefficient of expansion of mercury in glass ( $k$ ) is taken from the appropriate column of Table 8. A variation of a portion of the 
table is given in Table $8(\mathrm{~b})$, where the value of $\mathrm{k}$ corresponding to the bath temperature and faden thermometer reading can be easily determined.

The value $L B$ is equivalent to $n$, as discussed in Sections 6.3.1 thru 6.3.4. This variation of the formula is used because a value for $B$ is easier to measure then a value for $n$ degrees. This is done by placing a $1 \mathrm{~cm}$ scale along the thermometer as discussed in Section 6.3 .5 and counting the number of degrees in that $1 \mathrm{~cm}$. This value is then divided by 10 to determine the number of degrees in $1 \mathrm{~mm}$. The multiplication of the value $\mathrm{L}$ by $B$ gives the value of $n$ (number of degrees in the $100 \mathrm{~mm}$ length of thermometer adjacent to the faden thermometer bulb).

In the example a $100 \mathrm{~mm}$ faden thermometer is used and the measured $\mathrm{B}$ at the calibration temperature $\left(200{ }^{\circ} \mathrm{C}\right)$ was 13 degrees per $1 \mathrm{~cm}$, which is 1.3 degree for a $1 \mathrm{~mm}$ distance. The measured bath temperature was $199{ }^{\circ} \mathrm{C}$ and the corrected faden reading was $190{ }^{\circ} \mathrm{C}$. From this data the faden correction was computed as shown below:

$$
\begin{aligned}
\text { Faden correction } & =\operatorname{kLB}\left(t_{\mathrm{b}}-t_{f}\right) \\
& =(0.000167) *(100) *(1.3) *(199-190) \\
& =0.20{ }^{\circ} \mathrm{C} .
\end{aligned}
$$

The correction will always be subtracted from the thermometer correction, since the portion of the stem at the surface of the bath will always be cooler then it should be.

\subsubsection{Emergent Stem-temperature Correction for Calorimetric Thermometers}

Calorimetric thermometers are calibrated at total immersion, but are sometimes used at partial immersion. If this is the case an emergent stem-temperature correction must be made.

The correction may be computed from the following formula, which involves the difference between the initial and final readings, provided the mean temperature of the emergent stem remains constant.

Emergent stem-temperature correction $=k d\left(t_{i}+t_{f}-I-t\right)$

$$
\begin{aligned}
& k=\text { coefficient of expansion of mercury in glass } \\
& \mathrm{d}=t_{f}-t_{i} \\
& t_{i}=\text { initial thermometer reading } \\
& t_{f}=\text { final thermometer reading } \\
& I=\text { scale reading to which the thermometer is immersed } \\
& t=\text { mean temperature of the emergent stem }
\end{aligned}
$$

This correction must be applied (added if positive, subtracted if negative) to the difference of the readings to give the actual temperature difference. 
Beckmann thermometers are also calibrated at total immersion, but may be used at partial immersion. The formula used to compute the emergent stem-temperature correction is similar to the one used for calorimetric thermometers. The formula given below is applicable provided the thermometer is immersed near the zero degree indication on the scale and the temperature of the stem remains constant.

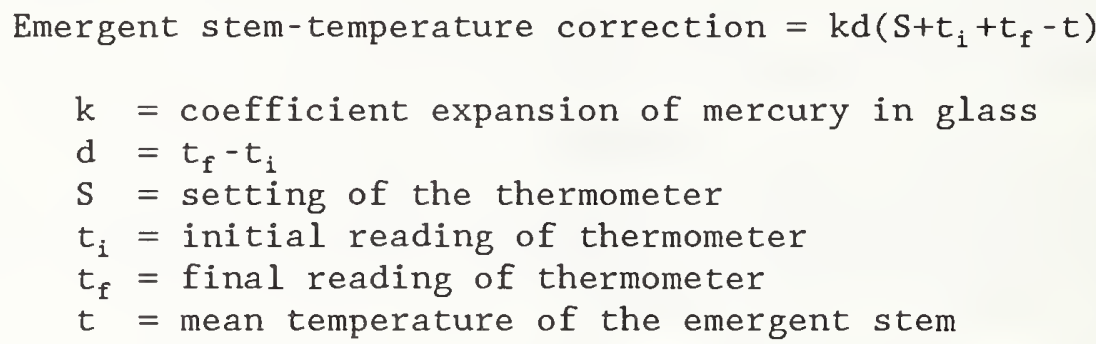

A Beckmann thermometer should not be used with any part of the lower portion of the stem exposed to ambient temperature. Since this part may contain 5 to 10 times more mercury per centimeter than the graduated portion, a large and uncertain error will be introduced if this section is not in the bath medium. If it is unavoidable, and a Beckmann thermometer must be used in this way, the necessary correction may be computed from the above formula, provided $S$ in the formula is replaced by $\mathrm{S}+\mathrm{m}$, where $\mathrm{m}$ is the number of degrees the temperature of the thermometer must be lowered to bring the meniscus from the zero mark on the scale to the point of immersion.

If the thermometer is immersed to some point other than the zero mark, as would ordinarily be the case with thermometers having the zero graduation at the top of the scale, the differential stem correction may be calculated from the above formula if $S$ is replaced by $s+m$. The formula is applicable whether the point of immersion is on the scale are below it, provided the points at which readings are made are above the point to which the thermometer is immersed.

All the calculations shown in Sections 6.3 .1 to 6.3 .6 are on a computer program stored in the main computer at NBS. Access to the program is through the NBS network.

\subsection{Documentation}

\subsection{Report of Calibration}

After corrections are made to the thermometers and the data are considered acceptable, a Report of Calibration is generated for each thermometer submitted for calibration. Figures 24 and 25 show a sample Report of Calibration that would be issued by NBS for thermometer serial number T0. All reports will include the following: 
U. S. DEPARTMENT OF COMMERCE

NATIONAL BUREAU OF STANDARDS

NAT IONAL MEASUREMENT LABORATORY

GAITHERSBURG; MD. 20899

\title{
REPQRT DF CALIBRA T I ON \\ LIQUID-IN-GLASS THERMOMETER .
}

\author{
TESTED FOR: NATIONAL EUREAU OF STANDARDS \\ DIVISION SE2 \\ MARKED: SURETY TO \\ RANGE: -2 TO +1QE DEgREES C IN 0.2 DEGREE
}

$\begin{array}{rc}\text { THERMOMETER } & \text { CORRECTION } \\ \text { READING } & \text { (IPTS-EB)** } \\ -.1010 & .10 \mathrm{C} \\ 20.0101 & .05 \\ 40.00 & -.07 \\ E 0.00 & .01 \\ 80.010 & -.04 \\ 180.00 & .00\end{array}$

**ALL TEMPERATURES IN THIS REPORT ARE BASED ON THE INTERNATIQNAL

PRACTICAL TEMPERATURE SCALE OF 1968, IPTS-EB. THIS TEMPERATURE SCALE WAS ADOPTED BY THE INTERNATIONAL COMMITTEE OF WEIGHTS AND MEASURES AT ITS MEETING IN OCTOBER, 19EB, AND IS DESCRIBED IN" THE INTERNATIONAL PRACTICAL TEMPERATURE SCALE OF 1968 AMENDED EDITION OF 1975,", METROLOGIA 12, NO. $1,7-17$ (197E).

ESTIMATED UNCERTAINTIES IN THE ABOVE CORRECTIONS DO NOT EXCEED 0.05 DEGREE UP TO 1DE DEGREES C.

FOR A DISCUSSION OF ACCURACIES ATTAINAELE WITH SUCH THERMOMETERS SEE NATIONAL EUREAU OF STANDARDS MONOGRAPH 150, LIQUID-IN-GLASS

THERMOMETRY.

IF NO SIGN IS GIVEN ON THE CORRECTION, THE TRUE TEMPERATURE IS HIGHER THAN THE INDICATED TEMPERATURE; IF THE SIGN GIVEN IS NEGATIVE, THE TRUE TEMPERATURE IS LOWER THAN THE INDICATED TEMPERATURE. TO USE THE CORRECTIONS PROPERLY, REFERENCE SHOULD BE MADE TO THE NOTES GIVEN BELOW.

THE TABULATED CORRECTIONS APPLY FOR THE CONDITION OF TOTAL IMMERSION OF THE EULB AND LIQUID COLUMN. IF THE THERMOMETER IS USED AT PARTIAL IMMERSION, APPLY AN EMERGENT STEM CORRECTION AS EXPLAINED IN THE ACCOMPANYING STEM CORRECTION SHEET.

TEST NUMBER 399999

COMPLETED $1-22-85$

Fig. 24. Facsimile of page 1 of an NBS Report of Calibration for thermometer, serial number TO. 
THE TAEULATED CORRECTIONS APPLY PROVIDED THE ICE-POINT READING, TAKEN AFTER EXPOSURE FOR NOT FEWER THAN 3 DAYS TO A TEMPERATURE OF ABOUT 23 DEGREES C (73 DEGREES $F)$, IS $-0.10 \mathrm{C}$. IF THE ICE-POINT READING IS FOUND TO BE HIGHER (OR LOWER) THAN STATED, ALL OTHER READINGS WILL BE HIGHER (OR LOWER) BY THE SAME AMOUNT. IF THE THERMOMETER IS USED AT A GIVEN TEMPERATURE SHORTLY AFTER BEING HEATED TO A HIGHER TEMPERATURE, AN ERROR OF 0.01 DEGREE OP: LESS, FOR EACH 10-DEGREE DIFFERENCE BETWEEN THE TWO TEMPERATURES, MAY BE INTRODUCED. THE TABULATED CORRECTIONS APPLY IF THE THERMOMETER IS USED IN ITS UPRIGHT POSITION; IF USED IN A HORIZONTAL POSITION, THE INDICATIONS MAY BE A FEW HUNDREDTHS OF A DEGREE HIGHER.

FOR THE DIRECTOR, NATIONAL MEASUREMENT LABORATORY

TEST NUMBER 999999

COMPLETED $1-2 こ-85$

ROBERT J. SOULEN, JR. CHIEF, TEMPERATURE AND PRESSURE DIVISION CENTER FOR BASIC STANDARDS

Fig. 25. Facsimile of page 2 of an NBS Report of Calibration for thermometer, serial number T0. 
1) Company, agency, or establishment that submitted the thermometer,

2) Manufacturer's trade name and serial number of the thermometer,

3) Range and graduation interval,

4) Calibration temperatures and corrections,

5) Temperature scale used (IPTS),

6) Estimated uncertainties,

7) Instructions for use of corrections,

8) NBS test number, and

9) Date of calibration.

One or more notes, specific to each thermometer, will also appear on the Report of Calibration. The following list contains examples of notes most commonly used.

ALL TOTAL-IMMERSION THERMOMETERS. The tabulated corrections apply for the condition of total immersion of the bulb and liquid column. If the thermometer is used at partial immersion, apply an emergent stem correction as explained in the accompanying stem correction sheet. (See Figures 26 and 27.)

ALL PARTIAL-IMMERSION THERMOMETERS WITH NO STEM-TEMPERATURE CORRECTIONS. The thermometer was tested in a large, closed-top, electrically heated, liquid bath at an immersion of ._. The temperature of the room was about $23^{\circ} \mathrm{C}\left(73^{\circ} \mathrm{F}\right)$. If the thermometer is used under conditions which would cause the average temperature of the emergent liquid column to differ markedly from that prevailing in the test, appreciable differences in the indications of the thermometer would result.

PARTIAL-IMMERSION THERMOMETERS WITH THE SAME STEM TEMPERATURE AT EACH CALIBRATION POINT. These corrections are applicable for __ immersion and for an emergent stem temperature of

PARTIAL-IMMERSION THERMOMETERS WITH DIFFERENT STEM TEMPERATURES AT EACH CALIBRATION POINT. These corrections are applicable for immersion and for temperatures of the emergent mercury column as given below:

Reading of thermometer

Temperature of emergent mercury

RECALIBRATION NOTE USING ICE POINT. The tabulated corrections apply provided the ice-point reading is _ If the ice-point reading is found to be higher (or lower) than stated, all other readings will be higher (or lower) by the same amount.

RECALIBRATION NOTE USING ICE POINT FOR TOTAL-IMMERSION THERMOMETERS GRADUATED UNDER $150{ }^{\circ} \mathrm{C}$ AND IN GRADUATION INTERVALS OF $0.2^{\circ}$ OR LESS. The tabulated corrections apply provided the ice-point reading taken after exposure for not fewer than 3 days to a temperature of about $23^{\circ} \mathrm{C}\left(73^{\circ} \mathrm{F}\right)$ is . If the ice-point reading is found to be higher (or lower) than stated, all other readings will be higher (or lower) by the same amount. If the thermometer is used at a given temperature shortly after being 


\section{CORRECTION FOR EMERGENT STEM}

This stem correction sheet is designed to explain the process of computing the corrections for emergent stem, but has not been specifically adapted to the individual thermometer with which it is issued.

If a total-immersion thermometer is actually used with a part of the liquid column in the capillary emergent from the bath, a stem correction must be calculated and applied as explained below, making use of the formulas given.

The general formula used in computing the correction for emergent stem is:

\section{Stem correction $=k \times n\left(t_{1}-t\right)$,}

where $k=$ the differential expansion coefficient of mercury (or other liquid in the thermometer such as alcohol, toluene, pentane, etc.) in the particular kind of glass of which the thermometer is made; (for numerical values see below)

$n=$ number of degrees emergent from the bath; $t_{1}=$ temperature of the bath;

$t=$ mean temperature of the emergent stem.

EXAMPLE 1.-Suppose the observed reading was $84.76^{\circ} \mathrm{C}$ and the thermometer was immersed to the $20^{\circ}$ mark on the scale, so that $65^{\circ}$ of the column projected into the air, and the mean temperature of the emergent column was found to be $38^{\circ} \mathrm{C}$, then-
Stem correction $=0.00016 \times 65\left(85^{\circ}-38^{\circ}\right)=+0.49^{\circ} \mathrm{C}$.

The true temperature is therefore the observed reading, $84.76^{\circ} \mathrm{C},+$ tabular correction as interpolated from the report, + emergent stem correction $\left(+0.49^{\circ} \mathrm{C}\right)$.

EXAMPLE 2.-Suppose the observed reading was $780^{\circ} \mathrm{F}$ and the thermometer was immersed to the $200^{\circ}$ mark on the scale, so that $580^{\circ}$ of the column projected into the air, and the mean temperature of the emergent column was found to be $170^{\circ} \mathrm{F}$, then-

Stem correction $=0.00009 \times 580\left(780^{\circ}-170^{\circ}\right)=+32^{\circ} \mathrm{F}$ as a first approximation.

Since the result shows that the bath temperature was approximately $780^{\circ} \mathrm{F}+32^{\circ} \mathrm{F}$, a second approximation should be made, using $t_{1}=812^{\circ} \mathrm{F}$ instead of $t_{1}=780^{\circ}$ F. This gives-

Stem correction $=0.00009 \times 580\left(812^{\circ}-170^{\circ}\right)=+34^{\circ} \mathrm{F}$.

The true temperature is therefore the observed reading, $780^{\circ} \mathrm{F}$, + tabular correction as interpolated from the report, + emergent stem correction $\left(+34^{\circ} \mathrm{F}\right)$.

It will be noted that if the average temperature of the stem is below that of the bulb, the sign of the correction will be + , while if the temperature of the stem is above that of the bulb, the sign of the correction will be -

\section{EXPLANATORY NOTES ON THE EMERGENT STEM CORRECTION}

Some thermometers are pointed and graduated by the maker to read correct, or approximately correct, temperatures when the buib and the entlre llquld Index in the stem are exposed to the temperature to be measured, whlle other thermometers are so pointed and graduated that they will read correct, or approxlmately correct, temperatures when the buib and only a short iength of the stem of the thermometer are lmmersed in the bath, the temperature of which is to be measured. Thermometers of the former class are known as "total-lmmersion thermometers," and those of the iatter class as "partlal-immerslon thermometers."

Total-immersion thermometers are tested under the condlion of total immersion and the correctlons resulting from such a test wili serve to reduce the observed readings of the thermometer to true temperatures only lf the thermometer ls used as a totalImmersion thermometer. If such a thermometer ls actually used as a partlal-lmmerslon thermometer, l.e., with a part of the mercury column emergent lnto the space above the bath, and wlth the emergent stem therefore either colder (or warmer) than the bulb, the thermometer will obvlously read lower (or hlgher) than lt would under the condltion of total immersion. Hence, if a totai-lmmersion thermometer ls so used, a so-called stem correctlon must be applied to the observed reading in addition to the correction taken from the accompanying tabie of corrections. Thls stem correctlon is very large if the number of degrees emergent and the difference of temperature between the bath and the space above lt are large. It may amount to more than $20^{\circ} \mathrm{C}\left(36^{\circ} \mathrm{F}\right)$ for measurements made wlth a mercury thermometer at $400^{\circ} \mathrm{C}\left(750^{\circ} \mathrm{F}\right)$.

The coefficient $k$ ls different for different klnds of glass and even for the same kind of giass, it differs for different temperature Intervais, 1. e., different values of $\left(t_{1}-t\right)$. Values for $k$ for two wldely used thermometric glasses, for use in calculating stem correctlons are tabulated as follows:
VALUES OF $\boldsymbol{k}$ FOR MERCURY-IN-GLASS THERMOMETERS

\begin{tabular}{|c|c|c|c|c|c|}
\hline \multicolumn{3}{|c|}{ For Celsius thermometers } & \multicolumn{3}{|c|}{ For Fahrenheit thermometers } \\
\hline $\begin{array}{c}\text { Mean } \\
\text { temp. } \\
\frac{t,+t}{2}\end{array}$ & $\mid \begin{array}{c}k \\
\text { for } \\
\text { "normal" } \\
\text { glass }\end{array}$ & $\begin{array}{c}k \\
\text { for "boro- } \\
\text { sllleate" } \\
\text { glass }\end{array}$ & $\begin{array}{c}\text { Mean } \\
\text { temp. } \\
\frac{t,+t}{2}\end{array}$ & $\mid \begin{array}{c}k \\
\text { for } \\
\text { "normal" } \\
\text { giass }\end{array}$ & $\mid \begin{array}{c}k \\
\text { for "boro- } \\
\text { sllicate" } \\
\text { glass }\end{array}$ \\
\hline $\begin{array}{l}0^{\circ} \\
100 \\
150 \\
200 \\
250 \\
300 \\
350 \\
400 \\
450\end{array}$ & $\begin{array}{r}0.000158 \\
158 \\
158 \\
159 \\
161 \\
164 \\
-0--\end{array}$ & $\begin{array}{r}0.000164 \\
164 \\
165 \\
167 \\
170 \\
174 \\
178 \\
183 \\
188\end{array}$ & $\begin{array}{l}0^{\circ} \\
200 \\
300 \\
400 \\
500 \\
600 \\
700 \\
800\end{array}$ & $\begin{array}{r}0.000088 \\
88 \\
88 \\
89 \\
90 \\
92 \\
\\
\end{array}$ & $\begin{array}{r}0.000091 \\
91 \\
92 \\
93 \\
95 \\
97 \\
97 \\
.000100 \\
103\end{array}$ \\
\hline
\end{tabular}

If the kind of glass of which the thermometer is made is known, the value of $k$ to be used in computing the stem correction may be taken from the above tabic. If the kind of glass is not known, use $k=0.00016$ for Ccisius or 0.00009 for Fahrenhelt thermometers. High-grilde thermometers are now generally made of "normal" or "borosilicate" glasses. If a thermometer is graduated only to about $450^{\circ} \mathrm{C}\left(850^{\circ} \mathrm{F}\right)$, lt may be made of either of the abore glasses; if it is graduated to $500^{\circ} \mathrm{C}\left(932^{\circ} \mathrm{F}\right)$ and ls actually usabic at that temperature, it is made of one of the borosilleate glasses or a similar glass.

The expansions of liquids such as alcohol, toluene, etc., vary The expansions of liquids such as alcohol, toluene, etc., vary quite rapidiy wlth the temperature, so that $k$ varles considerably for different temperaturc intervais. An approximate stem correction for such thermometers may be calculated by taklng $k$ in the ibove equation $=0.001$ for Cclsius thermometers or 0.0006 for Fahrenheit thermometcrs.

The value of $t$, the mean tempcrature of the emergent stem, is the inost difficul of the terms in the above formula to estimate. It may be quite accurately incasured by the use of speclai capillary thermometers. This is, lowerer, very rarely done except in the testing laboratory, and then only when the stem correction must be determined with considerable prcclsion (to 10 percent or better). In general, the value of $t$ may be determined to a sufficient approximation by judguent or preferably by suspending an cient approximation by judgucnt or preferably by stispending an atuxitiary thermometer close beside the emergent sten, with the of the bath than to the liquld meniscus. 


\section{DIFFERENTIAL CORRECTION FOR EMERGENT STEM}

'I'h is sleet is designed to explain a convenient process of computing the differential correction for emergent stcm but has not been specifically adupterl to the inclividual thermometer with which it is issued.

If a calorimetric or differential or a metastutl. (Beckmann) thermometer ls actually used with i part of its stem emergent from the bath, a differential stem correction must be calculated and applied as explained below, making use of the formulas there given.

Exampie 1.-Suppose the point, $I^{\circ}$. to which the thermometer was immerser was $16^{\circ} \mathrm{C}$ : its initial reading, $T^{\circ}{ }_{1}$, was $24.127^{\circ}$ : its final reading, $T^{\circ}{ }_{2}$, was $27.876^{\circ}$; the mean temperature. $t^{\circ}$, of the emergent stem was $26^{\circ}$; then-

Differential stem correction $=0.00016(28-24)\left(24^{\circ}+\right.$ $\left.28^{\circ}-16^{\circ}-26^{\circ}\right)=+0.006^{\circ}$.
I'he result, $0.006^{\circ}$, should be added to the dlfference between $T^{\circ}$ : and $T^{\circ}{ }_{1}$, found after applylng to each the correctlons tabuluted on the Report of Callbration.

LXaMPLE 2.-Suppose a Bockmann thermometer was inmersed to the $0^{\circ}$ murk on its scalc; its lnitlal reading, $T^{\circ}{ }_{1}$. was $2.058^{\circ}$; its final reading, $T^{\circ}$, was $5.127^{\circ}$; the mean temperature, $t^{\circ}$, of the emergent stcm was $24^{\circ}$ $\mathrm{C}$; and the setting, $S^{\circ}$, was $25^{\circ} \mathrm{C}$; then-

Differential stem correction $=0.00016(5-2) \quad\left(25^{\circ}+\right.$ $\left.2^{\circ}+5^{\circ}-24^{\circ}\right)=+0.004^{\circ}$.

The result $+0.004^{\circ}$, shonld he added to the difference lhetween $T^{\circ}$ a and $T^{\circ}{ }_{1}$, found apter applying to each the corrections tabulated on the Report of Calibration and inultiplying the difference $l, y$ the setting factor $(1.0014$ for a setting of $25^{\circ}$ ).

\section{EXPLANATORY NOTES ON THE EMERGENT STEM CORRECTION}

Calorimetric and differential and metastatic (Becknunn) thermometers are polnted and graduated hy the makers to read correct or approximately correct tenuperature intervals when the bulb and the entlre mercury index in the stem are exposed to the temperature to be measured, and woh thermometers are standardized for the condlton of "total immerslon," and the corrections given in reports apply for the condition of total lmmerslon.

In praetically all cases, Iowevir. wuch tlermometers aro aftually used with only the hulh and a portion of the stem immersed. the renainder of the stem projecting into the alr ibove the batl.

In such cases the accuracy attained can be incrosed hy applying the necessary forrectlons for the emergent stem. The energent stem correction corresponding to any readlng una be conputed by means of the formula-

$$
\text { Steul corroction }=k \times n\left(T^{\circ}-t^{\circ}\right) \text {; }
$$

wiere $k=$ the differential expansion coefficient of mereury in glass:

$=0.00016$ for Celsius thermometers ;

$=0.00009$ for Wahrenloit tiermoneters:

$u=$ unmber of degrees emercent from the hath

$T^{\circ}=$ temperature of the batl :

$t^{\circ}=$ mean temperature of the emergent steni.

However. in differential measurements the parts of the scale on which readlngs ar made are, in grueral. emergent from the bath and it is usually permisslhle to assume that $t^{\circ}$ will he constaut during tle measurement. In this fase, instead of calculatlug the stem corrections for the inltial and final readings. and applying them separately, the differentlal stem eorrection ean be more eonrelliently computed hy using the apiropriate formula of the two givell below.

Differential emergent stem corrcctiou for ordinary thcrmometers.- The differentlal stem eorrection may he eoniputer from the followlug formula :

Differentlal stem correction $=k \times d\left(T^{\circ}{ }_{1}+T^{\circ}{ }_{2}-I^{\circ}-t^{\circ}\right)$;

$k=0.00016$ for Celsius thermonieters :

$=0.00009$ for lihrenhis thrinometors:

$T^{\circ}{ }_{1}=$ the lnltial reading;

$T^{\circ}=$. the fintl readlug:

$d=T^{\circ}:-T^{\circ}$ :
$I^{\circ}=$ scale reading to which the thermometer was lmmersed; $t^{\circ}=$ mean temperature of the emcrgent stem.

It shonld be noted that this differential stem correctlon, as well as the difference $d^{\circ}$, may be either positlve or negatire, and the correction must be applled with due regard to these slgns.

Differential emergent stem correction for metastatic (Bcckmann) thermometers. - The differentlal emergent stem correction may be computed from the following formula, provided the thermometer is immersed to its $0^{\circ}$ mark:

Differential stem forrection $=k \times d\left(S^{\circ}+T^{\circ}{ }_{1}+T^{\circ}{ }_{2}-t^{\circ}\right)$;

where $S^{\circ}=$ the "setting" of the thermonieter, and $k, d, T^{\circ}$, $T^{\circ}$ and $t^{\circ}$ have the meanlngs given in the preceding parafrapli.

It should be noted that this differential stem eorrection, as well as the difference $d$, may be elther posltive or negative, and the correction must be applled with due regard to these signs.

A Beckmann thermometer of the ordinary type slould not be used with any part of the lower portion of the stem $p x$ posed. us thls part may eontaln fron 5 to 10 times as nuch mercury per centlmeter as the graduated portlon, and if exposed introduces a Iarge and uncertaln error.

In case it is necessary to use such a thermometer with some of the lower portion of the stem emergent from the bath. the nfcrssary correction may be computed from the abore formula, provlded $S^{\circ}$ in the formula is replaced by $s^{\circ}+m^{\circ}$, where $m$ is the number of degrees the temperature of the thernometer must be lowered to bring the menlscus from the zero position on its scale to the point of immerslon.

If the thermometer is immersed to some point other than its $0^{\circ}$ nark. as would ordlnarily be the case with thermometers having the $0^{\circ}$ graduation at the top of the scale, the differential stem correction may also be computed from the above formula, provided $S^{\circ}$ in the formula is replaced hy $s^{\circ}+m^{\circ}$, where $m$ is the number of degrees the temperature of the thermometer unst be Imoered to bring the meniscus from the zero position on its scale to the point of immerslon. Provlded the points at which readings are made are ahove the point to which the thermometer is immersed, the precedlng statemint is appllcable whether the polnt to whlch the thermometer ls immersed is on the scale or below it.

Fig. 27. Stem temperature explanation sheet attached to reports for calorimetric thermometers calibrated at total immersion. 
heated to a higher temperature, an error or $0.01{ }^{\circ} \mathrm{C}$ or less, for each 10 degree difference between the two temperatures, may be introduced. The tabulated corrections apply if the thermometer is used in its upright position; if used in a horizontal position, the indications may be a few hundredths of a degree higher.

STEAM POINT USED AS REFERENCE POINT. The tabulated corrections apply provided the reading when the thermometer is immersed in steam at $100{ }^{\circ} \mathrm{C}$ $\left(212^{\circ} \mathrm{F}\right.$ ) is . If the reading is found to be higher (or lower) than stated, all other readings will be higher (or lower) by the same amount. The temperature of steam is $100{ }^{\circ} \mathrm{C}\left(212^{\circ} \mathrm{F}\right)$ only if the pressure is $760 \mathrm{~mm}$ ( 29.921 inches). If the pressure differs from $760 \mathrm{~mm}$ (29.921 inches) allowance must be made for this. If the pressure is higher (or lower) than $760 \mathrm{~mm}$ (29.921 inches) the temperature will be higher (or lower) than $100{ }^{\circ} \mathrm{C}\left(212^{\circ} \mathrm{F}\right)$ by approximately $0.037{ }^{\circ} \mathrm{C}$ per mm difference $\left(1.68^{\circ} \mathrm{F}\right.$ per inch difference).

CALORIMETRIC THERMOMETERS HEATED TO TOP POINT BEFORE TESTING. The thermometer, before testing, was heated to the temperature of the highest test point. The application of the tabular corrections to the readings of the thermometer will give true temperature differences provided the thermometer is used in its upright position and is heated previously (within an hour before using) to the highest temperature to be measured.

SETTING FOR BECKMANN THERMOMETERS. The tabulated corrections apply for a "setting" of $20^{\circ} \mathrm{C}$. Setting factors for use with other settings are given on the accompanying sheet. (See Figure 28).

ICE POINT TAKEN AFTER TEST, SUCH AS CLINICAL AND KINEMATIC VISCOSITY THERMOMETERS. The tabulated corrections apply for the condition of immersion indicated provided the ice-point reading, taken after heating to for not fewer than 3 minutes, is

which should be taken within 5 minutes after removal of the thermometer from the heated bath, is found to be higher (or lower) than stated all other readings will be higher (or lower) by the same amount.

LOW TEMPERATURE PARTIAL-IMMERSION THERMOMETERS CALIBRATED AT TOTAL IMMERSION WITH NO SPECIFIED EMERGENT STEM TEMPERATURE. At temperatures below the ice point this thermometer was tested under conditions of total immersion of the bulb and liquid column. The stated corrections were computed using a value of $\mathrm{k}=$ /degree and an assumed temperature of for the emergent stem.

LOW TEMPERATURE PARTIAL-IMMERSION THERMOMETERS CALIBRATED AT TOTAL IMMERSION WITH SPECIFIED EMERGENT STEM TEMPERATURES. At temperatures below the ice point this thermometer was tested under conditions of total immersion of the bulb and liquid column. The stated corrections were computed using a value of $\mathrm{k}=$ /degree 
This sheet gives a table of setting factors and an example to explain the processes employed in calculations. The example, however, has not been specifically adapted to the individual thermometer with which this sheet is issued.

The thermometer is said to have a given setting, for instance $20^{\circ} \mathrm{C}$, if its scale reading is $0^{\circ}$ when the temperature of the bulb is $20^{\circ} \mathrm{C}$.

The following table, calculated for thermometers of Jena $16^{\text {III }}$ glass, gives a series of factors corresponding to different settings by which each observed temperature difference must be multiplied after applying the corrections given on the preceding page. This factor is made unity for a setting of $20^{\circ} \mathrm{C}$.

For any scale length up to $15^{\circ}$

\begin{tabular}{c|c||c|c}
\hline Setting & Factor & Setting & Factor \\
\hline $0^{\circ} \mathrm{C}$ & 0.9935 & $55^{\circ} \mathrm{C}$ & 1.0092 \\
5 & 0.9951 & 60 & 1.0102 \\
10 & 0.9967 & 65 & 1.0112 \\
15 & 0.9984 & 70 & 1.0121 \\
20 & 1.0000 & 75 & 1.0129 \\
25 & 1.0014 & 80 & 1.0137 \\
30 & 1.0029 & 85 & 1.0146 \\
35 & 1.0042 & 90 & 1.0154 \\
40 & 1.0056 & 95 & 1.0162 \\
45 & 1.0070 & 100 & 1.0170 \\
50 & 1.0082 & &
\end{tabular}

As an illustration, suppose the following observations were made:

$$
\begin{aligned}
& \text { Setting . . . . }=25^{\circ} \mathrm{C} . \quad \text { Lower reading }=2.058^{\circ} \\
& \text { Stem temperature }=24^{\circ} \quad \text { Upper reading }=5.127^{\circ} \\
& \text { Lower Upper } \\
& \text { Observed reading }=2.058 \quad 5.127 \\
& \text { Correction from certificate }=\underline{+.005} \quad \underline{-.008} \\
& \text { Corrected upper reading }=5.119 \\
& \text { Corrected.lower reading }=2.063 \\
& \text { Difference }=3.056 \\
& \text { Setting factor } 1.0014 \quad \text { corr. } \quad+.004 \\
& \text { Emergent stem correction* }=+.004 \\
& \text { Corrected difference }=3.064
\end{aligned}
$$

* See accompanying stem correction sheet.

Fig. 28. Table of setting factors attached to reports for Beckmann thermometers. 
Other notes that are occasionally used and are self explanatory are given below:

This thermometer complies with the accuracy requirement of the applicable ASTM specification to the extent of the tests made.

This thermometer does not comply with the accuracy requirement of the applicable ASTM specification.

Not tested at a sufficient number of points.

Not tested over the entire range of scale.

Not tested over the entire range of scale nor at a sufficient number of points.

Correction at exceeds the tolerance.

Corrections at and exceed the tolerance.

Graduated too close to the expansion chamber.

Graduated too close to the contraction chamber.

Graduated too close to the bulb.

No fixed point taken.

No fixed point.

If there is any other information concerning a specific thermometer that is considered important for the user to know, a note should be written and included on the report.

All Reports of Calibration are generated on the NBS computer.

\subsection{Internal Quality Control}

Obvious errors to be avoided in the calibration process are misreading the thermometers or recording the standard platinum resistance thermometer resistance values incorrectly. These errors can be reduced or eliminated by either repeating the calibration point, or double checking the information immediately after the calibration point has been recorded. The operator should be sure that the last resistance value, which is still set on the bridge, is the number written in the data book and that the values preceding it are reasonable. Look again at each thermometer that was read. See if it was read on the correct side of the nominal temperature (Was it 19.9 or 20.0 ?). Check that the two readings of each liquid-inglass thermometer are reasonable. See that the spread between the two readings varies from nothing (or a very small value) for the last liquidin-glass thermometer in the set to a value somewhat equal to the spread of 
the first and third platinum resistance thermometer values for the first liquid-in-glass thermometer. Check any faden or auxiliary thermometer readings for correctness.

\subsection{Use of Check Standards}

The above sources of error can be practically eliminated if care is taken during the calibration process. Another source of error, which is equipment failure during the day, is very difficult to detect.

At the beginning of the day the standard platinum resistance thermometer is placed in a triple point of water cell to see if the thermometer is still in calibration and that the bridge is performing properly. Any deviation in the resistance value at the triple point of water is due to the platinum resistance thermometer and/or the bridge and not the triple point of water cell. Checking this point assures that the bridge and resistance thermometer are producing good results at the beginning of the day, but what assurance is there that it will continue to perform properly during the day?

As a check on the system, liquid-in-glass thermometers, called check standards, belonging to NBS are incorporated into the calibration process. These thermometers are calibrated, at each calibration point requested for the other thermometers, as if they were submitted for test by an outside company. The computed corrections on the check standards are compared with the corrections obtained from previous calibrations. If they agree within the uncertainty of each type of thermometer, it can be assumed that the system was performing well and that the calibration of the other thermometers will be acceptable.

\subsection{Comparison of Corrections and Evaluation of Data on Check Standards}

At NBS corrections obtained from repeated calibration of the check standards are recorded in data books and compared with data taken at some previous time. A sample sheet of the data taken for thermometer serial number 274762 is given in Table 11. This thermometer has a range of -1 to $+51^{\circ} \mathrm{C}$ and is graduated in intervals of $0.1^{\circ}$. The expected uncertainty of this thermometer (which will be calculated in section 9) is $0.03{ }^{\circ} \mathrm{C}$.

The control procedure for liquid-in-glass thermometer calibrations is somewhat ad hoc because the data base of check standard values is sparse in temperature regions where calibrations are rarely requested. All new entries are compared with values taken at the same nominal temperature, or, if necessary, with values taken within one or two degrees of the specified temperature. If the new and old values agree within the uncertainty of the thermometer, in this case $0.03{ }^{\circ} \mathrm{C}$, then the calibration is considered acceptable. Explanations for unacceptable calibrations include: misreading of the thermometer; failure of the SPRT; and failure of the bridge.

In order for this procedure to work effectively, the old values must be representative of the check standard; i.e., a sufficient history must exist 
TABLE 11

RECORD OF CHECK STANDARD CORRECTIONS

Thermometer Serial Number 274762

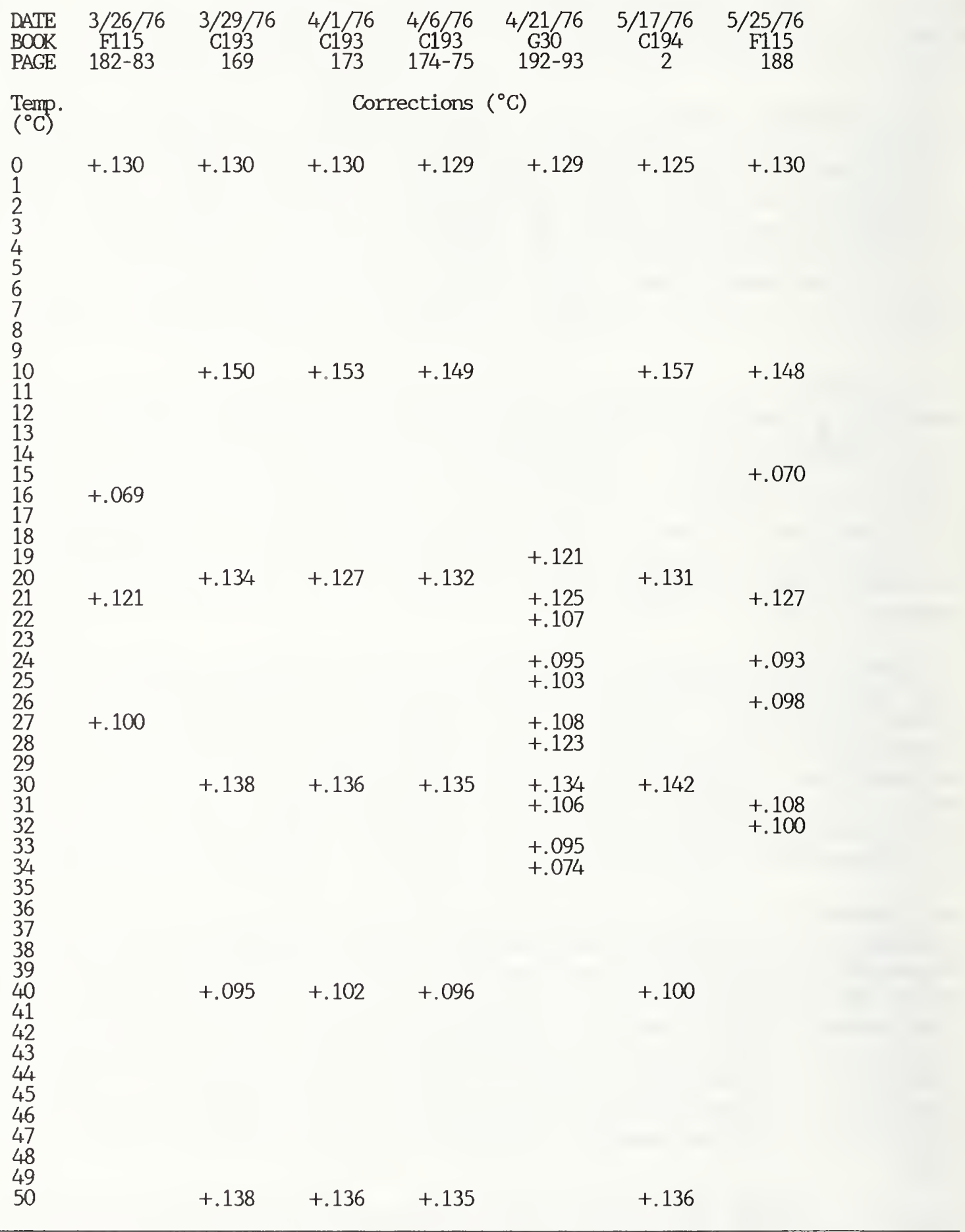


on the check standard to be able to tell whether it is the new or the old value that is out-of control. Lack of agreement is always taken as an indication of a problem with the current calibration, and calibrations on all thermometers in the group are repeated.

\subsection{Assessment of Uncertainties}

\subsection{Current Tolerance and Uncertainty Values}

Shortly after the turn of the century, when the liquid-in-glass thermometer calibration laboratory was established, tables listing tolerances and uncertainties for liquid-in-glass thermometers were published. These values can be found in NBS Monograph 150 [7]. These values varied for different temperature ranges, graduation intervals, and types of thermometers. Since there is a tremendous variety of liquid-in-glass thermometers covering many temperature ranges and divided in different graduation intervals, it would be impossible to evaluate all possible combinations. Tolerance and uncertainty values for the most widely used combinations are given in Tables 12 through 17 for both Celsius and Fahrenheit thermometers. These combinations will be discussed in Section 9.2.

The scale tolerances shown were chosen to be indicative of good manufacturing practice. When a thermometer is manufactured, small errors in pointing (marks placed on a blank thermometer at various temperatures to be used as guides for the placement of the graduation lines) and graduating are inevitable. These graduation marks are also subject to variations due to the inherent properties of the glass. The tolerances must be sufficiently restrictive to insure a satisfactory high-grade thermometer, and at the same time not cause undue manufacturing difficulties.

In addition to the scale tolerance limit, the error in any temperature interval should not exceed 5 percent of the nominal value of the interval. The purpose of this requirement is to eliminate thermometers having large corrections of alternating signs, which lead to uncertainties in the interpolation of scale corrections between the calibration points.

The word "uncertainty" used in these tables refers to the uncertainty of the best values attainable in the use of thermometers when all corrections are applied. The uncertainty bounds may seem broad in some instances, but the definite limitations of liquid-in-glass thermometry become apparent when all factors are considered. For example, if the scale is expanded by reducing the diameter of the capillary, a practical limit is reached beyond which capillary forces, in combination with the elasticity of the thermometer bulb, will prevent a smooth advance or retreat of the mercury column. The movement of the mercury meniscus may be erratic and occur in steps appreciably large in comparison to the graduation interval. This is particularly true when the temperature of the medium is decreasing. Less rigid bulbs (relatively large diameters and/or thin walls), as well as capillaries of small diameters, may cause large "meniscus jumps". Excessively elliptical or flattened bores are not recommended for the same 
TABLE 12

TOLERANCES AND UNCERTAINTIES FOR

LOW-TEMPERATURE TOTAL-IMMERS ION

THERMOMETERS

\begin{tabular}{c|c|c|c|c}
\hline $\begin{array}{c}\text { Temperature } \\
\text { range in } \\
\text { degrees }\end{array}$ & $\begin{array}{c}\text { Type of } \\
\text { thermometer }\end{array}$ & $\begin{array}{l}\text { Graduation } \\
\text { interval in } \\
\text { degrees }\end{array}$ & $\begin{array}{l}\text { Toler- } \\
\text { ance in } \\
\text { degrees }\end{array}$ & $\begin{array}{c}\text { Uncertainty } \\
\text { in degrees }\end{array}$ \\
\hline
\end{tabular}

Celsius thermometers

\begin{tabular}{|c|c|c|c|c|c|c|}
\hline-35 to 0 & Mercury & 1.0 or 0.5 & 0.5 & 0.1 & to & 0.2 \\
\hline-35 to 0 & Mercury & .2 & .4 & .02 & to & .05 \\
\hline-56 to 0 & $\begin{array}{l}\text { Mercury- } \\
\text { thallium }\end{array}$ & .5 & .5 & .1 & to & .2 \\
\hline-56 to 0 & $\begin{array}{l}\text { Mercury- } \\
\text { thallium }\end{array}$ & .2 & .4 & .02 & to & .05 \\
\hline-200 to 0 & $\begin{array}{l}\text { Organic } \\
\text { liquid }\end{array}$ & 1.0 & 2.0 & .2 & to & .5 \\
\hline
\end{tabular}

Fahrenheit thermometers

\begin{tabular}{|c|c|c|c|c|c|}
\hline-35 to 32 & Mercury & 1.0 or 0.5 & 1.0 & 0.1 to & 0.2 \\
\hline-35 to 32 & Mercury & .2 & .5 & & .05 \\
\hline-69 to 32 & $\begin{array}{l}\text { Mercury- } \\
\text { thallium }\end{array}$ & 1.0 or .5 & 1.0 & .1 to & .2 \\
\hline-69 to 32 & $\begin{array}{l}\text { Mercury- } \\
\text { thallium }\end{array}$ & .2 & .5 & & .05 \\
\hline-328 to 32 & $\begin{array}{l}\text { Organic } \\
\text { liquid }\end{array}$ & 2.0 or 1.0 & 3.0 & .3 to & .5 \\
\hline
\end{tabular}


TABLE 13

TOLERANCES AND UNCERTAINTIES FOR

LOW-TEMPERATURE PARTIAL-IMMERSION

THERMOMETERS

\begin{tabular}{c|c|c|c|c}
\hline $\begin{array}{c}\text { Temperature } \\
\text { range in } \\
\text { degrees }\end{array}$ & $\begin{array}{c}\text { Type of } \\
\text { thermometer }\end{array}$ & $\begin{array}{l}\text { Graduation } \\
\text { interval in } \\
\text { degrees }\end{array}$ & $\begin{array}{l}\text { Toler- } \\
\text { ance in } \\
\text { degrees }\end{array}$ & $\begin{array}{c}\text { Uncertainty } \\
\text { in degrees }\end{array}$ \\
\hline
\end{tabular}

Celsius thermometers

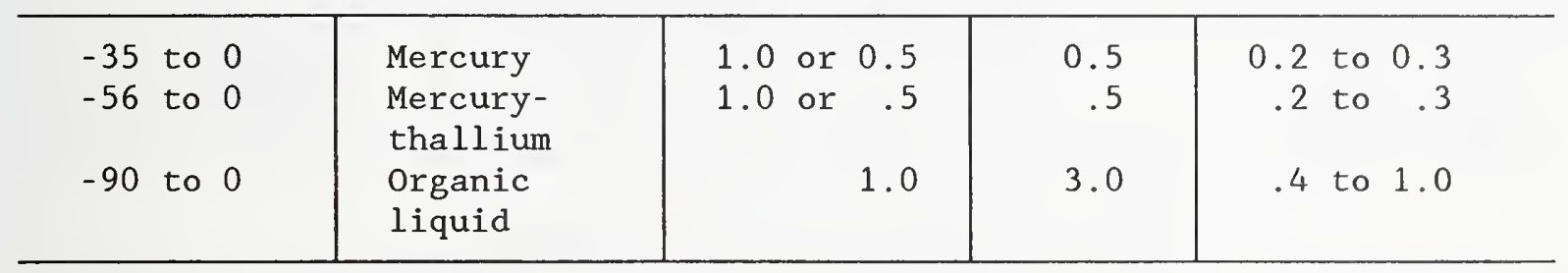

Fahrenheit thermometers

\begin{tabular}{|c|c|c|c|c|}
\hline-35 to 32 & Mercury & 1.0 or 0.5 & 1.0 & 0.3 to 0.5 \\
\hline-69 to 32 & $\begin{array}{l}\text { Mercury- } \\
\text { thallium }\end{array}$ & 1.0 or .5 & 1.0 & .3 to .5 \\
\hline-130 to 32 & $\begin{array}{l}\text { Organic } \\
\text { liquid }\end{array}$ & 2.0 or 1.0 & 5.0 & .8 to 2.0 \\
\hline
\end{tabular}




\section{TOLERANCES AND UNCERTAINTIES FOR \\ CELSIUS TOTAL-IMMERSION \\ MERCURY THERMOMETERS}

\begin{tabular}{c|c|c|c}
\hline $\begin{array}{c}\text { Temperature range in } \\
\text { degrees }\end{array}$ & $\begin{array}{c}\text { Graduation } \\
\text { interval in } \\
\text { degrees }\end{array}$ & $\begin{array}{c}\text { Tolerance } \\
\text { in } \\
\text { degrees }\end{array}$ & $\begin{array}{c}\text { Uncertainty } \\
\text { in degrees }\end{array}$ \\
\hline
\end{tabular}

Thermometers graduated under $150{ }^{\circ} \mathrm{C}$

\begin{tabular}{l|r|r|rrr}
\hline 0 up to 150 & 1.0 or 0.5 & 0.5 & 0.1 & to & 0.2 \\
0 up to 150 & .2 & .4 & .02 to & .05 \\
0 up to 100 & .1 & .3 & .01 to & .03 \\
\hline
\end{tabular}

Thermometers graduated under $300{ }^{\circ} \mathrm{C}$

\begin{tabular}{l|c|c|rr}
\hline up to 100 & 1.0 or 0.5 & 0.5 & 0.1 & to 0.2 \\
Above 100 up to 300 & & 1.0 & to & .3 \\
0 up to 100 & .2 & .4 & .02 to & .05 \\
Above 100 up to 200 & .5 & to & .1 \\
\hline
\end{tabular}

Thermometers graduated above $300{ }^{\circ} \mathrm{C}$

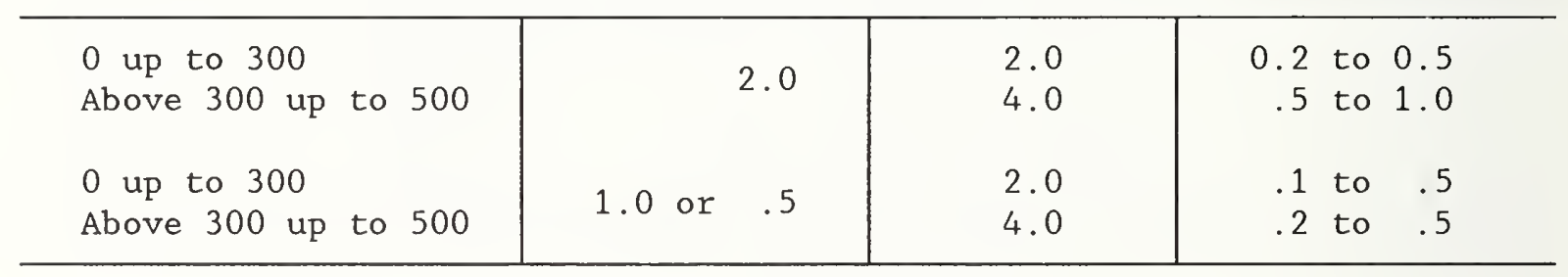


TABLE 15

TOLERANCES AND UNCERTAINTIES FOR

FAHRENHEIT TOTAL-IMMERS ION

MERCURY THERMOMETERS

\begin{tabular}{c|c|c|c}
\hline $\begin{array}{c}\text { Temperature range in } \\
\text { degrees }\end{array}$ & $\begin{array}{c}\text { Graduation } \\
\text { interval in } \\
\text { degrees }\end{array}$ & $\begin{array}{c}\text { Tolerance } \\
\text { in } \\
\text { degrees }\end{array}$ & $\begin{array}{c}\text { Uncertainty } \\
\text { in degrees }\end{array}$ \\
\hline
\end{tabular}

Thermometers graduated under $300^{\circ} \mathrm{F}$

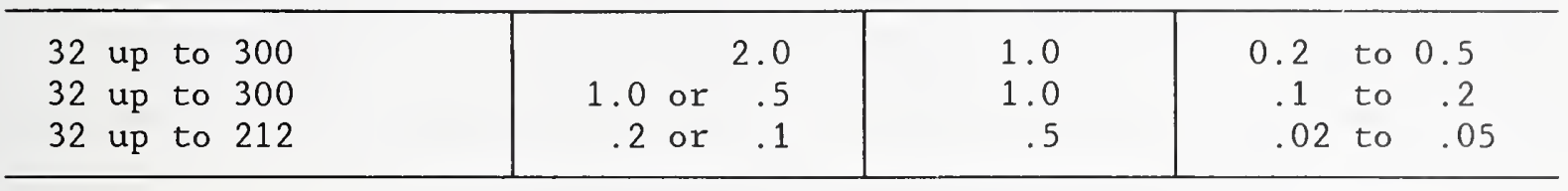

Thermometers graduated under $600{ }^{\circ} \mathrm{F}$

\begin{tabular}{l|l|l|r}
\hline 32 up to 212 & 2.0 or 1.0 & 1.0 & 0.2 to 0.5 \\
Above 212 up to 600 & 2.0 & .5 \\
\hline
\end{tabular}

Thermometers graduated above $600{ }^{\circ} \mathrm{F}$

\begin{tabular}{l|l|l|l}
\hline 32 up to 600 & 5.0 & 4.0 & 0.5 to 1.0 \\
Above 600 up to 950 & & 7.0 & 1.0 to 2.0 \\
32 up to 600 & 2.0 or 1.0 & 3.0 & .2 to 1.0 \\
Above 600 up to 950 & 6.0 & to 1.0 \\
\hline
\end{tabular}


TABLE 16

TOLERANCES AND UNCERTAINTIES FOR

CELSIUS PARTIAL-IMMERSION

MERCURY THERMOMETERS

\begin{tabular}{c|c|c|c}
\hline $\begin{array}{c}\text { Temperature range in } \\
\text { degrees }\end{array}$ & $\begin{array}{c}\text { Graduation } \\
\text { interval in } \\
\text { degrees }^{\mathrm{a}}\end{array}$ & $\begin{array}{c}\text { Tolerance } \\
\text { in } \\
\text { degrees }\end{array}$ & $\begin{array}{c}\text { Uncertainty } \\
\text { in degrees }\end{array}$
\end{tabular}

Thermometers graduated under $150{ }^{\circ} \mathrm{C}$

\begin{tabular}{l|l|l|rr}
\hline 0 up to 100 & $\begin{array}{l}1.0 \text { or } 0.5 \\
1.0 \text { or } .5\end{array}$ & $\begin{array}{l}1.0 \\
1.0\end{array}$ & $\begin{array}{r}0.1 \\
1\end{array}$ & to 0.3 \\
0 up to 150 & .5 \\
\hline
\end{tabular}

Thermometers graduated under $300{ }^{\circ} \mathrm{C}$

\begin{tabular}{l|l|l|r}
\hline 0 up to 100 & 1.0 & $\begin{array}{l}1.0 \\
1.5\end{array}$ & $\begin{array}{r}0.1 \text { to } 0.3 \\
5 \text { to } 1.0\end{array}$ \\
\hline
\end{tabular}

Thermometers graduated above $300{ }^{\circ} \mathrm{C}$

\begin{tabular}{l|l|l|l}
\hline 0 up to 300 & 2.0 or 1.0 & $\begin{array}{l}2.5 \\
5.0\end{array}$ & $\begin{array}{l}0.5 \text { to } 1.0 \\
1.0 \text { to } 2.0\end{array}$ \\
\hline
\end{tabular}

${ }^{a}$ Partial-immersion thermometers are sometimes graduated in smaller intervals than shown in these tables, but this in no way improves the performance of the thermometers, and the listed tolerances and uncertainties still apply.

$\mathrm{b}$ The uncertainties shown are attainable only if emergent-stem temperatures are closely known and accounted for. 
TABLE 17

TOLERANCES AND UNCERTAINTIES FOR

FAHRENHEIT PARTIAL-IMMERSION

MERCURY THERMOMETERS

\begin{tabular}{c|c|c|c}
\hline $\begin{array}{c}\text { Temperature range in } \\
\text { degrees }\end{array}$ & $\begin{array}{c}\text { Graduation } \\
\text { interval in } \\
\text { degrees }^{\mathrm{a}}\end{array}$ & $\begin{array}{c}\text { Tolerance } \\
\text { in } \\
\text { degrees }\end{array}$ & $\begin{array}{c}\text { Uncertainty } \\
\text { in degrees }\end{array}$
\end{tabular}

Thermometers graduated under $300^{\circ} \mathrm{F}$

\begin{tabular}{r|l|l|r}
\hline 32 up to 212 & 2.0 or 1.0 & 2.0 & 0.2 to 0.5 \\
32 up to 300 & 2.0 or 1.0 & 2.0 & to 1.0 \\
\hline
\end{tabular}

Thermometers graduated under $600^{\circ} \mathrm{F}$

\begin{tabular}{l|l|l|l}
\hline 32 up to 212 & 2.0 or 1.0 & $\begin{array}{l}2.0 \\
3.0\end{array}$ & $\begin{array}{l}0.2 \text { to } 0.5 \\
1.0 \text { to } 2.0\end{array}$ \\
\hline
\end{tabular}

Thermometers graduated above $600^{\circ} \mathrm{F}$

\begin{tabular}{l|l|l|l}
\hline 32 up to 600 & 5.0 or 2.0 & 5.0 & 1.0 to 2.0 \\
Above 600 up to 950 & 10.0 & 2.0 to 3.0 \\
\hline
\end{tabular}

a Partial-immersion thermometers are sometimes graduated in smaller intervals than shown in these tables, but this in no way improves the performance of the thermometers, and the listed tolerances and uncertainties still apply.

${ }^{b}$ The uncertainties shown are attainable only if emergent-stem temperatures are closely known and accounted for. 
reason. Therefore, increasing the length of a degree on the scale, for practical bulb sizes, improves thermometric performance only to a certain point. Beyond this point precision of reading may readily be mistaken for accuracy in temperature measurement. A study of the effects of bulb and capillary dimensions on thermometer performance, made by Hall and Leaver [14], provides valuable guidelines for design purposes.

Other factors such as ice-point reading changes, unless exactly accounted for, and differences in external pressure may also account for inaccuracies much greater than the imprecision with which a scale having 0.1 or 0.2 degree graduations may be read.

In Table 18, Tolerances and Uncertainties for Beckmann and Calorimetric Thermometers, the estimated accuracy attainable in the measurement of any interval within the limits of the scale is given under the heading "uncertainty of interval in degrees". No tolerances for scale error are given, although it is desirable that it be no larger than $0.02{ }^{\circ} \mathrm{C}$ over a $1.0{ }^{\circ} \mathrm{C}$ interval.

\subsection{Evaluation of Uncertainties}

In the past few years we at NBS have felt a need to determine realistic uncertainty values for items calibrated at NBS. No one in the Temperature and Pressure Division knows exactly how the published values were established for liquid-in-glass thermometers, or if the values are still valid. The check standard measurements produce an enormous data base which has been analyzed to determine the uncertainty of these types of liquid-in-glass thermometers over various temperature ranges.

TABLE 18

UNCERTAINTIES FOR BECKMANN AND CALORIMETRIC THERMOMETERS

\begin{tabular}{l|c|c|c}
\hline $\begin{array}{c}\text { Type of } \\
\text { thermometer }\end{array}$ & $\begin{array}{c}\text { Graduation } \\
\text { interval } \\
\text { in degrees }\end{array}$ & $\begin{array}{c}\text { Allowable change } \\
\text { in correction } \\
\text { in degrees }\end{array}$ & $\begin{array}{c}\text { Uncertainty } \\
\text { of interval } \\
\text { in degrees }\end{array}$ \\
\hline Beckmann & $0.01{ }^{\circ} \mathrm{C}$ & $\begin{array}{l}0.01 \text { over } 0.5^{\circ} \text { interval } \\
\text { for setting of } 20{ }^{\circ} \mathrm{C}\end{array}$ & 0.002 to 0.005 \\
Bomb calorimetric & $.01{ }^{\circ} \mathrm{C}$ & 0.02 over $1.5^{\circ}$ interval & .005 to .01 \\
Bomb calorimetric & $.02{ }^{\circ} \mathrm{C}$ & 0.02 over $1.5^{\circ}$ interval & .005 to .01 \\
Bomb calorimetric & $.05{ }^{\circ} \mathrm{F}$ & 0.04 over $2.5^{\circ}$ interval & .01 to .02 \\
Gas calorimetric & $.1{ }^{\circ} \mathrm{F}$ & 0.15 over a $5^{\circ}$ interval & .02 to .05 \\
\hline
\end{tabular}


Over the past sixteen years, fourteen liquid-in-glass thermometers, representing the most accurate types in a given temperature range, have been used as check standards. Two total-immersion thermometers of each type were chosen for the standards. The thermometers are allowed to rest at room temperature $\left(23^{\circ} \mathrm{C}\right)$ for three days before being calibrated, allowing the volume of the bulb to recover from a previous thermal cycling. Since no Celsius thermometers were available for the evaluation of low temperature calibration points, thermometers graduated in degrees Fahrenheit are used. All of the thermometers had an ice-point reading either on the main scale or on an auxiliary scale. The range, graduation interval, and resolution of the check standard thermometers are given in Table 19.

TABLE 19

THERMOMETERS USED AS CHECK STANDARDS

\begin{tabular}{|c|c|c|}
\hline $\begin{array}{c}\text { Temperature } \\
\text { Range }\end{array}$ & $\begin{array}{l}\text { Thermometer } \\
\text { Graduation }\end{array}$ & Resolution \\
\hline$\left({ }^{\circ} \mathrm{F}\right)$ & $\left({ }^{\circ} \mathrm{F}\right)$ & $\left({ }^{\circ} \mathrm{F}\right)$ \\
\hline-60 to -30 & 0.2 & 0.01 \\
\hline Temperature & Thermometer & Resolution \\
\hline$\left({ }^{\circ} \mathrm{C}\right)$ & $\left({ }^{\circ} \mathrm{C}\right)$ & $\left({ }^{\circ} \mathrm{C}\right)$ \\
\hline 0 to 50 & 0.1 & 0.005 \\
\hline 50 to 100 & 0.1 & 0.005 \\
\hline 0 to 100 & 0.2 & 0.01 \\
\hline 100 to 200 & 0.2 & 0.01 \\
\hline 200 to 300 & 0.5 & 0.05 \\
\hline 300 to 500 & 1.0 & 0.05 \\
\hline
\end{tabular}

Because the customer is allowed to request calibration at any number of points, every correction recorded for the check standards could not be analyzed. Most calibrations occur at temperature intervals of every 10 , 20 , or 30 degrees; therefore, the data taken at these intervals were used in the analysis. For each check standard, the correction versus temperature is plotted as a function of time over a period of five to twelve years. These plots are given in Figures 29(a) to 42(a2).

Several of the plots show the effect of a permanent change in bulb volume with time and use. As the volume of a liquid-in-glass thermometer bulb increases or decreases, the thermometer readings will decrease or increase, respectively, throughout the whole range. This accounts for the uniform shift of the correction versus temperature curves seen in some of the examples. In order to analyze the data accurately, an adjustment must be 
made for the bulb volume change. All of the data were normalized to a constant ice-point reading representing an approximate average of the ice-point corrections. The data for selected points were again plotted and the results are given in Figures $29(\mathrm{~b})$ to $41(\mathrm{~b})$.

The standard deviation as computed for each nominal bath temperature is a measure of both the instability of the thermometer and the random error in realizing the bath temperature. Three times the pooled standard deviation over the temperature range is taken as the limit to random error for the calibration process in that range. The results are given in Table 20. (Data for check standard, serial number 234456, were not included, because too few data points were taken.) The column titled "Degrees of Freedom" indicates one less then the number of measurements taken at the specified temperature.

It is also necessary to assess the systematic errors to establish the final uncertainty for each thermometer. Systematic errors recognized for this process are: the realization of the ice point; the uncertainty in the calibration of the standard platinum resistance thermometer; and the temperature gradients in the calibration baths. Any other sources of error are considered negligible.

The uncertainty in the realization of the ice point was determined by examining years of data accumulated from measuring the ice point on the standard platinum resistance thermometer before a triple point of water cell was used. The spread was found to be $0.005{ }^{\circ} \mathrm{C}$.

The uncertainty in the calibration of the standard platinum resistance thermometer is listed in Monograph 126, Platinum Resistance Thermometry, [13] as $\pm 0.0002{ }^{\circ} \mathrm{C}$ at the triple point of water, $\pm 0.001{ }^{\circ} \mathrm{C}$ at the freezing point of tin, and $\pm 0.001{ }^{\circ} \mathrm{C}$ at the freezing point of zinc. From the documentation on standard platinum resistance thermometers, the uncertainty of the interpolated values between the fixed points is $0.001{ }^{\circ} \mathrm{C}$ to $450{ }^{\circ} \mathrm{C}$ and increasing to $0.003{ }^{\circ} \mathrm{C}$ at $500{ }^{\circ} \mathrm{C}$.

The gradients in the calibration baths were determined by simultaneous measurements using three standard platinum resistance thermometers placed at various depths and at different locations in the baths. These measurements were made at several regulated temperatures throughout the range of each calibration bath. The values chosen for the systematic errors, due to the bath gradients, both radially and horizontally, were the maximum differences between the three standard platinum resistance thermometer readings and shown in Table 21. The sum of the systematic errors are given in Table 21.

The total uncertainty calculated for the liquid-in-glass thermometers is given in Table 22. These values are the sum of the random error limit (three standard deviation) and the systematic error. 


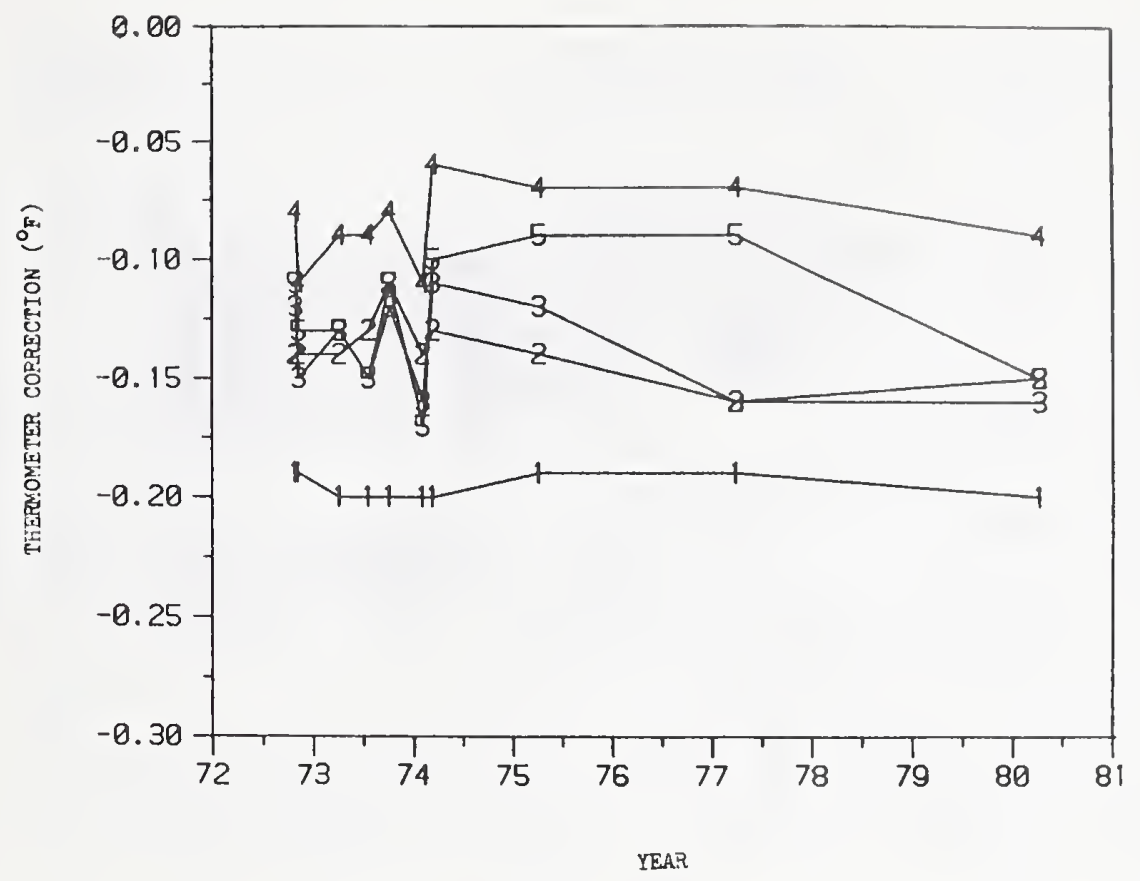

Fig. 29(a). Plot for thermometer, serial number T531432, at five temperatures ( 1 at $32{ }^{\circ} \mathrm{F}, 2$ at $-30{ }^{\circ} \mathrm{F}, 3$ at $-40{ }^{\circ} \mathrm{F}, \quad 4$ at $-50^{\circ} \mathrm{F}$, and 5 at $\left.-60^{\circ} \mathrm{F}\right)$. The readings were not corrected for ice-point shifts.

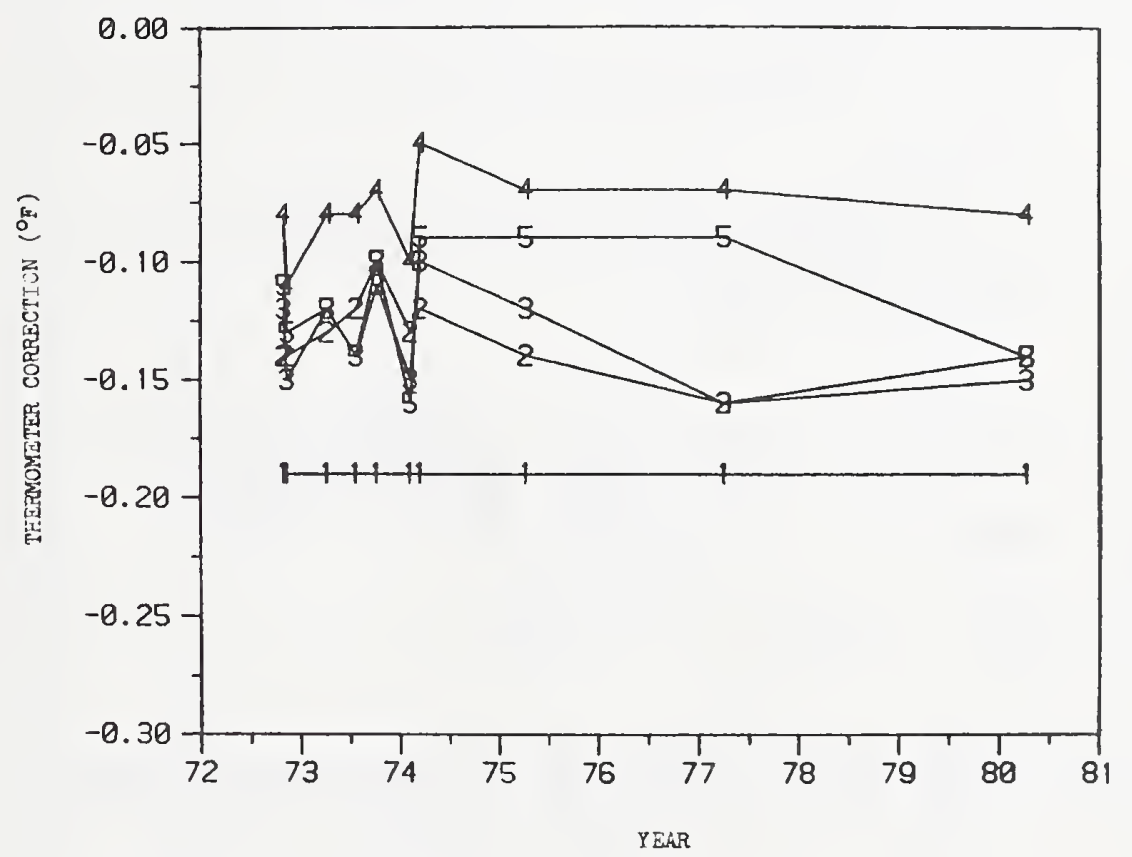

Fig. 29(b). Plot for thermometer, serial number T531432, at five temperatures $\left(1\right.$ at $32^{\circ} \mathrm{F}, 2$ at $-30{ }^{\circ} \mathrm{F}, 3$ at $-40{ }^{\circ} \mathrm{F}, 4$ at $-50^{\circ} \mathrm{F}$, and 5 at $\left.-60^{\circ} \mathrm{F}\right)$. The readings were corrected for ice-point shifts. 


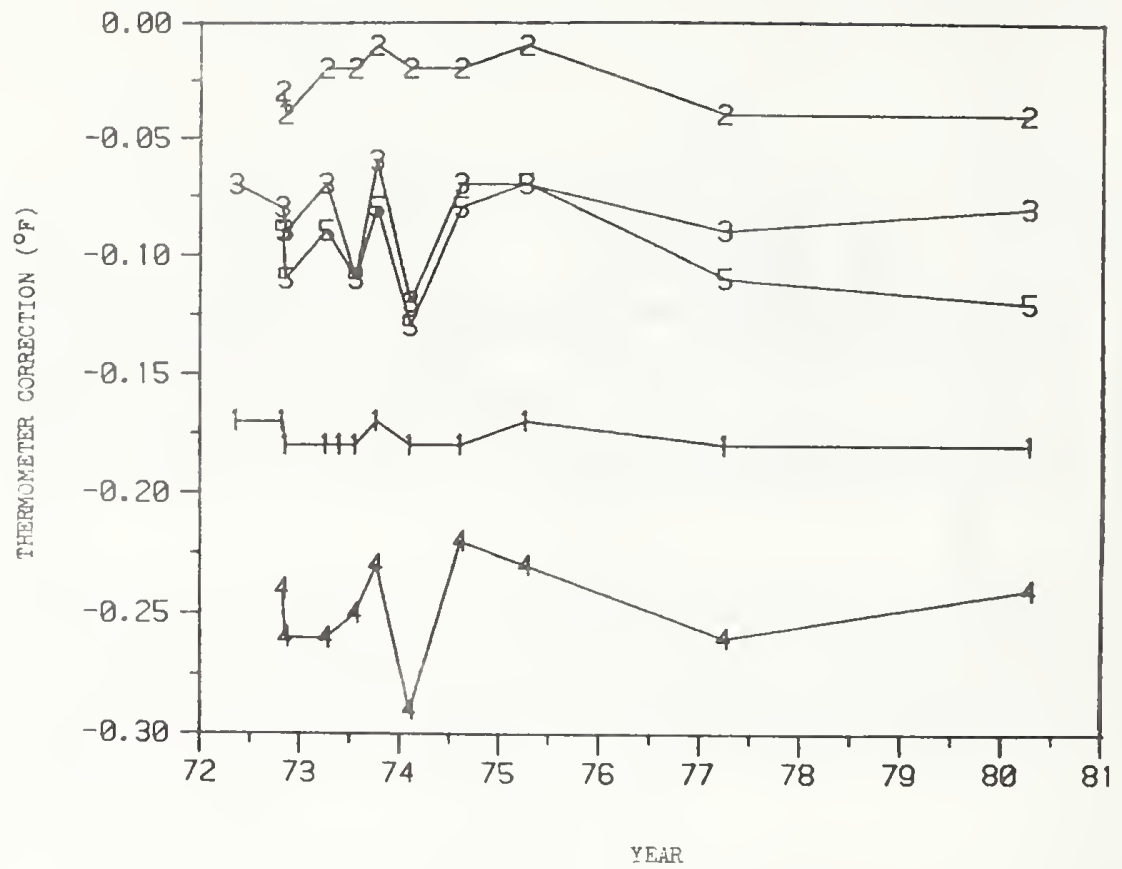

Fig. 30(a). Plot for thermometer, serial number T531438, at tive temperatures $\left(1\right.$ at $32^{\circ} \mathrm{F}, 2$ at $-30{ }^{\circ} \mathrm{F}, \quad 3$ at $-40{ }^{\circ} \mathrm{F}, \quad 4$ at $-50{ }^{\circ} \mathrm{F}$, and 5 at $\left.-60^{\circ} \mathrm{F}\right)$. The readings were not corrected for ice-point shifts.

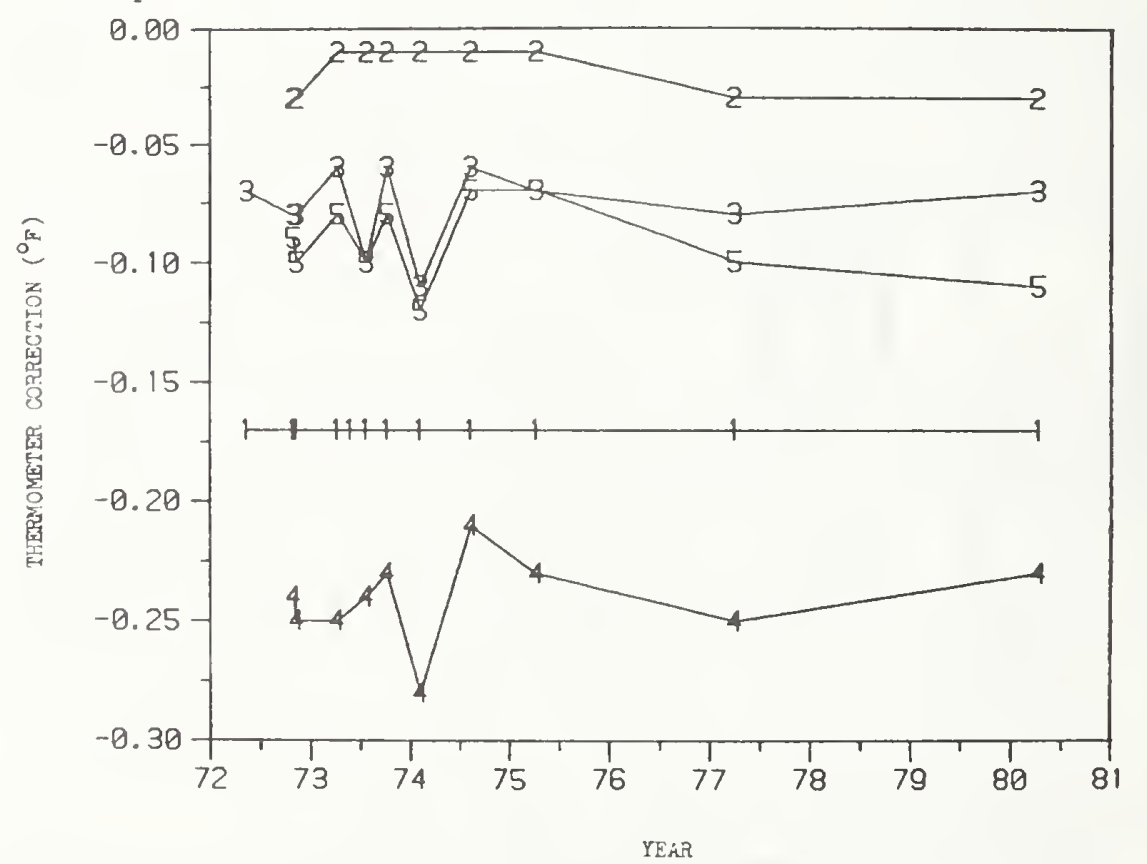

Fig. 30(b). Plot for thermometer, serial number T531438, at five temperatures ( 1 at $32{ }^{\circ} \mathrm{F}, 2$ at $-30{ }^{\circ} \mathrm{F}, \quad 3$ at $-40{ }^{\circ} \mathrm{F}, \quad 4$ at $-50^{\circ} \mathrm{F}$, and 5 at $\left.-60^{\circ} \mathrm{F}\right)$. The readings were corrected for ice-point shifts. 


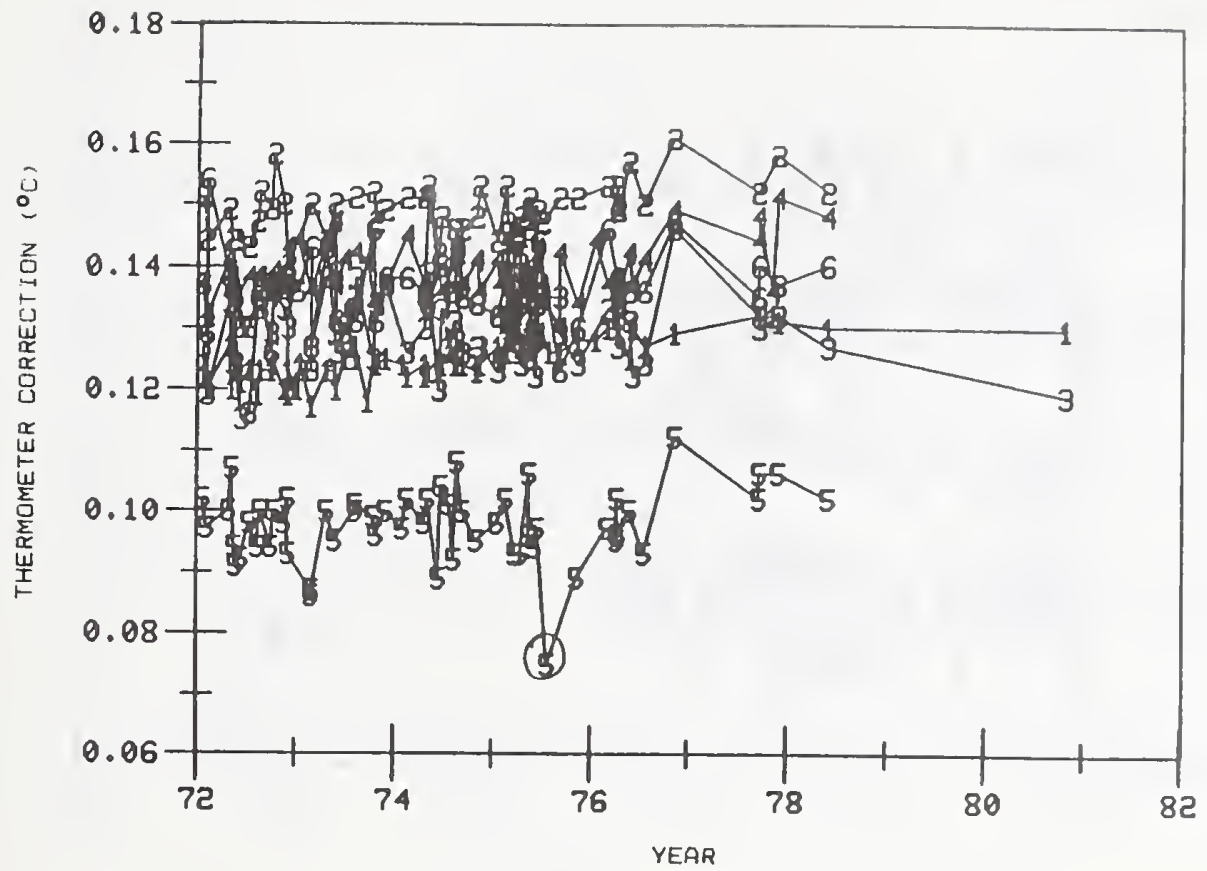

Fig. 31(a). Plot for thermometer, serial number 274762, at six temperatures $\left(1\right.$ at $0{ }^{\circ} \mathrm{C}, 2$ at $10{ }^{\circ} \mathrm{C}, 3$ at $20{ }^{\circ} \mathrm{C}, 4$ at $30{ }^{\circ} \mathrm{C}, 5$ at $40{ }^{\circ} \mathrm{C}$, and 6 at $50{ }^{\circ} \mathrm{C}$ ). The readings were not corrected for ice-point shifts.

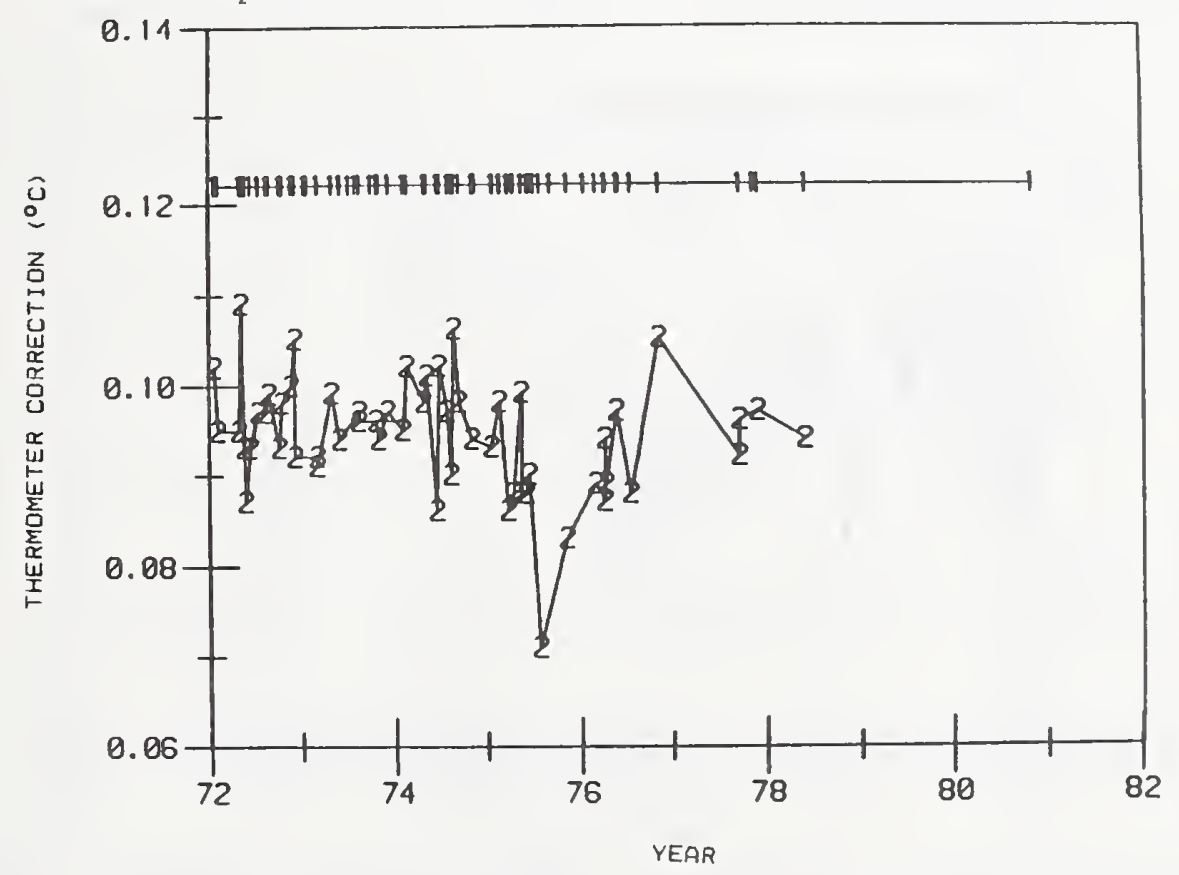

Fig. 31(b). Plot for thermometer, serial number 274762, at two temperatures $\left(1\right.$ at $0{ }^{\circ} \mathrm{C}$ and 2 at $40{ }^{\circ} \mathrm{C}$ ). The readings were corrected for ice-point shifts. 


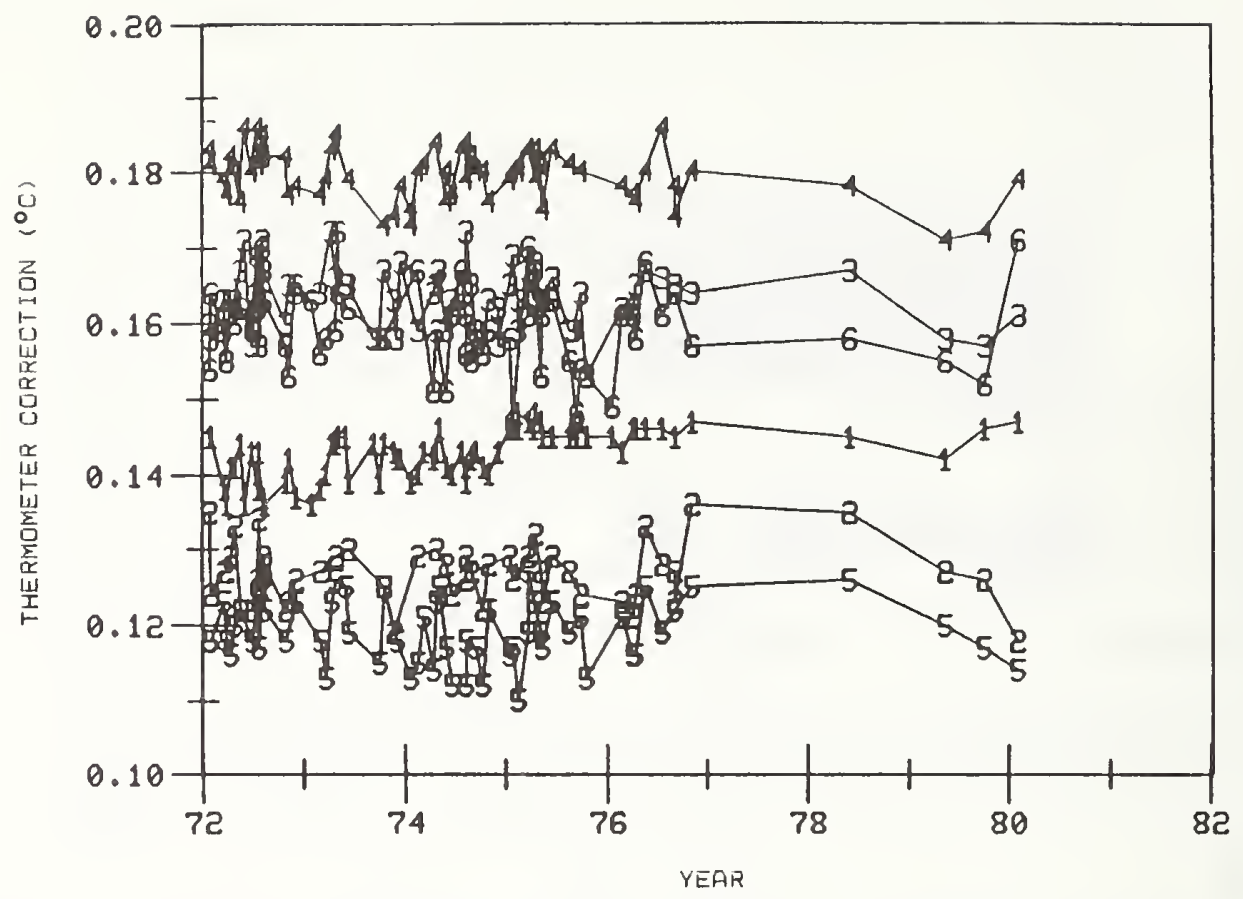

Fig. 32(a). Plot for thermometer, serial number 275764, at six temperatures $\left(1\right.$ at $0{ }^{\circ} \mathrm{C}, 2$ at $10{ }^{\circ} \mathrm{C}, 3$ at $20{ }^{\circ} \mathrm{C}, 4$ at $30{ }^{\circ} \mathrm{C}, 5$ at $40{ }^{\circ} \mathrm{C}$, and 6 at $50{ }^{\circ} \mathrm{C}$ ). The readings were not corrected for ice-point shifts.

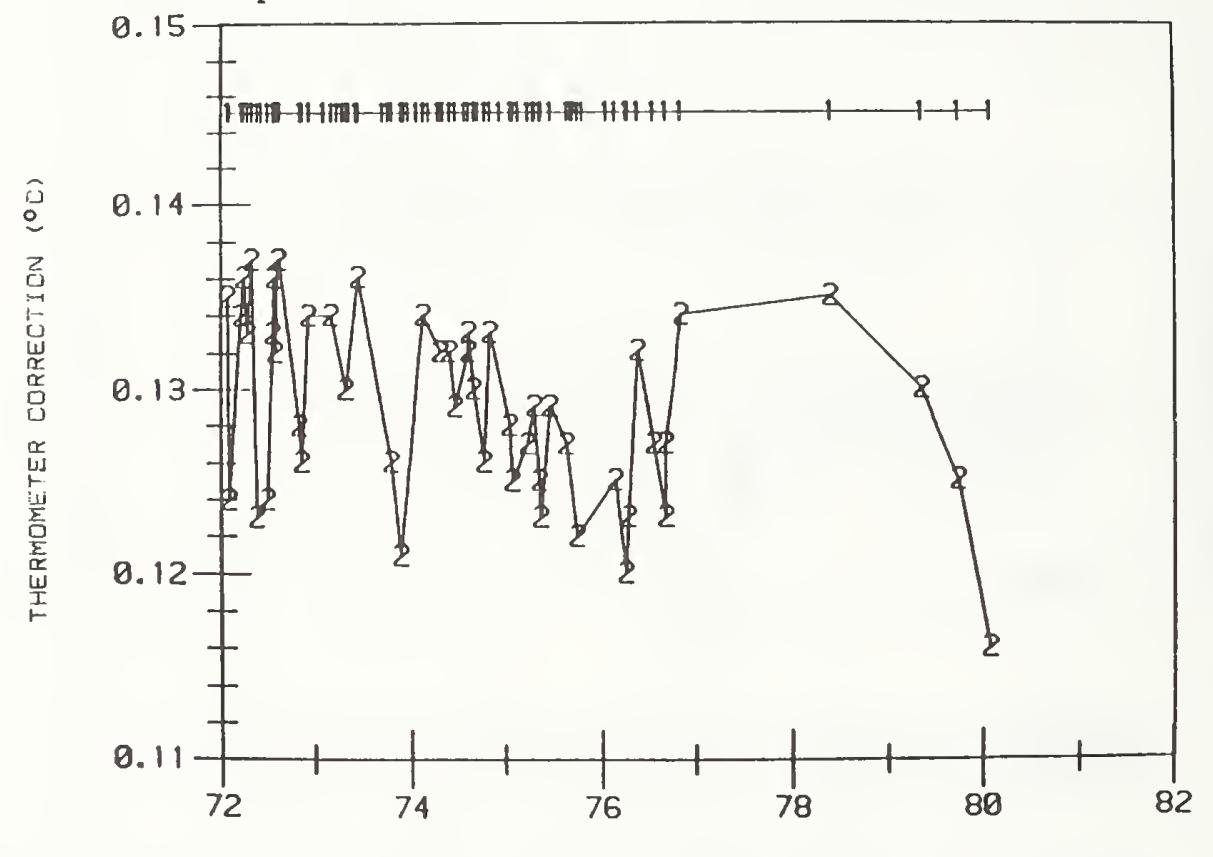

Fig. 32(b). Plot for thermometer, serial number 274764, at two temperatures $\left(1\right.$ at $0{ }^{\circ} \mathrm{C}$ and 2 at $10^{\circ} \mathrm{C}$ ). The readings were corrected for ice-point shifts. 


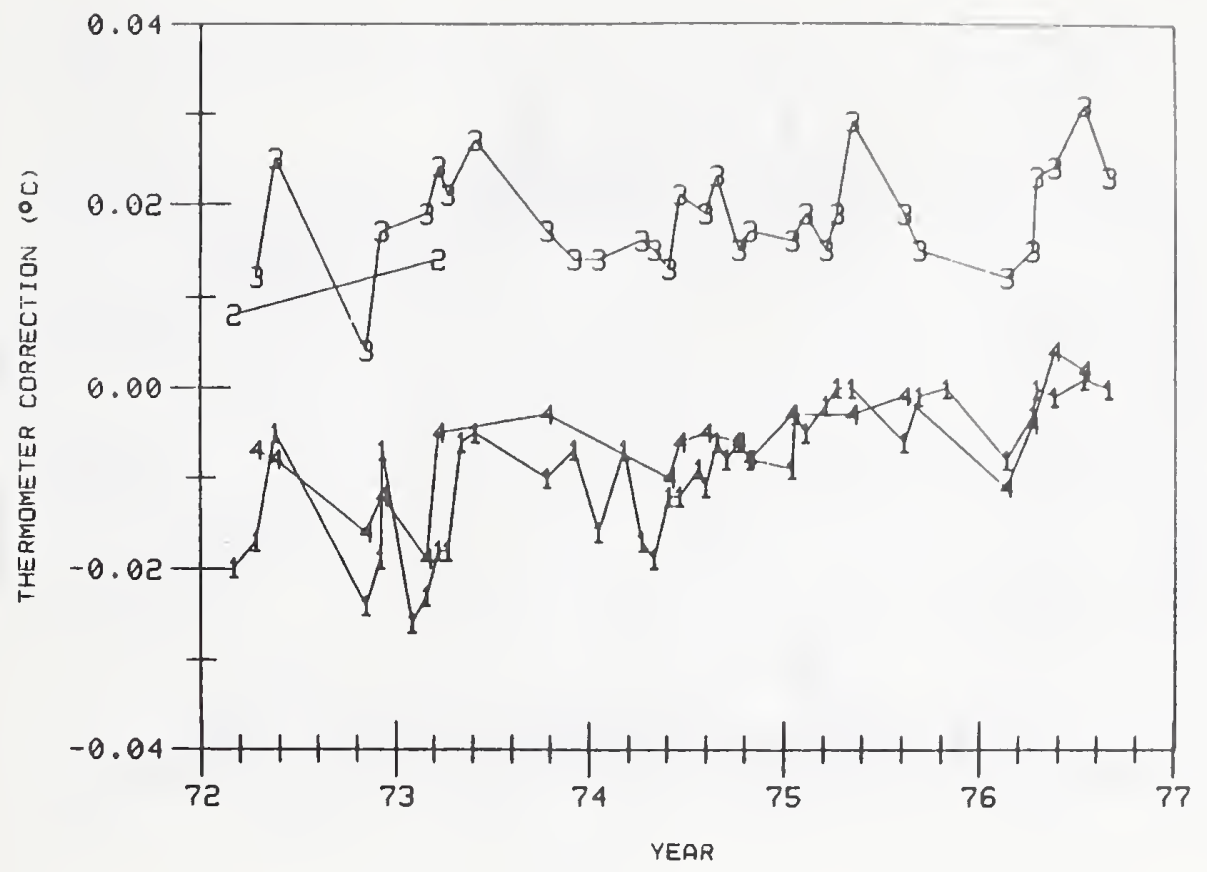

Fig. 33(a1). Plot for thermometer, serial number 4030424, at four temperatures $\left(1\right.$ at $0{ }^{\circ} \mathrm{C}, 2$ at $50^{\circ} \mathrm{C}, 3$ at $60^{\circ}$, and 4 at $\left.70{ }^{\circ} \mathrm{C}\right)$. The readings were not corrected for ice-point shifts.

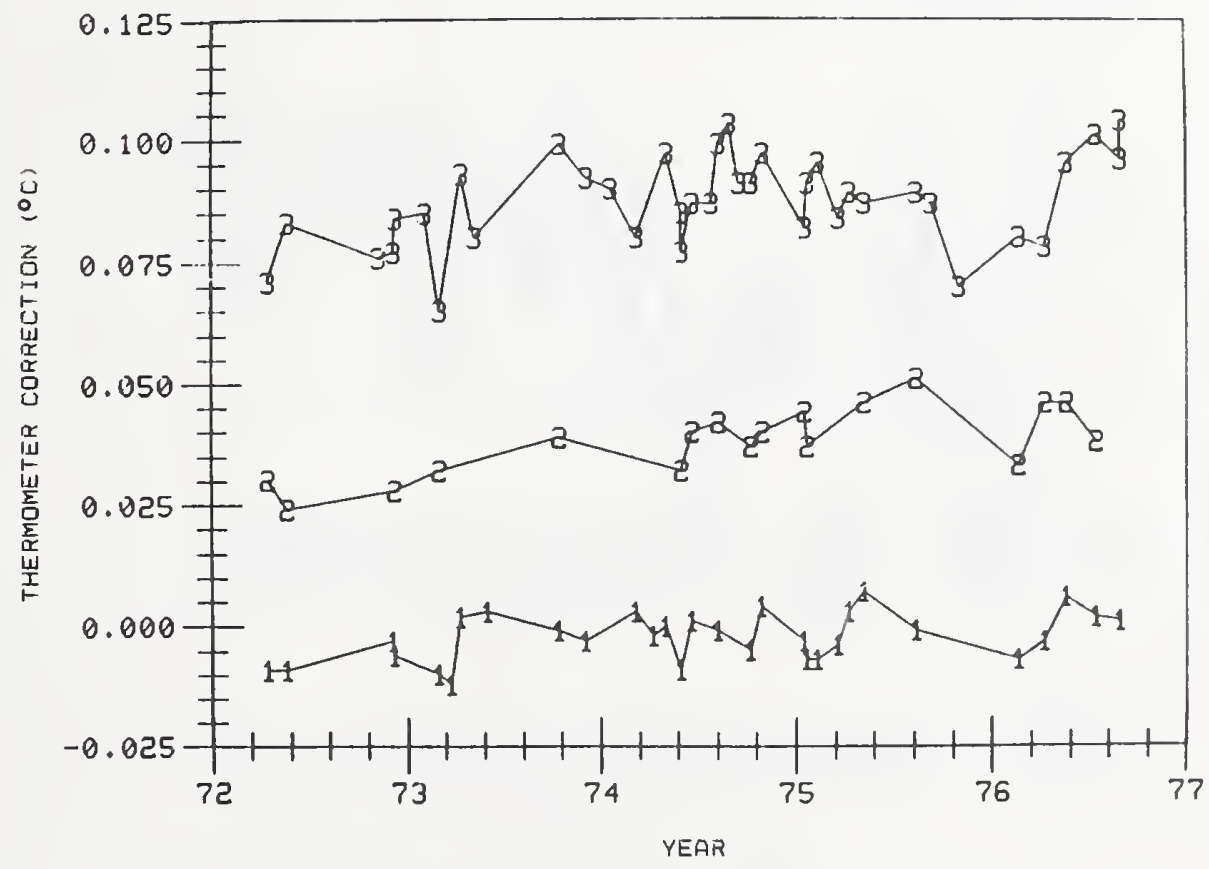

Fig. 33(a2). Plot for thermometer, serial number 4030424, at three temperatures $\left(1\right.$ at $80^{\circ} \mathrm{C}, 2$ at $90^{\circ} \mathrm{C}$, and 3 at $100{ }^{\circ} \mathrm{C}$ ). The readings were not corrected for ice-point shifts. 


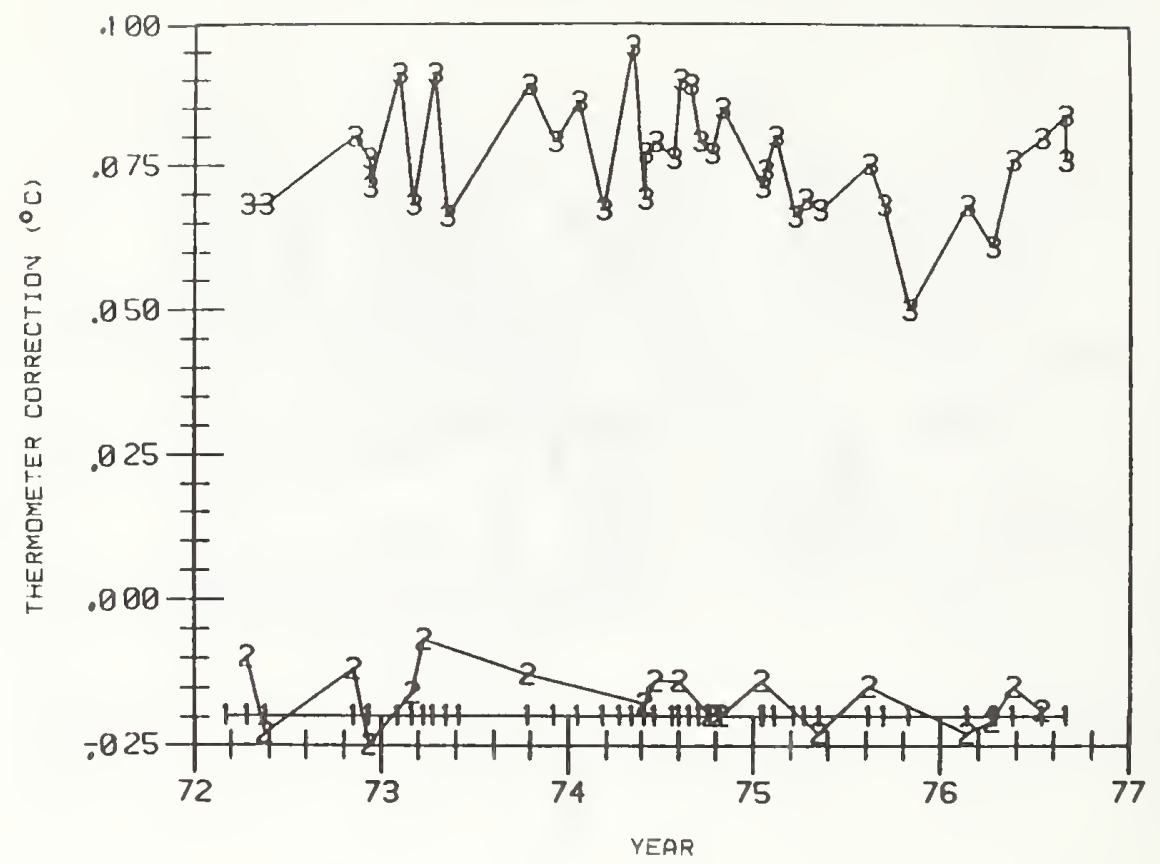

Fig. 33(b). Plot for thermometer, serial number 4030424, at three temperatures $\left(1\right.$ at $0{ }^{\circ} \mathrm{C}, 2$ at $70{ }^{\circ} \mathrm{C}$, and 3 at $100{ }^{\circ} \mathrm{C}$ ). The readings were corrected for ice-point shifts.

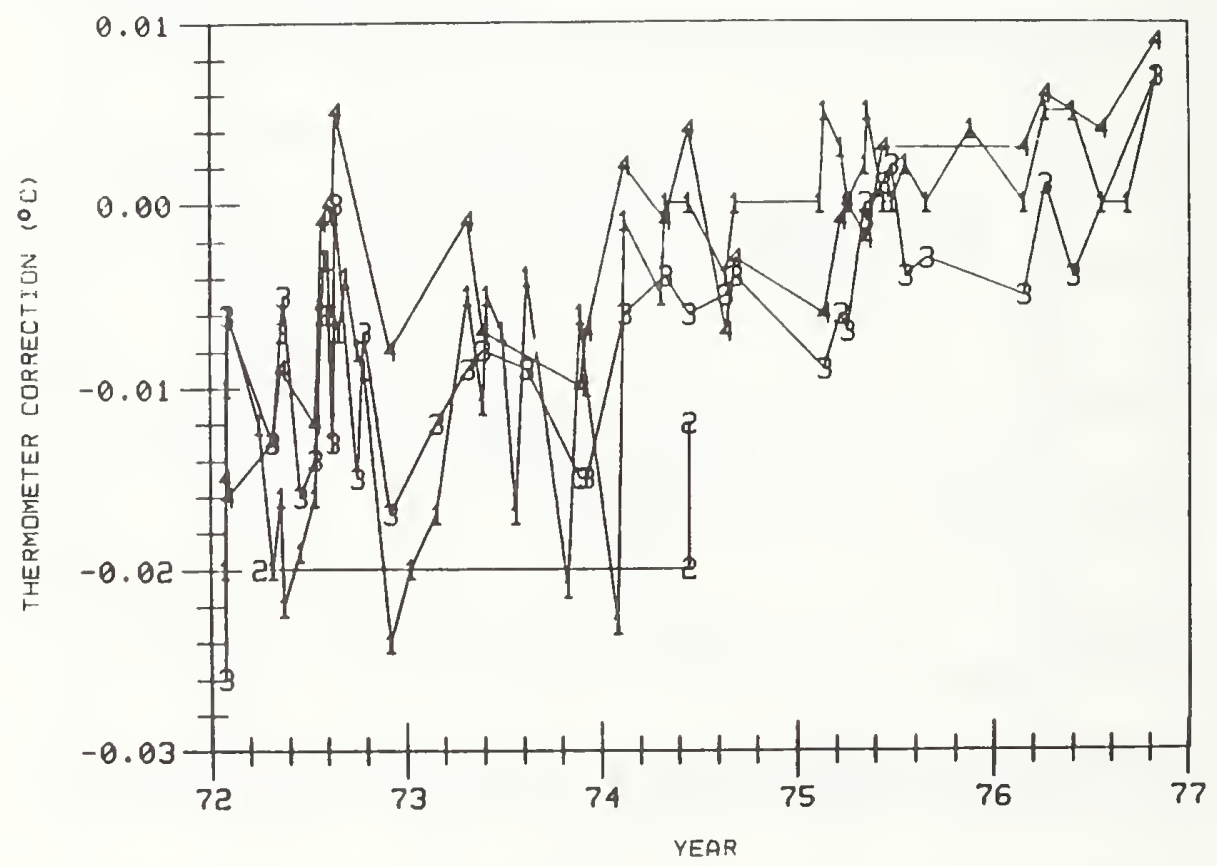

Fig. 34(a1). Plot for thermometer, serial number 4030425, at four temperatures $\left(1\right.$ at $0{ }^{\circ} \mathrm{C}, 2$ at $50{ }^{\circ} \mathrm{C}, 3$ at $60{ }^{\circ} \mathrm{C}$, and 4 at $\left.70{ }^{\circ} \mathrm{C}\right)$. The readings were not corrected for ice-point shifts. 


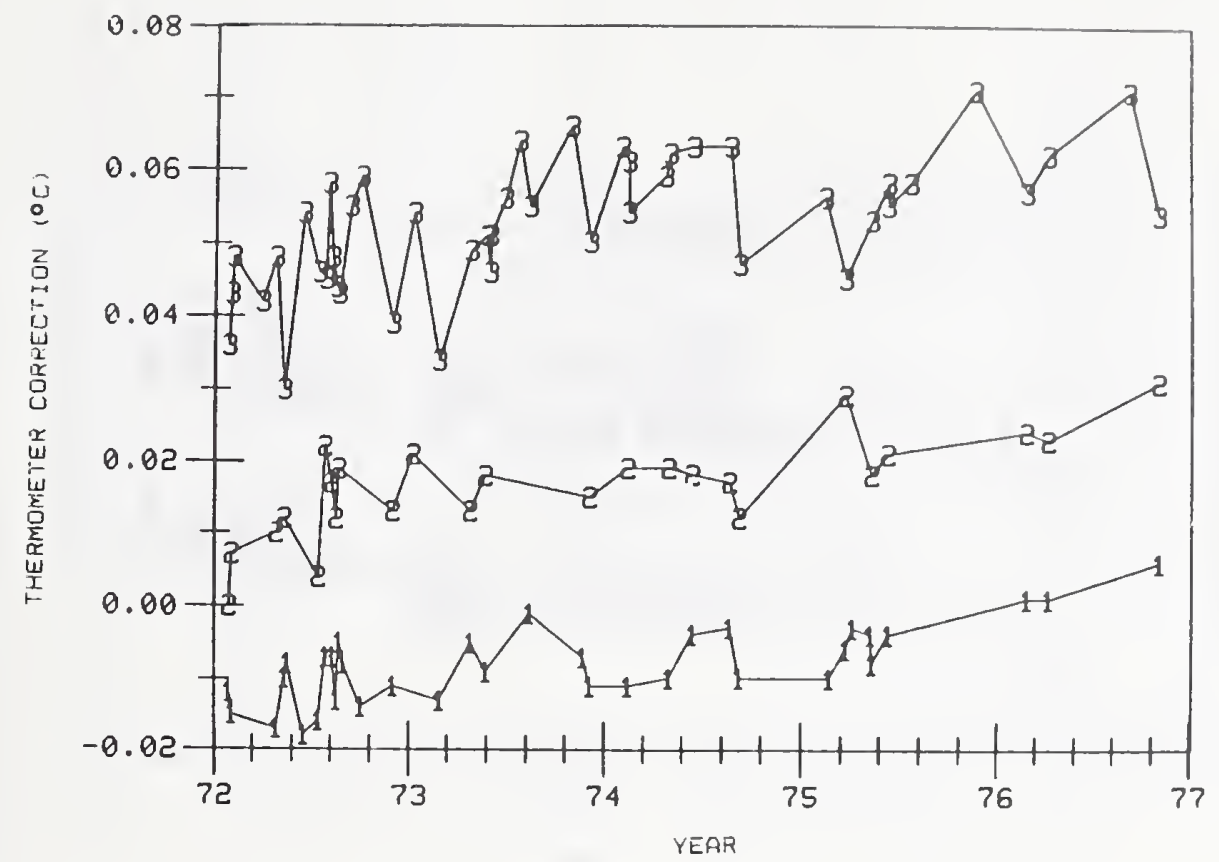

Fig. 34(a2). Plot for thermometer, serial number 4030425, at three temperatures ( 1 at $80^{\circ} \mathrm{C}, 2$ at $90^{\circ} \mathrm{C}$, and 3 at $100{ }^{\circ} \mathrm{C}$ ). The readings were not corrected for ice-point shifts.

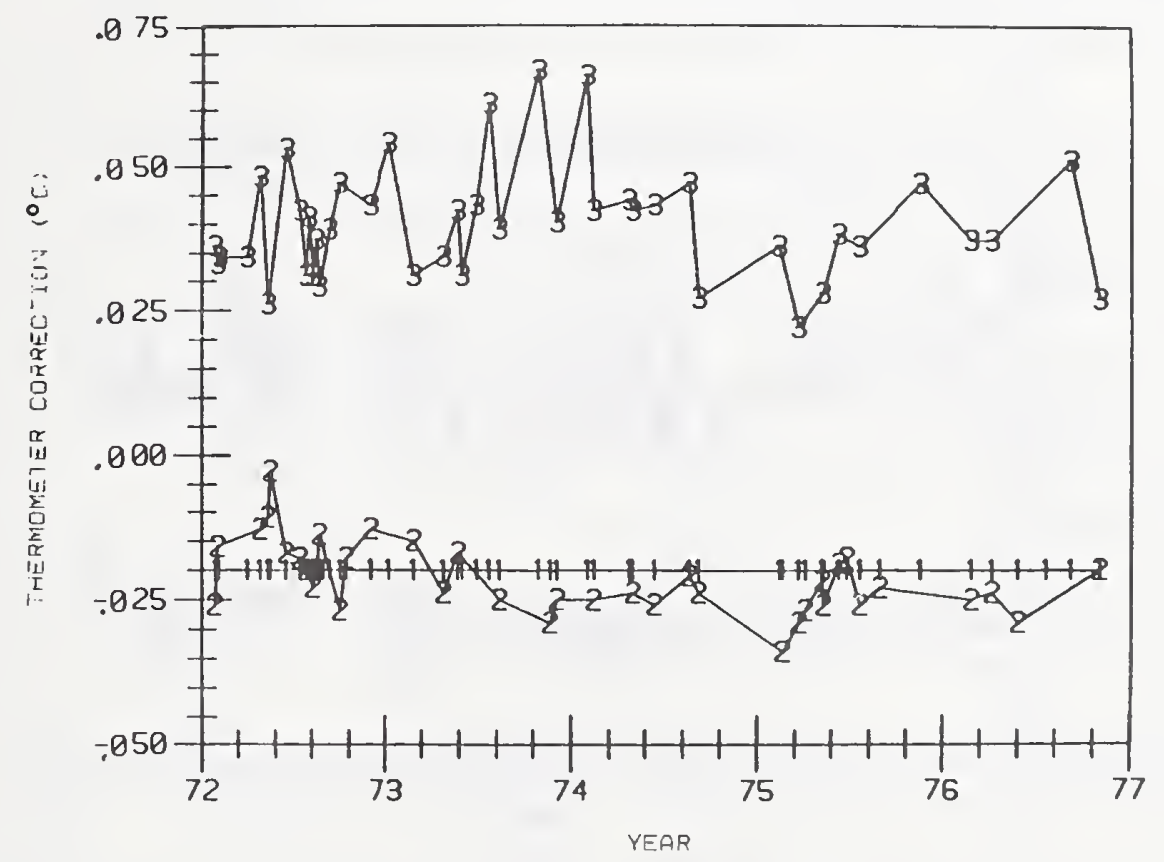

Fig. 34(b). Plot for thermometer, serial number 4030425, at three temperatures ( 1 at $0{ }^{\circ} \mathrm{C}, 2$ at $60{ }^{\circ} \mathrm{C}$, and 3 at $100{ }^{\circ} \mathrm{C}$ ). The readings were corrected for ice-point shifts. 


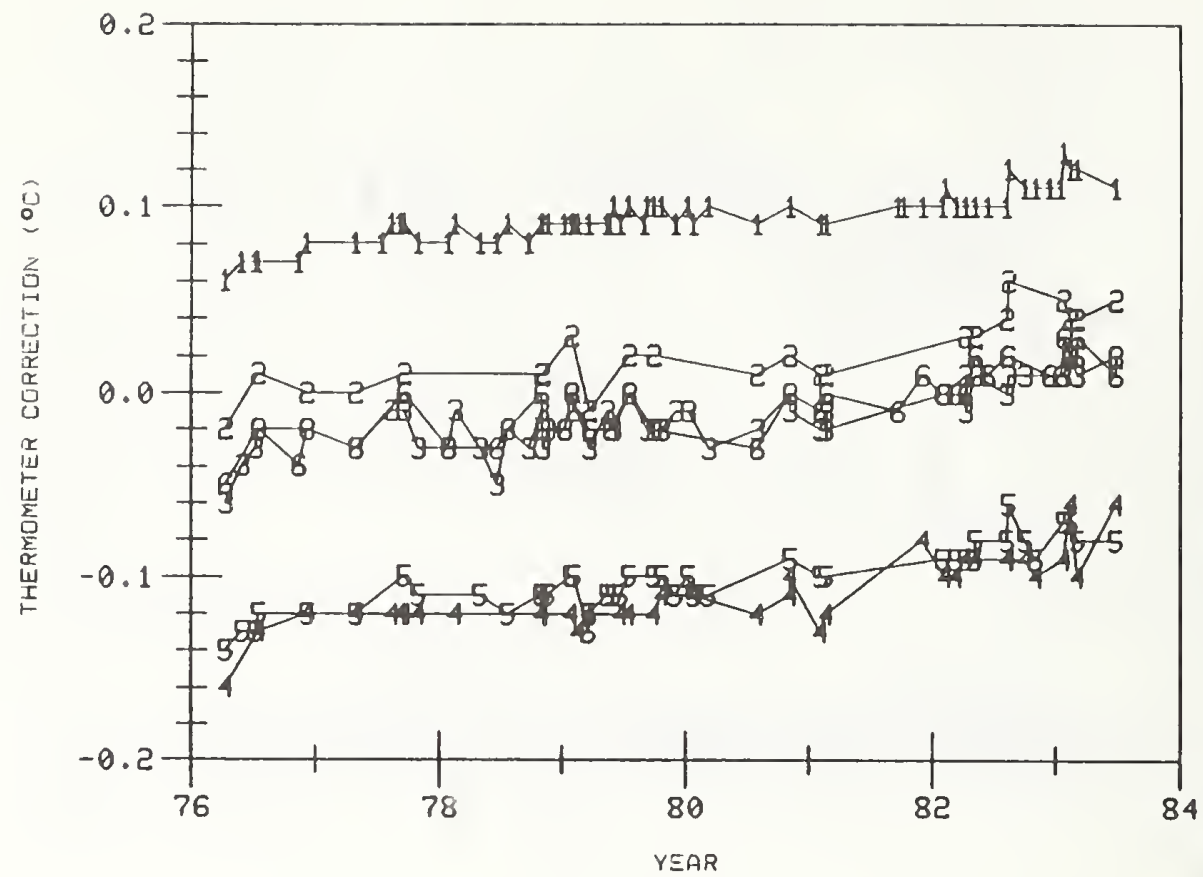

Fig. 35(a1). Plot for thermometer, serial number 48425, at six temperatures ( 1 at $0{ }^{\circ} \mathrm{C}, 2$ at $10^{\circ} \mathrm{C}, 3$ at $20{ }^{\circ} \mathrm{C}, 4$ at $30^{\circ} \mathrm{C}, 5$ at $40{ }^{\circ} \mathrm{C}$, and 6 at $50{ }^{\circ} \mathrm{C}$ ). The readings were not corrected for icepoint shifts.

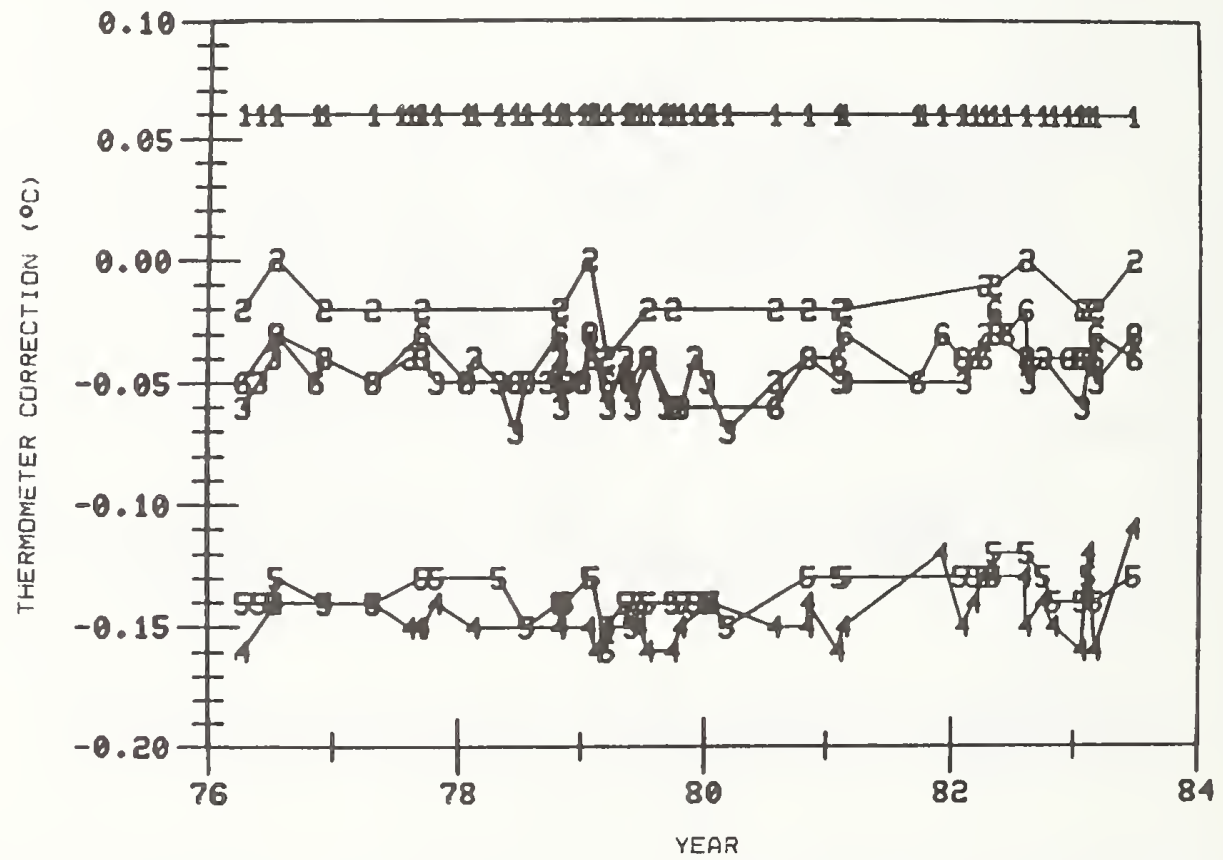

Fig. 35(b1). Plot for thermometer, serial number 48425, at six temperatures (1 at $0{ }^{\circ} \mathrm{C}, 2$ at $10{ }^{\circ} \mathrm{C}, 3$ at $20{ }^{\circ} \mathrm{C}, 4$ at $30{ }^{\circ} \mathrm{C}, 5$ at $40{ }^{\circ} \mathrm{C}$, and 6 at $50{ }^{\circ} \mathrm{C}$ ). The readings were corrected for ice-point shifts. 


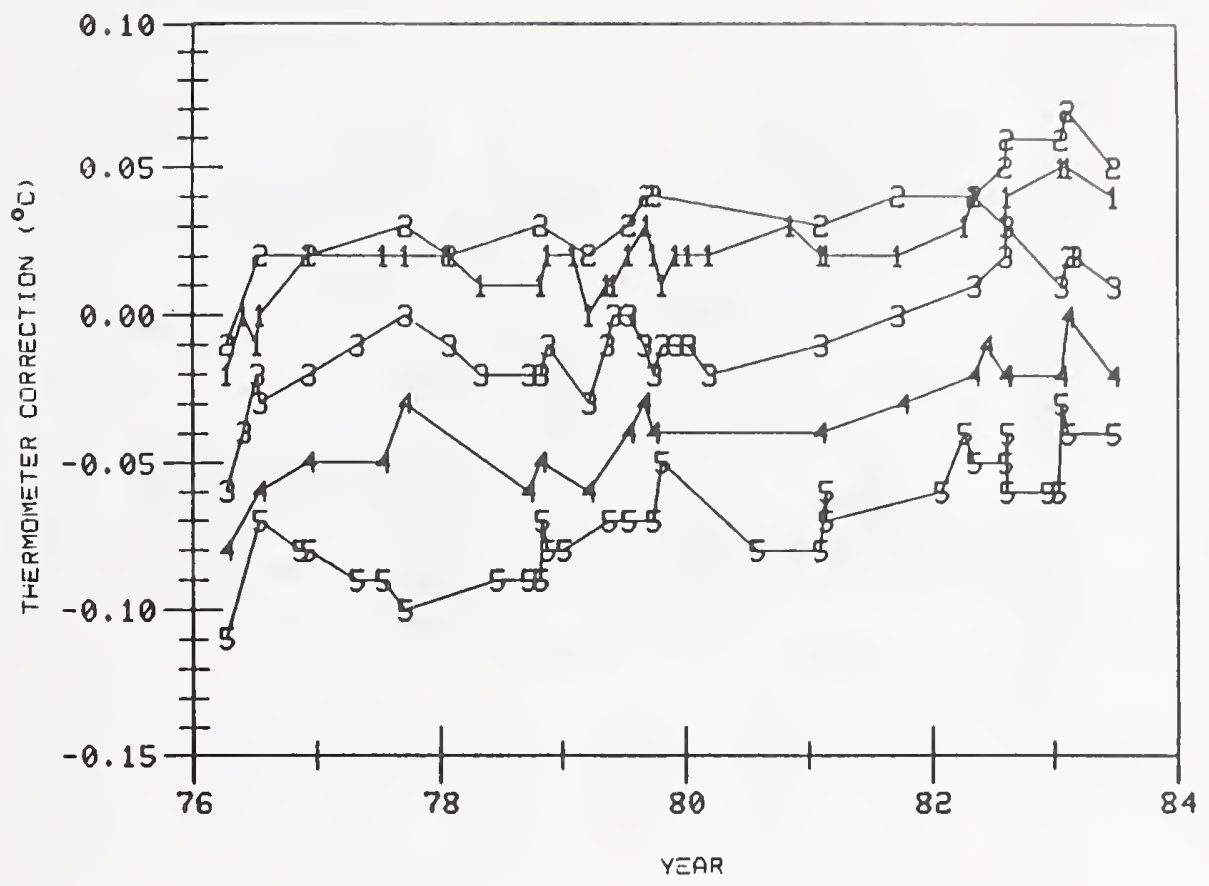

Fig. 35(a2). Plot for thermometer, serial number 48425, at five temperatures $\left(1\right.$ at $60{ }^{\circ} \mathrm{C}, 2$ at $70{ }^{\circ} \mathrm{C}, 3$ at $80{ }^{\circ} \mathrm{C}, 4$ at $90{ }^{\circ} \mathrm{C}$, and 5 at $100{ }^{\circ} \mathrm{C}$ ). The readings were not corrected for icepoint shifts.

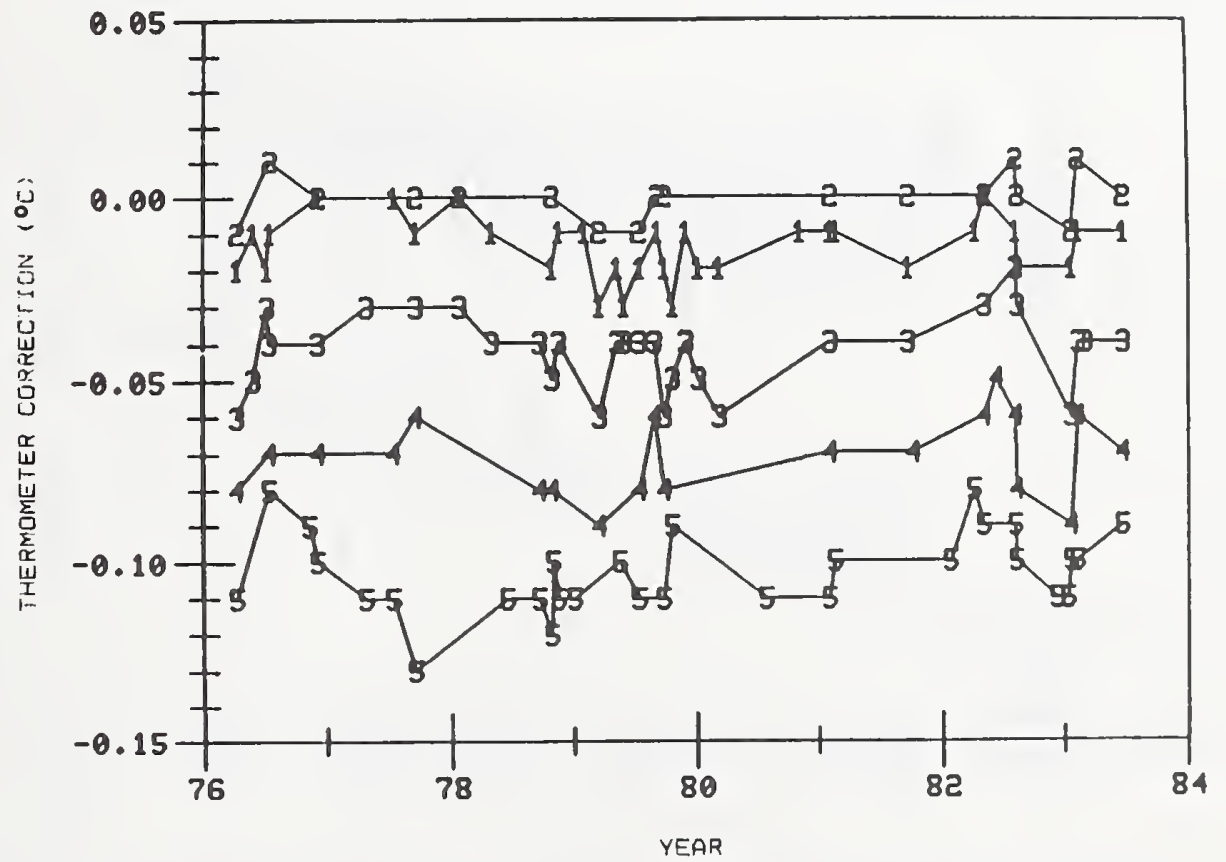

Fig. 35(b2). Plot for thermometer, serial number 48425, at five temperatures $\left(1\right.$ at $60{ }^{\circ} \mathrm{C}, 2$ at $70{ }^{\circ} \mathrm{C}, 3$ at $80{ }^{\circ} \mathrm{C}, 4$ at $90{ }^{\circ} \mathrm{C}$, and 5 at $100{ }^{\circ} \mathrm{C}$ ). The readings were corrected for ice-point shifts. 


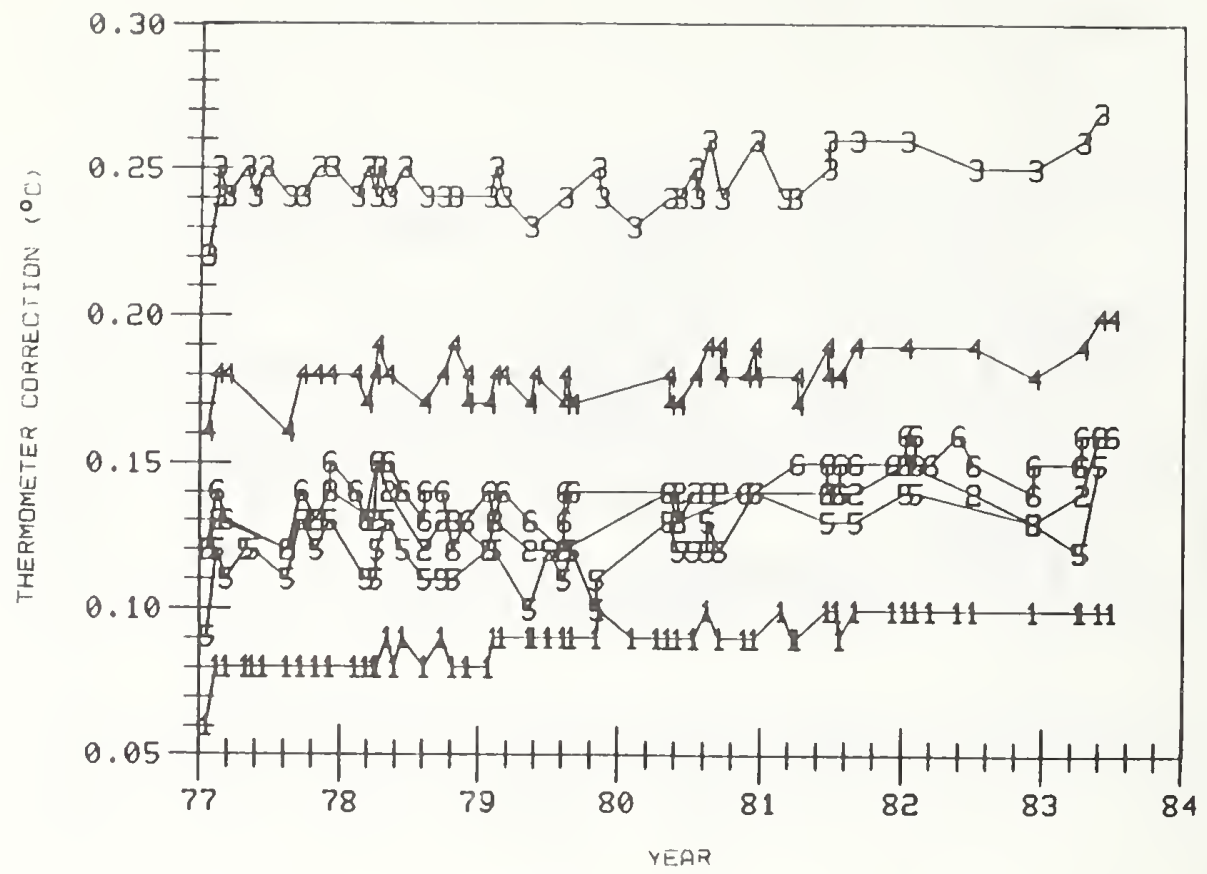

Fig. 36(a1). Plot for thermometer, serial number 198694, at six temperatures $\left(1\right.$ at $0{ }^{\circ} \mathrm{C}, 2$ at $10{ }^{\circ} \mathrm{C}, 3$ at $20{ }^{\circ} \mathrm{C}, 4$ at $30{ }^{\circ} \mathrm{C}, 5$ at $40{ }^{\circ} \mathrm{C}$, and 6 at $50{ }^{\circ} \mathrm{C}$ ). The readings were not corrected for ice-point shifts.

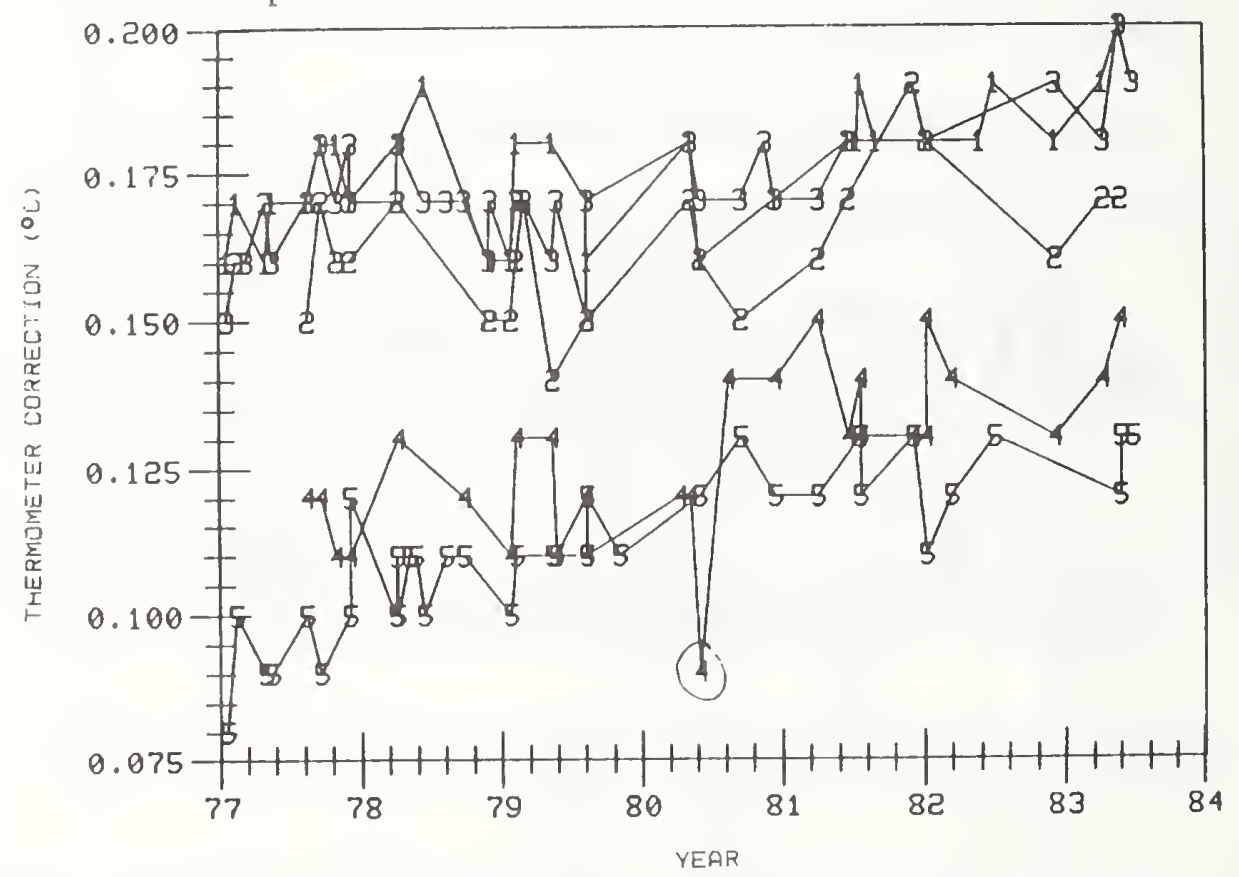

Fig. 36(a2). Plot for thermometer, serial number 198694, at five temperatures $\left(1\right.$ at $60{ }^{\circ} \mathrm{C}, 2$ at $70{ }^{\circ} \mathrm{C}, 3$ at $80{ }^{\circ} \mathrm{C}, 4$ at $90{ }^{\circ} \mathrm{C}$, and 5 at $100{ }^{\circ} \mathrm{C}$ ). The readings were not corrected for icepoint shifts. 


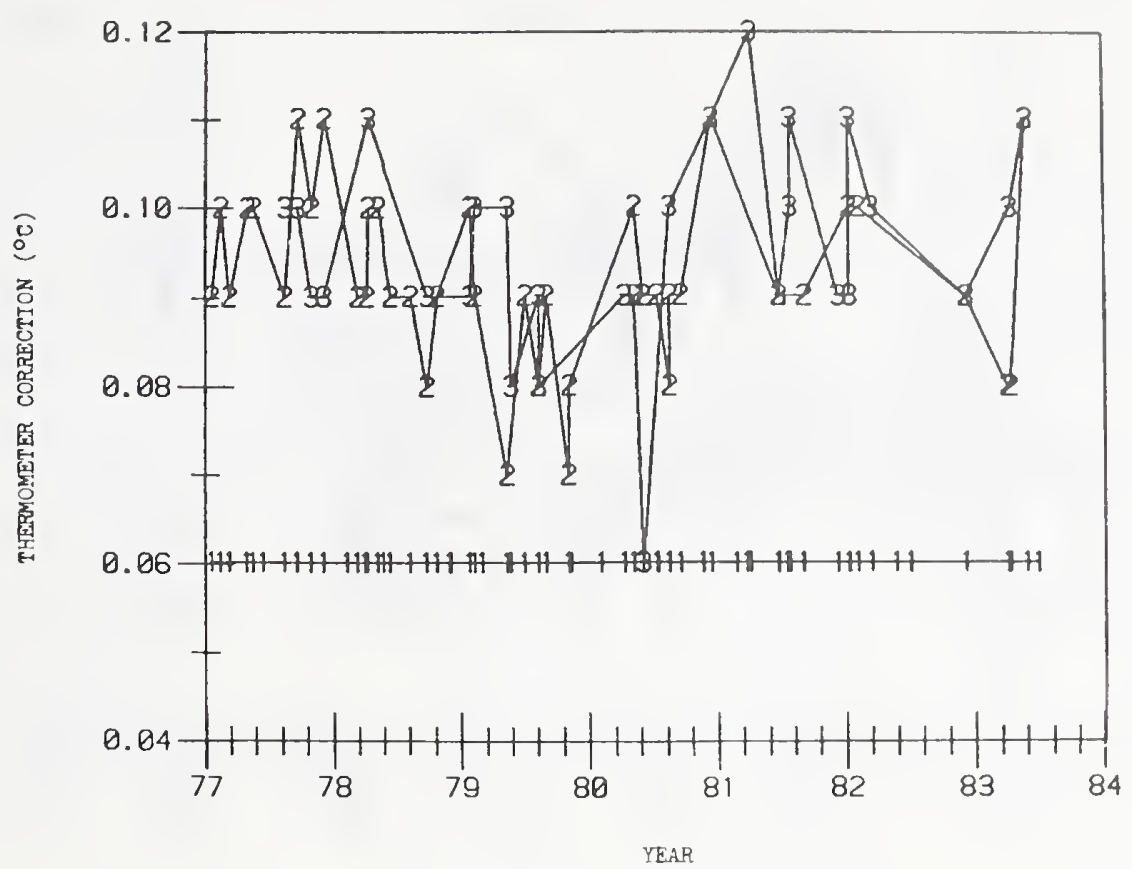

Fig. 36(b). Plot for thermometer, serial number 198694, at three temperatures ( 1 at $0{ }^{\circ} \mathrm{C}, 2$ at $40{ }^{\circ} \mathrm{C}$, and 3 at $90{ }^{\circ} \mathrm{C}$ ). The readings were corrected for ice-point shifts.

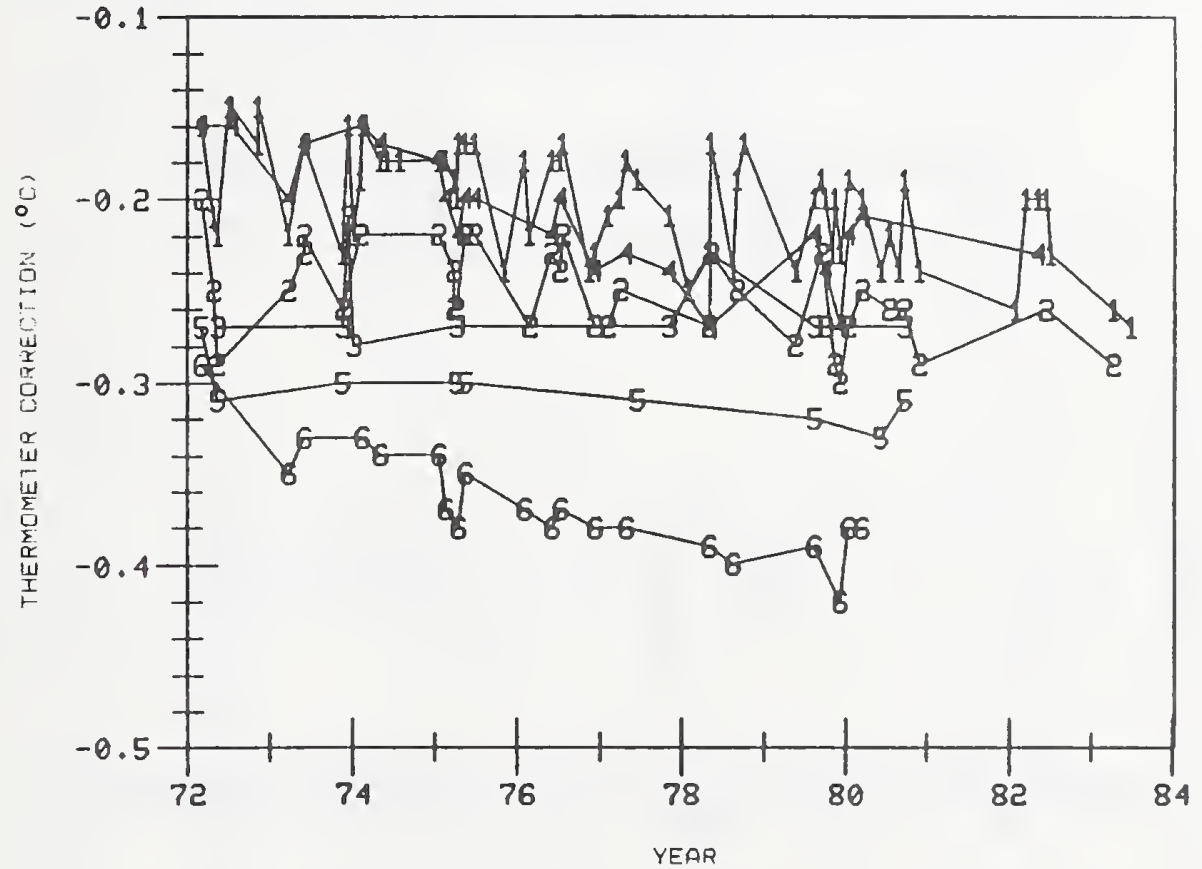

Fig. 37(a1). Plot for thermometer, serial number, 382213, at six temperatures ( 1 at $0{ }^{\circ} \mathrm{C}, 2$ at $100{ }^{\circ} \mathrm{C}, 3$ at $110{ }^{\circ} \mathrm{C}, 4$ at $120^{\circ} \mathrm{C}, 5$ at $130{ }^{\circ} \mathrm{C}$, and 6 at $140{ }^{\circ} \mathrm{C}$ ). The readings were not corrected for ice-point shifts. 


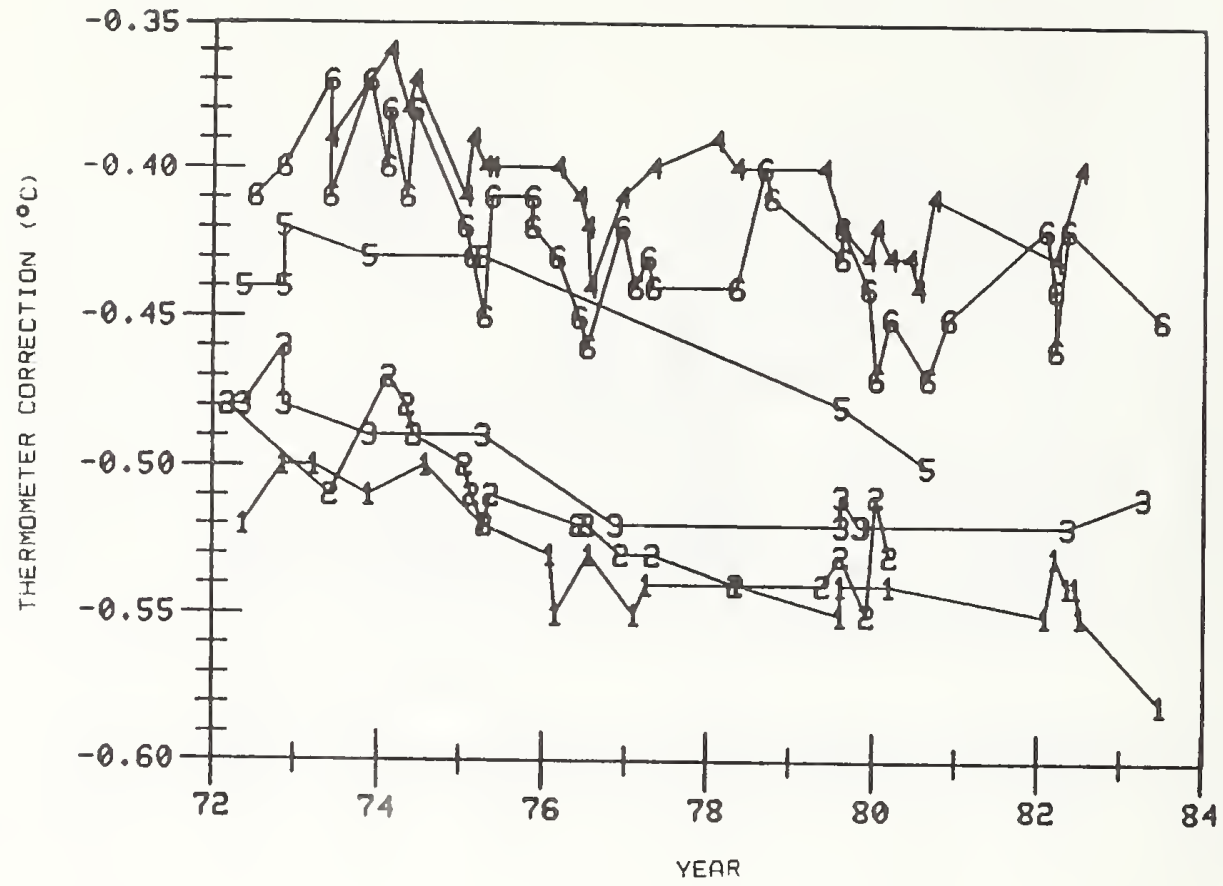

Fig. 37(a2). Plot for thermometer, serial number 382213, at six temperatures $\left(1\right.$ at $150{ }^{\circ} \mathrm{C}, 2$ at $160{ }^{\circ} \mathrm{C}, 3$ at $170{ }^{\circ} \mathrm{C}, 4$ at $180{ }^{\circ} \mathrm{C}, 5$ at $190{ }^{\circ} \mathrm{C}$, and 6 at $200{ }^{\circ} \mathrm{C}$ ). The readings were not corrected for ice-point shifts.

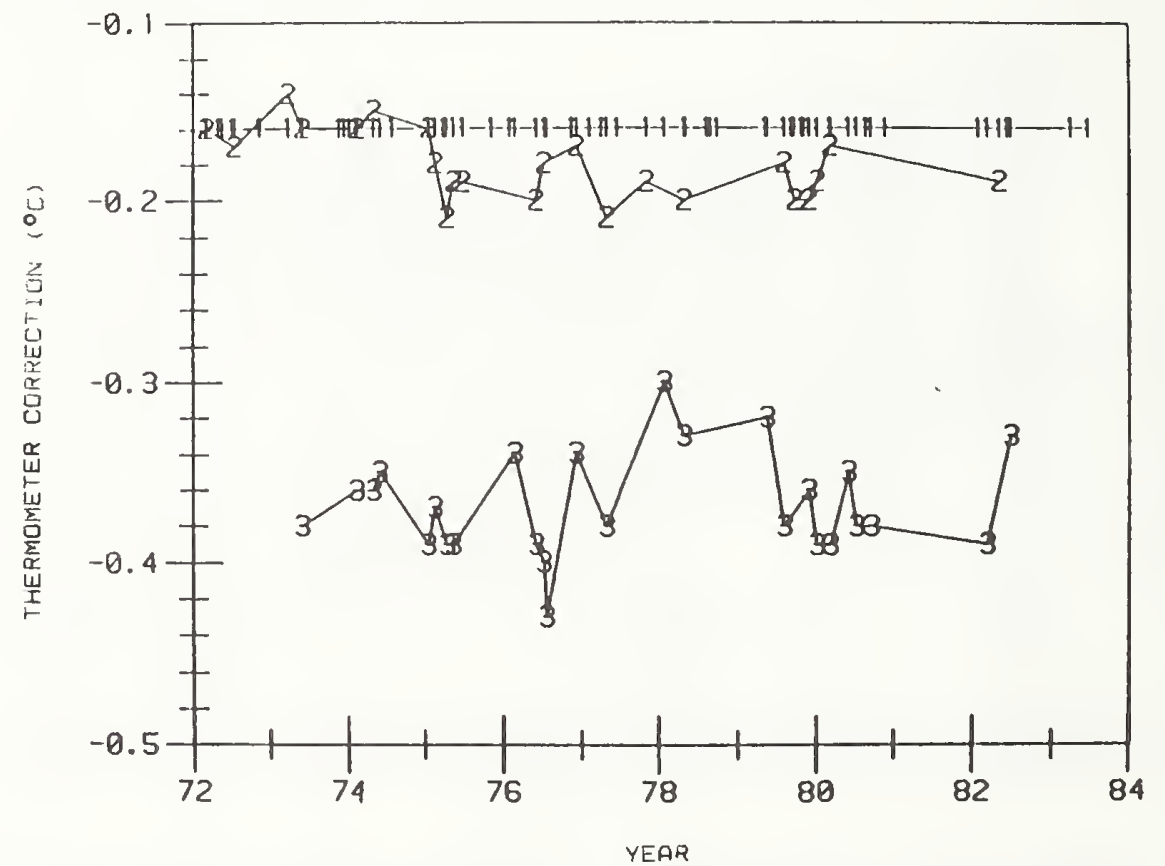

Fig. 37(b). Plot for thermometer, serial number 382213, at three temperatures $\left(1\right.$ at $0{ }^{\circ} \mathrm{C}, 2$ at $120{ }^{\circ} \mathrm{C}$, and 3 at $\left.180{ }^{\circ} \mathrm{C}\right)$. The readings were corrected for ice-point shifts. 


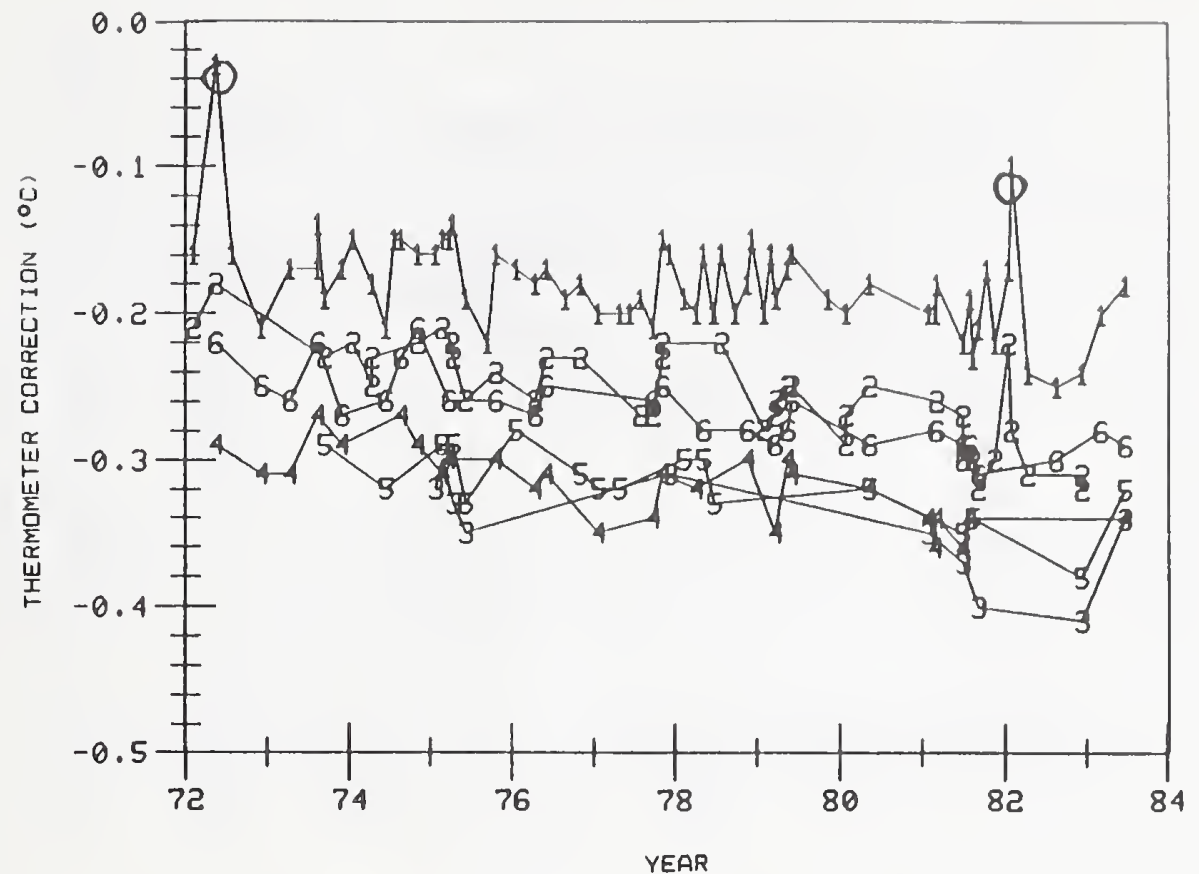

Fig. 38(a1). Plot for thermometer, serial number 382215, at six temperatures $\left(1\right.$ at $0{ }^{\circ} \mathrm{C}, 2$ at $100{ }^{\circ} \mathrm{C}, 3$ at $110{ }^{\circ} \mathrm{C}, 4$ at $120{ }^{\circ} \mathrm{C}, 5$ at $130{ }^{\circ} \mathrm{C}$, and 6 at $140{ }^{\circ} \mathrm{C}$ ). The readings were not corrected for ice-point shifts.

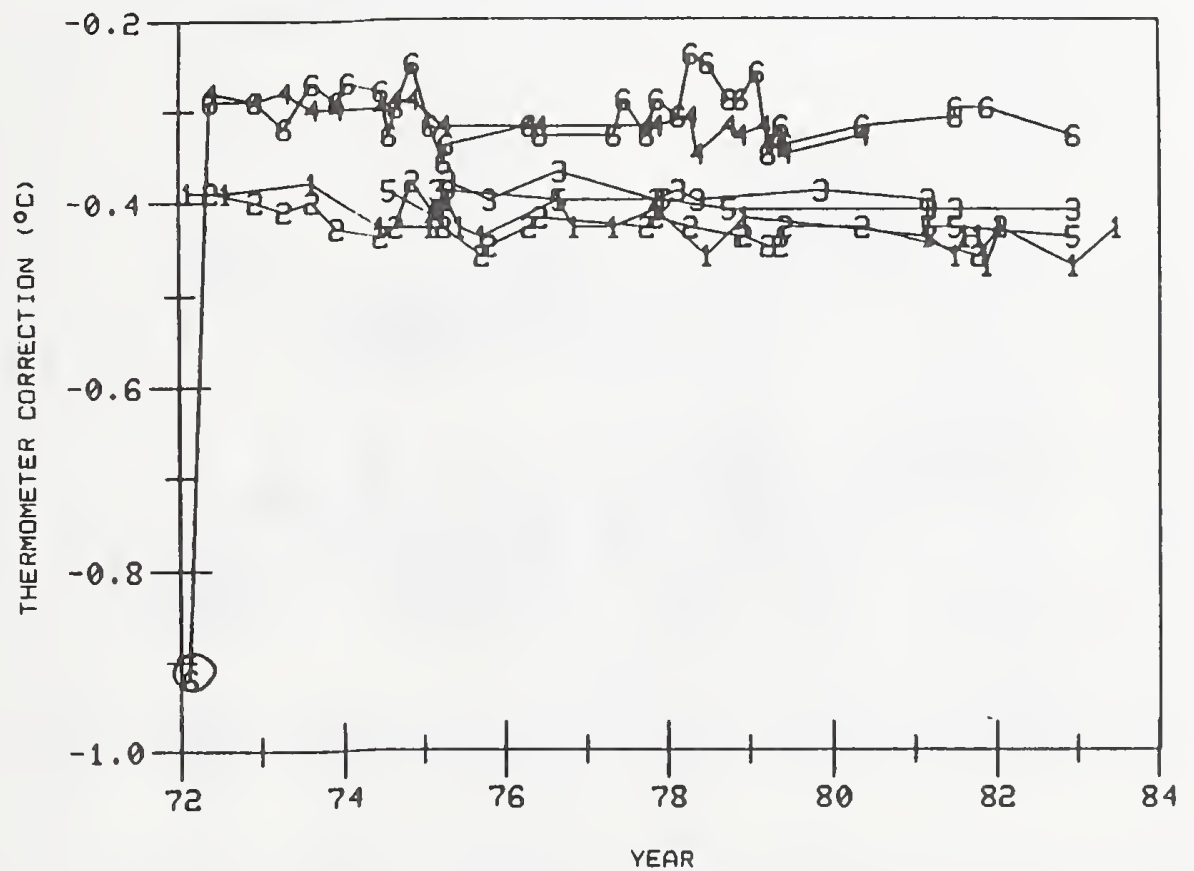

Fig. 38(a2). Plot for thermometer, serial number 382215, at six temperatures $\left(1\right.$ at $150{ }^{\circ} \mathrm{C}, 2$ at $160{ }^{\circ} \mathrm{C}, 3$ at $170{ }^{\circ} \mathrm{C}, 4$ at $180^{\circ} \mathrm{C}, 5$ at $190{ }^{\circ} \mathrm{C}$, and 6 at $200{ }^{\circ} \mathrm{C}$ ). The readings were not corrected for ice-point shifts. 


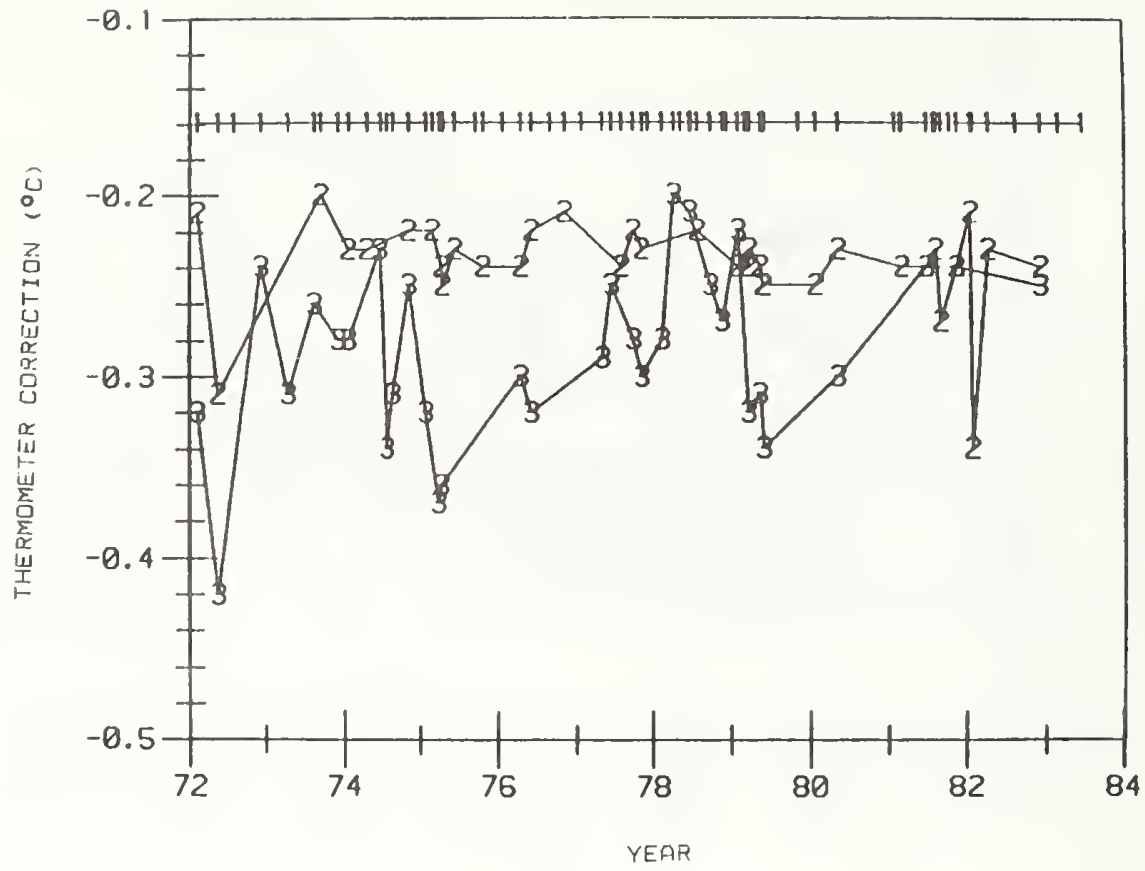

Fig. 38(b1). Plot for thermometer, serial number 382215, at three temperatures $\left(1\right.$ at $0{ }^{\circ} \mathrm{C}, 2$ at $100{ }^{\circ} \mathrm{C}$, and 3 at $\left.200{ }^{\circ} \mathrm{C}\right)$. The readings were corrected for ice-point shifts.

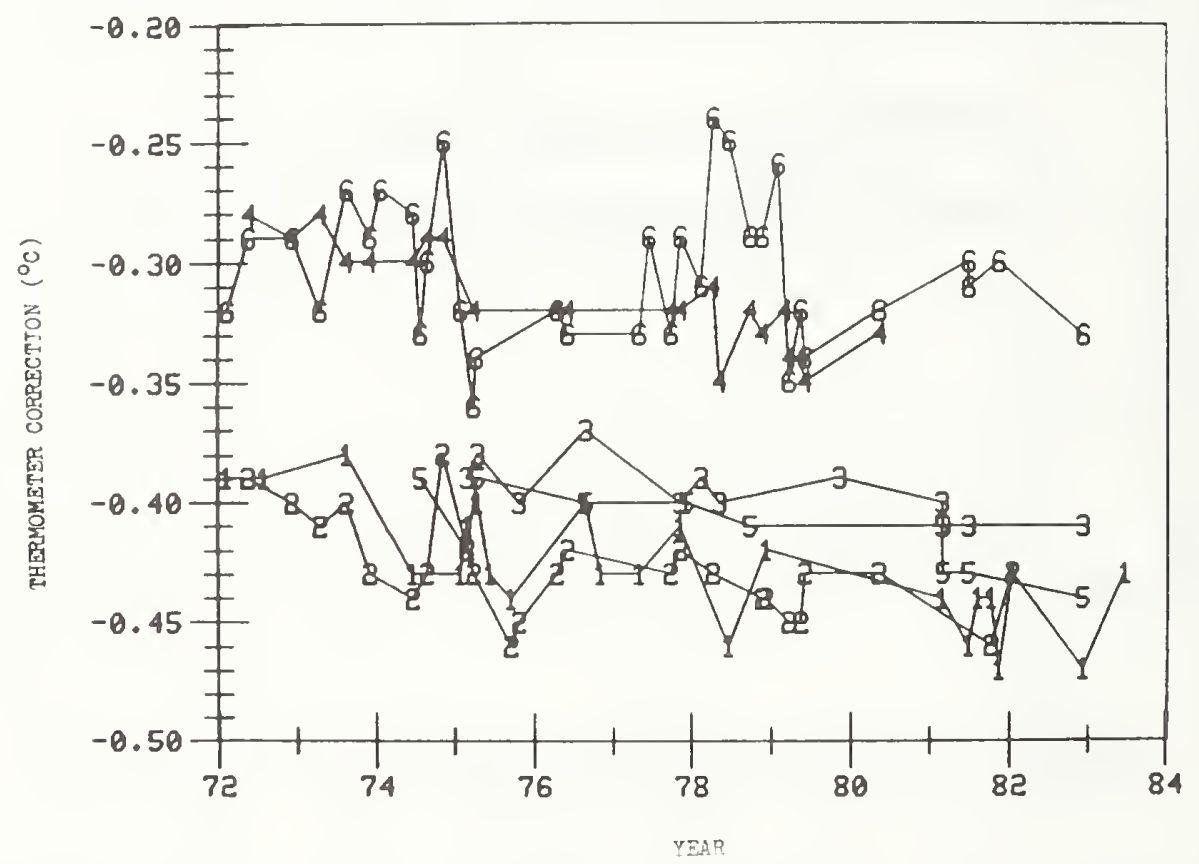

Fig. 38(b2). Plot for thermometer, serial number 382215, at six temperatures $\left(1\right.$ at $150{ }^{\circ} \mathrm{C}, 2$ at $160{ }^{\circ} \mathrm{C}, 3$ at $170{ }^{\circ} \mathrm{C}, 4$ at $180{ }^{\circ} \mathrm{C}, 5$ at $190{ }^{\circ} \mathrm{C}$, and 6 at $200{ }^{\circ} \mathrm{C}$ ). The readings were corrected for ice-point shifts. 


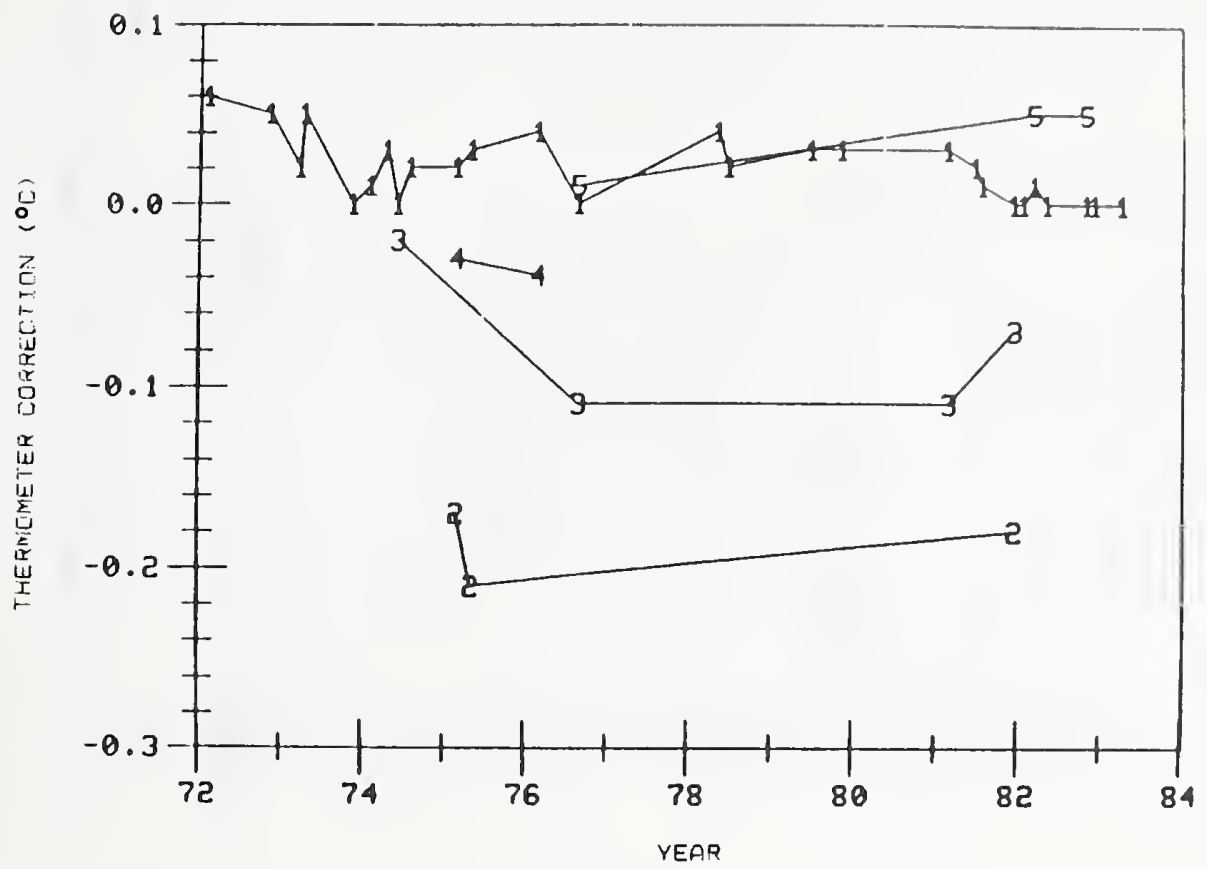

Fig. 39(a1). Plot for thermometer, serial number T1124411, at five temperatures ( 1 at $0{ }^{\circ} \mathrm{C}, 2$ at $200{ }^{\circ} \mathrm{C}, 3$ at $210{ }^{\circ} \mathrm{C}, 4$ at $220^{\circ} \mathrm{C}$, and 5 at $230^{\circ} \mathrm{C}$ ). The readings were not corrected for ice-point shifts.

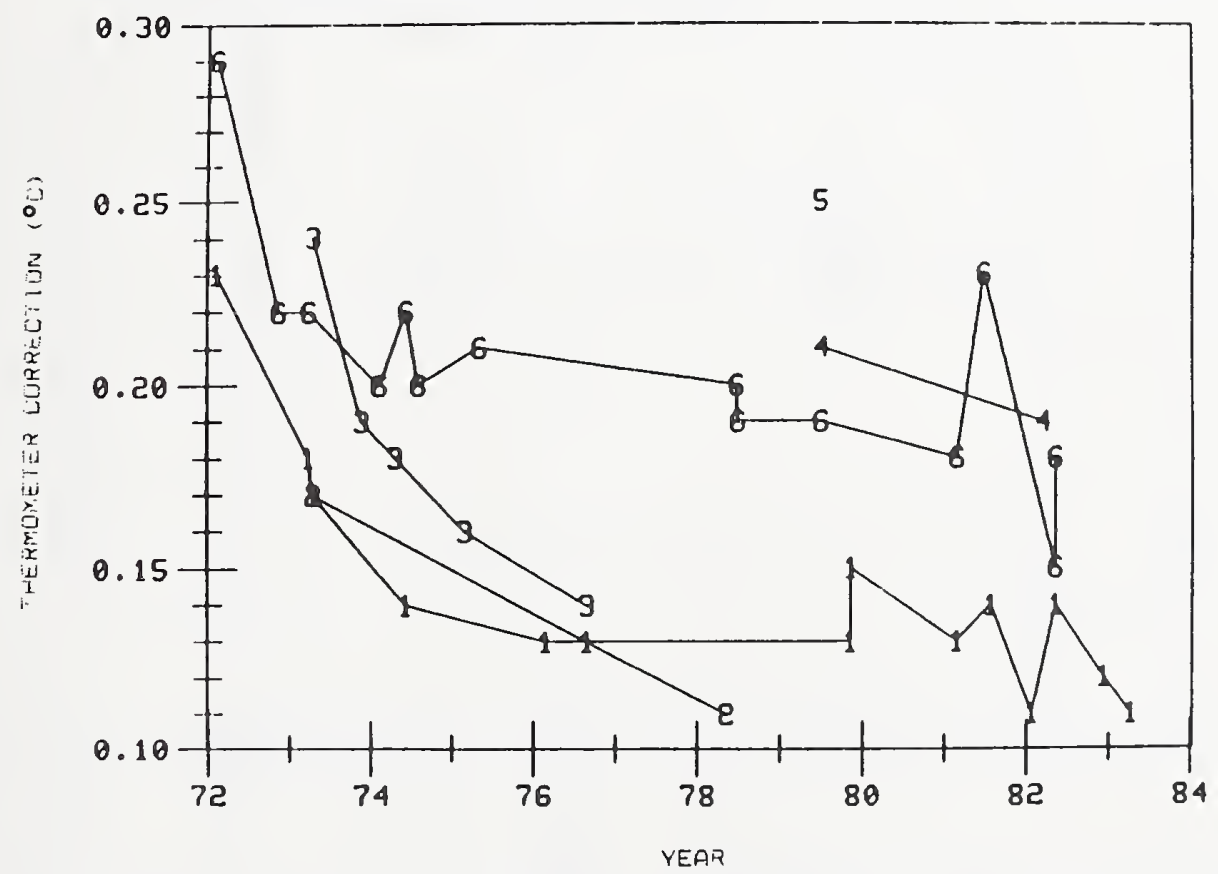

Fig. 39(a2). Plot for thermometer, serial number T1124411, at six temperatures ( 1 at $250{ }^{\circ} \mathrm{C}, 2$ at $260{ }^{\circ} \mathrm{C}, 3$ at $270{ }^{\circ} \mathrm{C}, 4$ at $280^{\circ} \mathrm{C}, 5$ at $290{ }^{\circ} \mathrm{C}$, and 6 at $300{ }^{\circ} \mathrm{C}$ ). The readings were not corrected for ice-point shifts. 


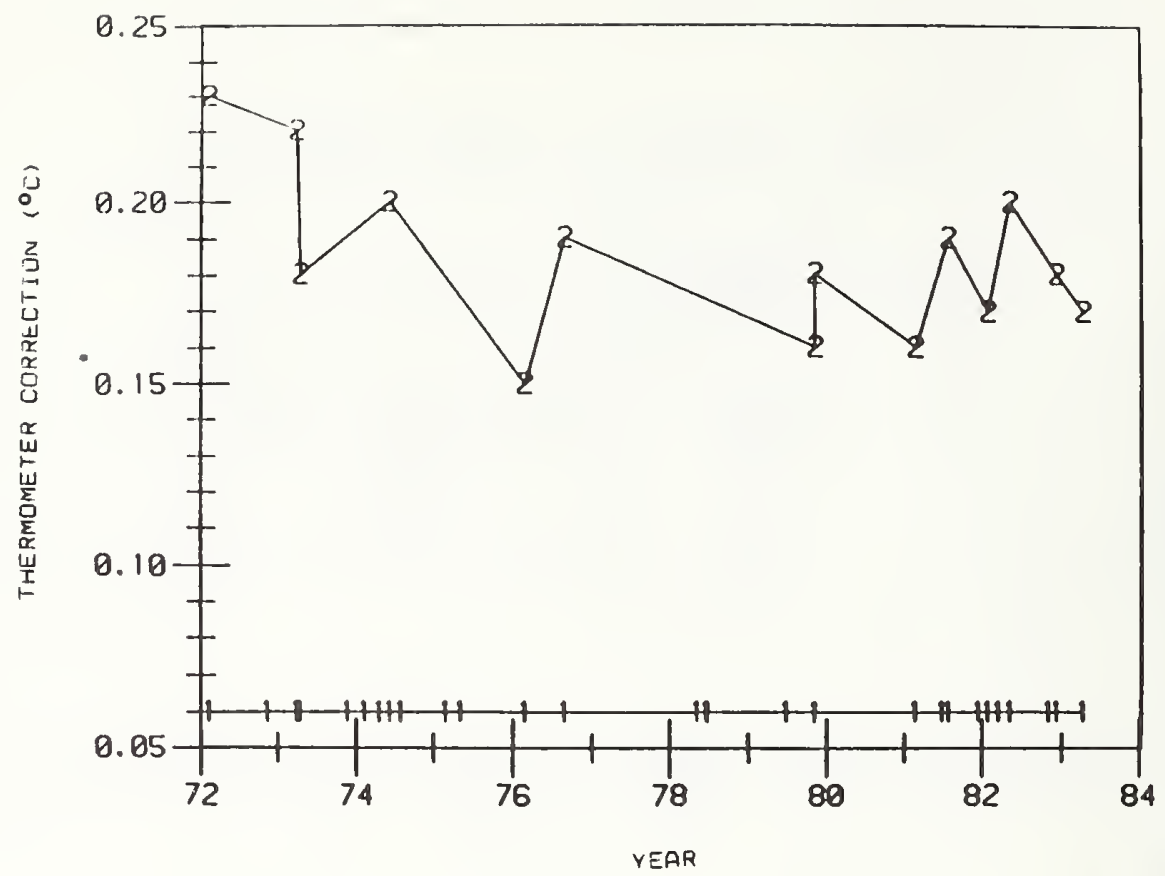

Fig. 39(b). Plot for thermometer, serial number T1124411, at two temperatures $\left(1\right.$ at $0{ }^{\circ} \mathrm{C}$ and 2 at $250{ }^{\circ} \mathrm{C}$ ). The readings were corrected for ice-point shifts.

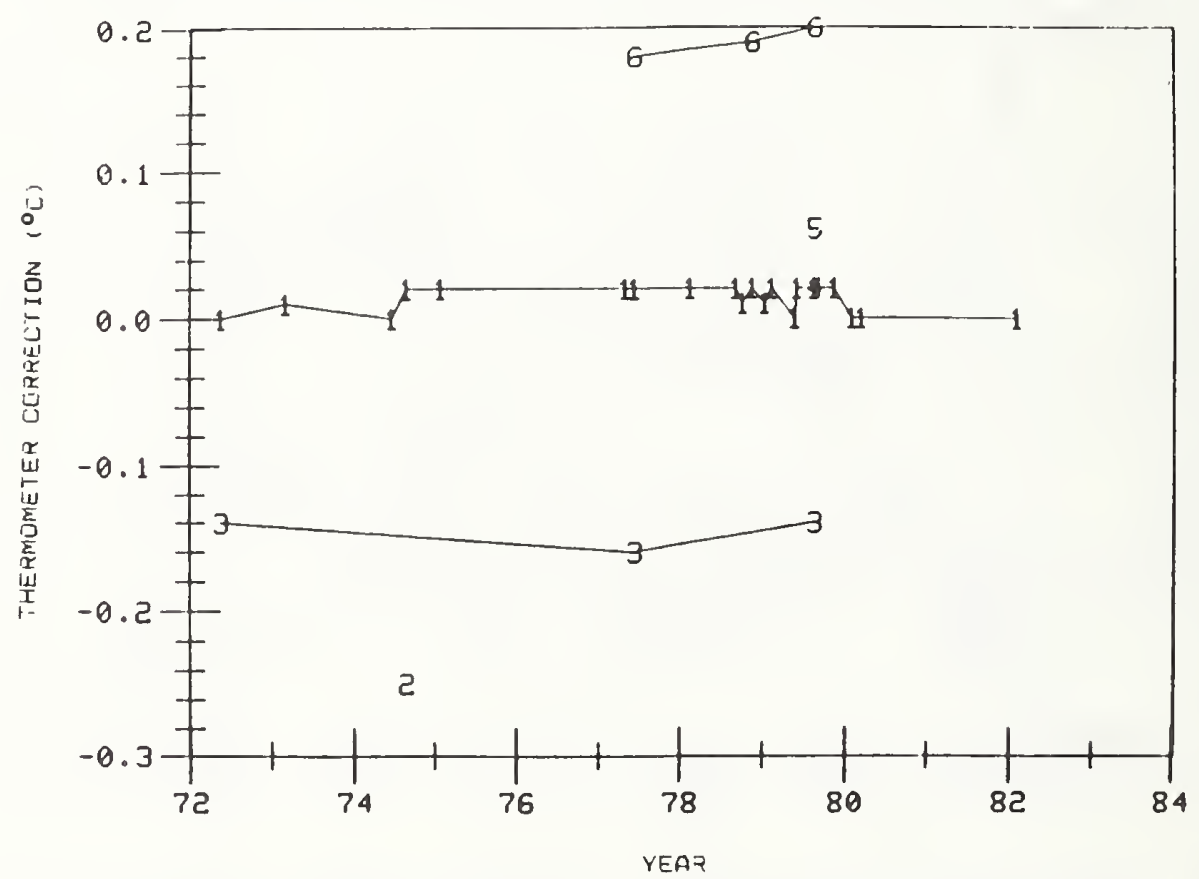

Fig. 40(a1). Plot for thermometer, serial number T1124412, at six temperatures $\left(1\right.$ at $0{ }^{\circ} \mathrm{C}, 2$ at $200{ }^{\circ} \mathrm{C}, 3$ at $210{ }^{\circ} \mathrm{C}, 4$ at $220^{\circ} \mathrm{C}, 5$ at $230{ }^{\circ} \mathrm{C}$, and 6 at $240{ }^{\circ} \mathrm{C}$ ). The readings were not corrected for ice-point shifts. 


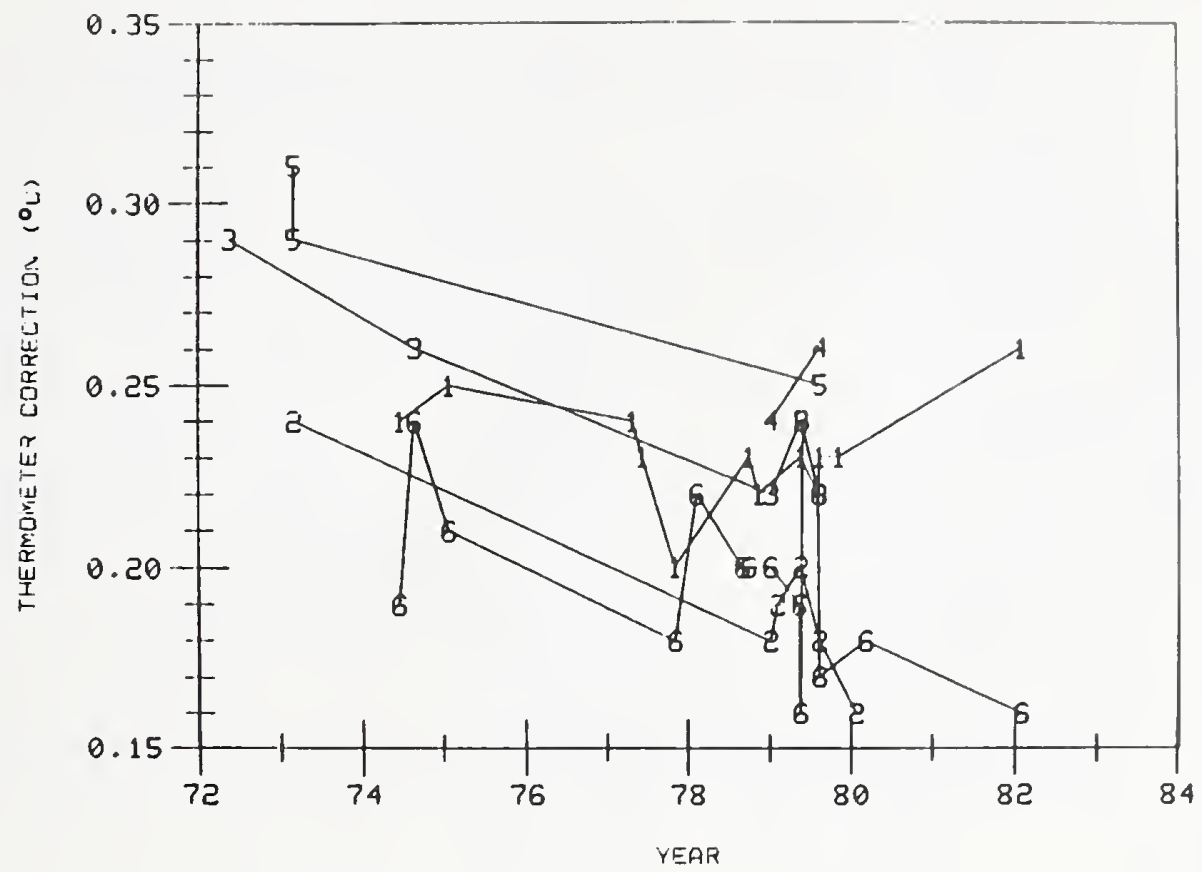

Fig. 40(a2). Plot for thermometer, serial number T1124412, at six temperatures $\left(1\right.$ at $250{ }^{\circ} \mathrm{C}, 2$ at $260{ }^{\circ} \mathrm{C}, 3$ at $270{ }^{\circ} \mathrm{C}, 4$ at $280^{\circ} \mathrm{C}, 5$ at $290{ }^{\circ} \mathrm{C}$, and 6 at $300{ }^{\circ} \mathrm{C}$ ). The readings were not corrected for ice-point shifts.

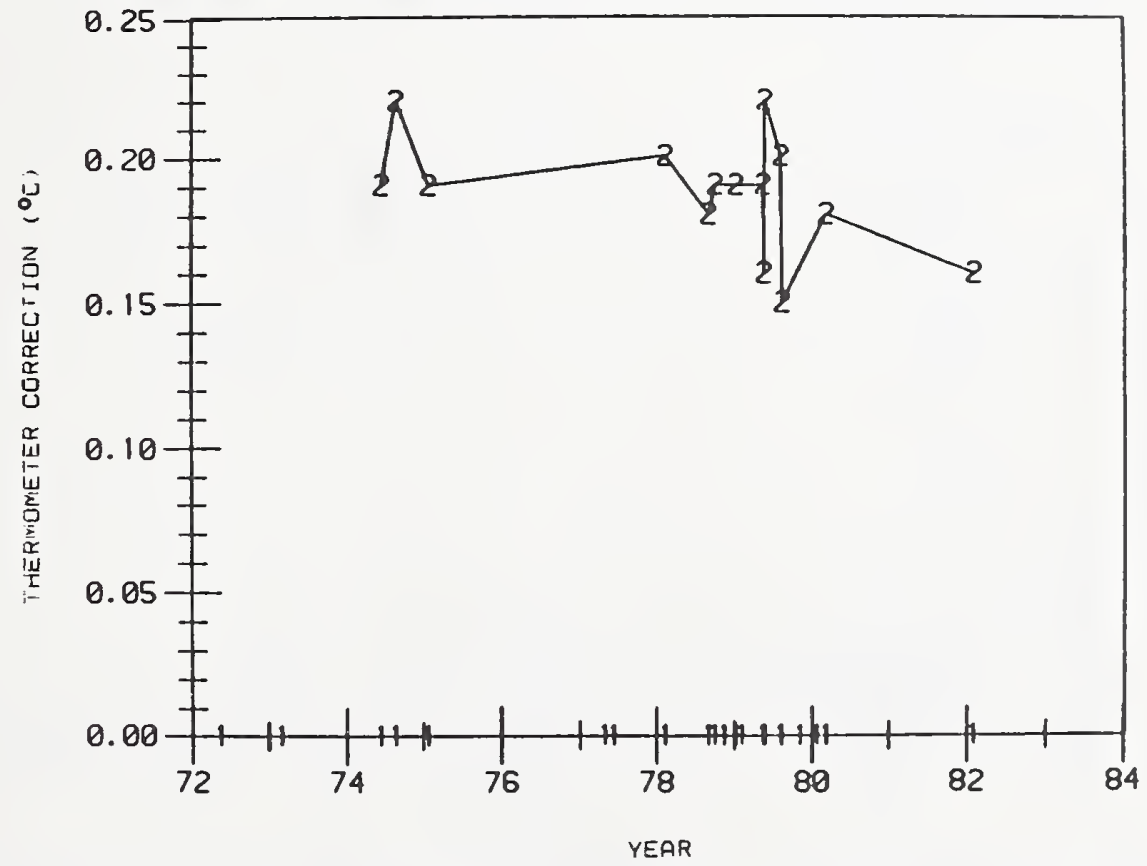

Fig. 40(b). Plot for thermometer, serial number T1124412, at two temperatures $\left(1\right.$ at $0{ }^{\circ} \mathrm{C}$ and 2 at $300{ }^{\circ} \mathrm{C}$ ). The readings were corrected for ice-point shifts. 


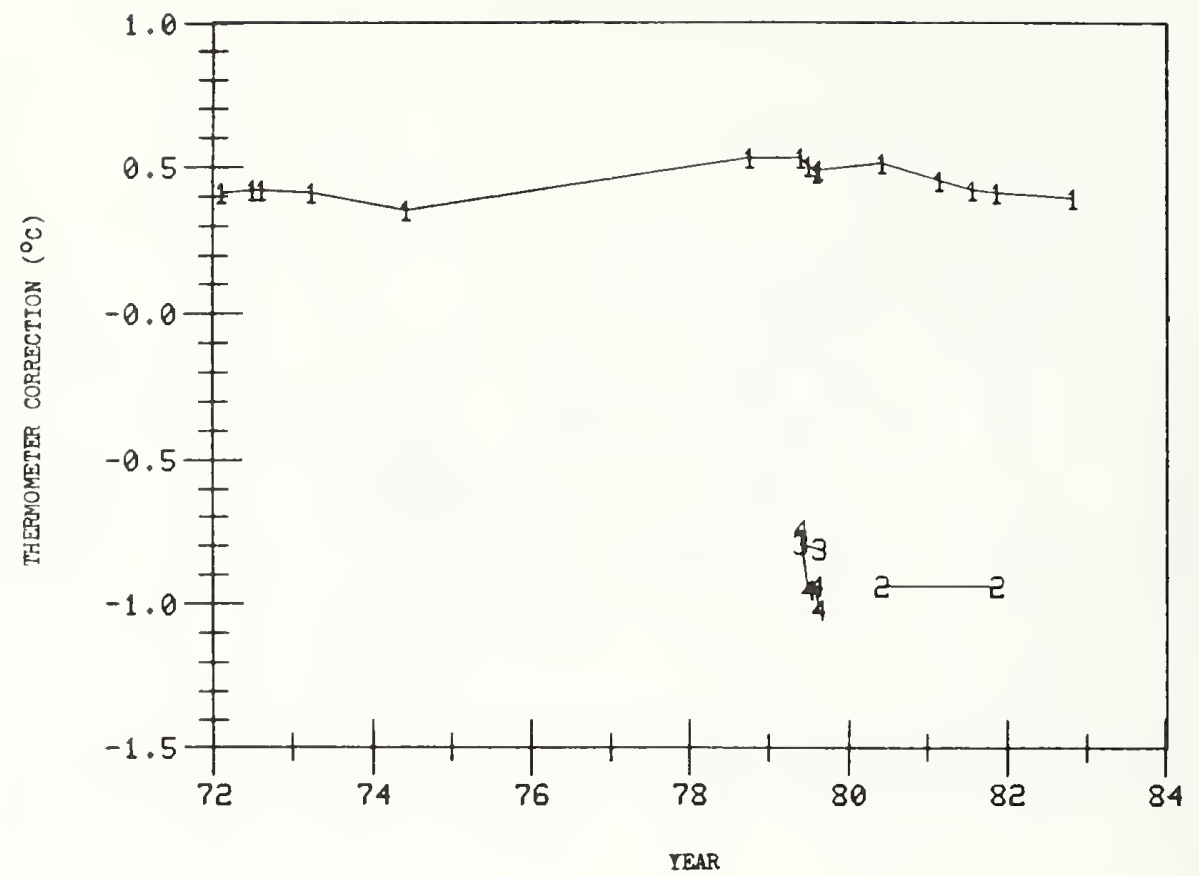

Fig. 41(a1). Plot for thermometer, serial number 234453, at four temperatures $\left(1\right.$ at $0{ }^{\circ} \mathrm{C}, 2$ at $300{ }^{\circ} \mathrm{C}, 3$ at $310{ }^{\circ} \mathrm{C}$, and 4 at $320{ }^{\circ} \mathrm{C}$ ). The readings were not corrected for ice-point shifts.

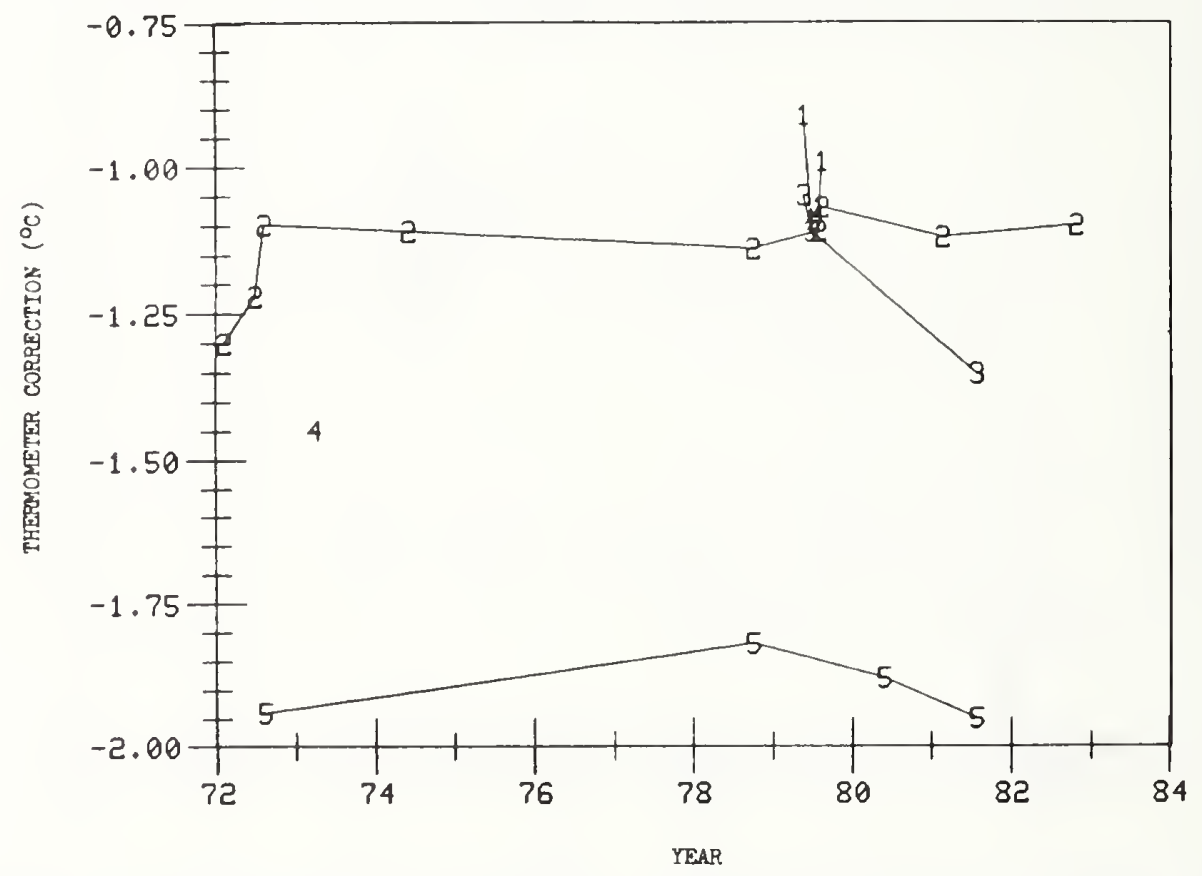

Fig. 41(a2). Plot thermometer, serial number 234453, at five temperatures ( 1 at $340{ }^{\circ} \mathrm{C}, 2$ at $350{ }^{\circ} \mathrm{C}, 3$ at $370{ }^{\circ} \mathrm{C}, 4$ at $380{ }^{\circ} \mathrm{C}$, and 5 at $400^{\circ} \mathrm{C}$ ). The readings wre not corrected for ice-point shifts. 


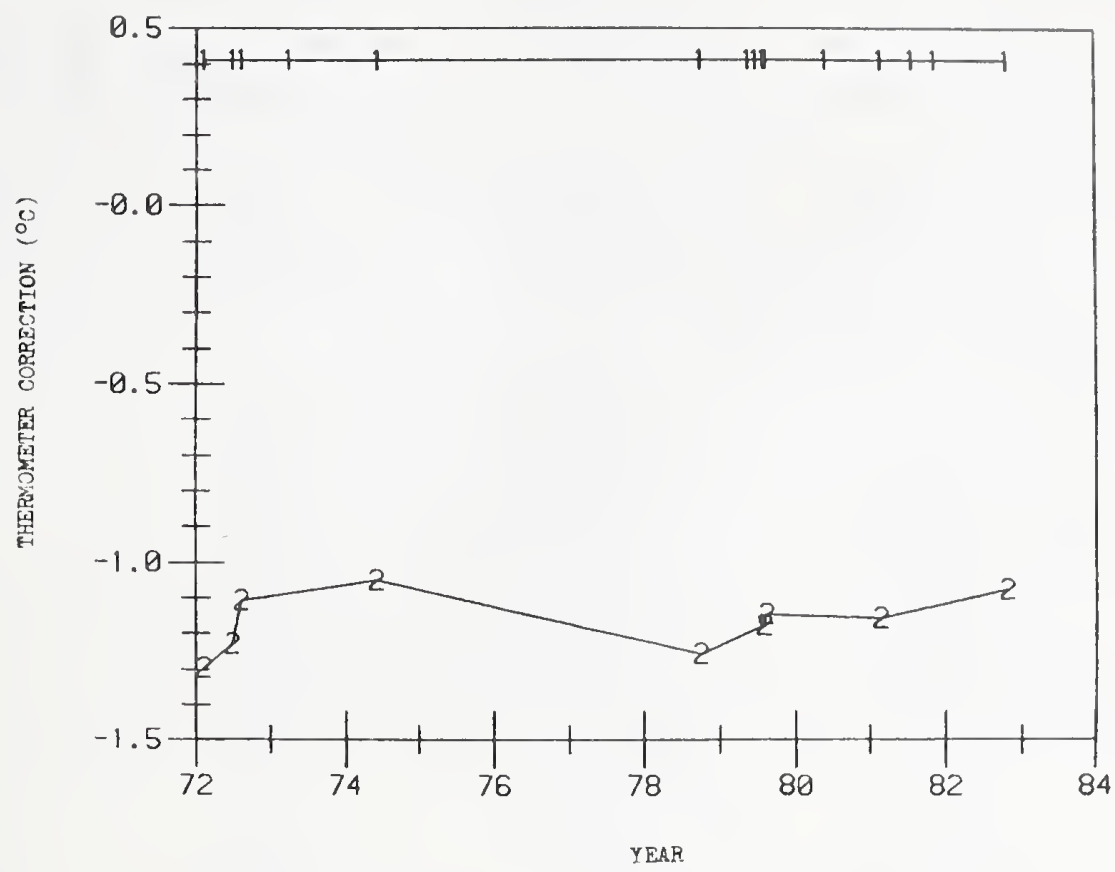

Fig. 41(b). Plot for thermometer, serial number 234453, at two temperatures $\left(1\right.$ at $0{ }^{\circ} \mathrm{C}$ and 2 at $350{ }^{\circ} \mathrm{C}$ ). The readings were corrected for ice-point shifts.

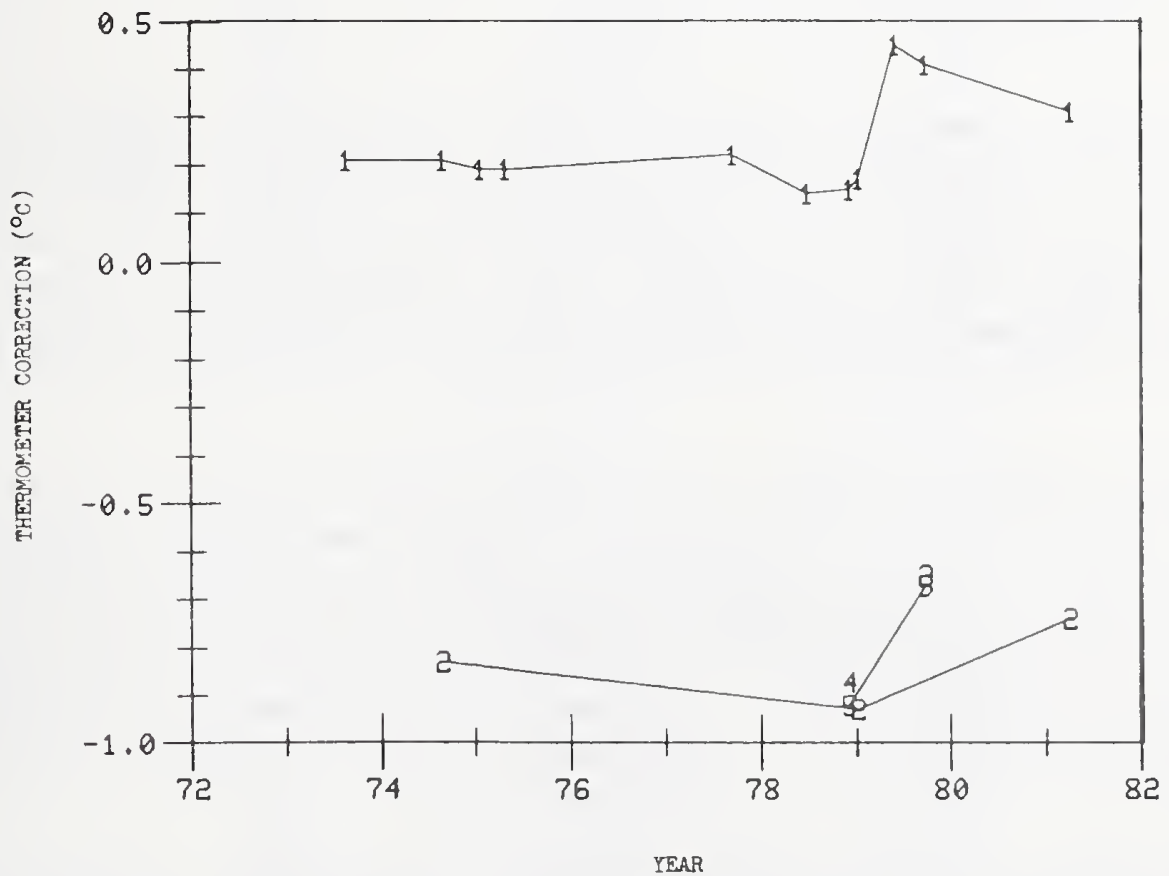

Fig. 42(a1). Plot for thermometer, serial number 234456, at five temperatures $\left(1\right.$ at $0{ }^{\circ} \mathrm{C}, 2$ at $310{ }^{\circ} \mathrm{C}, 3$ at $320{ }^{\circ} \mathrm{C}, 4$ at $330{ }^{\circ} \mathrm{C}$, and 5 at $340{ }^{\circ} \mathrm{C}$ ). The readings were not corrected for ice-point shifts. 


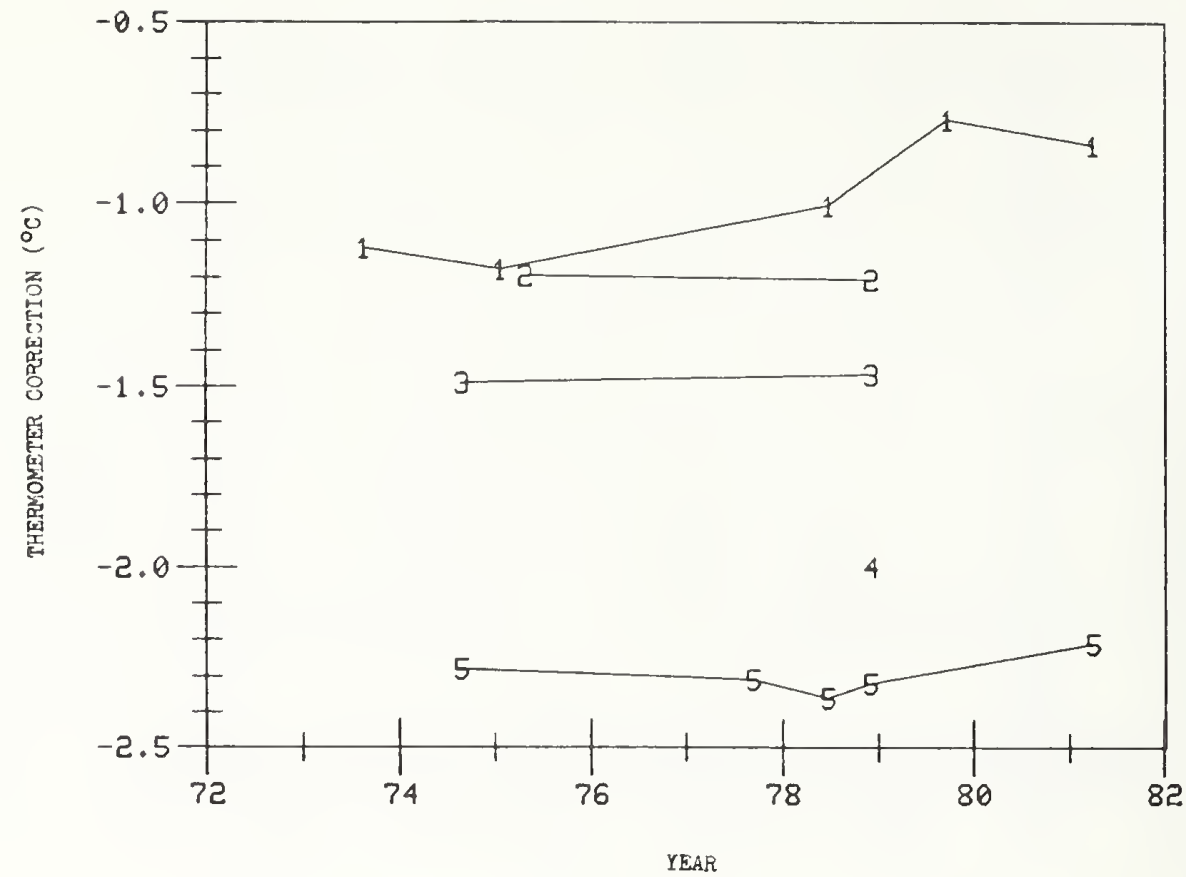

Fig. 42(a2). Plot for thermometer, serial number 234456, at five temperatures $\left(1\right.$ at $350{ }^{\circ} \mathrm{C}, 2$ at $360{ }^{\circ} \mathrm{C}, 3$ at $370{ }^{\circ} \mathrm{C}, 4$ at $390{ }^{\circ} \mathrm{C}$, and 5 at $400{ }^{\circ} \mathrm{C}$ ). The readings were not corrected for ice-point shifts.

A comparison of the calculated values in Table 22 with the values listed in Tables 12 and 14 are given in Table 23. In most cases the results are in good agreement. The uncertainty in the range of 200 to $300{ }^{\circ} \mathrm{C}$ should probably be changed to $0.2{ }^{\circ} \mathrm{C}$, which would be closer to the calculated value. This change will be considered. The calculated value for the low temperature thermometer in the range of -60 to $-30^{\circ} \mathrm{F}$ is higher than listed in Table 12. A change may be considered after more data is taken and analyzed.

The statistical analysis verifies some of the values originally published in Tables 12 and 14. Since no data was available for thermometers in the similar temperature ranges but with larger graduation intervals, statistical analysis was not possible. However, it has been noted that, in most cases, the standard deviation of the check standard approximates the resolution of the thermometer. Based on the above, the estimated uncertainties for other types of thermometers listed in Tables 12 and 14 seem reasonable.

The only area where the uncertainties appear to be larger than calculated is in the temperature range of -200 to $0{ }^{\circ} \mathrm{C}$. Thermometers in this range contain an organic liquid instead of mercury or a mercury alloy and the published uncertainty presumably takes into account additional problems associated with this type of thermometer. One such problem is that the 
TABLE 20

LIMITS TO RANDOM ERROR COMPUTED FROM CHECK STANDARD MEASUREMENTS

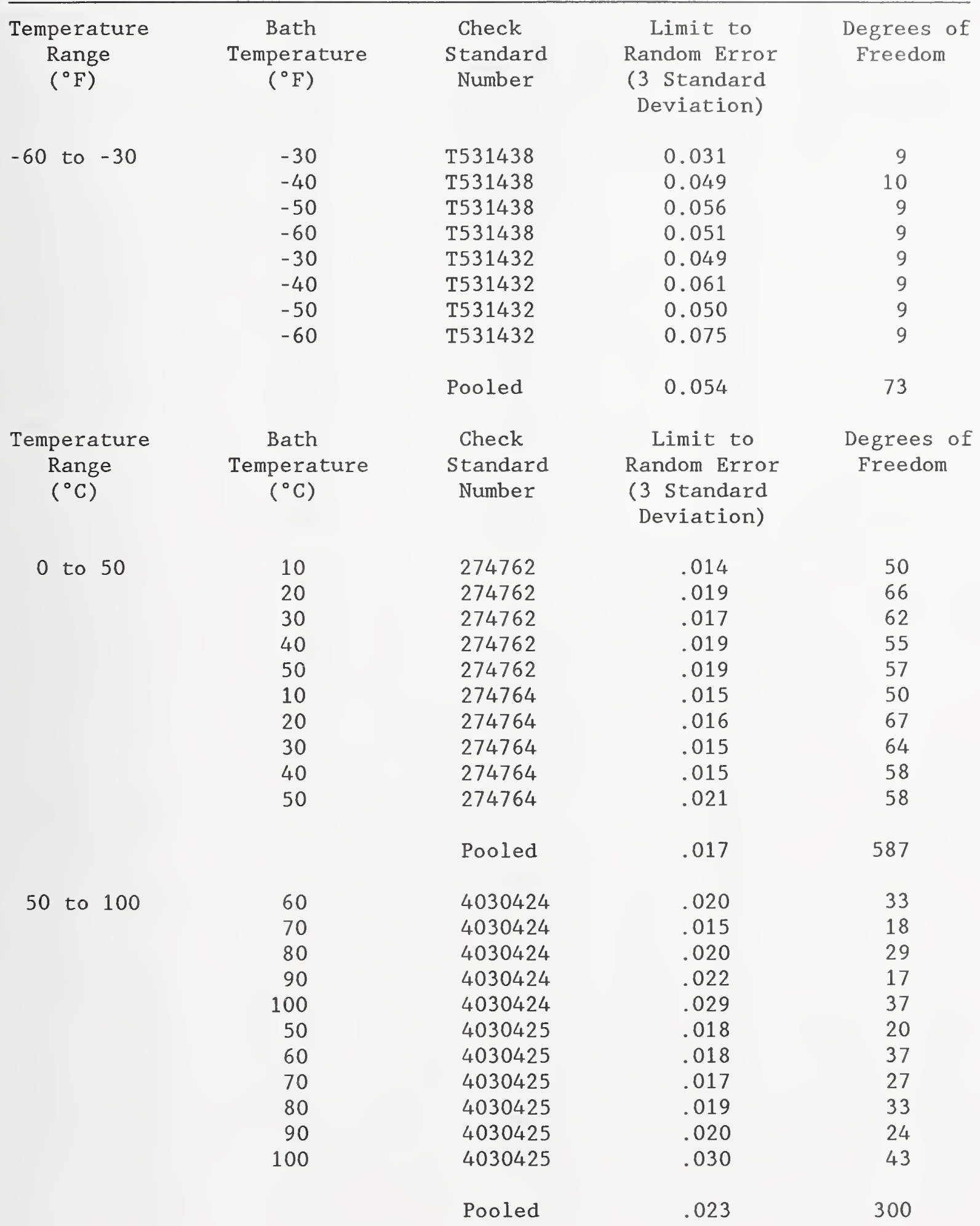




\begin{tabular}{|c|c|c|c|c|}
\hline $\begin{array}{c}\text { Temperature } \\
\text { Range } \\
\left({ }^{\circ} \mathrm{C}\right)\end{array}$ & $\begin{array}{c}\text { Bath } \\
\text { Temperature } \\
\left({ }^{\circ} \mathrm{C}\right)\end{array}$ & $\begin{array}{l}\text { Check } \\
\text { Standard } \\
\text { Number }\end{array}$ & $\begin{array}{l}\text { Limit to } \\
\text { Random Error } \\
\text { ( } 3 \text { Standard } \\
\text { Deviation) }\end{array}$ & $\begin{array}{c}\text { Degrees of } \\
\text { Freedom }\end{array}$ \\
\hline \multirow[t]{2}{*}{0 to 100} & $\begin{array}{r}10 \\
20 \\
30 \\
40 \\
50 \\
60 \\
70 \\
80 \\
90 \\
100 \\
10 \\
20 \\
30 \\
40 \\
50 \\
60 \\
70 \\
80 \\
90 \\
100\end{array}$ & $\begin{array}{l}48425 \\
48425 \\
48425 \\
48425 \\
48425 \\
48425 \\
48425 \\
48425 \\
48425 \\
48425 \\
198694 \\
198694 \\
198694 \\
198694 \\
198694 \\
198694 \\
198694 \\
198694 \\
198694 \\
198694\end{array}$ & $\begin{array}{l}.030 \\
.031 \\
.036 \\
.025 \\
.029 \\
.025 \\
.019 \\
.031 \\
.033 \\
.034 \\
.029 \\
.026 \\
.024 \\
.030 \\
.025 \\
.027 \\
.031 \\
.025 \\
.036 \\
.024\end{array}$ & $\begin{array}{l}22 \\
44 \\
38 \\
42 \\
40 \\
32 \\
17 \\
30 \\
19 \\
29 \\
30 \\
49 \\
52 \\
43 \\
55 \\
31 \\
23 \\
37 \\
27 \\
40\end{array}$ \\
\hline & & Pooled & .028 & 700 \\
\hline \multirow[t]{2}{*}{100 to 200} & $\begin{array}{l}100 \\
110 \\
120 \\
130 \\
140 \\
150 \\
160 \\
170 \\
180 \\
190 \\
200 \\
100 \\
110 \\
120 \\
130 \\
140 \\
150 \\
160 \\
170 \\
180 \\
190 \\
200\end{array}$ & $\begin{array}{l}382213 \\
382213 \\
382213 \\
382213 \\
382213 \\
382213 \\
382213 \\
382213 \\
382213 \\
382213 \\
382213 \\
382215 \\
382215 \\
382215 \\
382215 \\
382215 \\
382215 \\
382215 \\
382215 \\
382215 \\
382215 \\
382215\end{array}$ & $\begin{array}{l}.047 \\
.036 \\
.057 \\
.058 \\
.068 \\
.073 \\
.049 \\
.081 \\
.087 \\
.091 \\
.100 \\
.077 \\
.047 \\
.087 \\
.045 \\
.089 \\
.054 \\
.099 \\
.083 \\
.112 \\
.071 \\
.146\end{array}$ & $\begin{array}{r}35 \\
9 \\
23 \\
8 \\
19 \\
21 \\
18 \\
12 \\
26 \\
6 \\
36 \\
35 \\
9 \\
26 \\
16 \\
28 \\
25 \\
24 \\
11 \\
21 \\
9 \\
34\end{array}$ \\
\hline & & Pooled & .084 & 451 \\
\hline
\end{tabular}


Temperature Range

$\left({ }^{\circ} \mathrm{C}\right)$

200 to 300
Bath Temperature $\left({ }^{\circ} \mathrm{C}\right)$

200
210
230
250
270
300
210
240
250
260
270
290
300

300 to 500
320

340

350

360

400
Check Standard

Number

T112411

T112411

T112411

T112411

T112411

$\mathrm{T} 112411$

T112412

T112412

T112412

T112412

T112412

T112412

T112412

Pooled

234453

234453

234453

234453

234453

Pooled
Limit to Random Error

(3 Standard Deviation)
Degrees of Freedom
.096

.156

.062

.068

.078

.072

.060

.030

.040

.084

.105

.108

.062

.075

.306

.203

.249

.306

.051

.240
2

3

2

13

4

14

2

2

9

5

4

2

13

75

3

3

8

2

3

19

TABLE 21

SYSTEMATIC ERRORS

\begin{tabular}{rcccc}
\hline $\begin{array}{c}\text { Temperature } \\
\text { Range } \\
\left({ }^{\circ} \mathrm{C}\right)\end{array}$ & Ice Point & $\begin{array}{c}\text { Platinum } \\
\text { Resistance } \\
\text { Thermometer }\end{array}$ & $\begin{array}{c}\text { Bath } \\
\text { Gradient }\end{array}$ & $\begin{array}{c}\text { Total } \\
\text { Systematic } \\
\text { Error }\end{array}$ \\
\hline & & & & \\
-100 to 0 & 0.005 & 0.001 & 0.01 & 0.016 \\
0 to 50 & 0.005 & 0.001 & 0.005 & 0.011 \\
50 to 100 & 0.005 & 0.001 & 0.005 to 0.01 & 0.011 to 0.016 \\
0 to 100 & 0.005 & 0.001 & 0.005 to 0.01 & 0.011 to 0.016 \\
100 to 200 & 0.005 & 0.001 & 0.01 to 0.025 & 0.016 to 0.031 \\
200 to 300 & 0.005 & 0.001 & 0.05 & 0.056 \\
300 to 500 & 0.005 & 0.001 to 0.003 & 0.1 to 0.15 & 0.106 to 0.158 \\
\hline
\end{tabular}


TABLE 22

CALCULATED UNCERTAINTIES FOR LIQUID-IN-GLASS THERMOMETERS

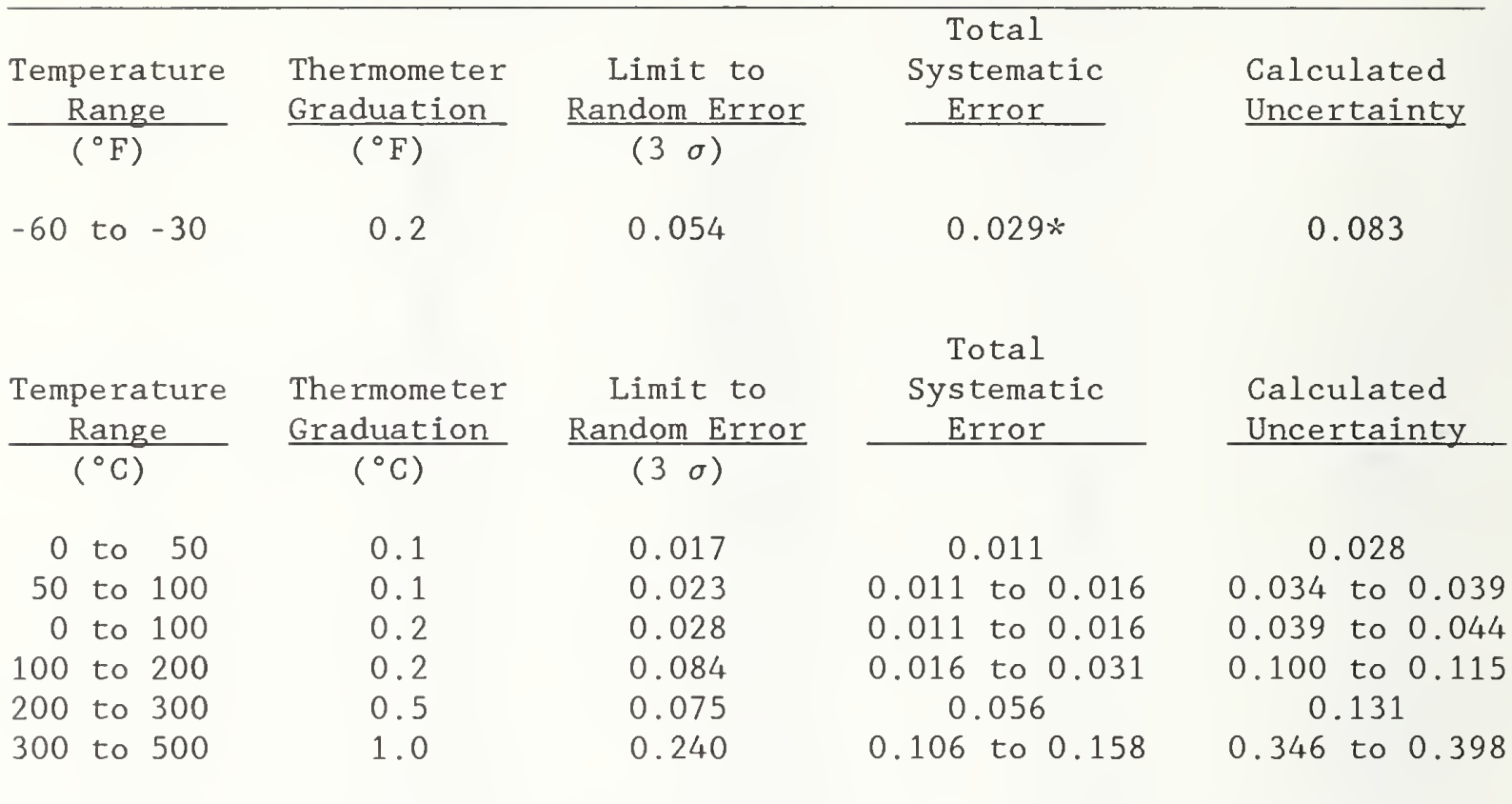

*Fahrenheit equivalent of calculated value.

TABLE 23

COMPARISON OF PUBLISHED UNCERTAINTY VALUES WITH CALCULATED UNCERTAINTY VALUES

Temperature

Range $\left({ }^{\circ} \mathrm{F}\right)$

-60 to -30

Temperature

$\frac{\text { Range }}{\left({ }^{\circ} \mathrm{C}\right)}$

0 to 50

50 to 100

0 to 100

100 to 200

200 to 300

300 to 500
Thermometer

Graduation

$\left({ }^{\circ} \mathrm{F}\right)$

0.2

Thermometer

Graduation

$\left({ }^{\circ} \mathrm{C}\right)$

0.1

0.1

0.2

0.2

0.5

1.0
Published Values

of Uncertainty

0.05

0.083
Calculated Values of Uncertainty 
fluid clings to the capillary wall as the liquid recedes into the bulb. Because of this the thermometer should not be read immediately after insertion into the medium. Up to one hour might be required before a reading can be recorded. Data will have to be taken on this type of thermometer to verify the published uncertainty value or before a change in this value is considered.

In Tables 12 and 15, uncertainties for Fahrenheit total-immersion thermometers are essentially the values given for Celsius thermometers having the same graduation interval in the various temperature ranges. In some cases, where the thermometer graduation is much larger than the Celsius equivalent, the uncertainty is approximately doubled (due to a decrease in resolution). Since one standard deviation seems to be an approximation of the resolution of the thermometer, the uncertainties published for Fahrenheit thermometers seem reasonable.

The uncertainties given in Table 18 are for temperature differences for Beckmann and calorimetric thermometers. Systematic errors are not involved in this uncertainty value, since they are eliminated when temperature differences are obtained. Therefore, the resolution of the thermometer is essentially the governing factor. Thermometers graduated in intervals of 0.01 or 0.02 degree can be read to the nearest 0.001 degree and thermometers graduated in intervals of 0.05 degree can be read to 0.005 degree. Considering these numbers, the values given in Table 18 seem reasonable. Data will be taken on this type of thermometer to verify these estimates.

No data is available for the uncertainty of partial-immersion thermometers. Several partial-immersion thermometers are currently being used as check standards and data is being recorded for future statistical analysis. Corrections are calculated both with and without emergent stem-temperature corrections being applied. Until sufficient data is available for analysis, the current published values given in Tables 13 , 16 , and 17 will be used.

10.0 Glass Changes and Recalibration of Thermometers

\subsection{Glass Changes}

The changes which occur in the glass of a liquid-in-glass thermometer bulb after first heating to a high temperature within the acceptable exposure limits of the glass and subsequent cooling to ambient temperatures, are a function of time and temperature. They will depend upon the thermal history of the glass (both during manufacture and previous use), the time of exposure to the high temperature, and the rate of cooling. Evidence from many investigations [2, 15, 16] seems to indicate that when a glass is held indefinitely at some fixed temperature, density (and volume) changes proceed toward a preferred density, corresponding to a quasi equilibrium condition characteristic of the particular kind of glass and the temperature. Since these changes involve molecular rearrangements, they proceed more rapidly at high temperatures where the viscosity of the glass is lower, and the molecular mobility consequently higher. For this reason, a 
close approach to quasi equilibrium may be reached in the order of hours at annealing temperatures, while infinite time may be required at much lower temperatures.

If a glass that has been heated to a high temperature is allowed to cool rapidly, it will be seen that equilibrium is not reached at the lower temperatures during cooling, and an equilibrium density more nearly corresponding to the high temperature is "frozen" into the glass. This characteristic behavior of glass has a lasting effect on the performance of liquid-in-glass thermometers. For the entire lifetime of the thermometer, it may retain a "memory" of the thermal history at the higher temperature.

The techniques of good manufacture are designed to produce in the thermometer glass a state which will result in maximum stability for the range of temperature indicated on the scale. To achieve perfect stability for all conditions of use is not possible in thermometer manufacture; therefore, changes in the ice-point readings are observed periodically. The changes observed at the ice point are reflected at all points on the scale by the same magnitude and sign, since they are the result of changes in the bulb volume. The volume of the capillary also changes, but the volume of mercury contained in the stem is so small, in comparison to the amount of mercury in the bulb, that changes in the stem volume can usually be ignored. Because of this behavior of glass, the changes in the bulb volume can be either temporary or permanent.

\subsubsection{Temporary Changes}

Upon heating to a high temperature, the bulb of a thermometer will expand from its initial state. After a short period of time, an equilibrium condition corresponding to that particular high temperature will appear to be reached. If the thermometer is cooled slowly through critical temperature regions, the glass will nearly return to its initial state, and the ice-point reading will show no change. If, on the other hand, the thermometer is cooled rapidly (such as cooling naturally in still air), the bulb will retain a portion of its expanded condition, and the ice-point reading will be lower than the reading taken before heating. This phenomenon is known as "zero, or ice-point depression". Thermometers which have been heated to high temperatures recover from this ice-point depression in an unpredictable way, and frequently there will be no significant recovery after a period of one year at room temperature. Since the ice-point depression has a reproducible value, ice-point readings may be used reliably to show changes in the volume of the thermometer bulb with time and use, provided the thermometer is allowed to cool in still air and the ice point is taken within a reasonable period of time, not to exceed one hour, after being heated.

Thermometers below approximately $100{ }^{\circ} \mathrm{C}$ will usually exhibit a relatively rapid recovery from the ice-point depression, and the original bulb volume will recover within the equivalent of 0.01 or $0.02{ }^{\circ} \mathrm{C}$ in approximately three days. This phenomenon has an important bearing on the precision attainable with mercury thermometers, and must be taken into consideration, especially in the range of 0 to $100{ }^{\circ} \mathrm{C}$. If a thermometer is used to 
measure a given temperature, it will indicate an erroneously low value if it has, within a short period of time, previously been exposed to a higher temperature. With the better grades of thermometric glasses the error resulting from this hysteresis will not exceed (in the interval of 0 to $\left.100^{\circ} \mathrm{C}\right) \quad 0.01$ of a degree for each 10-degree difference between the temperature being measured and the higher temperature to which the thermometer has recently been exposed. With the best glasses the error may only be a few thousandths of a degree for each 10-degree difference. The errors due to this hysteresis become somewhat erratic at temperatures above $100{ }^{\circ} \mathrm{C}$. For these reasons it is customary, in precision thermometry, to apply a scale correction after the temperature measurement (See NBS Monograph 150 [7], Section 5.2).

Where the range of temperature is small and the time between observations is short (as in the use of calorimetric thermometers), it is more satisfactory, each time the thermometer is used, to first heat to the highest temperature to be measured, so that all the depression has taken place before the observations are begun. The condition to be observed is that the time required for observations is so short that no appreciable recovery shall have taken place during this time. As this condition is fairly well satisfied in calorimetric work, and as it is the only one for which consistent measurements of the same temperature interval can be made repeatedly, calorimetric thermometers should be used in this way.

\subsubsection{Permanent Changes}

A "secular change" in thermometer glasses, which may progress with time, results in a non-recoverable decrease in the bulb volume as indicated by an increase in the ice-point reading. At room temperature there may be a gradual change which will continue for years, but at high temperatures the changes will be markedly accelerated. With better grades of thermometer glasses the change will not exceed $0.1{ }^{\circ} \mathrm{C}$ over a period of many years, provided the thermometer has not been heated to temperatures above approximately $150{ }^{\circ} \mathrm{C}$. Initially, at high temperatures, the secular change usually progresses more rapidly, but with continued heating and time it tends toward a lower rate of change. The rate of secular change will depend upon the kind of glass used in the thermometer bulb and the particular heat treatment given the thermometer in manufacture. Thermometers manufactured according to good practices will evidence only small secular changes. However, thermometers made of glass unsuitable for the temperature range indicated on the scale, or improperly annealed, may show changes as large as $12{ }^{\circ} \mathrm{C}$ after heating for approximately 200 hours at high temperatures [17]. Permanent changes in the bulb volume have also been observed when thermometers have been repeatedly cycled at low temperatures (between -30 and $\left.+25^{\circ} \mathrm{C}\right) \quad[18]$.

When using thermometers for high temperature measurements, one must use care to avoid overheating. After only a few minutes of heating the thermometer at a temperature higher than its intended range, the increased gas pressure above the liquid column may cause a permanent distortion of the bulb resulting in lower thermometer indications. 
The thermometer scale corrections quoted in the NBS Report of Calibration apply as long as the ice-point reading remains the same as observed during the calibration. As discussed above, subsequent changes in the ice-point reading of the thermometer will result from small changes in the glass of the thermometer bulb which affects its volume. As a result, changes in the ice-point reading of the thermometer, taken after exposure of not fewer than three days at a temperature of approximately $23^{\circ} \mathrm{C}$, will be reflected by similar changes in readings at each point along the scale. Therefore, when the correction at the ice point is found to be higher (or lower) than that observed at the time of calibration, the other reported scale corrections will be higher (or lower) by the same amount. An example is given in Table 24.

TABLE 24

RECALIBRATION OF LIQUID-IN-GLASS THERMOMETERS

\begin{tabular}{ccc}
\hline $\begin{array}{c}\text { Thermometer } \\
\text { Reading }\end{array}$ & $\begin{array}{c}\text { Correction from } \\
\text { NBS Report of } \\
\text { Calibration }\end{array}$ & $\begin{array}{c}\text { Correction Changed } \\
\text { for Change in Ice- } \\
\text { Point Reading }\end{array}$ \\
\cline { 2 - 3 }$\left({ }^{\circ} \mathrm{C}\right)$ & $\left({ }^{\circ} \mathrm{C}\right)$ & \\
+0.011 & -0.011 & -0.019 \\
10.000 & -.015 & -.023 \\
20.000 & -.020 & -.028 \\
30.000 & +.008 & -.000 \\
40.000 & -.033 & -.008
\end{tabular}

In Table 24, the thermometer readings are given in the first column and the corrections that were determined at NBS are given in the second column. The third column shows that the new ice-point correction was $-0.019{ }^{\circ} \mathrm{C}$, indicating that the thermometer reading was $+0.019{ }^{\circ} \mathrm{C}$ when the thermometer was placed in an ice bath. This means that the thermometer bulb volume has changed by an amount equal to $0.008^{\circ}$ on the thermometer scale. Since the thermometer now reads 0.008 of a degree higher at the ice point, it will be reading 0.008 of a degree higher at all of the other calibration points also. These values are given in the third column. These new corrections should be used until a subsequent recalibration, by checking the ice point again, is performed.

Once a thermometer has been calibrated, an ice-point check is all that is necessary to obtain a current calibration, provided the thermometer has not been abused, such as heating it beyond the highest temperature indicated on the main scale. If the International Practical Temperature Scale changes, an additional correction for the difference between the two scales will be provided by NBS. The difference between the two scales is added to the 
current set of corrections for the thermometer (see NBS Monograph 150 [7], Section 4). A liquid-in-glass thermometer will never have to be returned to a calibration laboratory, such as NBS, for recalibration.

\subsection{Future}

The demand for liquid-in-glass thermometer calibrations has been holding steady at about 700 calibrations per year. A significant change in demand is not anticipated, but the demand for other laboratory thermometers, such as industrial resistance thermometers and thermistors, may increase. Calibration services at present staffing levels can meet these new demands if they amount to less than 50 per year. If the demand increases beyond this point NBS may have to consider additional staff. No automation of liquid-in-glass thermometers is contemplated, since the reading of these thermometers by a computer would be difficult and costly to achieve.

\subsection{Bibliography}

[1] Thompson, R. D., Recent developments in liquid-in-glass thermometry, Temperature, Its Measurement and Control in Science and Industry 3 , Part 1 (Reinhold Publishing Corp., New York, 1962) p 201.

[2] Liberatore, L. C., and Whitcomb, H. J., Density changes in thermometer glasses, J. Am. Ceram. Soc. 35, 67 (1952).

[3] American Society for Testing and Materials, Designation C162, Standard Definitions of Terms Relating to Glass and Glass Products, Vol. 15.02.

[4] American Society for Testing and Materials, Designation E-77, Verification and Calibration of Liquid-in-Glass Thermometers, Vol. 14.03

[5] The International Practical Temperature Scale of 1968 Amended Edition of 1975, Metrologia 12, No. 1, 7-17 (1976).

[6] Cutkosky, R. D., An AC resistance thermometer bridge, J. Res. Nat. Bur. Stand. (U.S.) 74C (Engr. and Instr.), Nos. 1 and 2, 15-18 (Jan.-June 1970).

[7] Wise, Jacquelyn A., Liquid-in-Glass Thermometry. Nat. Bur. Stand. (U.S.) Monogr. 150; January 1976.

[8] Based on the data of Osborne, N. S., and Meyers, C. H., A formula and tables for the pressure of saturated water vapor in the range 0 to $374{ }^{\circ} \mathrm{C}, \mathrm{J}$. Res. NBS 13, 1 (1934) RP691.

[9] American Society for Testing and Materials, Designation E-1, Standard Specification for ASTM Thermometers, Vol. 14.03. 
[10] Ween, Sidney, "The Beckmann Differential Thermometer: Its Principles of Construction and Application," Materials Research and Standards, MTRSA, Vol. 12, No. 8, August 1972, p. 31.

[11] Buckingham, E., The correction for emergent stem of the mercurial thermometer, Bul. BS 8, 239 (1912) S170.

[12] Pemberton, L. H., Further consideration of emergent column correction in mercury thermometry, J. Sci. Inst. 41, 234 (1964).

[13] Riddle, John L., Furukawa, George T., and Plumb, Harmon H., Platinum Resistance Thermometry, Nat. Bur. Stand. (U.S.), Monogr. 126, April 1973,126 pages.

[14] Hall, J. A., and Leaver, V. M., The design of mercury thermometers for calorimetry, J. Sci. Instr. 36, 183 (1959).

[15] Lillie, H. R., and Shaver, W. W., Method of tempering glass, U. S. Patent No. 2,148,630 (Feb. 28, 1939).

[16] Liberatore, L. C., Method of stabilizing the molecular arrangement of glass thermometers, U. S. Patent No. 2,610,445 (Sept. 16, 1952).

[17] Ruh, E. L., and Conklin, G. E., Thermal stability in ASTM thermometers, ASTM Bul. No. 233, 35 (Oct. 1958).

[18] Martin, W. I., and Grossman, S. S., Calibration drift with thermometers repeatedly cooled to $-30{ }^{\circ} \mathrm{C}$, ASTM Bul. No. 231, 62 (July 1958). 
NBS-114A (REV. 2-8C)

U.S. DEPT. OF COMM

BIBLIOGRAPHIC DATA

SHEET (See in structions) 1. PUBLICATION OR
REPORTNO. NIST/SP-250/23

2. Performing Organ. Report No. 3. Publication Date

September 1988

4. TITLE AND SUBTITLE

Liquid-In-Glass Thermometer Calibration Service

5. AUTHOR(S)

Jacquelyn Wise

6. PERFORMING ORGANIZATION (If joint or other than NBS, see instructions)

NATIONAL INSTITUTE OF STANDARDS AND TECHNOLOGY

(formerly NATIONAL BUREAU OF STANDARDS)

U.S. DEPARTMENT OF COMMERCE

GATHERSBURG, MD 20899

. Contract Grant No.

8. Type of Report \& Period Covered

Final

9. SPONSORING ORGANIZATION NAME AND COMPLETE ADDRESS (Street, City, State, ZIP)

Same as item 6

10. SUPPLEMENTARY NOTES

Library of Congress Catalog Card Number: 88-600580

[] Document describes a computer program; SF-185, FIPS Software Summary, is attached.

11. ABSTRACT (A 200-word or less factual summary of most significant information. If document includes a significant bibliography or literature survey. mention it here)

This document gives a description of the calibration of liquid-in-glass thermometers at the National Bureau of Standards. The calibration equipment and procedures used at NBS are discussed in detail. Calculations and stem-temperature corrections are shown and a discussion of the sources of error encountered in calibration and estimates of uncertainties is presented.

12. KEY WORDS (Six to twelve entries; alphabetical order: capitalize only proper names; and separate key words by semicolons) calibration; ice point; IPTS-68; 1iquid-in-glass thermometer; temperature; uncertainty

13. AVAILABILITY

X] Unlimited

$\square$ For Official Distribution. Do Not Release to NTIS

X Order From Superintendent of Documents, U.S. Government Printing Office, Washington, D.C. 20402.

14. NO. OF

PRINTED PAGES

128

15. Price

[X] Order From National Technical Information Service (NTIS), Springfield, VA. 2216I 



SP 250-1 Spectral Radlance Calibratlons SN003-003-02792-8 $\$ 3.50$

SP 250-2 Far Uitraviolet Detector Standards PB87227609

SP 250-3 Radiometric Standards in the Vacuum Uitravioiet SN003-003-02806-1 $\$ 6.50$

SP 250-4 Fricke Dosimetry in High-Energy Electron Beams SN003-003-02816-9 $\$ 2.75$

SP 250-5 Alpha-Particle Calibrations SN003-003-02823-1 $\$ 2.00$

SP 250-6 Regular Spectral Transmittance SN003-003-02805-3 \$3.25

SP 250-7 Radiance Temperature Calibrations SN003-003-02827-4 \$2.25

SP 250-8 Spectral Reflectance PB88109905

SP 250-9 Calibration of Beta-Particle-Emitting Ophthaimic Appilcators SN003-003-02817-7 $\$ 2.00$

SP 250-10 Radioactlvity Calibratlons with the "4 $\pi$ " Gamma lonization Chamber, and Other Radioactivity Calibration Capabilities SN003-003-02824-0 $\$ 2.25$

SP 250-11 Dosimetry for High-Dose Appilcations SN003-003-02854-1 \$2.75

SP 250-12 Neutron Personnel Dosimetry SN003-003-02811-8 $\$ 2.50$

SP 250-13 Activation Foll Irradiation with Californium Fission Sources SN003-003-02866-5 \$2.25

SP 250-14 Activation Foll Irradiation by Reactor Cavity Fission Sources SN003-003-02861-4 \$3.25

SP 250-15 Photometric Callibrations PB88153747

SP 250-16 Calibration of X-Ray and Gamma-Ray Measuring Instruments SN003-003-02862-2 \$7.00

SP 250-17 The NBS Photodetector Spectral Response Calibration Transfer Program SN003-003-02857-6 \$3.25
SP 250-18 Neutron Source Strength Calibrations SN003-003-02863-1 \$3.25

SP 250-19 Calibration of Gamma-Ray-Emitting Brachytherapy Sources

SP 250-20 Spectral Irradiance Calibrations SN003-003-02829-1 $\$ 5.50$

SP 250-21 Calibration of Beta-Particle Radiation instrumentation PB88201579

SP 250-22 Platinum Resistance Thermometer Calibrations PB88138367

SP 250-23 Liquid-In-Glass Thermometer Calibration Service

SP 250-24 Standard Cell Calibrations SN003-003-02825-8 $\$ 2.75$

SP 250-25 Calibration Service for Inductive Voitage Dividers

SP 250-26 Phase Angie Calibrations SN003-003-02871-1 $\$ 5.00$

SP 250-27 AC-DC Difference Calibrations

SP 250-28 Solid-State DC Voltage Standard Calibrations SN003-003-02842-8 $\$ 2.00$

SP 250-29 Traceable Frequency Calibrations SN003-003-02844-4 \$2.25

SP 250-30 GOES Sateilite Time Code Dissemination: Description and Operation SN003-003-02845-2 $\$ 2.75$

SP 250-31 Mass Calibrations at the National Bureau of Standards

SP 250-32 A Calibration Service for $30 \mathrm{MHz}$ Attenuatlon and Phase Shift SN003-003-02875-4

SP 250-33 A Calibration Service for Voitage Transformers and High-Voltage Capacitors SN003-003-02880-1

* Those entries containing a stock number (003-003-- ) and price can be purchased from the Superintendent of Documents, U.S. Government Printing Office, Washington, DC 20402. GPO will accept checks, money orders, VISA, and Mastercharge. For more infomation, or to place an order, call (202) 783-3238. Be sure to use the stock number in all orders.

Entries containing PB numbers can be purchased from the National Technical Information Service, Springfleld, VA 22161. NTIS will accept American Express in addition to the payment methods listed for GPO. For more information call (703) 487-4650; to piace an order call (800) 336-4700. Be sure to use the PB number on all orders.

Titles without stock numbers are in preparation. 
U.S. Department of Commerce

National Institute of Standards and Technology

(formerly National Bureau of Standards)

Gaithersburg, MD 20899

Official Business

Penalty for Private Use $\$ 300$

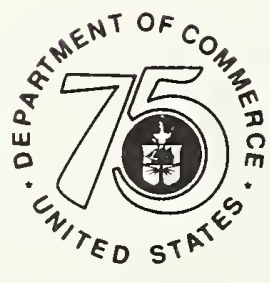

Stimulating America's Progress

1913.1988 